\title{
Aufbau einer Silicanin-1-haltigen Modellmembran des Silicafällungsvesikels aus Thalassiosira pseudonana
}

\author{
Dissertation \\ zur Erlangung des mathematisch-naturwissenschaftlichen Doktorgrades \\ Doktor rerum naturalium \\ der Georg-August-Universität Göttingen \\ im Promotionsstudiengang Chemie \\ der Georg-August University School of Science (GAUSS)
}

vorgelegt von

Philipp Werner Schwarz

aus Göttingen

Göttingen, 2021 


\section{Betreuungsausschuss:}

Prof. Dr. Claudia Steinem

Institut für Organische und Biomolekulare Chemie

Georg-August-Universität Göttingen

Prof. Dr. Ivo Feußner

Albrecht-von-Haller-Institut

Georg-August-Universität Göttingen

\section{Mitglieder der Prüfungskommission:}

Referentin: Prof. Dr. Claudia Steinem, Institut für Organische und Biomolekulare Chemie, Göttingen

Koreferent: Prof. Dr. Ivo Feußner, Albrecht-von-Haller-Institut, Göttingen

Weitere Mitglieder der Prüfungskommission:

Prof. Dr. Jörg Enderlein, Drittes Physikalisches Institut, Göttingen

Prof. Dr. Thomas Friedl, Abteilung für Experimentelle Phykologie und Sammlung von Algenkulturen, Göttingen

Dr. Sebastian Kruss, Institut für Physikalische Chemie, Göttingen sowie Fakultät für Chemie und Biochemie, Bochum

Prof. Dr. Kai Tittmann, Albrecht-von-Haller-Institut, Göttingen

Tag der mündlichen Prüfung: 25.02.2021 


\section{Erklärung}

Ich, Philipp Werner Schwarz, erkläre hiermit, dass meine Doktorarbeit mit dem Titel „Aufbau einer Silicanin-1-haltigen Modellmembran des Silicafällungsvesikels aus Thalassiosira pseudonana" selbstständig angefertigt wurde und keine anderen Quellen und Hilfen als angegeben verwendet wurden.

Göttingen, 2021

Philipp Werner Schwarz 


\section{Abstract}

Silica polycondensation occurring in diatom organelles called silica deposition vesicles (SDVs) leads to valve and girdle band formation to complete the biosilica cell wall after cell division. This biosilica shows species-specific nano-patterned porous structures. The SDV membrane's role in silica biogenesis is not well understood to date. The use of model membranes may help to elucidate the influence of lipid bilayers and membrane constituents like transmembrane proteins via interactions with silica precipitating biomolecules on silica precipitation and morphogenesis.

In the first section, total lipid analysis of the diatom species Thalassiosira pseudonana was performed with GC-FID and LC-MS/MS. The lipid composition of two synchronized cultures in different cell cycle stages was compared to draw conclusions about SDV membrane lipid composition. The lipid classes phosphatidylcholine (PC) and phosphatidylethanolamine (PE) next to phosphatidic acid (PA) and lysophosphatidylcholine (LPC) were found elevated in valve SDV enriched cells. Therefore, their use in SDV membranes is assumed. Furthermore, the relative profile of main polar lipid classes MGDG, SQDG, PG, DGDG and PC was determined by means of TLC, followed by GC-FID. Thalassiosira pseudonana showed similar polar lipid class distributions like Cyclotella meneghiniana from literature.

In the second section, recombinant Silicanin-1 (Sin1, a SDV transmembrane protein) was isolated and characterized regarding its secondary structure and $\mathrm{pH}$ dependent self-aggregation by means of CD-spectroscopy and DLS, respectively. This protein was reconstituted into vesicles with an efficiency of 30-60\% for PC/PE containing vesicles. Sin 1 orientation was determined by chymotrypsin digest and anti-Sin 1 Western blotting. Proteoliposomes were used in silica precipitation experiments and it was found that vesicles exhibit silica precipitation properties whereas a clear statement about Sin1 regarding direct silica precipitation or a synergistic effect in presence of LCPA was not possible due to low protein concentration. Finally, a protocol was successfully established to form a planar solid supported model membrane by vesicle fusion with lipid monolayer. CLSM and FRAP were used to confirm the lipid bilayer's diffusive properties according to literature values. Sin1 confined to the membrane was visualized via fluorescent antibodies. This SDV model membrane enables future investigations of membrane interactions with SDV associated biomolecules. 


\section{Inhaltsverzeichnis}

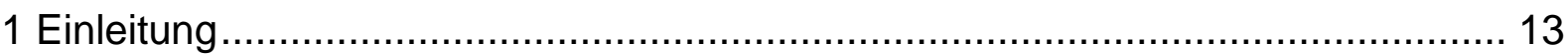

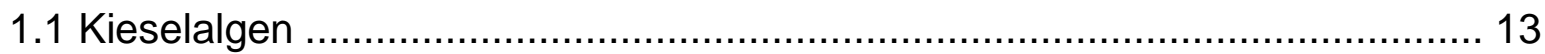

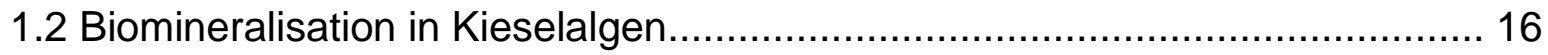

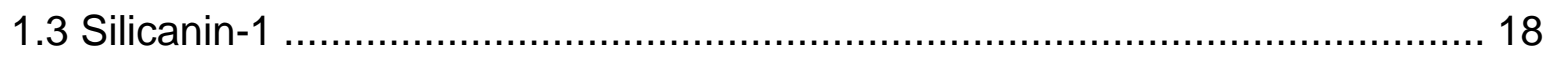

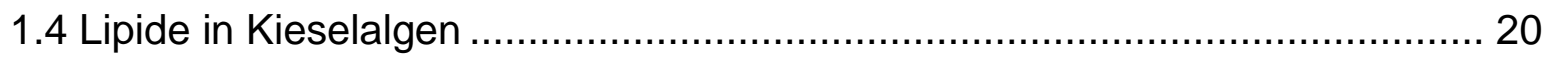

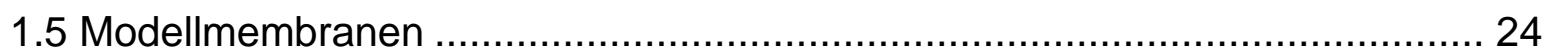

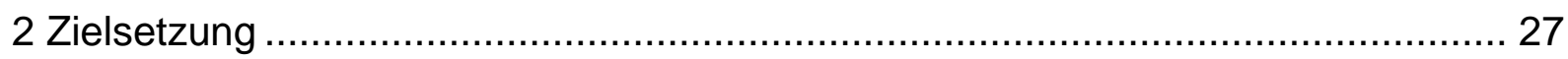

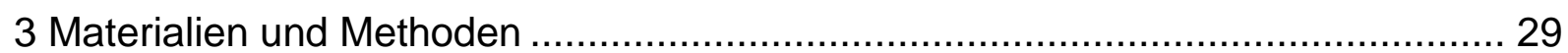

3.1 Lipidanalysen von Thalassiosira pseudonana............................................... 29

3.1.1 Kultivierung, Synchronisation und Ernte der Diatomeenkulturen.............. 29

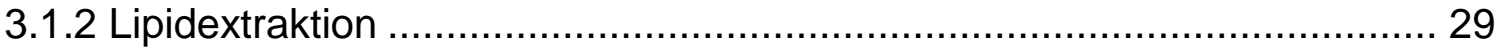

3.1.3 Chemische Modifikation der Lipidextrakte ........................................... 30

3.1.3.1 Methylierung von (Lyso-)Phosphatidsäure ……………………….... 30

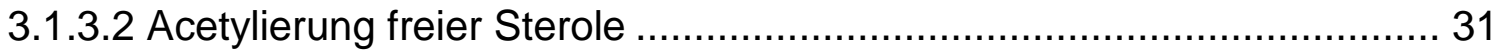

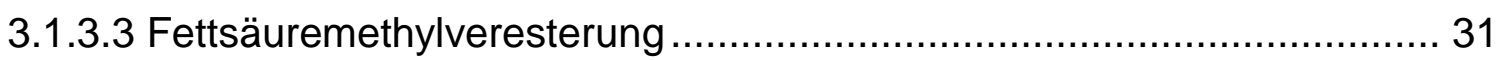

3.1.4 Dünnschichtchromatographische Trennung von polaren Lipidklassen..... 32

3.1.5 Gaschromatografie mit Flammenionisationsdetektion (GC-FID) .............. 33

3.1.6 Flüssigchromatografie mit tandemmassenspektrometrischer Detektion von

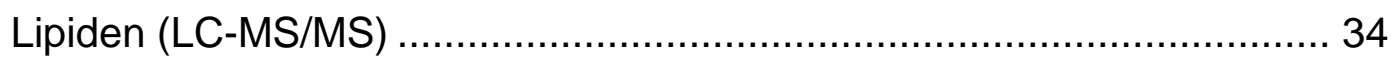

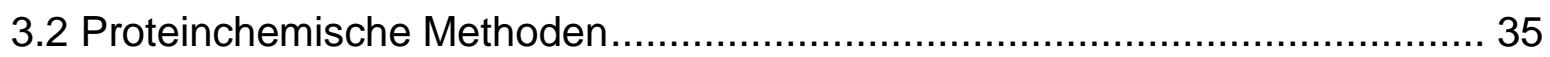

3.2.1 Transformation und Kultivierung von Escherichia coli ............................ 35

3.2.2 Expression von $\mathrm{rSin} 1^{-\mathrm{SP}}$ in E. coli und Zellernte................................... 37

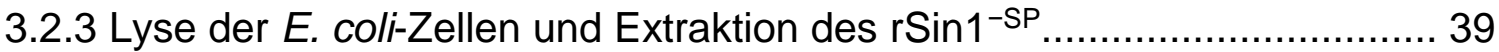

3.2.4 Aufreinigung durch Nickel-Affinitätschromatografie ............................... 40

3.2.5 Umpuffern durch Dialyse ........................................................... 42 
3.2.6 Konzentrationsbestimmung von Proteinlösungen.................................. 44

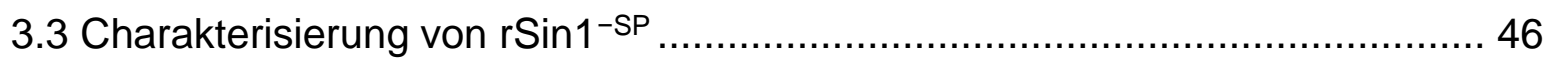

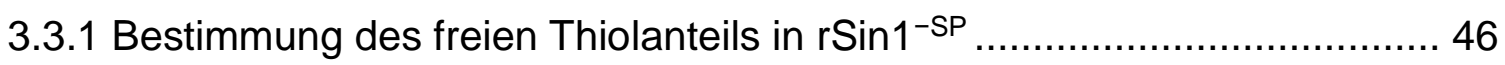

3.3.2 SDS-Polyacrylamidgelelektrophorese ............................................... 47

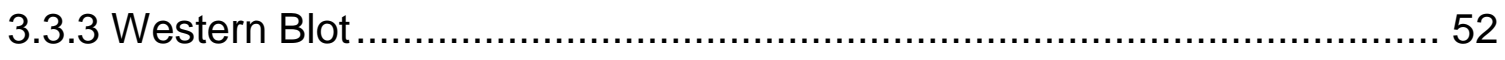

3.3.4 Circulardichroismus-spektroskopische Analyse der sekundären

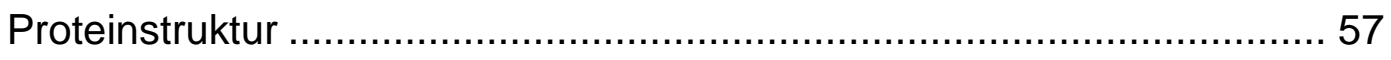

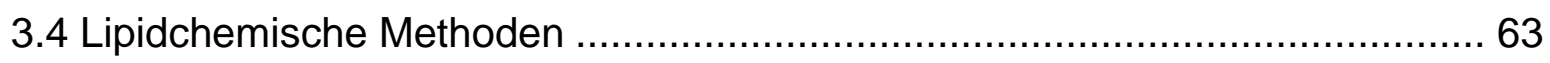

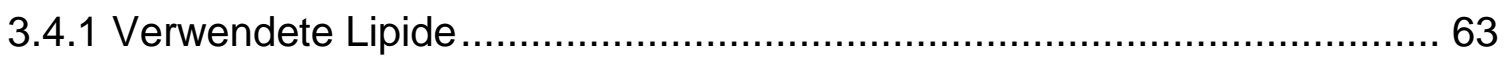

3.4.2 Herstellung von Lipidfilmen und Lipidlösungen ..................................... 66

3.4.3 Präparation von $\mathrm{rSin} 1^{-\mathrm{SP}}$ enthaltenen Proteoliposomen mittels

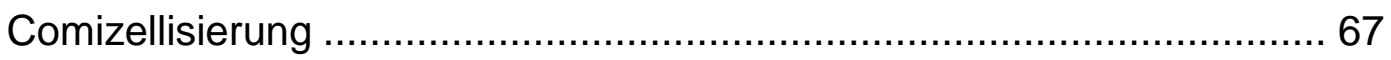

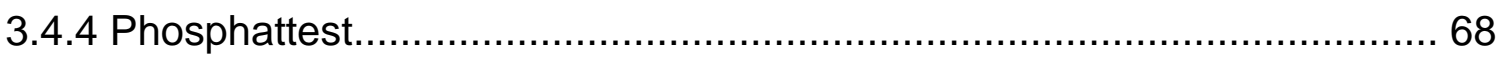

3.5 Charakterisierung von Sin1-Aggregaten, Vesikeln und Proteoliposomen ....... 69

3.5.1 Größenbestimmung von Proteinaggregaten und Vesikeln mit dynamischer Lichtstreuung (DLS) 69

3.5.2 Rekonstitutionsbestätigung durch Carbonatextraktion ............................. 71

3.5.3 Co-Flotationsassay von Proteoliposomen durch Dichtegradientenzentrifugation ......................................................... 72

3.5.4 Verdauexperiment zur Bestimmung der Proteinorientierung in Vesikeln.. 73

3.5.5 Silicafällung von Proteoliposomen und $\beta$-Silicomolybdattest. 74

3.6 Herstellung und Charakterisierung von Sin1-haltigen festkörperunterstützten Membranen

3.6.1 Präparation einer festkörperunterstützten Lipideinzelschicht mittels

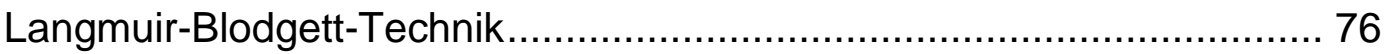

3.6.2 Vesikelfusion mit Lipideinzelschicht................................................... 78

3.6.3 Antikörperanbindung an rSin1 in festkörperunterstützten Membranen..... 79

3.6.4 Konfokale Laserscanningmikroskopie von festkörperunterstützten

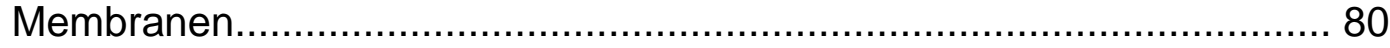




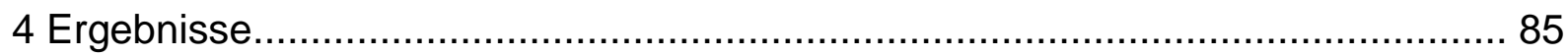

4.1 Lipidanalysen von synchronisierten Thalassiosira pseudonana-Kulturen ....... 85

4.1.1 Fettsäureanalyse des Totallipidextrakts von Thalassiosira pseudonana.. 85

4.1.2 Bestimmung und Quantifizierung der polaren Hauptlipidklassen ............. 88

4.1.3 Bestimmung relativer Lipid- und Fettsäureprofile einzelner Lipidklassen . 94

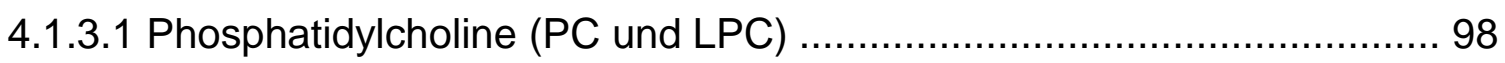

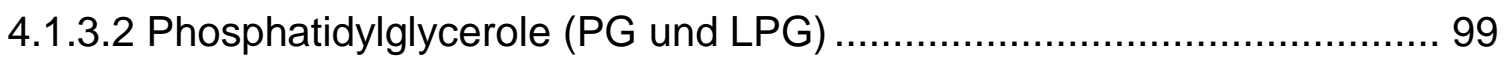

4.1.3.3 Phosphatidylethanolamine (PE und LPE) .................................. 99

4.1.3.4 Phosphatidylinositole (PI und LPI) ...................................... 100

4.1.3.5 Phosphatidylserine (PS und LPS) ........................................... 100

4.1.3.6 Phosphatidsäuren (PA und LPA) ............................................... 100

4.1.3.7 Monogalactosyldiacyl- und monoacylglycerole (MGDG und MGMG) .. 101

4.1.3.8 Digalactosyldiacyl- und monoacylglycerole (DGDG und DGMG) ....... 101

4.1.3.9 Sulfoquinovosyldiacyl- und monoacylglycerole (SQDG und SQMG) ... 101

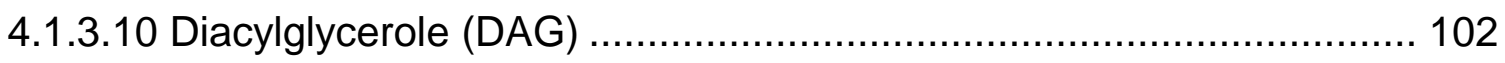

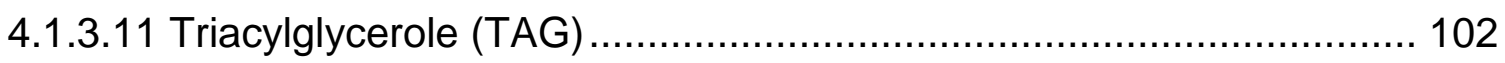

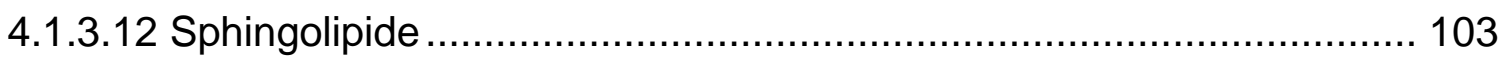

4.1.3.13 Sterole und Sterolester (SE) ............................................ 106

4.1.4 Charakterisierung der FA-Zusammensetzung einzelner Lipidklassen nach

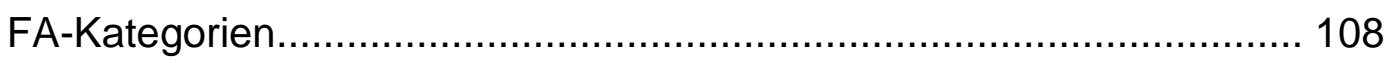

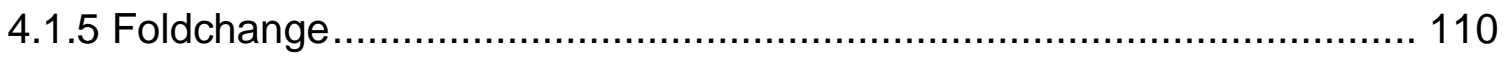

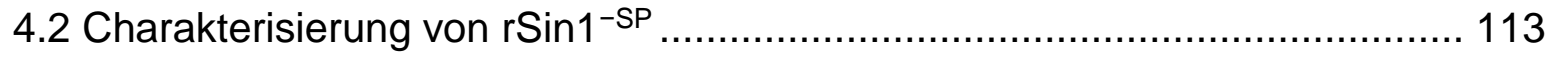

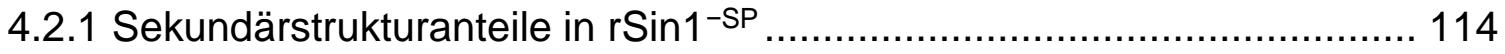

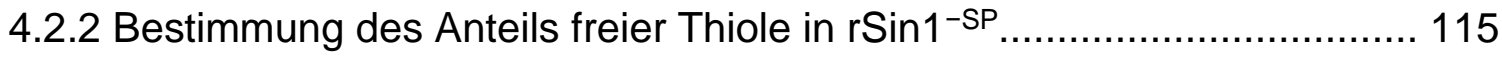

4.2.3 Aggregatbildung von rSin1 in saurer Lösung .................................... 116

4.3 Charakterisierung von Vesikeln mit rekonstituiertem rSin1 ..................... 118

4.3.1 Realer Lipidanteil der Proteoliposomen nach Comizellisierung .............. 118

4.3.2 Größenbestimmung der mittels Comizellisierung präparierten Vesikel .. 119 
4.3.3 Bestimmung des integral in Proteoliposomen gebundenen rSin1-Anteils 120

4.3.4 Rekonstitutionseffizienz von $r \operatorname{Sin} 1^{-S P}$ in kleine unilammelare Vesikel .... 122

4.3.5 rSin1-Orientierung in Vesikeln...................................................... 125

4.3.6 Silicafällung von rSin1-haltigen Proteoliposomen ................................. 129

4.4 Charakterisierung rSin1-haltiger festkörperunterstützter Membranen........... 131

4.4.1 Präparation einer Lipideinzelschicht auf einem hydrophilen Substrat.... 132

4.4.2 Charakterisierung der kontinuierlichen Lipiddoppelschicht nach Einzelschicht-Vesikel-Fusion ......................................................... 133

4.4.3 Nachweis von rSin1 in festkörperunterstützten Membranen .................. 136

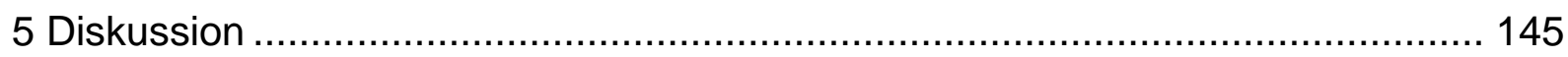

5.1 Lipidkomposition in Tp-div und Tp-G1 …........................................... 145

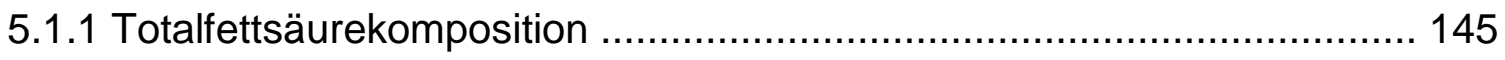

5.1.2 Hauptlipidklassen in Thalassiosira pseudonana.................................. 148

5.1.3 Lipid- und Fettsäureprofile einzelner Lipidklassen............................... 149

5.1.4 Foldchange einzelner Lipidklassen..................................................... 153

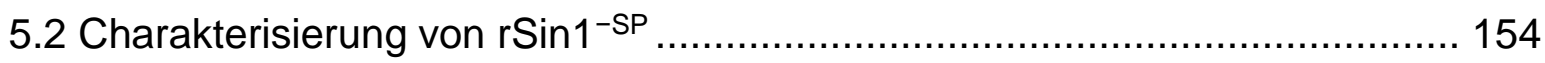

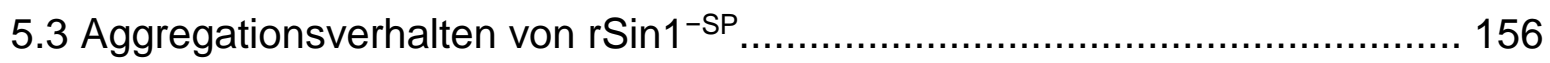

5.4 Rekonstitution von rSin 1-SP in kleine unilamellare Vesikel.......................... 157

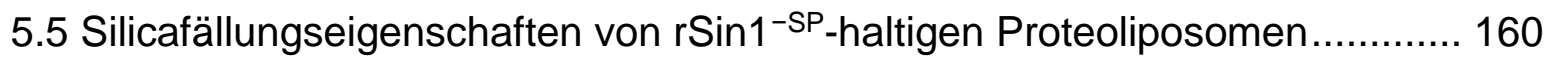

5.6 Visualisierung von rSin1-SP in festkörperunterstützten Membranen.............. 162

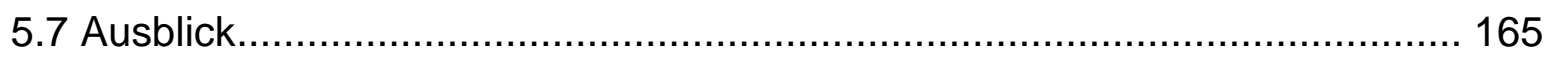

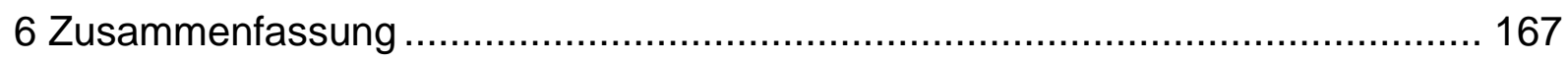

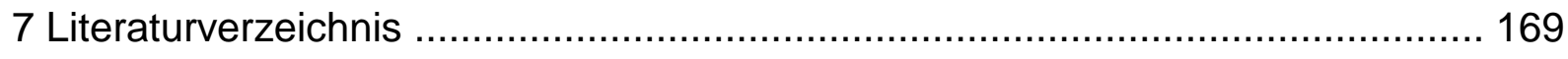

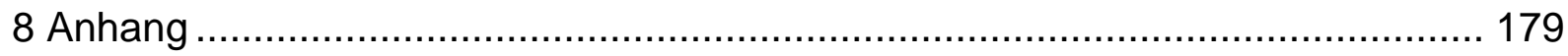

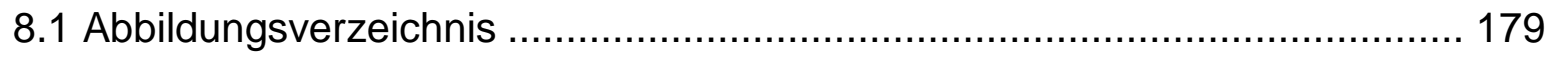

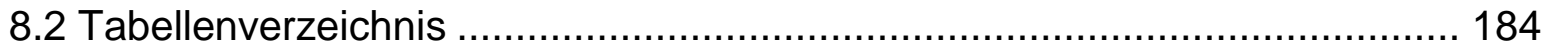

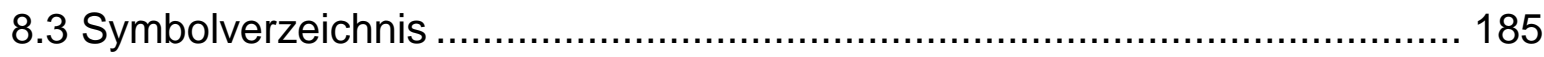




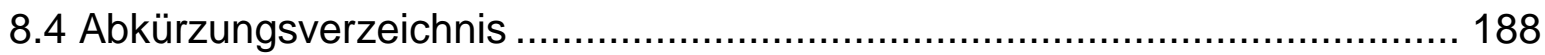

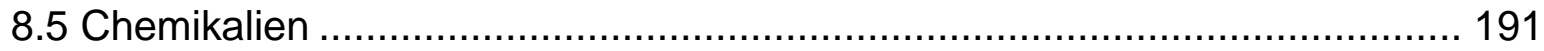

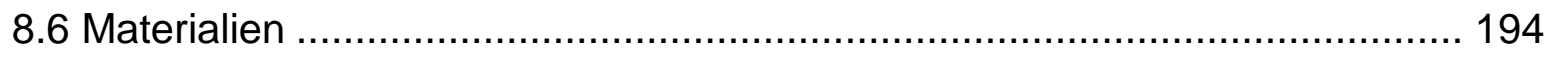

8.7 Geräte- und Softwareverzeichnis ......................................................... 195

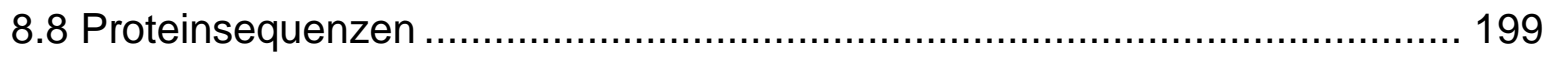

8.9 Exemplarisches Chromatogramm der GC-FID von PC .............................. 200

8.10 Relative FA-Profile aus der TLC-GC-FID .............................................. 200

8.11 Relative Lipid- und FA-Profile aus der LC-MS/MS ................................... 204

8.12 Verdauvorhersage für rSin $1^{-S P}$ durch Chymotrypsin................................ 223 
Inhaltsverzeichnis 


\section{Einleitung}

\subsection{Kieselalgen}

Kieselalgen, auch Diatomeen genannt, sind einzellige Eukaryoten der Algenklasse Bacillariophyceae, die zehntausende (vielleicht hunderttausende ${ }^{[1]}$ ) Arten und mehrere hundert Gattungen umfasst. Kieselalgen kommen in Salz- und Süßwasser vor, sind photoautotroph und tragen erheblich zur globalen $\mathrm{CO}_{2}$-Fixierung und Sauerstoffproduktion bei. Darüber hinaus bilden sie als wichtige Primärproduzenten mariner organischer Stoffe ${ }^{[2]}$ die Nahrungsgrundlage einer Vielzahl von Lebewesen. Sie existieren nachweislich seit mindestens 185 Millionen Jahren (Jura) und auch molekular-genetische Auswertungen sprechen für diesen Zeitraum. ${ }^{[3]}$ Mit ihrer Fossilierung zu Kieselgur (Diatomeenerde) lieferten sie der Menschheit eine wertvolle Ressource, die nicht nur Alfred Nobel die Erfindung des Dynamits ermöglichte, sondern auch zur Filtration von z.B. Wasser und Bier verwendet wird. ${ }^{[4]}$ Kieselalgen unterscheiden sich von anderen Mikroalgen durch ihre Produktion einer Frustel genannten Zellwand, die vor allem aus Silica (Siliciumdioxid) besteht und durch Polykondensation von Kieselsäure unter Beteiligung vieler Biomoleküle entsteht (siehe Kapitel 1.2). Diese Frustel dient aufgrund ihrer mechanischen Stabilität in erster Linie dem Schutz vor Fressfeinden ${ }^{[5]}$, doch auch Funktionen als photonischer Kristall zur Verbesserung der Lichtausbeute ${ }^{[6]}$ sowie eine Protonenpufferkapazität zur Erhöhung der $\mathrm{CO}_{2}$-Aufnahme ${ }^{[7]}$ werden diskutiert. Kieselalgen werden nach der Form ihrer Frusteln in zentrische und pennate Arten unterschieden. Zentrische Kieselalgen zeigen entweder eine radiale Symmetrie oder aber bi- oder multipolare Symmetrien der Frusteln. Pennate Kieselalgen haben eine bilaterale Symmetrie mit lang gestreckten Formen. Sie können Raphen besitzen, die eine schlitzartige Öffnung in der Frustel darstellen und die dem Einzeller mittels direkten Kontakts des Protoplasten mit einer Substratoberfläche die Fortbewegung ermöglicht, bei der ein Aktin-MyosinSystem involviert ist. ${ }^{[8]}$ Araphide Pennaten sowie zentrische Kieselalgen sind dagegen unbeweglich. Jede Kieselalgenart zeigt spezifische Porenstrukturen, die der Zelle den Austausch von Stoffen mit dem umgebenden Medium ermöglicht. ${ }^{\left[{ }^{[0]}\right.}$ 
Die Frustel ist unterteilt in zwei deckelartige Valven und dazwischenliegende Gürtelbänder, wie in Abb. 1.1 für die zentrische Kieselalge Thalassiosira pseudonana gezeigt wird. Die beiden Valven sind dabei in ihrer Größe leicht verschieden, sodass sie wie Deckel und Schachtel ineinandergreifen. Die größere Valve heißt Epitheca, die kleinere Hypotheca. Abb. 1.2 zeigt schematisch den Reproduktionszyklus von Thalassiosira pseudonana durch Zellteilung. ${ }^{[1]}$ Durch Zellteilung des Protoplasten entstehen zwei Zellen, die noch von der selben Frustel umhüllt sind. An der Teilungsfurche bildet sich auf der cytoplasmatischen Seite nahe der Plasmamembran ein sogenanntes Silicafällungsvesikel (engl. silica deposition vesicle, SDV) aus, das eine eigene Membran, das Silicalemma, besitzt. Das zunächst kleine SDV ist der Ort der Silicafällung und damit der Morphogenese der neuen Valve. Mit zunehmender Größe der neuen Valve, wächst auch das SDV. Schließlich wird die Valve vermutlich durch Exocytose aus der Zelle ausgeschleust. Die Schwesterzellen können sich endgültig trennen und produzieren neue Gürtelbänder, ebenfalls in SDVs, womit die Zelle an Größe zunimmt, sodass sie erneut eine Zellteilung durchlaufen kann. ${ }^{[1]}$ Eine Kieselalgenschwesterzelle, die die Hypotheca von der Mutterzelle als Epitheca geerbt hat, kann die ursprüngliche Größe niemals erreichen. Dies hat zur Folge, dass Kieselalgenzellen mit der Zeit und fortdauernder Vermehrung durch Zellteilung theoretisch an Größe verlieren. Sexuelle Reproduktion erlaubt es der Kieselalgenkultur die Zellgrößen konstant zu halten. ${ }^{[10]}$ Außerdem zeigte die Proteingruppe der Silacidine einen Einfluss auf die Zellgröße von Thalassiosira pseudonana. Die Deregulierung des Proteins bewirkte eine Zunahme der Zellgröße. ${ }^{[11]}$

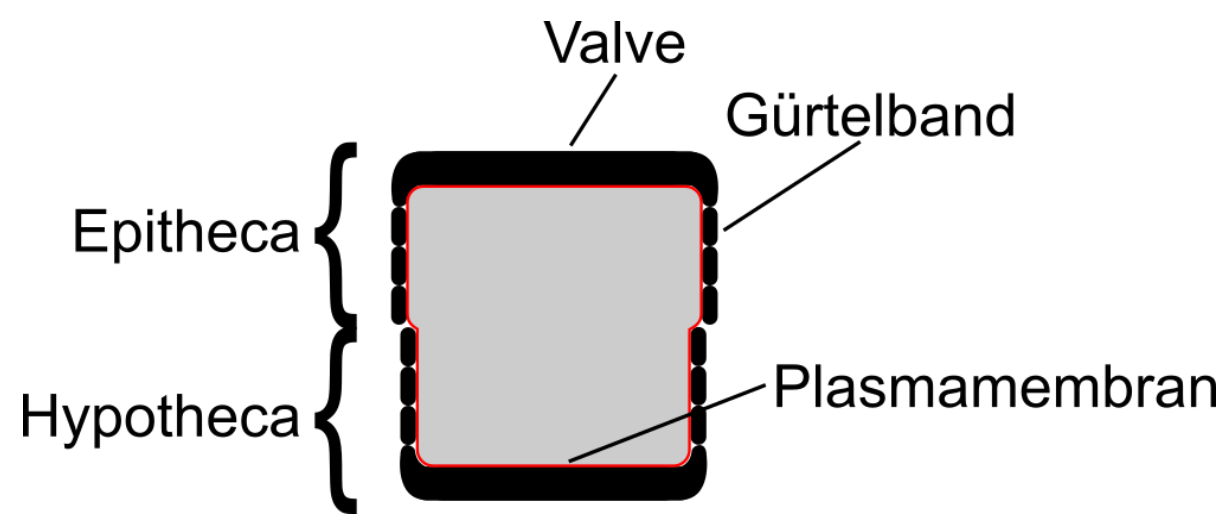

Abbildung 1.1: Schematische Zelldarstellung von Thalassiosira pseudonana aus Gürtelbandperspektive. Zur besseren Übersichtlichkeit sind Zellorganellen nicht abgebildet. Frei nach [1]. 


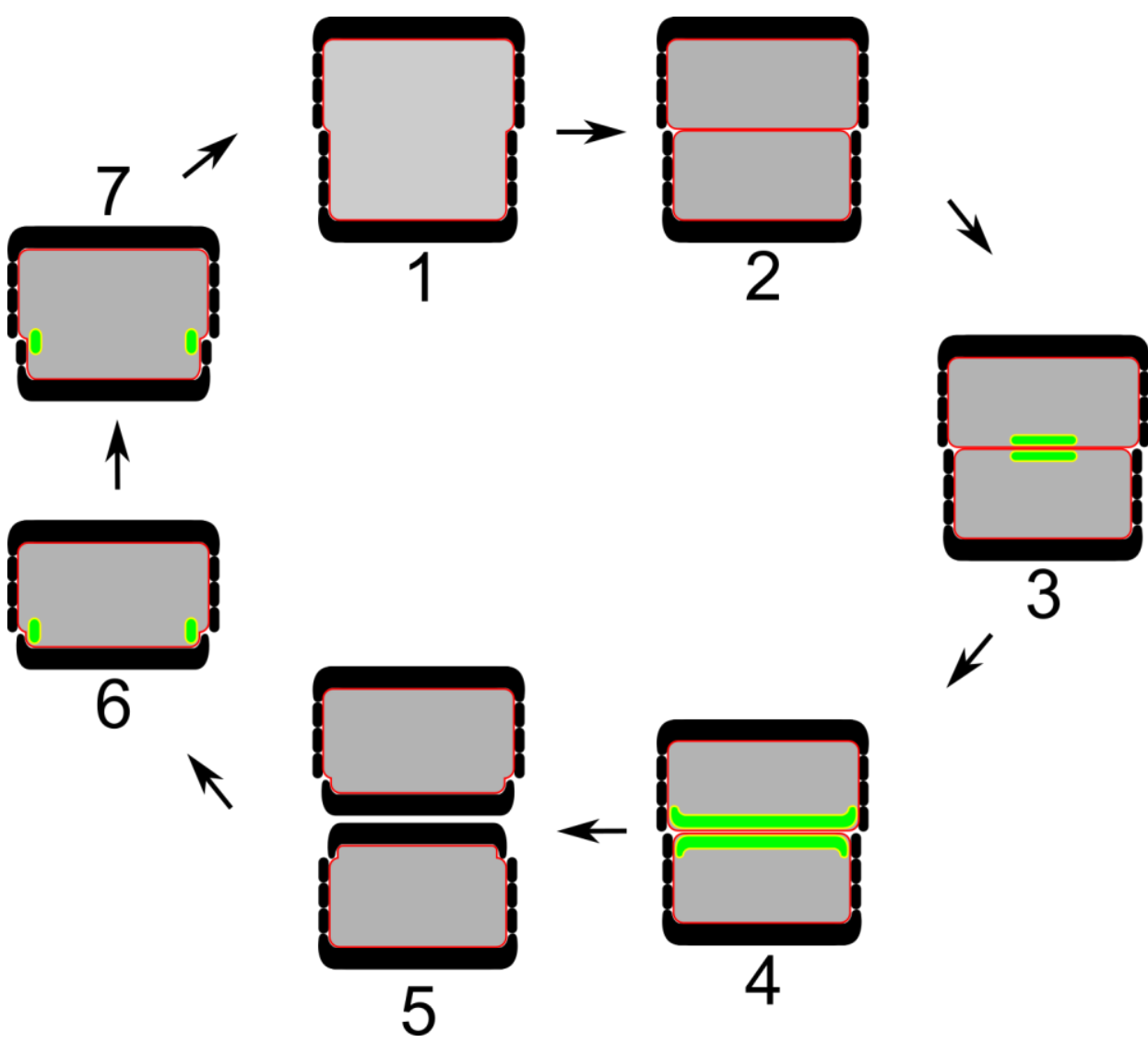

Abbildung 1.2: Schematische Übersicht über die Reproduktion von Thalassiosira pseudonana durch Zellteilung. Die reife Zelle (1) durchläuft die Zellteilung und bildet zwei Protoplasten (2). Nahe der Teilungsfurche entsteht ein Silicafällungsvesikel (SDV, gelbe Membran), in dem die Biomineralisation durch Fällung von Silica (grün) zu einer neuen Valve beginnt (3). Das SDV wächst, bis eine vollständige Valve mineralisiert ist (4). Die neue Valve tritt aus der Zelle aus, wird Bestandteil der Frustel und ermöglicht den Schwesterzellen die endgültige Trennung (5). Es werden neue Gürtelbänder in SDVs produziert, die die Frustel erweitern (6+7), sodass eine reife Zelle entsteht (1), welche den Zyklus von neuem beginnen kann. Frei nach [1].

Ein eukaryotischer Zellzyklus besteht aus vier Phasen. Phase M entspricht der Mitose, also der Zellteilung der Mutterzelle. Es folgt die Interphase bis zur nächsten Mitose. Die Interphase kann unterteilt werden in G1-, S- und G2-Phase. Die G1-Phase ist vom Zellwachstum geprägt. In der S-Phase wird die Desoxyribonukleinsäure (DNA) repliziert, damit eine erneute Zellteilung möglich wird. Phase G2 dient der Vorbereitung auf Phase M durch die Produktion benötigter Proteine und Faktoren. ${ }^{[12]}$

Kieselalgenkulturen können synchronisiert werden, sodass sie ihren Zellzyklus parallel durchlaufen. ${ }^{[13]}$ Dies gelingt, indem sie für mindestens $24 \mathrm{~h}$ einem Silicatmangel ausgesetzt werden, ehe sie erneut mit Silicat versorgt werden. Ohne Silicat bzw. 
Kieselsäure können Kieselalgen keine neuen Frusteln aufbauen und müssen ihren Zellzyklus unterbrechen. Dabei ruhen sie zumeist entweder in der G1-Phase oder in der späten G2+M-Phase. ${ }^{[12]}$ Nach Silicatzugabe starten die meisten Zellen ihren Zyklus gleichzeitig. Der Anteil an synchronisierten Zellen kann erhöht werden, wenn die Synchronisation zweimal hintereinander durchgeführt wird. ${ }^{[14]}$ Die während der Mangelphase in der G1-Phase ruhenden Thalassiosira pseudonana-Zellen brauchen 1-4 h, um in die nächsten Phasen (S gefolgt von G2+M) zu gelangen. ${ }^{[15]}$ Die ValvenProduktion im SDV findet in der G2+M-Phase statt. ${ }^{[13]}$ Eine maximale Konzentration an Valven-SDVs konnte $3 \mathrm{~h}$ nach Silicatzugabe beobachtet werden. ${ }^{[14]}$

\subsection{Biomineralisation in Kieselalgen}

- Teile dieses Kapitels wurden aus der Masterarbeit des Autors übernommen. ${ }^{[16]}$

Die Biogenese der Silicazellwand von Kieselalgen findet in einem speziellen Organell statt, dem Silica Deposition Vesicle (SDV), das ein saures Lumen besitzt. ${ }^{[17]}$ Dieses Organell wurde nicht nur in Kieselalgen, sondern auch in Schwämmen, Kragengeißeltierchen und Strahlentierchen sowie der Algenordnung der Synurophyceae gefunden. ${ }^{[18]}$ Es ist bislang nicht gelungen Kieselalgen-SDVs zu isolieren. ${ }^{[1,15]}$ Der anorganische Rohstoff des Biosilicas ist die ortho-Kieselsäure $\mathrm{Si}(\mathrm{OH})_{4}$. Diese kommt in allen Gewässern i.d.R. in mikromolarer Konzentration, in den Diatomeen jedoch bis zu millimolar vor. ${ }^{[19]}$ Es bedarf eines aktiven $\mathrm{Si}(\mathrm{OH})_{4}$-Transports in die Zelle, der über $\mathrm{Si}(\mathrm{OH})_{4}$-Transportproteine (engl. silicic acid transporter proteins, SIT) erfolgt. ${ }^{[20]}$ Es wurde gezeigt, dass ein Teil dieser SITs eine eher untergeordnete Rolle im Transportvorgang selbst spielt, wenn die $\mathrm{Si}(\mathrm{OH})_{4}-\mathrm{Konzentration} \mathrm{hoch} \mathrm{genug}$ ist. Vielmehr haben diese Proteine eine Sensorfunktion für den $\mathrm{Si}(\mathrm{OH})_{4}-\mathrm{Gehalt}$ in der Zelle und beeinflussen die Bewertung, ob Zellwandausbildung und Zellteilung fortgesetzt werden können. ${ }^{[21]}$ Dass die Polykondensation der Kieselsäure zu Silica nur im SDV stattfindet und nicht an anderer Stelle der Zelle, hängt vermutlich mit dem sauren pH-Wert im Lumen des SDVs zusammen. Dieser wird auf ca. 5 geschätzt. ${ }^{[17,1]}$ Ein saures Milieu maskiert die negative Nettooberflächenladung des Silicas, sodass kleine Silicapartikel aggregieren können und unter Umständen ein Gelnetzwerk ausbilden. ${ }^{[15]}$

Die Biogenese der Zellwand nutzt nicht nur die Polykondensation der Kieselsäure, es ist vielmehr eine Vielzahl an Biomolekülen an der Biomineralisierung beteiligt. Zu den 
Proteinen, die in Diatomeenzellwänden gefunden wurden, gehören Silaffine, Cinguline, Silacidine, langkettige Polyamine (engl. long-chain polyamines, LCPA), Frustuline und Pleuraline. Für Frustuline konnte gezeigt werden, dass sie nicht an der Biogenese teilnehmen, sondern erst anschließend an die Zellwand assoziieren. ${ }^{[22]}$ Pleuraline konnten insbesondere innerhalb der Teilungsfurche und resultierend daraus an Pleuralbänder genannten finalen Gürtelbändern nachgewiesen werden. ${ }^{[23]}$ Als Funktion wird eine Bindung an Silaffinen und Frustulinen und die Verknüpfung der letzteren an die Zellwand diskutiert. [24]

Silaffine und Silacidine besitzen $N$-terminale Signalpeptide, die für den Transport in das ER nötig sind und dort posttranslationalen Modifikationen (PTM) wie Phosphorylierungen oder der Verknüpfung mit LCPAs über Lysinreste unterzogen werden. Es konnte gezeigt werden, dass diese PTMs die Silicamineralisierung erheblich beschleunigen. ${ }^{[25]}$ Während LCPAs positiv geladen und Silacidine stark negativ geladen sind, zeigen Silaffine zwitterionischen Charakter. Diese Ladungsstruktur sowie die ungeordnete Sekundärstruktur in diesen Proteinen lassen vermuten, dass sie als Polyelektrolytketten fungieren. ${ }^{[26]}$ Die proteingebundenen LCPAs können Polykieselsäure-Nanopartikel binden und die Silicabildung beschleunigen. ${ }^{[27,1]}$ Sowohl Silacidine als auch Silaffine zeigen insbesondere in Gegenwart von LCPAs die Tendenz große Aggregate zu bilden. Diese Aggregate können in Lösung poröse Silicastrukturen ausbilden, die allerdings einer unregelmäßigen Musterung unterliegen. ${ }^{[26,1]}$ Während Silaffine eine Rolle für die Valvensynthese zu spielen scheinen, kommen die Cinguline in der GürtelbandZellwand vor. ${ }^{[28]}$ Letztere sind Teil der organischen Mikroringe, die den Ringformen mitsamt filamentöser Muster der Gürtelbänder entsprechen und vermutlich Hohlräume für Silacidin-LCPA-Aggregate bereitstellen. ${ }^{[26]}$ Auch für Cinguline konnten posttranslationale LCPA-Bindungen gezeigt werden. ${ }^{[29]}$

Für die Silicabildung wird angenommen, dass die phosphoproteingebundenen LCPAs kleine Mikrotropfen darstellen, um die das Silica in hexagonaler Form ausfällt. [30] Diese Theorie erklärt nicht-hexagonale Zellwandmuster der Diatomeen jedoch nicht. ${ }^{[26]}$ Der genaue Ablauf der Biomineralisation wurde insbesondere für Thalassiosira pseudonana untersucht. So konnten verschiedene Wachstumsphasen der Valve detailliert visualisiert und beschrieben werden. ${ }^{[14]}$ Zudem wurde nachgewiesen, dass das Silica mit organischer Materie versetzt ist, ein Beleg für die organische Matrix. ${ }^{[14]}$ Bei der Valvensynthese bildet sich zunächst eine sehr flexible Basisschicht in $x-y-$ 
Ebene. ${ }^{[31]}$ Die Basisschicht bildet später die proximale Seite der Valve und die Porenmuster und grundlegenden Strukturen sind dabei bereits angelegt. ${ }^{\left[{ }^{[1]}\right.}$ Sobald die Ausdehnung in $x$-y-Richtung abgeschlossen ist, beginnt das Wachstum in zRichtung. ${ }^{[31]}$ Die Morphologie des Silicas unterscheidet sich dabei örtlich und auch im zeitlichen Verlauf der Valvensynthese. ${ }^{[31,15]}$ Die vollständig ausgebildete Valve wird schließlich mittels Exocytose aus der Zelle ausgeschleust und in die Frustel eingebaut. Der genaue Vorgang der SDV-Exocytose ist unklar, doch wird vermutet, dass die SDVMembran mit der Plasmamembran verschmilzt und große Teile der ehemaligen SDVMembran anschließend wieder durch Endocytose entfernt werden, um die Funktionalität der Plasmamembran nicht zu gefährden. ${ }^{[1]}$

Die Plastizität der Silicamembran scheint die Form des Silicas zu beeinflussen. ${ }^{[15]}$ So führt die Kompression zweier Schwesterzellen zu einer Verformung[32], wie auch Mikrotubuli Vertiefungen im Biosilica hinterlassen können. ${ }^{[33]}$ Es ist wahrscheinlich, dass Mikrotubuli und Aktin mit Proteinen des SDV interagieren, sie positionieren und so die Silicabildung mitbestimmen. ${ }^{[15]}$ Die ersten identifizierten SDV-assoziierten Transmembranproteine sind die Silicanine ${ }^{[29,34]}$ (siehe Kapitel 1.3) der Spezies Thalassiosira pseudonana. Kurz danach wurden auch die SAPs (silicalemma associated proteins) als Transmembranproteine derselben Spezies beschrieben, die in der Membran des SDVs eingebaut sind. ${ }^{[35]}$ Der Knockdown von zwei der SAPs bewirkte die Ausbildung fehlgeformter Valven, was ihre Bedeutung für die ValvenSilicabiogenese unterstreicht. TpSAP3 hinterlässt seine luminale $N$-terminale Domäne im Biosilica, während die cytosolische $C$-terminale Domäne abgespalten wird.

\subsection{Silicanin-1}

Silicanin-1 (Sin1) aus Thalassiosira pseudonana war das erste identifizierte SDVassoziierte Transmembranprotein und wurde zuerst SiMat7 (SiMat für silica matrix protein) genannt. ${ }^{[29]}$ Es wurde in der unlöslichen Fraktion der organischen Matrix des Biosilicas gefunden und besitzt 426 Aminosäuren und eine molare Masse von $46.7 \mathrm{kDa}$, wobei die ersten $15 \mathrm{~N}$-terminalen Aminosäuren als Signalpeptid für den Zugang zum ER identifiziert wurden und im reifen Sin1 fehlen dürften (Abb. 1.3). Die Aminosäuresequenz ist in Anhang 8.8 gezeigt. Seine Funktion als Transmembranprotein konnte mittels Carbonat-Extraktion nachgewiesen werden. ${ }^{[34]}$ 
Sin1 wird ähnlich stark exprimiert wie Silaffine und Cinguline ${ }^{[36]}$ und Silicanin-Gene sind in Kieselalgen stark konserviert, was ihre Bedeutung für die Silicabiogenese hervorheben könnte. Dem Signalpeptid folgt ein RRL-Domäne genannter Bereich von 30 Aminosäuren, der auf $R R L$ endet und damit dem $R X L-M o t i v$ entspricht, das viele Biosilica-assoziierte Proteine in Kieselalgen gemeinsam haben. Möglicherweise dient dieses Motiv als Schnittstelle für Enzyme. Die weiterhin 341 Aminosäuren große $N$ terminale Domäne ist reich an Glutamin $(Q)$ und Asparagin $(N)$, typisch für clusterbildende Proteine, und besitzt zudem 18 Cysteine. Transmembrandomäne und $C$-terminale Domäne haben jeweils 20 Aminosäuren. Experimente mit GFPmarkiertem $\operatorname{Sin} 1$ zeigten, dass die $N$-terminale (extrazelluläre oder luminale) Domäne im Biosilica der Valve lokalisiert war, während die $C$-terminale (intrazelluläre oder cytosolische) Domäne abgespalten wird. ${ }^{[34]}$ Hierin ähnelt sie TpSAP3. Eine mögliche Schnittstelle zwischen luminaler Domäne und Transmembrandomäne oder ein damit verbundenes Enzym wurden noch nicht identifiziert. Die Aufgabe der SDV-assoziierten Transmembranproteine könnte die Mediation zwischen cytosolischen Komponenten wie Mikrotubuli oder Aktin und dem SDV-Lumen sein. ${ }^{[34,36,35]}$ Versuche mit Sin1Knockout-Mutanten zeigten, dass auch ohne funktionierendes Sin1 Valven produziert werden, diese allerdings morphologische Abweichungen und weniger Biosilica aufweisen. Dies führt zu einem Verlust an mechanischer Robustheit. ${ }^{[37]}$ Versuche mit einer rekombinanten luminalen Sin1-Domäne (rSin1 1um, Abb. 1.3, Proteinsequenz im Anhang 8.8) zeigten, dass es bei SDV-Lumen typischem $\mathrm{pH}$-Wert in der Nähe von 5 beginnt Aggregate zu bilden. ${ }^{[34]}$ Erklärbar ist dies durch den niedrigen pl-Wert von Sin1 um 4.7, sodass die nettonegative Ladung des Proteins bei saurem pH-Wert maskiert wird und Selbstaggregation begünstigt. Diese Aggregate könnten eine Rolle bei der Silicabiogenese spielen. Dabei ist denkbar, dass isotropische oder anisotropische Sin1-Cluster in Wechselwirkungen mit anderen Komponenten im SDV-Lumen involviert sind, oder dass Sin1-Cluster die SDV-Membran großflächig bedecken und so als Separator zwischen Biosilica und Membran dienen. ${ }^{[34]}$ Eine äquimolare Mischung von rSin1lum mit LCPAs zeigte einen synergistischen Effekt bezüglich der Silicafällungseigenschaften. Negativ geladenes Sin1 könnte dabei die Akkumulation von positiv geladenen LCPAs bewirken, an denen Silica ausgefällt wird. ${ }^{[34]}$ Neben rSin $1^{\text {lum }}$ wird rSin1-SP erwähnt ${ }^{[34]}$, das als rekombinantes Sin1 Transmembrandomäne und cytosolische Domäne besitzt und dem nur das Signalpeptid fehlt (Abb. 1.3, Proteinsequenz im Anhang 8.8). Die Isolation dieses Hexa-Histidin-markierten 
Proteins (409 Aminosäuren, $45.1 \mathrm{kDa}$ ) war Bestandteil der Masterarbeit des Autors. ${ }^{[16]}$ Als Transmembranprotein ist Sin1 in die SDV-Membran eingebaut. Aus welchen Lipiden diese Membran besteht, ist noch unbekannt.

\section{$\operatorname{Sin} 1$}

rSin1 $1^{\text {lum }}$

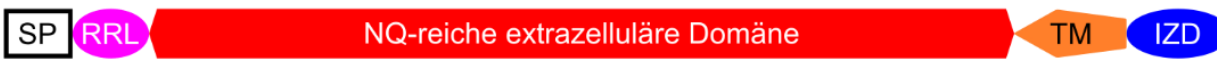

rSin1-SP
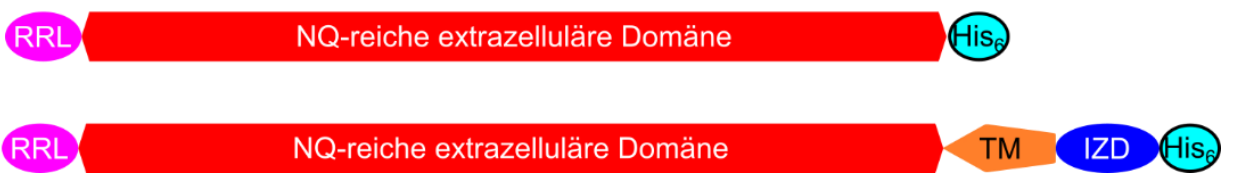

Abbildung 1.3: Schema der Domäneneinteilung von Silicanin-1 (Sin1) und seine rekombinanten Varianten (rSin1). SP: Signalpeptid, TM: Transmembrandomäne, IZD: intrazelluläre Domäne, His6: Hexa-Histidin-Markierung.

\subsection{Lipide in Kieselalgen}

Kieselalgen sind wie alle Lebewesen auf die Stoffgruppe der Lipide angewiesen, einerseits als Energiespeicher, andererseits als Hauptbestandteil von Membranen. Dabei können Lipide über $25 \%$ der Trockenmasse von Kieselalgen ausmachen. [38,39] Lipide sind kleine hydrophobe oder amphipathische Moleküle. ${ }^{[40]}$ Membranlipide weisen neben einer hydrophoben Gruppe („Schwanz“) eine hydrophile Kopfgruppe auf, sodass sie in wässriger Lösung zur spontanen Bildung von Lipiddoppelschichten oder mizellenartigen Strukturen neigen. Membranlipide können in die drei Klassen der Phospholipide, Glycolipide und Sterole unterteilt werden. Phospho- und Glycolipide basieren dabei entweder auf einem Glycerol- oder aber auf einem SphingosinGrundgerüst, an das Fettsäuren verestert sein können, die den hydrophoben Bereich des Lipids bilden. Abb. 1.4 zeigt eine Auswahl an Glycerolipiden. Die polaren Glycound Phosphoglycerolipide Monogalactosyldiacylglycerol (MGDG), Digalactosyldiacylglycerol (DGDG), Sulfoquinovosyldiacylglycerol (SQDG), Phosphatidsäure (engl. phosphatidic acid, PA), Phosphatidylcholin (PC), Phosphatidylethanolamin (PE), Phosphatidylglycerol (PG), Phosphatidylinositol (PI), Phosphatidylserin (PS) und die Neutrallipide Diacylglycerol (DAG) und Triacylglycerol (TAG) sind für viele Kieselalgen, so auch Thalassiosira pseudonana, nachgewiesen. Das in dieser Spezies einzig auftretende Betainlipid ist Diacylglyceryl-3-O- 
carboxyhydroxymethylcholin (DGCC), das bei Phosphatmangel PC ersetzen kann. ${ }^{[41]}$ Für manche Kieselalgen wurde neben SQDG die Existenz weiterer Sulfolipide bestätigt, so etwa 1-Deoxyceramid-1-sulfat und Phosphatidylsulfocholin. ${ }^{[42,39]}$ Die drei Glycolipide MGDG, DGDG und SQDG sowie PG sind die hauptsächlichen Lipidkomponenten von Thylakoidmembranen und daher für die Photosynthese nicht nur in Kieselalgen unerlässlich. ${ }^{[43]}$ DAG ist ein wichtiges Intermediat in der Synthese vieler Lipide. ${ }^{[44]}$ TAG dagegen dient als Energiespeicher und Fettsäurereservoir ${ }^{[45]}$ und befindet sich in Lipidtröpfchen, deren Funktion über eine bloße Energiespeicherfunktion hinausgeht. ${ }^{[46]}$ Bei bis zu 24-stündigem Silicatmangel erhöht Thalassiosira pseudonana die Fettsäure- und TAG-Menge und akkumuliert so seine Energiereserven für den Fall, dass die ungünstigen Bedingungen länger anhalten. ${ }^{[47]}$

Sphingolipide in Kieselalgen können einfache Ceramide sein, die aus mit einer Fettsäure verestertem Sphingosin bestehen ${ }^{[48]}$, oder aber Cerebroside, deren Ceramid zusätzlich mit Glucose- oder Mannosemolekülen verknüpft ist. ${ }^{[49,48]}$ Die physiologische Funktion von pflanzlichen Cerebrosiden liegt in der Beeinflussung der Membranstabilität, Membranpermeabilität sowie Pathogenese, während Ceramide eine Rolle beim programmierten Zelltod spielen. ${ }^{[50]}$ Glycosylinositolphosphoceramide (GIPCs) sind als weitere Sphingolipidgruppe für koloniebildende Mikroalgen nachgewiesen worden. ${ }^{[51]}$

Sterolverbindungen in Mikroalgen werden zur Gruppe der Phytosterole gerechnet. Sie liegen entweder als freie Sterole (FS) vor oder sind mit einer Fettsäure zu Sterolestern (SE), mit Zuckereinheiten zu Sterylglycosiden (SG) oder zusätzlich dazu mit einer Fettsäure zu acylierten Sterylglycosiden (ASG) verbunden. Ihre Anteile an der Gesamtsterolmenge können dabei von Spezies zu Spezies stark variieren. ${ }^{[52]}$ Sterole beeinflussen die Membrandynamik und -fluidität ${ }^{[53]}$ und Kieselalgen zeigen Sterollevelanpassungen, wenn sie anderen Salzgehalten oder Temperaturen ausgesetzt werden. ${ }^{[54]}$ Hier nicht weiter behandelte Lipidgruppen, die in Kieselalgen nachgewiesen wurden, sind Oxylipine und Isoprenoide. ${ }^{[39]}$ 
<smiles>[R]C(=O)OCC(CO)OC([R])=O</smiles>

Diacylglycerol (DAG)

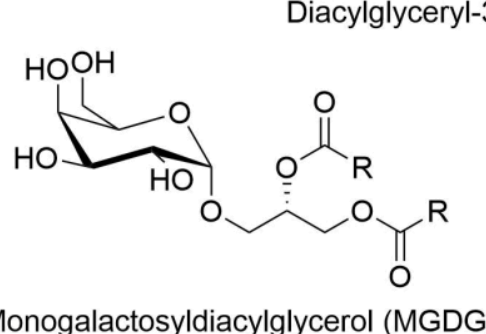

Monogalactosyldiacylglycerol (MGDG)<smiles>[R]C(=O)OCC(COP(=O)([O-])OCC[NH3+])OC([R])=O</smiles>
Phosphatidylethanolamin (PE)<smiles>[R]C(=O)OCC(COP(=O)([O-])OC[C@H](N)C(=O)[O-])OC([R])=O</smiles>

Phosphatidylserin (PS)<smiles>[R]C(=O)OCC(COC(OCC[NH3+])C(=O)[O-])OC([R])=O</smiles>$$
\text { (n) }
$$

oxymethylcholin (DGC

lin (DGCC)

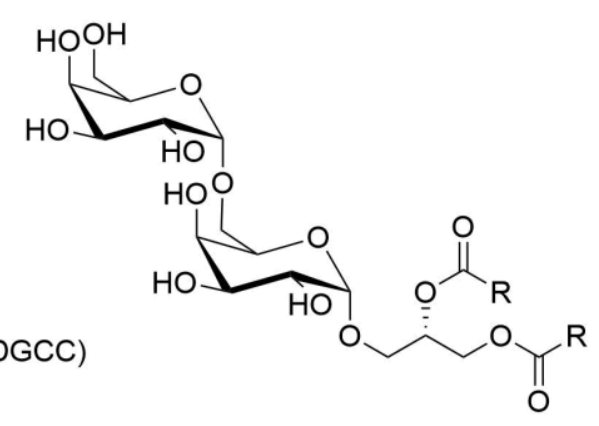

Digalactosyldiacylglycerol (DGDG)

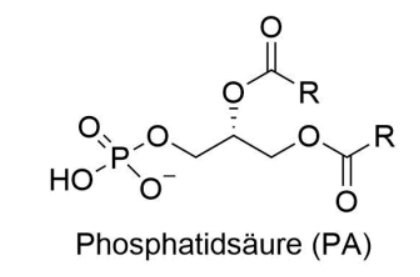<smiles>[R]C(=O)OC[C@H](COP(=O)([O-])OC[C@H](O)CO)OC([R])=O</smiles>

Phosphatidylglycerol (PG)

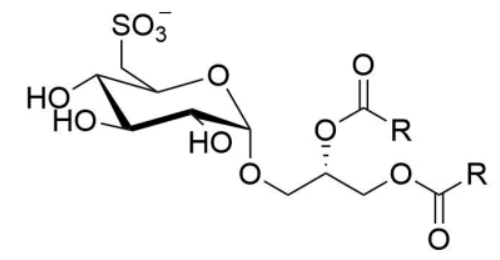

Sulfoquinovosyldiaycylglycerol (SQDG)<smiles>[R]C(=O)OCC(COP(=O)([O-])OCC[N+](C)(C)C)OC([R])=O</smiles>

Phosphatidylcholin (PC)<smiles>[R]C(=O)OCC(COP(=O)([O-])OC1C(O)C(O)C2OC1C(O)C(O)C2O)OC([R])=O</smiles>

Phosphatidylinositol (PI)<smiles>[R]C(=O)OCC(COC([R])=O)OC([R])=O</smiles>

Abbildung 1.4: Auswahl an Glycerolipiden, die in Kieselalgen vorkommen. Die carboxygebundenen Reste $R$ unterscheiden sich je nach gebundener Fettsäure. Ist stattdessen nur eine Fettsäure gebunden, handelt es sich um Lyso- bzw. Monoacylformen.

Die Benennung von Fettsäuren kann nach dem Schema „Kohlenstoffkettenlänge:Anzahl der C-C-Doppelbindungen“ erfolgen. So besitzt Palmitinsäure 16 Kohlenstoffatome und keine C-C-Doppelbindung, sodass sie auch als 16:0 bezeichnet wird (Abb. 1.5). Eine einfach ungesättigte C-16-Fettsäure mit der C-C-Doppelbindung zwischen C9 und C10 in cis-Konfiguration heißt 16:1 (9Z). Die fünffach ungesättigte Eicosapentaensäure (engl. eicosapentaenoic acid, EPA) mit 20 C-Atomen heißt 20:5, die sechsfach ungesättigte Docosahexaensäure (engl. docosahexaenoic acid, DHA) wird als 22:6 bezeichnet. 20:5- und 22:6-Synthese in 
Kieselalgen finden i.d.R. im ER statt, während Fettsäuren mit bis zu $18 \mathrm{C}$-Atomen vor allem in Plastiden produziert werden. ${ }^{[44]}$ 20:5 und 22:6 sind als hochgradig ungesättigte Omega-3-Fettsäuren aus nahrungsmittelwissenschaftlicher aber auch pharmakologischer Sicht sehr wertvolle Fettsäuren. ${ }^{[39]}$ Für 22:6 konnte gezeigt werden, dass es in Membranen eine Aversion gegen Cholesterol aufweist, sodass es zu Phasenseparation mit der Ausbildung von 22:6-haltigen stark ungeordneten Bereichen kommt. Diese ungeordneten Bereiche werden als Gegenstück zu den sogenannten lipid rafts (Lipidflößen) beschrieben. ${ }^{[55]}$ Die Nutzung von Kieselalgenkulturen zur Biotreibstoffproduktion wird ebenfalls untersucht. Dabei sind vor allem die Gesamtfettsäureproduktion sowie die Synthese von Triacylglycerol (TAG) von Interesse. Die Erhöhung dieser Produktionen in Kieselalgen durch optimierte Kultivierungsbedingungen oder Genmanipulation ist Gegenstand zahlreicher Veröffentlichungen. ${ }^{[56,39,44]}$<smiles>CCCCCCCCCCCCCCCC(=O)O</smiles><smiles>CCCCCCCCCCCCCCCCCC(=O)O</smiles>

18:0<smiles>CCCCCC/C=C/CCCCCCCC(=O)O</smiles><smiles>CC/C=C/C/C=C/C/C=C/C/C=C/C/C=C/CCCC(=O)O</smiles><smiles>CC/C=C\C/C=C\C/C=C\C/C=C\C/C=C\C/C=C\CCC(=O)O</smiles>

Abbildung 1.5: Beispiele für Fettsäuren und ihre in dieser Arbeit verwendete Nomenklatur. 


\subsection{Modellmembranen}

Membranen sind biomolekulare Barrieren, die Reaktions- und Funktionsräume voneinander abgrenzen. Diese Kompartimentierung erlaubt es der Zelle gleichzeitig viele verschiedene Reaktionen und Prozesse zu durchlaufen, die miteinander interagieren könnten. Membranen bestehen aus Membranlipiden, die eine Doppelschicht ausbilden, sodass die hydrophoben Lipidbereiche zueinander gerichtet den hydrophoben Membrankern bilden, während die hydrophilen Lipidkopfgruppen die beiden Grenzen zu dem wässrigen Medium darstellen. Diese Barriere ist für kleine ungeladene oder auch unpolare Moleküle durchlässig, nicht jedoch für geladene oder sehr große Teilchen. Die notwendige Translokation von Ionen und Biomolekülen wie Zucker oder Proteinen von einer Membranseite auf die andere erfolgt daher über Membranproteine wie Transporter, Pumpen oder kanalbildende Proteine. ${ }^{[57]}$ Membranproteine können jedoch auch der Interaktion mit Stoffen aus dem wässrigen Medium dienen, sodass z.B. Cytoskelettkomponenten an Membranen fixiert werden oder Botenstoffe an Rezeptoren binden. Integrale Membranproteine sind mit hydrophoben Transmembrandomänen in der Lipiddoppelschicht verankert. Die Membran stellt quasi eine zweidimensionale Flüssigkeit dar und ist nach dem Fluidmosaic-Modell von Singer und Nicolson ${ }^{[58]}$ wie ein See aus Lipiden vorstellbar, in dem Membranproteine schwimmen. Die Lipide und Membranproteine können lateral diffundieren. Die transverse Diffusion von Membranlipiden ist dagegen stark gehemmt und geschieht in Zellen vor allem mit Hilfe von Flippasen genannten Enzymen. ${ }^{[59]}$

Die Untersuchung von Membrandynamiken, den zugrundeliegenden Energien oder der Interaktion von Membranen mit verschiedensten Stoffen kann experimentell auf zwei Arten erfolgen. In vivo-Untersuchungen an lebenden Organismen bieten den Vorteil eine Membran in ihrer natürlichen Umgebung zu beobachten, allerdings befinden sich viele verschiedene Stoffe im System und die sehr heterogene Umgebung übt unterschiedlichste Einflüsse auf die betrachtete Membran aus. Diese Komplexität erschwert die Analyse spezifischer Prozesse und Wechselwirkungen. Zudem sind hochauflösende Analysetechniken oftmals inkompatibel mit lebenden Organsimen. ${ }^{[60]}$ In vitro-Experimente finden unter kontrollierten, künstlichen Bedingungen statt, die i.d.R. eine deutlich geringere Komplexität aufweisen als in vivoSysteme. 
Modellmembranen sind vergleichsweise einfach aufgebaute artifizielle Membranen, die genutzt werden um spezifischen Fragestellungen nachzugehen. Die Präparation von Modellmembranen aus beliebig zusammengesetzten Lipidfilmen ermöglicht Studien zu vielen verschiedenen Lipidkompositionen, die eventuell stark von der Natur abweichen können. Auf diese Weise können z.B. Einflüsse von verschiedenen Cholesterolgehalten auf die Fluidität oder Stabilität einer Membran untersucht werden.

Die Präparation von unilamellaren Vesikeln (Liposomen) verschiedener Größen kann dabei bereits als eine Form der Modellmembran betrachtet werden, in der die vesikuläre Lipiddoppelschicht zu einer Kugel gekrümmt vorliegt. Dies macht sie zu guten Modellen für in Organismen auftretenden Liposomen. ${ }^{[61]}$ Durch die Möglichkeit der Rekonstitution von Transmembranproteinen in Vesikel können auch Proteoliposomen modellhaft dargestellt werden.

Planare Membranen zeigen keine Krümmung und ähneln daher zellulären Membranen, die in vielen Bereichen ebenfalls kaum Krümmung aufweisen. Festkörperunterstützte Membranen sind i.d.R. sehr stabil und eignen sich gut um laterale Organisationen von Proteinen und Lipiden mittels abbildender Methoden zu untersuchen. ${ }^{[62]}$ Auch Rezeptor-Ligand-Wechselwirkungen können mit festkörperunterstützten Membranen im Rahmen von stark oberflächensensitiven Messmethoden wie Oberflächenplasmonenresonanzspektroskopie oder dem Einsatz der Quarzmikrowaage analysiert sowie thermodynamisch und kinetisch quantifiziert werden ${ }^{\left[{ }^{62]}\right]}$ Festkörperunterstützte Membranen bieten nur ca. $1 \mathrm{~nm}$ Platz zwischen unterer Lipidschicht und dem Substrat. ${ }^{[63]}$ Rekonstituierte Proteine könnten daher in starke Wechselwirkung mit dem Substrat treten und denaturieren oder kleben bleiben. Um dies zu verhindern, sind alternative Modelle wie tethered membranes geeignet, wobei ein Abstandshalter Platz zwischen Substrat und Lipiddoppelschicht generiert, sodass Proteindomänen in diesem Bereich genügend Raum finden, ohne direkt mit dem Substrat in Kontakt zu kommen. ${ }^{[64]}$ Ist es experimentell gewünscht, dass Membranen auf beiden Seiten Zugang zum wässrigen Medium haben, sind porenüberspannende Membranen das Mittel der Wahl, da sie die Stabilität von festkörperunterstützten Membranen mit den Eigenschaften von freitragenden Membranen kombinieren. ${ }^{[62]}$

Die Verwendung von Modellmembranen in Studien zu Kieselalgen ist bisher kaum gebräuchlich. Gräb et al.[65] nutzten eine artifizielle festkörperunterstützte Membran 
aus MGDG-, DGDG-, SQDG-, PG- und PC-Lipiden, um die Membranwechselwirkung mit LCPAs zu untersuchen. Diese Lipidkomposition beruhte auf Totallipidkompositionen von Kieselalgen. Die Herstellung einer SDV-Modellmembran kann ein wichtiger Schritt in der Erforschung der Bedeutung der Membran und seiner einzelnen Komponenten für die Silicabiogenese in Kieselalgen werden. Ein erweitertes Verständnis der in der Silicabiogenese involvierten Prozesse kann dazu dienen, nanoporöse anorganische Strukturen biomimetisch zu erzeugen. Dies kann relevant für den Transport von Medikamenten im Organismus[66] oder für die unter milden Bedingungen ablaufende Produktion von Materialien mit überlegenen Eigenschaften sein. ${ }^{[67]}$ 


\section{Zielsetzung}

Ziel dieser Arbeit ist die Präparation einer planaren Modellmembran des Silicafällungsvesikels (SDV) aus Kieselalgen. Diese erlaubt die in vitro-Untersuchung von Wechselwirkungen der SDV-Membran mit für die Biomineralisation relevanten Biomolekülen sowie ihren Einfluss auf die Menge oder Struktur des gefällten Biosilicas. Für die Entwicklung einer solchen Modellmembran wird das Lipidom der Kieselalgenspezies Thalassiosira pseudonana (Tp) analysiert. Es werden die Lipidanalysen von synchronisierten Tp-Kulturen verglichen, die entweder in der Zellzyklusphase der Zellteilung bei angereicherten Valven-SDVs (Tp-div) oder aber in der G1-Phase nach der Zellteilung (Tp-G1) geerntet werden. Der Unterschied im Lipidom dieser beiden Tp-Kulturen kann einen Hinweis auf die Lipidkomposition der Valven-SDVs liefern, da diese Organellen in Tp-div vorhanden, in Tp-G1 jedoch nicht präsent sind. Die Identifikation von SDV-spezifischen Lipidklassen ist der Ausgangspunkt der Präparation artifizieller SDV-Modellmembranen.

Für eine elaboriertere Nachstellung der SDV-Membran wird die Modellmembran nicht nur aus Lipiden aufgebaut, sondern enthält das SDV-assoziierte Transmembranprotein Silicanin-1 (Sin1), das in Tp-Valven nachgewiesen wurde. Das rekombinante Sin1 ohne Signalpeptid ( $\left.r \operatorname{Sin} 1^{-S P}\right)$ wird dazu nach seiner Charakterisierung in kleine unilamellare Vesikel rekonstituiert. Um eine planare Modellmembran zu generieren, werden die Proteoliposomen auf hydrophilen Substraten gespreitet. Die Visualisierung und Charakterisierung dieser festkörperunterstützten Membran mittels Fluoreszenzmikroskopie dient der Überprüfung des Spreiterfolgs sowie der generellen Funktionsfähigkeit der Membran. Die Visualisierung des rSin1 erfolgt auf indirektem Weg mit fluoreszierenden Antikörpern unter Vermeidung einer kovalenten Mehrfachmarkierung mit Fluorophoren. Ebenfalls von Interesse sind die Silicafällungseigenschaften der rSin1haltigen Proteoliposomen sowie die Selbstaggregation von $r$ Sin1 bei Ansäuerung, die beide eine wichtige Rolle in der Tp-spezifischen Biomineralisation spielen könnten. Diese Untersuchungen sollen helfen, die Funktion des Sin1 im Membranraum für die Biomineralisation von $\mathrm{Tp}$ zu verstehen. 


\section{Materialien und Methoden}

\subsection{Lipidanalysen von Thalassiosira pseudonana}

\subsubsection{Kultivierung, Synchronisation und Ernte der Diatomeenkulturen}

-Die Arbeiten des Kapitels 3.1.1 wurden von Christoph Heintze (BCUBE Dresden) durchgeführt.-

Alle Diatomeenkulturen der Spezies Thalassiosira pseudonana (Tp) CCMP1335 (je $300 \mathrm{~mL}$ ) wurden ungefähr 5 Tage bei einem Tag/Nacht-Zyklus von $12 \mathrm{~h} / 12 \mathrm{~h}$ in modifiziertem artifiziellem Meerwasser ${ }^{[14]}$ (artificial sea water, ASW) bei 5000 10000 lux kultiviert und bis zu einer Dichte von $5 \cdot 10^{5}$ Zellen pro $\mathrm{mL}$ wachsen gelassen. Die Zelldichtemessung erfolgte mit einem TC10 Automated Cell Counter (Bio-Rad). Nach einer Ernte durch Zentrifugation (3000 g, $10 \mathrm{~min}$ ) wurden die Zellpellets in Silicamangelmedium $\mathrm{ASW}\left(\mathrm{Si}^{-}\right)$resuspendiert und $24 \mathrm{~h}$ inkubiert, bevor sie mit $\mathrm{Na}_{2} \mathrm{SiO}_{3}$ (final $200 \mu \mathrm{M}$ ) versetzt wurden $(t=0 \mathrm{~h})$. Nach $t=2-3 \mathrm{~h}$ wurden die synchronisierten Zellen im Stadium der Zellteilung bei angereicherten ValvenSilicafällungsvesikeln (Tp-div) geerntet. Bei $t=6 \mathrm{~h}$ wurden die Zellen im Stadium der G1-Interphase und Abwesenheit von Valven-Silicafällungsvesikeln (Tp-G1) geerntet. Die Zellen wurden dreimal mit Wasser gewaschen und anschließend in flüssigem Stickstoff eingefroren und lyophilisiert (Christ Alpha 2-4 LD Plus). Die getrockneten Zellen wurden bei $-80^{\circ} \mathrm{C}$ gelagert.

\subsubsection{Lipidextraktion}

-Die Arbeiten in Kapitel 3.1.2 wurden im Arbeitskreis von Prof. Ivo Feußner durchgeführt.-

Die Extraktion von Lipiden aus den Diatomeenkulturproben erfolgte nach dem Protokoll von Bligh und Dyer ${ }^{[68]}$ mit folgenden Modifikationen. Je 2-8 mg des Probenmaterials wurden nach dem Lyophilisieren mit $3 \mathrm{~mL}$ Chloroform/Methanol (1:2, $v / v$ ) versetzt, mit Argon überschichtet und $4 \mathrm{~h}$ bei $4^{\circ} \mathrm{C}$ geschüttelt. Die Überschichtung mit Argon erfolgte stets, wenn Chloroform oder Tetrahydrofuran verwendet wurde. Die Probe wurde zentrifugiert $\left(450 \mathrm{~g}, 4{ }^{\circ} \mathrm{C}, 10 \mathrm{~min}\right)$ und der Überstand in ein neues Reagenzglas überführt. Der Rückstand wurde mit Chloroform/Methanol $(2: 1, v / v)$ 
versetzt, kräftig geschüttelt und ü. N. bei $4^{\circ} \mathrm{C}$ geschüttelt. Die Probe wurde zentrifugiert $\left(450 \mathrm{~g}, 4{ }^{\circ} \mathrm{C}, 10 \mathrm{~min}\right)$ und die Überstände vereint. Die vereinigten Überstände wurden mit $1.5 \mathrm{~mL} 0.45 \%(w / v) \mathrm{NaCl}$ versetzt und $20 \mathrm{~s}$ kräftig geschüttelt. Nach dem Zentrifugieren ( $450 \mathrm{~g}, 4^{\circ} \mathrm{C}, 3 \mathrm{~min}$ ) wurde die untere Phase in ein neues Reagenzglas überführt. Es wurde jeweils eine Spatelspitze $\mathrm{Na}_{2} \mathrm{SO}_{4}$ (wasserfrei) zugegeben und $20 \mathrm{~s}$ kräftig geschüttelt, um restliches Wasser zu binden. Nach erneuter Zentrifugation $\left(450 \mathrm{~g}, 4^{\circ} \mathrm{C}, 10 \mathrm{~min}\right)$ wurde der Überstand in ein neues Reagenzglas überführt und das Lösungsmittel im Stickstoffstrom bis zur Trockene eingeengt. Der Lipidfilm wurde in $800 \mu \mathrm{L}$ Tetrahydrofuran/Methanol/Wasser (TMW; 4:4:1, $v / v / v)$ aufgenommen, kräftig geschüttelt, 1 min im Ultraschallbad sonifiziert und zentrifugiert ( $450 \mathrm{~g}, 4^{\circ} \mathrm{C}, 10 \mathrm{~min}$ ). Der Überstand wurde in eine $1.5 \mathrm{~mL}$-Probenflasche überführt und bei $-20^{\circ} \mathrm{C}$ gelagert.

\subsubsection{Chemische Modifikation der Lipidextrakte}

Für die Analyse bestimmter Lipidklassen oder Fettsäuren im Allgemeinen mussten die Lipidextrakte chemisch verändert werden.

\subsubsection{Methylierung von (Lyso-)Phosphatidsäure}

-Die Arbeiten in Kapitel 3.1.3.1 wurden im Arbeitskreis von Prof. Ivo Feußner von Sabine Freitag durchgeführt.-

Für die LC-MS/MS-Analyse (siehe Kapitel 3.1.6) von Phosphatidsäure (PA) und Lysophosphatidsäure (LPA) wurde eine Methylierung der Lipidextrakte durchgeführt. ${ }^{[69]}$ Hierfür wurden $80 \mu \mathrm{L}$ des Lipidextrakts (siehe Kapitel 3.1.2) im Stickstoffstrom bis zur Trockene eingeengt und anschließend in $400 \mu \mathrm{L}$ Methanol aufgenommen. Die Probe wurde mit $6.5 \mu \mathrm{L}$ Trimethylsilyldiazomethan $(2 \mathrm{M}$ in Hexan; Merck KGaA Darmstadt) versetzt, 30 min bei RT geschüttelt und $2 \mu \mathrm{L} 10 \%(v / v)$ Essigsäure zugefügt. Die Probe wurde im Stickstoffstrom bis zur Trockene eingeengt, in $80 \mu \mathrm{L} \mathrm{TMW}$ aufgenommen, mit Argon überschichtet und bei $-20^{\circ} \mathrm{C}$ gelagert. 


\subsubsection{Acetylierung freier Sterole}

-Die Arbeiten in Kapitel 3.1.3.2 wurden im Arbeitskreis von Prof. Ivo Feußner von Sabine Freitag durchgeführt.-

Für die LC-MS/MS-Analyse (siehe Kapitel 3.1.6) von freien Sterolen wurden die Lipidextrakte nach einem modifizierten Protokol|[70] acetyliert. Dazu wurden $40 \mu \mathrm{L}$ der Lipidextrakte im Stickstoffstrom bis zur Trockene eingeengt, mit $100 \mu \mathrm{L}$ Pyridin und $50 \mu \mathrm{L}$ Acetanhydrid versetzt und kräftig geschüttelt. Nach der Inkubation bei $50{ }^{\circ} \mathrm{C}$ für 30 min wurde die Probe im Stickstoffstrom bis zur Trockene eingeengt und in $40 \mu \mathrm{L}$ TMW aufgenommen, mit Argon überschichtet und bei $-20^{\circ} \mathrm{C}$ gelagert.

\subsubsection{Fettsäuremethylveresterung}

-Die Arbeiten in Kapitel 3.1.3.3 wurden im Arbeitskreis von Prof. Ivo Feußner durchgeführt.-

Für die GC-FID-Analysen wurden die freien und lipidgebundenen Fettsäuren zunächst in Fettsäuremethylester (engl. fatty acid methyl esters, FAME) umgewandelt. ${ }^{[71]}$ Dazu wurden $40 \mu \mathrm{L}$ der Lipidextrakte im Stickstoffstrom bis zur Trockene eingeengt. Für die saure Methanolyse wurde je $1 \mathrm{~mL}$ FAME-Lösung (Methanol/Toluol/Dimethoxypropan/Schwefelsäure $=66: 33: 2: 2.5, v / v / v / v)$ sowie als interner Standard 2 bzw. $3 \mu \mathrm{L}$ Triheptadecanoylglycerol in Toluol $(c=1.58 \mathrm{mg} / \mathrm{mL})$ zugegeben, die Probe mit Argon überschichtet und kurz kräftig geschüttelt. Die Probe wurde $1 \mathrm{~h}$ bei $80^{\circ} \mathrm{C}$ im Wasserbad schüttelnd inkubiert. Anschließend wurden $1.5 \mathrm{~mL}$ gesättigte $\mathrm{NaCl}$-Lösung und $1.2 \mathrm{~mL} n$-Hexan zugegeben, mit Argon überschichtet und $10 \mathrm{~s}$ kräftig geschüttelt. Nach der Zentrifugation $\left(450 \mathrm{~g}, 20^{\circ} \mathrm{C}, 10 \mathrm{~min}\right.$ ) wurde die obere Phase in ein neues Reagenzglas überführt und im Stickstoffstrom bis zur Trockene eingeengt. Der Rückstand wurde in $100 \mu \mathrm{L}$ Acetonitril aufgenommen und $10 \mathrm{~s}$ kräftig geschüttelt. Nach der Zentrifugation $\left(450 \mathrm{~g}, 20^{\circ} \mathrm{C}, 2 \mathrm{~min}\right.$ ) wurde die Probe in eine $1.5 \mathrm{~mL}$-Probenflasche überführt und im Stickstoffstrom bis zur Trockene eingeengt. Der Rückstand wurde in $20 \mu \mathrm{L}$ Acetonitril aufgenommen, mit Argon überschichtet, kräftig geschüttelt und zentrifugiert $\left(800 \mathrm{~g}, 20^{\circ} \mathrm{C}, 5 \mathrm{~min}\right)$. Die Lagerung der Proben erfolgte bei $-20^{\circ} \mathrm{C}$. 


\subsubsection{Dünnschichtchromatographische Trennung von polaren Lipidklassen}

-Die Arbeiten in Kapitel 3.1.4 wurden im Arbeitskreis von Prof. Ivo Feußner zusammen mit Sabine Freitag durchgeführt. Die Silicaplatten wurden von Sabine Freitag vorbereitet.-

Die Dünnschichtchromatographie ${ }^{[72]}$ (thin layer chromatography, TLC) diente der Trennung der polaren Lipidklassen PC, PE, SQDG/PI/PS, DGDG, PG, MGDG und PA. Dazu wurde als stationäre Phase eine Silica-beschichtete Glasplatte (DC Kieselgel 60 mit Konzentrationszone 2.5×20 cm; 20x20 cm; Merck KGaA, Darmstadt) verwendet, die in $0.15 \mathrm{M}\left(\mathrm{NH}_{4}\right)_{2} \mathrm{SO}_{4}$-Lösung zur Imprägnierung inkubiert und an der Luft mindestens $2 \mathrm{~d}$ getrocknet wurde. Zur Aktivierung der Platte wurde sie direkt vor Gebrauch $2.5 \mathrm{~h}$ auf $120^{\circ} \mathrm{C}$ erhitzt. Die Lipidextraktprobe (ca. $1 \mu \mathrm{mol}$ bzw. $270 \mu \mathrm{g}$ Fettsäuren) wurde im Stickstoffstrom bis zur Trockene eingeengt, sukzessive in insgesamt $150 \mu \mathrm{L}$ Chloroform/Methanol $(2: 1, v / v)$ gelöst, kräftig geschüttelt und in eine $1.5 \mathrm{~mL}$-Probenflasche überführt. Die Probe wurde im Stickstoffstrom bis zur Trockene eingeengt, der Rückstand in $30 \mu \mathrm{L}$ Chloroform/Methanol $(2: 1, v / v)$ gelöst, kräftig geschüttelt und zentrifugiert $\left(450 \mathrm{~g}, 20^{\circ} \mathrm{C}, 20 \mathrm{~s}\right)$. Nach Abkühlen der Platte auf RT wurden die Proben in ca. $3 \mathrm{~cm}$ breiten Streifen auf der Startlinie aufgetragen. Neben den Lipiextraktproben wurde am linken und rechten Rand der Platte jeweils eine Mischung aus Lipidreferenzsubstanzen aufgetragen. Die Trennung der Lipide erfolgte mit Aceton/Toluol/Wasser (91:30:8, v/v/v) für ca. $1.5 \mathrm{~h}$. Die Platte wurde anschließend an der Luft getrocknet und die Seitenbereiche der Platte, die mit den Lipidreferenzsubstanzen versehen waren, wurden abgeschnitten. Die Färbung der Lipidreferenzsubstanzen erfolgte durch Eintauchen in $0.4 \mathrm{M} \mathrm{CuSO}_{4}$ in $6.8 \%(v / v)$ $\mathrm{H}_{3} \mathrm{PO}_{4}$ und anschließendem Erhitzen der Platte auf mindestens $180^{\circ} \mathrm{C}$. Die Färbung der Diatomeenlipidproben erfolgte reversibel über das Besprühen mit $0.05 \%$ Primulin (in $80 \%$ Aceton). Die Visualisierung der Lipide erfolgte im UV-Licht. Dort wurden angefärbte Silicabereiche mit einem Bleistift eingekreist. Die Silicabereiche wurden anschließend mit einem Spatel ausgekratzt in Probengefäße überführt. Die Proben wurden nun der Fettsäuremethylveresterung zugeführt (siehe Kapitel 3.1.3.3). Vor der Inkubation bei $80^{\circ} \mathrm{C}$ im Wasserbad wurden die Proben zusätzlich bei RT ü. N. stehen gelassen. 


\subsubsection{Gaschromatografie mit Flammenionisationsdetektion (GC-FID)}

-Die Arbeiten in Kapitel 3.1.5 wurden im Arbeitskreis von Prof. Ivo Feußner durchgeführt. Die Messdurchführung erfolgte durch Dr. Cornelia Herrfurth oder zusammen mit Sabine Freitag.-

Zur Detektion der Fettsäuremethylester (siehe Kapitel 3.1.3.3) wurde eine Gaschromatografie mit Flammenionisationsdetektion (GC-FID) durchgeführt. ${ }^{\text {[73] }}$ Diese Technik ermöglicht eine quantitative Bestimmung der Fettsäuremengen. Die Analysen wurden an einem Agilent 6890 Chromatografen (Agilent Technologies, Waldbronn, Deutschland) mit einem Kapillarsystem DB-23 Column (30 m x $0.25 \mathrm{~mm} ; 0.25 \mu \mathrm{m}$ Beschichtungsdicke; J\&W Scientific, Agilent Technologies, Waldbronn, Deutschland) ausgeführt. Das Probeninjektionsvolumen betrug $1 \mu \mathrm{L}$. Helium wurde als Trägergas mit einer Durchflussrate von $1 \mathrm{~mL} / \mathrm{min}$ verwendet. Es wurde folgender Temperaturgradient verwendet: $1 \mathrm{~min} 150{ }^{\circ} \mathrm{C}, 150-200^{\circ} \mathrm{C}$ bei $8 \mathrm{~K} / \mathrm{min}, 200-250{ }^{\circ} \mathrm{C}$ bei $25 \mathrm{~K} / \mathrm{min}$ und $250^{\circ} \mathrm{C}$ für $6 \mathrm{~min}$. Für die Analyse der Fettsäuremethylester resultierend von MGDG und DGDG nach der TLC-Trennung wurde ein Temperaturgradient mit $1 \mathrm{~min} 150^{\circ} \mathrm{C}, 150-200^{\circ} \mathrm{C}$ bei $4 \mathrm{~K} / \mathrm{min}, 200-250^{\circ} \mathrm{C}$ bei $5 \mathrm{~K} / \mathrm{min}$ und $250^{\circ} \mathrm{C}$ für 6 min genutzt, um die Trennung der Signale für 16:2 und 17:0 zu verbessern. Die Detektion erfolgte mittels Flammenionisation, wobei die Analyten vom Trägergas in eine Knallgasflamme transportiert wurden und dort durch Hitze ionisierten. Die frei werdenden Elektronen wurden als Strom erfasst, verstärkt und als Signal ausgegeben. Die Kohlenstoffanzahl in organischen Molekülen ist dabei maßgeblich für die Stärke des Signals. Es wurde neben den Proben mit dem internen Standard Triheptadecanoylglycerol auch ein externes Standardgemisch (FAME 37) vermessen, dessen Signale die genaue Retentionszeitzuordnung verschiedener FAMEs erlaubte. Die Signalzuordnung und -integration erfolgte mit der Agilent ChemStation Datenanalyse-Software. Zur Auswertung der detektierten Signale wurde Gleichung 3.1 genutzt. Die Bedeutungen der Variablen und Abkürzungen sind FA=Fettsäure, FE=Flächeneinheit des FID-Signalintegrals, Std=interner Standard, $M=$ Molare Masse, $D W=$ Trockengewicht, $n_{\mathrm{FA}}=$ Stoffmenge der Fettsäuren.

$$
\frac{F A[\mathrm{FE}] \cdot S t d[\mu \mathrm{g}]}{S t d[\mathrm{FE}] \cdot M_{\mathrm{FA}}[\mathrm{g} / \mathrm{mol}] \cdot D W[\mathrm{~g}]}=\frac{n_{\mathrm{FA}}[\mu \mathrm{mol}]}{D W[\mathrm{~g}]}
$$

Etwaige Blindprobensignale wurden vor der Division durch das Probengewicht von den Probensignalen subtrahiert. Die Resultate wurden $\mathrm{zu}$ Fettsäureprofilen zusammengetragen. 


\subsubsection{Flüssigchromatografie mit tandemmassenspektrometrischer Detektion von Lipiden (LC-MS/MS)}

-Die Arbeiten in Kapitel 3.1.6 wurden im Arbeitskreis von Prof. Ivo Feußner durchgeführt. Die Messdurchführung erfolgte durch Dr. Cornelia Herrfurth.-

Die Analyse konkreter Lipidspezies in Totallipidextraktproben erfolgte mittels Flüssigchromatografie mit Tandemmassenspektrometrie (LC-MS/MS). Die LC-MS/MS wurde in modifizierter Weise nach einem Protokoll von Tarazona ${ }^{[74]}$ angewandt.

Verwendet wurde hier eine ultra-performance liquid chromatography (UPLC) in Umkehrphase (engl. reversed-phase). Es handelte sich um ein ACQUITY UPLC Iclass-System (Waters, Milford, USA) mit einer ACQUITY UPLC HSS T3-Säule (100 mm x 1 mm, $1 \mu \mathrm{m}$; Waters, Milford, USA). Es wurden i.d.R. $2 \mu \mathrm{L}$ der Proben in TMW injiziert. Die Durchflussrate betrug $0.1 \mathrm{~mL} / \mathrm{min}$ bei einer Trennungstemperatur von $35^{\circ} \mathrm{C}$. Mit einem linearen binären Lösungsgradienten aus $A$ (Methanol/Ammoniumacetat $(20 \mathrm{~mm})=3: 7, \quad \mathrm{v} / \mathrm{v})$ und $\mathrm{B}$ (Tetrahydrofuran/Methanol/Ammoniumacetat $(20 \mathrm{~mm})=6: 3: 1, v / v / v)$ wurden die Lipide getrennt. A und B enthielten zudem $0.1 \%$ Essigsäure $(v / v)$. Die genauen Startbedingungen unterschieden sich je nach zu detektierenden Lipiden. Der Ablauf folgte jedoch dem Schema: 50-100\% B für 2 min, linearer Anstieg auf $100 \%$ B innerhalb von 8 min, Halten der $100 \%$ für 2 min und schließlich das Erreichen der Startbedingungen innerhalb von $4 \mathrm{~min}$.

Das Eluat wurde von der UPLC mit einer Durchflussrate von $250 \mathrm{~nL} / \mathrm{min}$ zur nanoElektrosprayionisationsquelle TriVersa Nanomate (Advion, Ithaca, USA) geleitet, die mit einem $5 \mu \mathrm{m}$-Zerstäuber verbunden war. Die lonenquellensteuerung erfolgte mit der Advion ChipSoftManager-Software. Die lonisierungsspannung $U$ wurde an die Lipidklassen angepasst. Phospho- und Glycolipide (auch ihre Lysospezies) wurden negativ ionisiert, Sphingolipide, Sterole/Sterolderivate, DAG und TAG wurden positiv ionisiert. Die lonendetektion erfolgte mit einem 6500 QTRAPTandemmassenspektrometer (AB Sciex, Framingham, MA, USA) im multiple reaction monitoring (MRM)-Modus.

Die Mutterionen der Lipidklassen waren $[\mathrm{M}+\mathrm{H}]^{+}$(Cer, GlcCer, Glc 2 Cer), $\left[\mathrm{M}+\mathrm{NH}_{4}\right]^{+}$ (Sterole/Sterolderivate, DAG, TAG), [M-H]- (Phospholipide außer PC, SQDG) und $[\mathrm{M}-\mathrm{H}+\mathrm{CH} 3 \mathrm{COOH}]^{-}$(PC, neutrale Glycolipide). Lipide mit mehr als einer Fettsäurekette wurden im negativen Modus auf Fettsäurefragmente analysiert, 
während im positiven Modus der Neutralverlust der Fettsäure detektiert wurde. Sphingolipide (Cer, GlcCer, Glc ${ }_{2} \mathrm{Cer}$ ) wurden im positiven Modus auf die Fragmentierung der dehydratisierten langkettingen Basen (LCB) analysiert.

Die Zuordnung der MRM-spezifischen Peaks in den Chromatogrammen erfolgte im Retentionszeitenvergleich mit anderen Proben sowie mit der Bedingung für asymmetrische Lipide mit zwei Fettsäuren, dass beide MRM-Signale gleiche Retentionszeiten und ähnliche Signalstärken aufwiesen. Die Integration der Peaks wurde mit der Software MultiQuant (AB Sciex, Framingham, MA, USA) durchgeführt und gegebenenfalls manuell angepasst, wenn die Integralflächen vom Programm nicht sinnvoll definiert wurden. Es folgte eine Kohlenstoffisotopenkorrektur der Peakintegrale (ICF, isotope correction factor) in Microsoft Excel mit der Gleichung 3.2. Dieser von der Anzahl an Kohlenstoffatomen $N(C)$ abhängige ICF wurde mit den Peakflächen multipliziert. ${ }^{[75]}$

$$
\mathrm{ICF}=1+0.011 \cdot N(\mathrm{C})+0.011^{2} \cdot N(\mathrm{C}) \cdot \frac{N(\mathrm{C})-1}{2}
$$

Korrigierte Peakflächen von asymmetrischen Lipiden mit mehr als einer Fettsäure wurden miteinander addiert, wenn sie als MRM-Kombination eine Lipidspezies darstellten. Etwaige Signale in Blindproben wurden von den Probensignalen subtrahiert. Die Werte wurden anschließend auf die Einwaage normiert und Daten von Tp-div bzw. Tp-G1 gemittelt. Aus den relativen Lipidprofilen wurden relative Fettsäureprofile berechnet.

\subsection{Proteinchemische Methoden}

\subsubsection{Transformation und Kultivierung von Escherichia coli}

Das für die Expression von rekombinantem Silicanin-1 ( $\mathrm{rSin} 1^{-\mathrm{SP}}$ ) verwendete Plasmid wurde von Dr. Alexander Kotzsch hergestellt ${ }^{[34]}$ und von Prof. Dr. Nils Kröger vom B Cube Center for Molecular Bioengineering der Technischen Universität Dresden für diese Arbeit zur Verfügung gestellt. Dabei diente pJ404 der Firma DNA 2.0 (heute Atum) als Vektor mit Ampicillinresistenz. ${ }^{[76]}$ 
Der Escherichia coli (E. coll)-Stamm BL21 (DE3) der Firma Invitrogen wurde mit dem Plasmid transformiert, indem das One Shot-Protokoll verwendet wurde. ${ }^{[77]}$ Dazu wurden die bei $-80^{\circ} \mathrm{C}$ gelagerten chemisch kompetenten Zellen $(50 \mu \mathrm{L})$ auf Eis mit $1 \mu \mathrm{L}$ der Plasmidlösung ( $\left.c=48.4 \mathrm{ng} \cdot \mu \mathrm{L}^{-1}\right)$ versetzt und 30 min inkubiert. Anschließend erfolgte ein Wärmeschock in einem Wasserbad bei $42{ }^{\circ} \mathrm{C}$ für $30 \mathrm{~s}$ mit anschließender Kühlung auf Eis für $5 \mathrm{~min}$. Es wurden $250 \mu \mathrm{L} 37^{\circ} \mathrm{C}$ warmes S.O.C.-Medium (Tab. 3.1) zugegeben und $1 \mathrm{~h}$ bei $37^{\circ} \mathrm{C}$ inkubiert.

Die Zellsuspension wurde auf Agarplatten (2\% (w/v) Agar-Agar in LB-Medium (Tab. 3.2); $50 \mu \mathrm{g} \cdot \mathrm{mL}^{-1}$ Ampicillin) mittels 13-Strich-Technik verstrichen und über Nacht bei $37^{\circ} \mathrm{C}$ inkubiert. Es wurde eine vereinzelt gewachsene Kolonie mittels Pipettenspitze gepickt und in LB-Nährmedium (50 mL; $100 \mu \mathrm{g} \cdot \mathrm{mL}^{-1}$ Ampicillin) überführt. Das Wachstum dieser Vorkultur erfolgte über Nacht bei $37^{\circ} \mathrm{C}$ und $175 \mathrm{rpm}$.

Puffer und Lösungen

Tabelle 3.1: Zusammensetzung des S.O.C-Mediums (Thermo Fisher Scientific). ${ }^{[78]}$

\begin{tabular}{cc}
\hline Komponente & Menge \\
\hline Trypton & $2 \%(w / v)$ \\
Hefeextrakt & $0.5 \%(w / v)$ \\
$\mathrm{NaCl}$ & $10 \mathrm{mM}$ \\
$\mathrm{KCl}$ & $2.5 \mathrm{mM}$ \\
$\mathrm{MgCl}_{2}$ & $10 \mathrm{mM}$ \\
$\mathrm{MgSO}_{4}$ & $10 \mathrm{mM}$ \\
Glucose & $20 \mathrm{mM}$ \\
\hline
\end{tabular}

Tabelle 3.2: Zusammensetzung des LB-Mediums.

\begin{tabular}{cc}
\hline Komponente & Menge \\
\hline Trypton & $1 \%(w / v)$ \\
Hefeextrakt & $0.5 \%(w / v)$ \\
$\mathrm{NaCl}$ & $1 \%(w / v)$ \\
\hline
\end{tabular}

Das Medium wurde in Reinstwasser angesetzt und autoklaviert. 


\subsubsection{Expression von rSin $1^{-\mathrm{SP}}$ in E. coli und Zellernte}

- Teile dieses Kapitels wurden aus der Masterarbeit des Autors übernommen. ${ }^{[16]}$

Es wurden Hauptkulturen der Bakteriensuspension angesetzt, indem LB-Nährmedium (250 mL; $100 \mu \mathrm{g} \cdot \mathrm{mL}^{-1}$ Ampicillin) mit $1 \mathrm{~mL}$ Vorkultur angeimpft wurde. Die Inkubation dieser Hauptkulturen erfolgte bei $37^{\circ} \mathrm{C}$ und $225 \mathrm{rpm}$ im Schüttelinkubator. Nach dem Animpfen der Hauptkulturen wurde die optische Dichte bei $600 \mathrm{~nm} O D_{600}$ als Maß für das bakterielle Wachstum photometrisch ermittelt. Erreichte der $O D_{600}$ einen Wert von ungefähr 1, wurden pro $250 \mathrm{~mL}$ Hauptkultur $250 \mu \mathrm{L} 1 \mathrm{M}$ Isopropyl- $\beta$-Dthiogalactopyranosid (IPTG)-Lösung (Abb. 3.1) induziert, sodass jede Hauptkultur $1 \mathrm{~mm}$ IPTG enthielt. Die Inkubation der Hauptkulturen wurde nach IPTG-Induktion $4 \mathrm{~h}$ fortgeführt. Ein exemplarischer Verlauf der $O D_{600}$-Entwicklung ist in Abb. 3.2 dargestellt und zeigt eine sigmoidale Wachstumskurve.

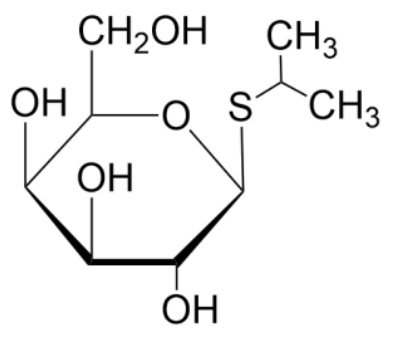

Abbildung 3.1: Haworthprojektion des Isopropyl- $\beta$-D-thiogalactopyranosids (IPTG). ${ }^{[16]}$ 


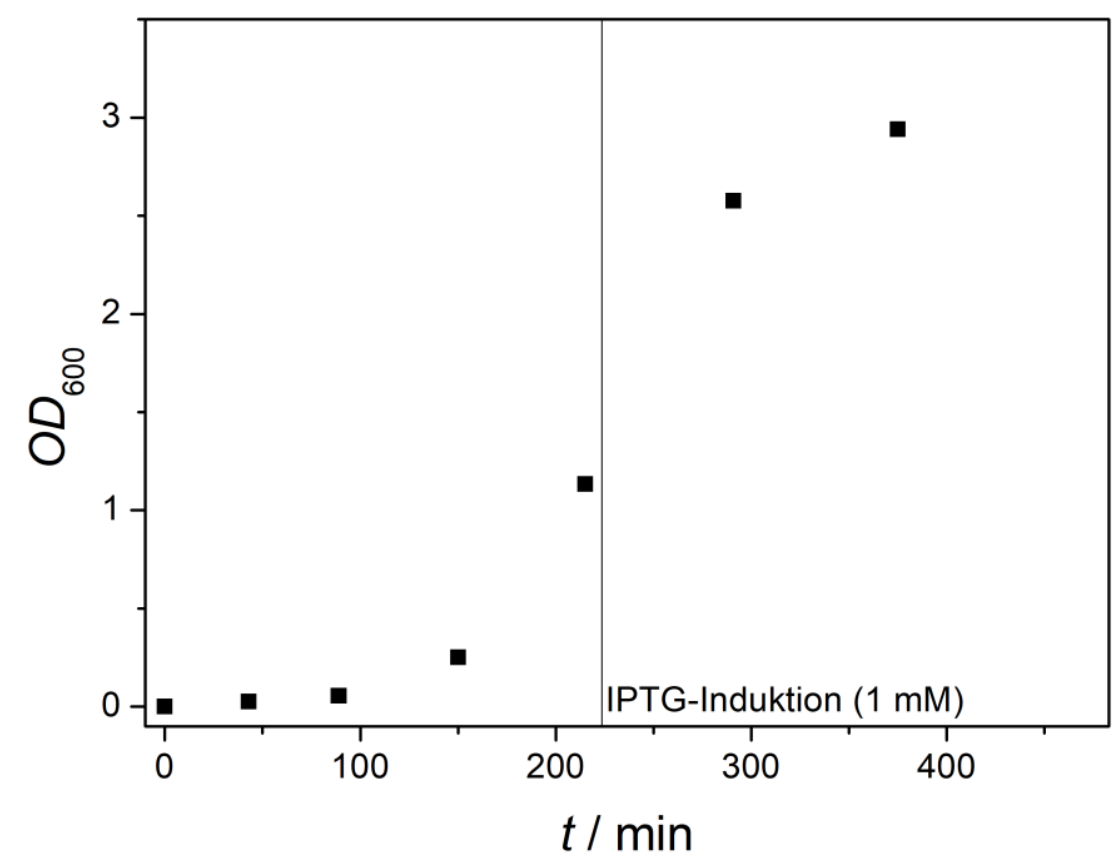

Abbildung 3.2: Exemplarische Darstellung des bakteriellen Wachstums von E. coli als Auftragung der optischen Dichte bei $600 \mathrm{~nm} O D_{600}$ gegen die Zeit $t$. Gekennzeichnet ist der Zeitpunkt der IPTGInduktion mit einer resultierenden Konzentration von $1 \mathrm{mM}$. Das Wachstum zeigt einen sigmoidalen Verlauf.

Nach 400 bis 500 min erreichte das Bakterienwachstum eine Sättigung. Die Hauptkulturen wurden anschließend für 20 min auf Eis gestellt und schließlich zentrifugiert (3082 g, $4^{\circ} \mathrm{C}, 20 \mathrm{~min}$ ), wobei je $2 \times 250 \mathrm{~mL}$ für die Ernte eines Zellpellets zusammengenommen wurden. Pro $500 \mathrm{~mL}$ Hauptkultur wurde so ein Zellpellet erhalten. Die Überstände wurden verworfen und die Pellets in je $10 \mathrm{~mL}$ Lysepuffer (Tab. 3.3) resuspendiert. Die Lagerung erfolgte bei $-80^{\circ} \mathrm{C}$. 


\section{Puffer und Lösungen}

Tabelle 3.3: Zusammensetzung des Lysepuffers.

\begin{tabular}{|c|c|}
\hline Komponente & Menge \\
\hline HEPES & $40 \mathrm{mM}$ \\
\hline $\mathrm{NaCl}$ & $300 \mathrm{mM}$ \\
\hline$\beta$-Mercaptoethanol & $5 \mathrm{mM}$ \\
\hline Lysozym & $1 \mathrm{mg} \cdot \mathrm{mL}^{-1}$ \\
\hline \multirow[t]{2}{*}{ Protease-Inhibitor } & Bei $<20 \mathrm{~mL}: 1$ Minitablette \\
\hline & Bei >20 mL: 1 Tablette \\
\hline
\end{tabular}

\subsubsection{Lyse der E. coli-Zellen und Extraktion des rSin1-SP}

Ein Zellpellet wurde aufgetaut, indem es mindestestens $30 \mathrm{~min}$ auf Eis gestellt und dann mit weiteren $10 \mathrm{~mL}$ Lysepuffer resuspendiert wurde. Die Suspension wurde mit $20 \mu \mathrm{L}$ DNase I-Lsg. (Tab. 3.4) versetzt, um DNA in ihre Nucleotide zu spalten. Es wurde 90 min bei RT gerührt, bis die Suspension homogen war. Am Microfluidizer erfolgte der endgültige Zellaufschluss durch Einwirken sehr großer Scherkräfte bei einem Druck von 1000 bar. Die lysierten Zellen wurden anschließend zentrifugiert (20379 g, $4{ }^{\circ} \mathrm{C}, 15 \mathrm{~min}$ ) und der Überstand abdekantiert. Das Pellet wurde in $20 \mathrm{~mL}$ Extraktionspuffer (Tab. 3.5) resuspendiert und $2 \mathrm{~h}$ bei RT gerührt. Nach weiterer Zentrifugation wurde mit dem Zielprotein enthaltenen Überstand weitergearbeitet. 
Puffer und Lösungen

Tabelle 3.4: Zusammensetzung der DNase I-Lsg.

\begin{tabular}{cc}
\hline Komponente & Menge \\
\hline DNase I & $5 \mathrm{mg} \cdot \mathrm{mL}^{-1}$ \\
TRIS & $20 \mathrm{mM}$ \\
$\mathrm{MgCl}_{2}$ & $1 \mathrm{mM}$ \\
\hline \multicolumn{2}{c}{$\mathrm{pH}=7.5(\mathrm{HCl})$} \\
\hline \\
\multicolumn{2}{c}{ Lösung in $50 \%$ Glycerin angesetzt. } \\
\hline
\end{tabular}

Tabelle 3.5: Zusammensetzung des Extraktionspuffers.

\begin{tabular}{cc}
\hline Komponente & Menge \\
\hline Harnstoff & $8 \mathrm{M}$ \\
$\mathrm{NaH}_{2} \mathrm{PO}_{4}$ & $100 \mathrm{mM}$ \\
TRIS & $10 \mathrm{mM}$ \\
$\beta$-Mercaptoethanol & $5 \mathrm{mM}$ \\
Protease-Inhibitor & 1 Minitablette \\
\hline
\end{tabular}

$\mathrm{pH}=8.0(\mathrm{NaOH})$

\subsubsection{Aufreinigung durch Nickel-Affinitätschromatografie}

- Teile dieses Kapitels wurden aus der Masterarbeit des Autors übernommen. ${ }^{[16]}$

Die Immobilisierte-Metallionen-Affinitätschromatografie (engl. Immobilized Metal Ion Affinity Chromatography, IMAC) ist ein Chromatografieverfahren zur Aufreinigung von Proteinen, bei dem an die stationäre Phase gebundene Metallkationen in spezifische Wechselwirkungen mit dem zu isolierenden Protein treten. So bindet beispielsweise der Hexahistidin (His6)-Tag eines entsprechend gelabelten Proteins spezifisch an das $\mathrm{Ni}^{2+}$-Ion, das über eine Nitrilotriessigsäure (NTA)-Gruppe koordinativ an das Säulenmaterial gebunden ist (Abb. 3.3). Im Waschprozess werden idealerweise alle unspezifisch gebundenen Proteine eluiert, während das Zielprotein an der stationären Phase der Säule gebunden bleibt. Durch Erhöhung der Konzentration eines mit dem His-Tag um das $\mathrm{Ni}^{2+-}$ Ion konkurrierenden Moleküls wie Imidazol kann das Protein schließlich eluiert und fraktioniert aufgefangen werden. Eine Elution ist aber auch durch Änderung des pH-Werts zu einem sauren Bereich möglich[79], sodass die 
Histidine des His-Tags protoniert werden und ihre Wechselwirkung zum $\mathrm{Ni}^{2+-}$ Ion gestört wird.
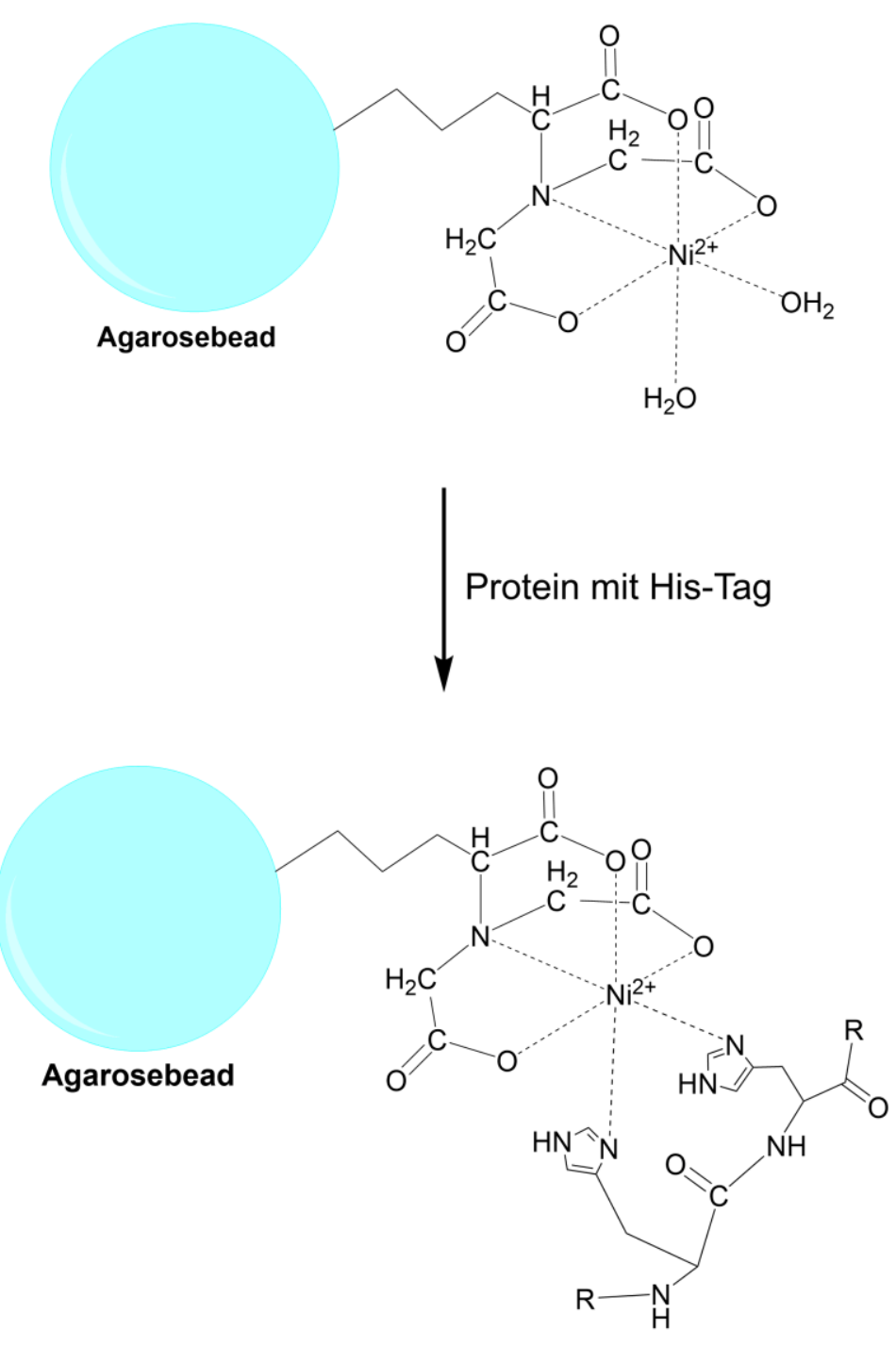

Abbildung 3.3: Wechselwirkung zwischen einer an einem Agarosebead gebundenen Ni-NTA-Gruppe und einem Polyhistidin-Tag (His-Tag). ${ }^{[16]}$

Die Aufreinigung des His-Tag tragenden $\mathrm{rSin}^{-\mathrm{SP}}$ erfolgte mittels NickelAffinitätschromatografie nach einem Protokoll der Firma iba ${ }^{[80]}$. Dazu wurden $6 \mathrm{~mL}$

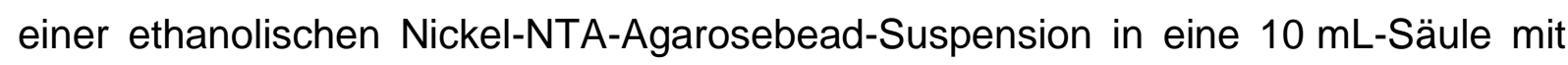
Fritte überführt. Das Trockenvolumen der Beads entsprach $3 \mathrm{~mL}$. Die Säule wurde mit 5 Säulenvolumen (SV) EtOH p. A. und 10 SV Reinstwasser gespült und mit 3 SV Extraktionspuffer äquilibriert und aufgeschlämmt. Die aufgeschlämmten Beads

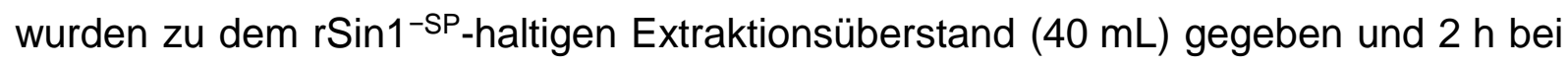
RT schwenkend inkubiert. 
Die mit Protein angebundenen Beads wurden als Suspension zurück in die $10 \mathrm{~mL}$ Säule überführt und der Durchlauf aufgefangen. Das Protein sollte mittels $\mathrm{pH}$-Gradient eluiert werden. Dazu wurde die Säule erst mit $5 \mathrm{~mL}$ Extraktionspuffer, dann mit $5 \mathrm{x}$ $10 \mathrm{~mL}$ Waschpuffer ( $\mathrm{pH}$ 6.3) (Tab. 3.6) gewaschen und das $\mathrm{rSin} 1^{-\mathrm{SP}}$ anschließend mit $3 \times 10$ mL Elutionspuffer 1 (pH 5.9) (Tab. 3.6) bzw. 2 (pH 4.5) (Tab. 3.6) eluiert. Die Beads wurden zum Schluss in Waschpuffer ohne Proteaseinhibitor und Mercaptoethanol (5 mL) aufgeschlämmt und zu Analysezwecken $20 \mu \mathrm{L}$ entnommen.

Puffer und Lösungen

Tabelle 3.6: Zusammensetzung des Waschpuffers, Elutionspuffers 1 und Elutionspuffers 2.

\begin{tabular}{|c|c|}
\hline Komponente & Menge \\
\hline Harnstoff & $8 \mathrm{M}$ \\
\hline $\mathrm{NaH}_{2} \mathrm{PO}_{4}$ & $100 \mathrm{mM}$ \\
\hline TRIS & $10 \mathrm{~mm}$ \\
\hline$\beta$-Mercaptoethanol & $5 \mathrm{~mm}$ \\
\hline \multicolumn{2}{|c|}{$\mathrm{pH}=6.3$ (voreingestellt) $\rightarrow$ Waschpuffer } \\
\hline \multicolumn{2}{|c|}{$\mathrm{pH}=5.9(\mathrm{HCl}) \rightarrow$ Elutionspuffer 1} \\
\hline \multicolumn{2}{|c|}{$\mathrm{pH}=4.5(\mathrm{HCl}) \rightarrow$ Elutionspuffer 2} \\
\hline
\end{tabular}

\subsubsection{Umpuffern durch Dialyse}

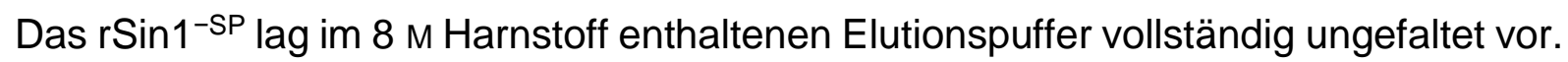
Das Volumen der Proteinlösung musste vor einer Dialyse reduziert werden. Dazu wurde $r \operatorname{Sin} 1^{-\mathrm{SP}}$ mit eiskaltem Ethanol bei $-20^{\circ} \mathrm{C}$ über Nacht gefällt und dann durch Zentrifugation (3901 g, $4{ }^{\circ} \mathrm{C}, 1 \mathrm{~h}$ ) pelletiert. Die Pellets wurden mit eiskaltem Ethanol gewaschen, zentrifugiert und in insgesamt $8 \mathrm{~mL}$ Waschpuffer $(+10 \mathrm{mM}$ Mercaptoethanol) über Nacht bei RT resuspendiert. Um die Rückfaltung des Proteins zu erreichen, wurde die Proteinlösung gegen einen harnstofffreien Puffer dialysiert, wobei jegliche denaturierenden Reagenzien entfernt werden sollten. Zudem sollte eine langsame Ausbildung von internen Disulfidbrücken zwischen den Cysteinresten des Proteins herbeigeführt werden. Deshalb wurden dem Dialysepuffer L-Glutathion und 
Glutathionsdisulfid als Redoxpaar zugefügt, um ein geeignetes Redoxpotential für die Umknüpfung der Disulfidbrücken zu erhalten. Das Dialyseprotokoll wurde in ähnlicher Form von der Kröger-Gruppe zur Rückfaltung des rSin1 ${ }^{\text {lum }}$ verwendet. ${ }^{[34]}$

Für die Dialyse wurden Dialyseschläuche mit einer Molekularausschlussgröße von $14 \mathrm{kDa}$ verwendet. Diese wurden zunächst zurechtgeschnitten und $15 \mathrm{~min}$ in Reinstwasser aufgeweicht. Danach wurden die Membranschläuche mit $10 \mathrm{~mm}$ $\mathrm{NaHCO}_{3}$-Lsg. bei $80^{\circ} \mathrm{C}$ für 30 min vorsichtig gerührt. Nach Abgießen der Lösung wurden die Schläuche mit $10 \mathrm{~mm}$ EDTA-Lsg. bei $80^{\circ} \mathrm{C}$ für 30 min vorsichtig gerührt. Nach Abkühlen und Spülen mit Reinstwasser wurden sie in $10 \mathrm{~mm} \mathrm{NaN} \mathrm{N}_{3}$-Lsg. im Kühlschrank gelagert.

Ein in $\mathrm{NaN}_{3}$-Lsg. gelagerter Dialyseschlauch wurde vor Verwendung $20 \mathrm{~min}$ in Reinstwasser gewaschen, mit Dialyseklemmen verschlossen und mit Dialysepuffer gefüllt, um die Dichtigkeit zu testen. Schließlich wurde Proteinlösung in den Schlauch pipettiert, der Schlauch verschlossen und ein Becherglas mit dem 50 - 100-fachen Volumen an Dialysepuffer gefüllt. Der Schlauch wurde in den Puffer überführt und die Dialyse erfolgte unter mäßigem Rühren. Der Ablauf der Dialyse ist in Tab. 3.7 dargestellt. Nach der Dialyse wurde die Proteinlösung aliquotiert und mit Hilfe von Flüssigstickstoff tiefgefroren und bei $-80^{\circ} \mathrm{C}$ gelagert.

Für manche Experimente wurde das Protein anschließend erneut umgepuffert. Dazu wurde ein Eppendorf-Gefäß $(1.5 \mathrm{~mL})$ mit Proteinlösung befültt, und mit einem Dialyseschlauch bespannten löchrigen Deckel geschlossen. Es wurde gegen ein 150x größeres Volumen $20 \mathrm{~h}$ bei $4^{\circ} \mathrm{C}$ dialysiert, wobei nach 3-4 h ein Pufferwechsel durchgeführt wurde. 
Tabelle 3.7: Übersicht über die Dialysepuffer und -bedingungen zur Proteinrückfaltung und Umknüpfung von Disulfidbrücken.

\begin{tabular}{|c|c|c|}
\hline Dialysedauer & Dialysepuffer & $\begin{array}{l}\text { Verdünnungsfaktor } \\
\text { (Proteinlsg.:Dialysepuffer) }\end{array}$ \\
\hline $4-24 \mathrm{~h}(2 \mathrm{x})$ & $\begin{array}{l}\text { Puffer A: } \\
20 \mathrm{~mm} \mathrm{Tris/HCl} \\
300 \mathrm{mM} \mathrm{NaCl} \\
5 \%(v / v) \text { Glycerin } \\
2.5 \mathrm{~mm} \text { L-Glutathion } \\
0.25 \mathrm{~mm} \text { Glutathionsdisulfid } \\
\mathrm{pH} 8.5\end{array}$ & $1: 50-1: 100$ \\
\hline $4-24 h(2 x)$ & $\begin{array}{l}\text { Puffer B: } \\
20 \mathrm{~mm} \text { Tris/HCl } \\
300 \mathrm{mM} \mathrm{NaCl} \\
5 \%(v / v) \text { Glycerin } \\
\mathrm{pH} 8.5\end{array}$ & $1: 50-1: 100$ \\
\hline $4-24 \mathrm{~h}(2 \mathrm{x})$ & $\begin{array}{l}\text { Puffer C: } \\
10 \text { mM MOPS } \\
\text { pH } 7.7\end{array}$ & $1: 50-1: 100$ \\
\hline
\end{tabular}

\subsubsection{Konzentrationsbestimmung von Proteinlösungen}

- Teile dieses Kapitels wurden aus der Masterarbeit des Autors übernommen. ${ }^{[16]}$

Die UV/vis-Spektroskopie ist eine bewährte Methode, um die Konzentration von Proteinen und anderen Biomolekülen in Lösung zu bestimmen und wurde in dieser Arbeit für die Proteinkonzentrationsbestimmung verwendet. Der Aufbau eines Einstrahl-UV/vis-Spektrometers ist in Abb. 3.4 gezeigt. ${ }^{[81]}$

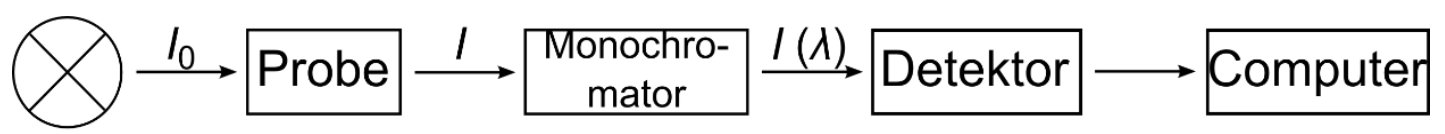

Abbildung 3.4: Schematischer Aufbau eines Einstrahl-UV/vis-Spektrometers. ${ }^{[16]}$

Das volle Frequenzspektrum einer Weißlichtlampe trifft mit der Ausgangsintensität $I_{0}$ auf eine Probe, die bestimmte Wellenlängen absorbiert und das Licht mit einer 
geringeren Intensität / austreten lässt. Das Licht wird in einem Monochromator in seine spektralen Bestandteile zerlegt, sodass jede Wellenlänge einzeln von einem CCDArray-Detektor erfasst werden kann.

Die Lichtintensität / weist einen wellenlängenabhängigen exponentiellen Abfall auf, wenn das Licht durch eine homogen isotrope Lösung der Schichtdicke $d$ tritt, wobei der Grad der Abnahme von dem materialspezifischen Absorptionskoeffizienten $\alpha$ abhängt (Gl. 3.3):

$$
I=I_{0} \cdot \mathrm{e}^{-\alpha \cdot d} .
$$

$\alpha$ hängt von der Konzentration $c$ des Chromophors in der Lösung ab und wird nach Gl. 3.4 beschrieben:

$$
\alpha=\ln 10 \cdot \varepsilon \cdot c .
$$

Bei $\varepsilon$ handelt es sich um den wellenlängenabhängigen molaren dekadischen Extinktionskoeffizienten. Wird Gl. 3.4 in Gl. 3.2 eingesetzt, erhält man Gl. 3.5.

$$
I=I_{0} \cdot 10^{-\varepsilon \cdot c \cdot d}
$$

Dieses Lambert-Beersche Gesetz kann logarithmisch dargestellt werden (GI. 3.6) und liefert eine Formel für die Extinktion $E$ bei einer bestimmten Wellenlänge.

$$
E=\log _{10} \frac{I_{0}}{I}=\varepsilon \cdot c \cdot d
$$

Bei $280 \mathrm{~nm}$ absorbieren die aromatischen Aminosäuren Tryptophan, Tyrosin und Phenylalanin, aber auch Disulfidbrücken der oxidierten Cysteine das Licht und die bei dieser Wellenlänge gemessene Extinktion (Absorbanz) E280 hängt nach Gleichung 3.6 von der Konzentration des Proteins, dem Extinktionskoeffizienten $\varepsilon_{280}$ des Proteins und der Schichtdicke der Lösung $d$ ab. Umgestellt ergibt sich für die Konzentration Gl. 3.7.

$$
c=\frac{E_{280}}{\varepsilon_{280} \cdot d}
$$

Absorbtionsspektroskopisch vermessen wurden die Proteinlösungen an einem Nanodrop 2000c-UV/vis-Spektrometer. Die ausgegebenen Extinktionen waren auf $d=1 \mathrm{~cm}$ genormt. Der Extinktionskoeffizient wurde von dem Online-Programm ExPASy-ProtParam Tool[82,83] für die beiden Fälle, dass alle Cysteine reduziert bzw. oxidiert (in Form von Disulfidbrücken) waren, anhand der Primärstruktur berechnet und ist in Tab. 3.8 angegeben. $\varepsilon_{280}$ (reduziert) wurde verwendet, wenn das Protein in 
Gegenwart von $\beta$-Mercaptoethanol vorlag, $\varepsilon_{280}$ (oxidiert) nur nach einer Dialyse in einen Puffer ohne reduzierendes Reagenz. Da in der Regel vor allem die Absorption die Abschwächung des durchdringenden Lichts verursacht und Streuungen, Reflexionen etc. vernachlässigbar klein sind, wird hier in Messungen von der Absorbanz $A$ statt der Extinktion $E$ gesprochen.

Tabelle 3.8: Extinktionskoeffizienten $\varepsilon_{280}$ bei $\lambda=280 \mathrm{~nm}$ von rSin $1^{-\mathrm{SP}}$ im vollständig reduzierten oder oxidierten Zustand.

\begin{tabular}{|l|l|}
\hline Protein & Extinktionskoeffizient $\boldsymbol{\varepsilon}_{280}\left[\mathbf{M}^{-1} \cdot \mathbf{c m}^{-1}\right]$ \\
\hline rSin1 ${ }^{-S P}$ (reduziert) & 42750 \\
\hline rSin1 ${ }^{\text {-SP }}$ (oxidiert) & 43875 \\
\hline
\end{tabular}

\subsection{Charakterisierung von rSin $1^{-\mathrm{SP}}$}

\subsubsection{Bestimmung des freien Thiolanteils in rSin $1^{-S P}$}

Die Dialyse in Gegenwart des Redoxpaars Glutathion/Glutathionsdisulfid sollte rSin $1^{-S P}$ in einen vollständig oxidierten Zustand überführen, bei dem alle 18 Cysteine in Disulfidbindungen involviert sind. Der Anteil an freien Thiolen der Cysteinreste wurde in einem Sulfhydrylquantifizierungsassay mittels Ellmans Reagenz bestimmt. Bei diesem Molekül handelt es sich um 5,5'-Dithiobis-2-nitrobenzoesäure (DTNB). Es reagiert mit freien Thiolen aus zum Beispiel Proteinen zum Monomer TNB $^{2-}$ und einem gemischten Disulfid im basischen oder neutralen Milieu (Abb. 3.5). TNB ${ }^{2-}$ in wässriger Lösung ist gelb und absorbiert bei $412 \mathrm{~nm}$ mit einem Absorptionskoeffizienten von $14150 \mathrm{M}^{-1} \cdot \mathrm{cm}^{-1} \cdot{ }^{[84]}$

$\mathrm{R}^{-\mathrm{SH}+}$

Abbildung 3.5: Reaktion von DTNB mit einer freien Thiolgruppe zu einem gemischten Disulfid und TNB $^{2-}$. 
L-Glutathion (GSH) wurde für die Kalibrierung genutzt. Dazu wurde eine $1 \mathrm{~mm}$ Stammlösung in Dialysepuffer C angesetzt und DTNB wurde in Ethanol gelöst (11.1 mM). Für die Kalibrationsmessung wurden Küvetten zu je $1 \mathrm{~mL}$ befüllt und $5 \mathrm{~min}$ inkubiert. Dabei variierte die GSH-Konzentration von 0 bis $100 \mu \mathrm{m}$. Die DTNBKonzentration betrug stets $111 \mu \mathrm{M}$. Die Messungen mit $r \operatorname{Sin} 1^{-\mathrm{SP}}$ wurden bei drei unterschiedlichen Proteinkonzentrationen (0.7, 1.4 und $2.8 \mu \mathrm{M}$ ) durchgeführt. Dies entspräche bei vollständig reduziert vorliegenden Cysteinen 12.5, 25 und $50 \mu \mathrm{m}$ freier Thiole.

\subsubsection{SDS-Polyacrylamidgelelektrophorese}

- Teile dieses Kapitels wurden aus der Masterarbeit des Autors übernommen.[16]_

Die elektrophoretische Auftrennung von Proteinen und ihre Detektion erlauben sowohl die Bestimmung des Reinheitsgrads einer Proteinprobe als auch die Abschätzung der Massen eines Proteins. Die SDS-Polyacrylamidgelelektrophorese (SDS-PAGE) nutzt Natriumdodecylsulfat (engl. Sodium dodecyl sulfate, SDS) als anionisches Detergens, das an Protein bindet und dessen Eigenladung mit seiner eigenen negativen Ladung umhüllt und überdeckt. ${ }^{[57]}$ Dabei binden i. d. R. ungefähr $1.4 \mathrm{~g}$ SDS an $1 \mathrm{~g}$ Protein. ${ }^{[79]}$ Die negative Gesamtladung ist somit proportional zur Masse des Proteins. Das starke Detergens sorgt zusammen mit reduzierenden Reagenzien wie Dithiothreitol (DTT) im Probenpuffer für eine Denaturierung des Proteins, insbesondere wenn zusätzlich eine thermische Denaturierung durchgeführt wird. Fast sämtliche Sekundär-, Tertiär- und Quartärstrukturen werden somit zerstört und das SDS kann im Idealfall ungehindert an jeden Bereich des Proteins binden.

Bei der SDS-PAGE handelt es sich um eine Gelelektrophorese, die mit Polyacrylamidgelen arbeitet. Diese entstehen durch Vernetzung von Acrylamid/Bisacrylamid-Mischungen unter Einfluss des Radikalstarters Ammoniumpersulfat (APS) und des Katalysators $N, N, N^{*}, N^{*}$-Tetramethylethylendiamin (TEMED oder TMEDA). Der Vernetzungsgrad wird durch den Bisacrylamidanteil bestimmt und resultiert in verschiedenen Maschengrößen des Gels, wenn das genannte Verhältnis verändert wird. In einem Trenngel (typischerweise mit 10 oder $12.5 \%$ Bisacrylamidanteil) wandern die Proteine ihrer Größe entsprechend unterschiedlich schnell durch das Gel. Große Proteine sind langsamer, kleine sind schneller. Die Größe wird hierbei jedoch nicht nur durch die Anzahl an Aminosäuren 
oder der Masse des Proteins bestimmt, sondern auch durch die Form, die es annimmt. Je stärker das Protein von einer im denaturierten Zustand ungefalteten, linearen Form abweicht, desto mehr wird auch das Laufverhalten im Vergleich zu ähnlich großen Proteinen abweichen. Eine gut aufgelöste Auftrennung wird dann erzielt, wenn der Bisacrylamidanteil und damit die Maschengröße an die Größe des Proteins angepasst ist (Tab. 3.9).

Tabelle 3.9: Auftrennungsbereiche von SDS-PAGE-Trenngelen für verschieden große Proteine, je nach Vernetzungsgrad der Gele. ${ }^{[79]}$

\begin{tabular}{|l|l|}
\hline Molekulargewicht [kDa] des Proteins & Bisacrylamidanteil im Trenngel [\%] \\
\hline $10-60$ & 15 \\
\hline $30-120$ & 10 \\
\hline $50-200$ & 8 \\
\hline $1.5-10$ & 18 (7-8 M Harnstoff) \\
\hline
\end{tabular}

Wie der Name Gelelektrophorese schon impliziert, wird bei dieser Analysemethode eine Spannung angelegt, die die geladenen SDS-Proteincluster durch das Gel hin zur Anode zieht. Um schärfere Banden zu erhalten, wird die diskontinuierliche SDS-PAGE genutzt. Das großmaschige Sammelgel (4-5\% Bisacrylamid) besitzt einen pH-Wert, der um zwei Einheiten kleiner ist als im Trenngel. Bei diesem pH-Wert liegt das im Laufpuffer befindliche Glycin zwitterionisch vor und bewegt sich sehr viel langsamer als die Chloridionen aus Probenpuffer und Gel. Chloridionen werden hier als Leitionen bezeichnet, Glycinionen als Folgeionen. ${ }^{[85]}$ Durch die größer werdende räumliche Trennung der beiden lonensorten entsteht ein Spannungsgradient, der zwischen Chlorid und Glycin laufende Proteine beschleunigt, wenn sie weiter hinten laufen, und abbremst, wenn sie weiter vorne laufen. So kommen alle Proteine gleichzeitig an der Grenze zwischen Sammel- und Trenngel an, sodass die Bandenschärfe erhöht wird. Im Trenngel überholen die Glycinionen die Proteine wieder, da sie nicht mehr zwitterionisch vorliegen. Zwei unterschiedliche diskontinuierliche SDS-PAGESysteme, die oft verwendet werden, sind das Lämmli- und das Schäggersystem. Das Lämmlisystem ${ }^{[86]}$ nutzt einen einheitlichen Laufpuffer für beide Elektroden, der neben SDS TRIS und Glycin enthält. Im Schäggersystem ${ }^{[87]}$ enthält der Anodenpuffer nur TRIS und der Kathodenpuffer SDS, TRIS und Tricin. Markerproben werden genutzt, um eine Größenabschätzung parallellaufender Banden zu ermöglichen. Wird der 
Logarithmus des bekannten Molekulargewichts der Markerproteine gegen ihre Retentionsfaktoren als Quotienten aus zurückgelegter Wegstrecke des betrachteten Markerproteins und der Wegstrecke der Lauffront aufgetragen, ergibt sich eine sigmoidale Kurve, die im mittleren Bereich ein nahezu lineares Verhalten zeigt (Abb. 3.6). Proteine mit zu hoher Masse sind zu groß, um die Maschen des Gels zu durchdringen und werden deshalb aufgehalten. Zu leichte Proteine werden in ihrer Motilität nicht mehr vom Gel eingeschränkt und laufen zusammen mit anderen motilen Molekülen. Der lineare Bereich beschreibt den Massenbereich, für den eine gute Auflösung von Proteinen durch das Gel vorliegt. Das Schäggersystem liefert eine gute Trennung bei Proteinmassen von 1-100 kDa, das Lämmlisystem dagegen bei 5$250 \mathrm{kDa}$.

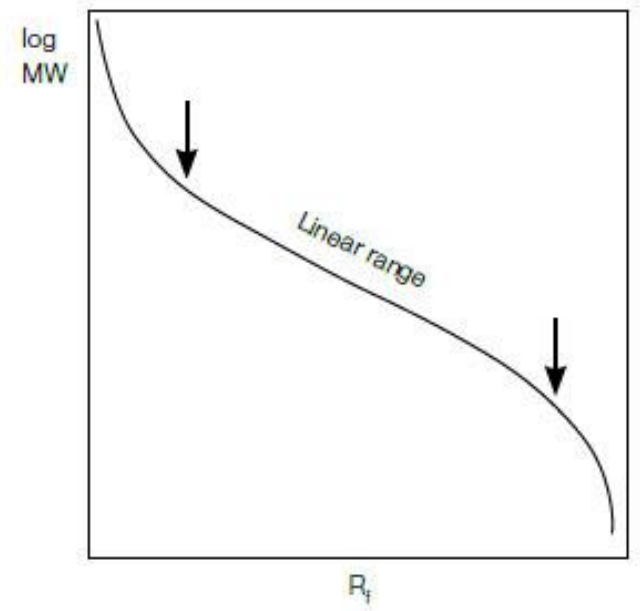

Abbildung 3.6: Auftragung des Logarithmus des Molekulargewichts MW von Proteinen gegen ihre Retentionsfaktoren $R_{f}$. Es ergibt sich ein sigmoidaler Verlauf mit linearem Bereich im mittleren Abschnitt. ${ }^{[88]}$

Die Proteinbanden sind nach der Gelelektrophorese zunächst nicht sichtbar. Ihre Anfärbung mit Coomassie-Färbelösung oder der Silberfärbung ermöglicht eine Visualisierung der Banden, wenn der Hintergrund wieder entfärbt wird. Die Färbung der Banden ist umso intensiver, je mehr Protein vorliegt. 


\section{Durchführung}

Polyacrylamidgele wurden hergestellt, indem ihre Bestandteile nach Tab. 3.10 zusammengegeben wurden und zuerst die Trenngellösung in den Zwischenraum (z. B. $0.8 \mathrm{~mm}$ dick) zweier Glasplatten gegossen wurde. Die Lösung wurde mit Isopropanol überschichtet und 45 min ausgehärtet. Isopropanol wurde entfernt und die Sammelgellösung über das polymerisierte Trenngel gegossen. Durch einen Teflonkamm wurden Geltaschen für die Probenauftragung ausgebildet. Das Sammelgel wurde mindestens 30 min ausgehärtet. Entweder wurden die Gele direkt für die SDS-PAGE verwendet oder mit feuchten Tücher umhüllt und bei $4{ }^{\circ} \mathrm{C}$ für bis zu eine Woche gelagert. Gele wurden stets nach dem Schäggersystem gegossen und verwendet.

Proben der SDS-PAGE wurden vor der Elektrophorese mit 2x-Probenpuffer oder 6xProbenpuffer (Tab. 3.11) versetzt und thermisch denaturiert (300 rpm, $95^{\circ} \mathrm{C}, 10 \mathrm{~min}$ ). Die Elektrophorese erfolgte bei einer Spannung von $60 \mathrm{~V}$ (konstant) für die ersten 20 min und $160 \mathrm{~V}$ (konstant) für weitere ca. $70 \mathrm{~min}$. Das Gel wurde anschließend in Reinstwasser gewaschen, indem es $45 \mathrm{~s}$ in einer Mikrowelle erhitzt und $1 \mathrm{~min}$ geschwenkt wurde. Dies wurde dreimal durchgeführt, wobei das Wasser jeweils ausgetauscht wurde. Danach wurde das Gel mit wässriger Coomassie Brilliant BlueFärbelösung (Tab. 3.11) versetzt, $30 \mathrm{~s}$ in der Mikrowelle erhitzt und 5 min geschwenkt. Durch Waschen mit Reinstwasser und Entfärbelösung (Tab. 3.11) (1-2 h) wurde der Hintergrund des Gels weitestgehend entfärbt, während die Proteinbanden die blaue Farbe behielten. Die Dokumentation erfolgte fotografisch an einem Gelimager. Die Massen der Proteinbanden konnten anhand des parallel gelaufenen Proteinmarkers abgeschätzt werden. 


\section{Puffer und Lösungen}

Tabelle 3.10: Übersicht über die Zusammensetzung der Schäggergele für die SDS-PAGE.

\begin{tabular}{l|l} 
Gelsystem & Zusammensetzung (für 1 Gel) \\
\hline Schägger & Trenngel (10\%): \\
& $\begin{array}{l}1.66 \mathrm{~mL} \text { Acrylamidmischung, } 1.68 \mathrm{~mL} \text { Gelpuffer (3 M TRIS, 0.3 \% SDS, pH 8.45), } \\
1.06 \mathrm{~mL} 50 \% \text { Glycerin, } 570 \mu \mathrm{L} \mathrm{H} \mathrm{O}, 25 \mu \mathrm{L} 10 \% \text { APS, } 3 \mu \mathrm{L} \text { TEMED }\end{array}$ \\
& $\begin{array}{l}\text { Sammelgel (4 \%): } \\
1.23 \mathrm{~mL} \mathrm{H} \mathrm{H}_{2} \mathrm{O}, 500 \mu \mathrm{L} \text { Gelpuffer, } 267 \mu \mathrm{L} \text { Acrylamidmischung, } 13.35 \mu \mathrm{L} 10 \% \text { APS, } \\
2.65 \mu \mathrm{L} \text { TEMED }\end{array}$
\end{tabular}

Tabelle 3.11: Übersicht der für die SDS-PAGE verwendeten Puffer und Lösungen.

\begin{tabular}{ccc}
\hline Puffer/Lösung & Komponente & Menge \\
\hline Schägger-Anodenpuffer (10x) & TRIS & $2 \mathrm{M}$ \\
\cline { 2 - 3 } & \multicolumn{2}{c}{$\mathrm{pH}=8.9$} \\
\hline Schägger-Kathodenpuffer (10x) & TRIS & $1 \mathrm{M}$ \\
& Tricin & $1 \mathrm{M}$ \\
& SDS & $1 \%(w / v)$ \\
\hline Färbelösung & Coomassie R-250 & $0.008 \%(w / v)$ \\
& $\mathrm{HCl}(37 \%)$ & $35 \mathrm{mM}$ \\
\hline Entfärbelösung & Ethanol & $5 \%(v / v)$ \\
& Eisessig & $7.5 \%(v / v)$ \\
\hline 2x-Probenpuffer & TRIS/HCl, pH $=6.8$ & $125 \mathrm{mM}(375 \mathrm{mM})$ \\
& DTT & $100 \mathrm{mM}(300 \mathrm{mM})$ \\
& Glycerin & $20 \%(v / v)(60 \%(v / v))$ \\
& SDS & $2 \%(w / v)(6 \%(w / v))$ \\
& Bromphenol & $0.02 \%(w / v)(0.06 \%(w / v))$
\end{tabular}




\subsubsection{Western Blot}

- Teile dieses Kapitels wurden aus der Masterarbeit des Autors übernommen. $\left.{ }^{[16]}\right]_{-}$

Der Western Blot ist eine immunhistochemische Nachweismethode für Proteine, die auf der Wechselwirkung von im Protein befindlichen Antigenen und extern zugefügten Antikörpern beruht. Diese Antikörper sind entweder fluoreszierend oder chemilumineszierend und erlauben die genaue Identifizierung von Proteinbanden in einer PAGE als Träger des entsprechenden Antigens. ${ }^{[57]}$

Ein Western Blot beginnt mit einer PAGE, die eine Auftrennung eines Proteingemischs nach den Proteinmassen erlaubt (siehe 3.3.2). Anschließend werden die Proteine im Gel jedoch nicht angefärbt, sondern in einem Blotting-Prozess vom Gel auf eine Trägermembran übertragen, z. B. auf eine Nitrocellulosemembran (NCM) oder Polyvinylidenfluorid (PVDF). Die von Protein unbesetzten Stellen der Membran werden mit Rinderalbumin (engl. Bovine Serum Albumin, BSA) oder Magermilch geblockt, um eine spätere unspezifische Bindung der Antikörper an diesen Stellen zu unterbinden. Das Antigen (z. B. His-Tag) tragende Protein wird im nächsten Schritt von einem entsprechenden primären Antikörper gebunden (Abb. 3.7), während Proteine, die das Antigen nicht besitzen, keine spezifische Bindung zum Antikörper aufweisen. Ein nachfolgender Waschschritt entfernt unspezifisch gebundene Antikörper. 


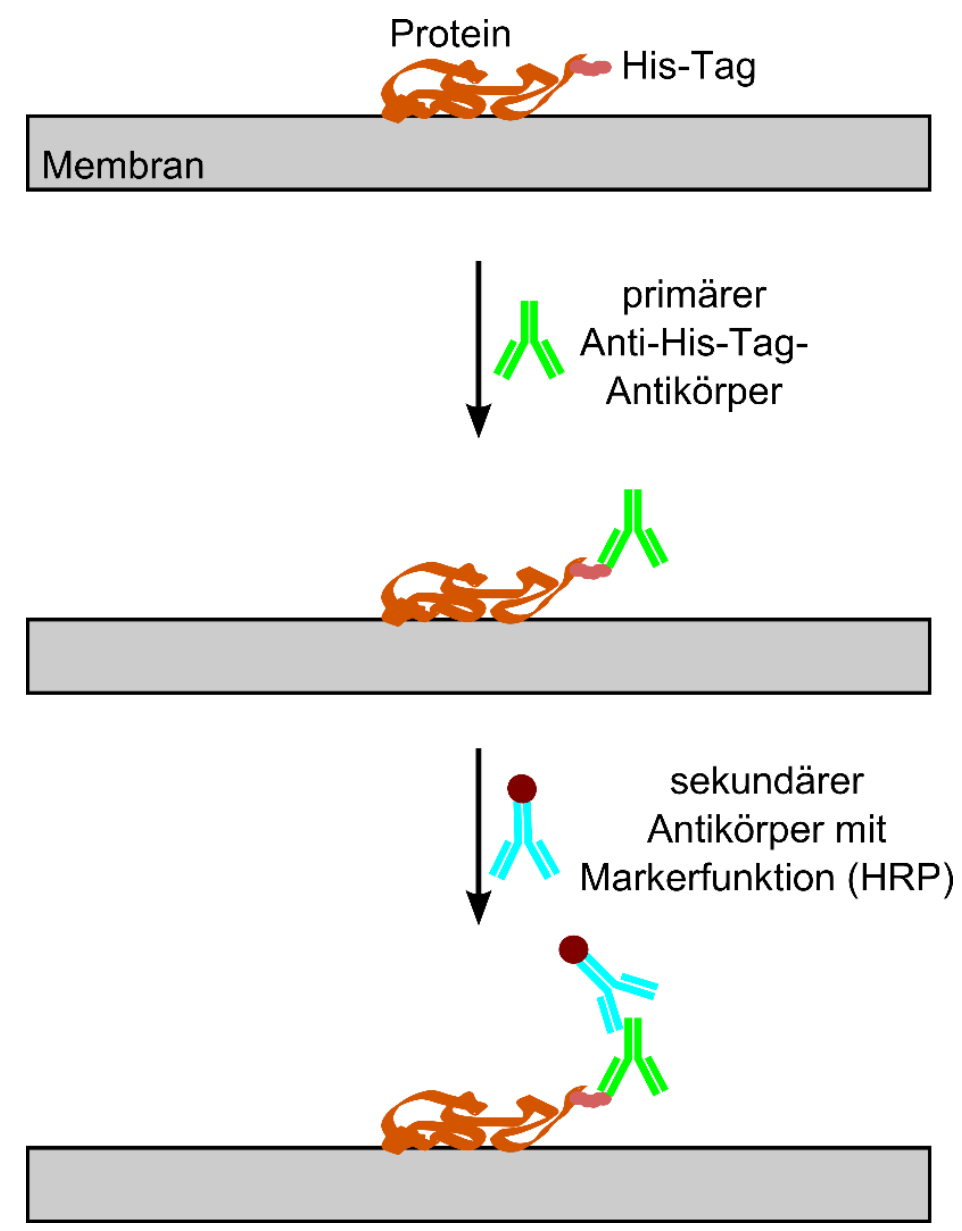

Abbildung 3.7: Ablauf der Antikörperanbindung während des Western Blots. An einer Membran (grau) assoziiert liegt das mit einem in diesem Fall His-Tag (rosa) gelabelte Zielprotein (orange-braun). Ein primärer Antikörper (grün) erkennt den His-Tag als Antigen und bindet spezifisch an ihn. Ein sekundärer Antikörper (cyanblau) bindet spezifisch an den primären und besitzt seinerseits eine Markerfunktionalität (rot-braun, z. B. HRP). ${ }^{[16]}$

Ein sekundärer Antikörper bindet spezifisch an den primären Antikörper und besitzt eine Signalfunktion, so z. B. eine Meerrettichperoxidasefunktionalität (engl. Horseradish peroxidase, HRP). Dieser Marker katalysiert die Oxidation von Luminol mit Wasserstoffperoxid unter Chemilumineszenz und liefert so einen indirekten, optischen Nachweis für das Antigen tragende Protein. Die Reaktion ist in Abb. 3.8 dargestellt und zeigt, wie Luminol im basischen Milieu dehydriert wird, sodass ein formeller, aus dem $\mathrm{H}_{2} \mathrm{O}_{2}$ stammender Disauersstoff an die elektrophilen Kohlenstoffatome der Amidfunktionen binden kann und Stickstoff freisetzt. ${ }^{[89]}$ Das Dianion liegt zunächst im angeregten Triplettzustand $\left(T_{1}\right)$ vor, gelangt über ein Intersystemcrossing (ISC) in den angeregten Singulettzustand $\left(\mathrm{S}_{1}\right)$ und erreicht den 
Grundzustand $\left(\mathrm{S}_{0}\right)$ durch Emission von Licht. ${ }^{[00]}$ Das emittierte Licht kann detektiert und konkreten Proteinbanden zugeordnet werden.

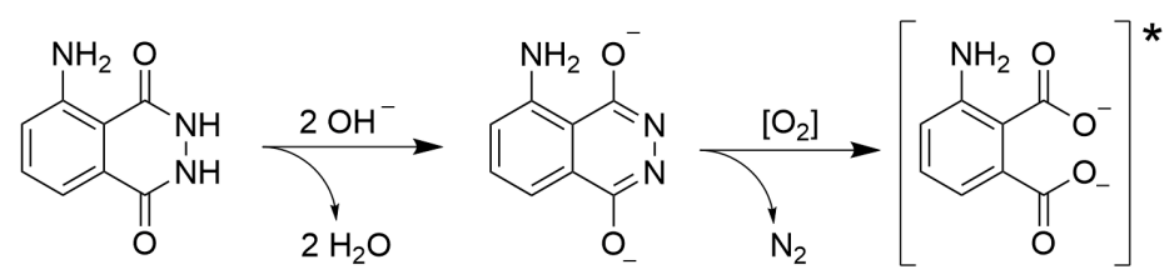

$\left[\mathrm{T}_{1}\right]$ angeregter Zustand

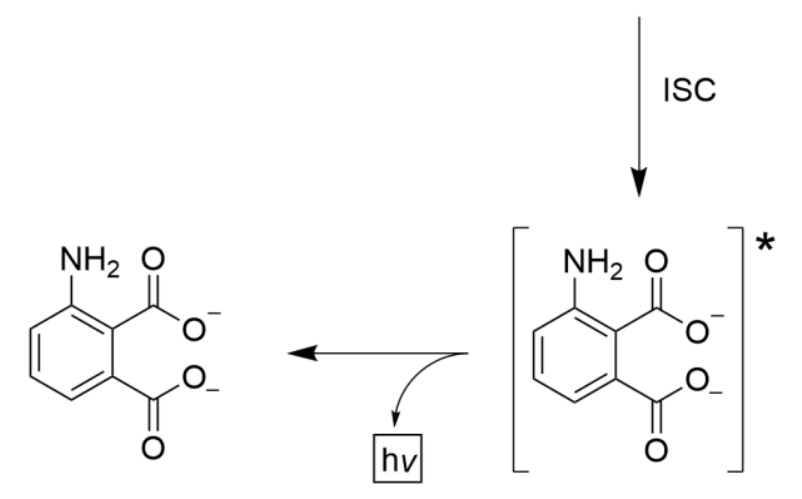

$\left[\mathrm{S}_{0}\right]$ Grundzustand

$\left[\mathrm{S}_{1}\right]$ angeregter Zustand

Abbildung 3.8: Reaktion von Luminol mit dem aus Wasserstoffperoxid generierten Sauerstoff unter Katalyse der Meerrettichperoxidase (HRP). Die Abstraktion zweier Protonen des Luminols führt zu einem Dianion, das mit Sauerstoff unter Stickstofffreisetzung reagiert. Das Produkt liegt erst im angeregten Triplettzustand $T_{1}$, dann nach einem Intersystemcrossing (ISC) im angeregten Singulettzustand $S_{1}$ vor. Durch Emission elektromagnetischer Strahlung landet das Molekül im Singulettgrundzustand $\mathrm{S}_{0}{ }^{[16]}$

\section{Durchführung des Anti-His-Tag-Western Blots}

Die Proteinbanden wurden nach der SDS-PAGE (siehe Kapitel 3.3.2) in einem halbtrockenen Blotting vom Gel auf eine NCM übertragen. Dafür wurden das Gel, die der Gelgröße entsprechende NCM und zwei ebenfalls zugeschnittene Whatmanpaper (WMP) mindestens $30 \mathrm{~min}$ in Blotting-Puffer (Tab. 3.12) eingeweicht und nach dem Schema in Abb. 3.9 aufeinander in einer Transferzelle mit Elektrodenplatten auf beiden Seiten platziert. 


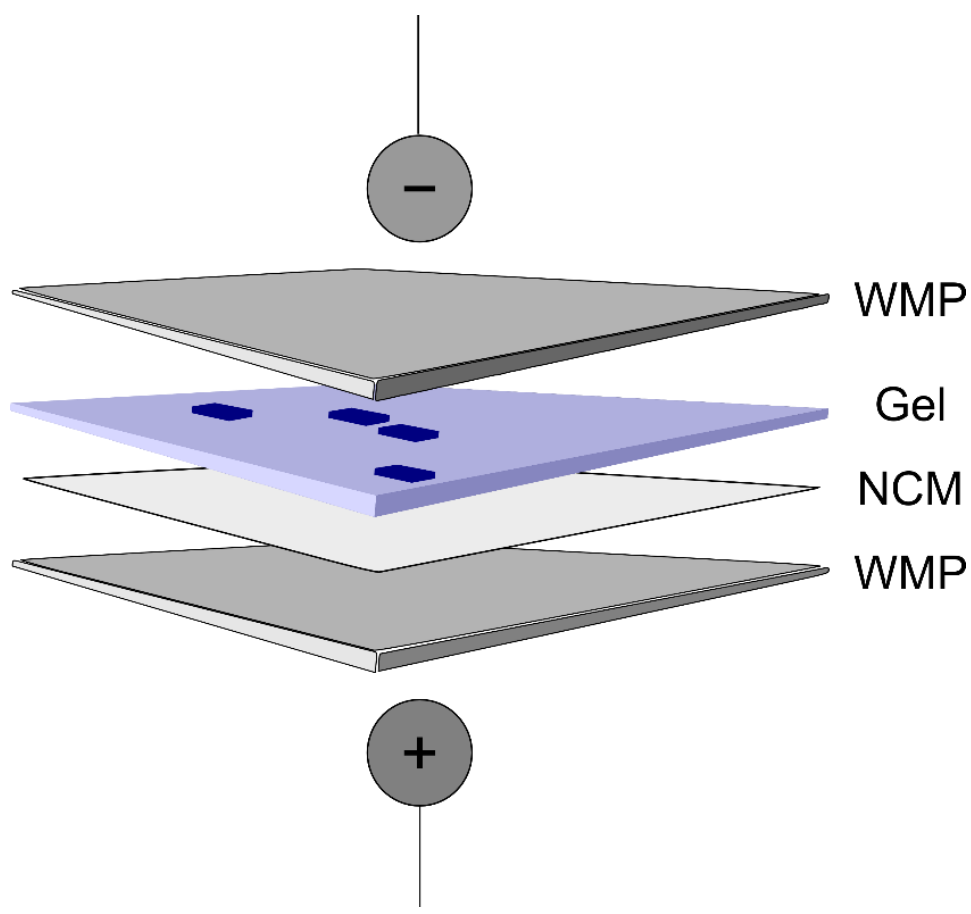

Abbildung 3.9: Schematischer Blottingaufbau. In einer Transferzelle mit Elektrodenplatten (+ und -) werden ein Whatmanpaper (WMP), Nitrocellulosemembran (NCM), ein PAGE-Gel und wieder ein WMP übereinandergeschichtet. Der Transfer der Proteinbanden erfolgt von der Kathode zur Anode, da die Proteine mit SDS-Anionen umhüllt sind. ${ }^{[16]}$

Der Blotting-Prozess erfolgte bei $180 \mathrm{~mA}$ pro Gel für $45 \mathrm{~min}$. Nach dem Blotting konnte das Gel mit Coomassie angefärbt werden (siehe 3.3.2). Das Blocken der NCM wurde mit $25 \mathrm{~mL} 5 \%$ Magermilchlösung in TBT-Puffer (Tab. 3.12) $1 \mathrm{~h}$ bei RT durchgeführt. Die Magermilchlösung wurde ausgetauscht $(25 \mathrm{~mL})$ und der primäre Antikörper zugefügt. Dabei handelte es sich um einen kommerziellen, aus Mäusen isolierten AntiHis5-Tag-Antikörper der Firma Qiagen mit einer Konzentration von $0.2 \mathrm{mg} / \mathrm{mL}$, der spezifisch an His5-Motive in Proteinen bindet. Es wurde i.d.R. mit einer Verdünnung von 1:2500 gearbeitet. Die Inkubation erfolgte schwenkend für $1 \mathrm{~h}$ bei RT oder über Nacht bei $4^{\circ} \mathrm{C}$. Danach wurde die NCM dreimal mit je $40 \mathrm{~mL}$ TBT-Puffer für je $10 \mathrm{~min}$ bei $4{ }^{\circ} \mathrm{C}$ gewaschen. Die Membran wurde erneut mit $25 \mathrm{~mL} 5 \%$ Magermilch/TBT versetzt und der sekundäre Antikörper zugefügt. Hierbei handelte es sich um einen kommerziellen, aus der Ziege isolierten an den primären Maus-Antikörper bindenden Antikörper mit HRP-Funktion von der Firma BD Pharmingen. Die Verdünnung betrug i.d.R. 1:2500. Die Inkubation erfolgte für $1 \mathrm{~h}$ oder über Nacht bei $4^{\circ} \mathrm{C}$. Die Membran wurde dreimal mit je $40 \mathrm{~mL}$ TBT-Puffer für je 20 min bei $4^{\circ} \mathrm{C}$ gewaschen. Auf ein Waschen mit Reinstwasser erfolgte die Fotodokumentation am Gelimager, dessen 
CCD-Detektor in der Lage ist auch schwache Chemilumineszenzsignale zu detektieren. Es wurde mit normaler Sensitivität und mit der Einstellung Autoexposure oder aber mit festgelegten Belichtungszeiten von 5 bzw. $10 \mathrm{~s}$ gearbeitet. Dazu wurde die NCM mit je $1 \mathrm{~mL}$ ECL 1- bzw. ECL 2-Lösung (Tab. 3.12) 2 min benetzt, dann in die Kammer des Gelimagers gelegt und sowohl das Chemilumineszenzbild als auch eine Fotografie der NCM mit den farbigen Markerbanden aufgenommen.

\section{Durchführung des Anti-Sin $1^{\text {ntd-Western Blots }}$}

Es wurde ebenfalls ein Western Blot mit einem polyklonalen Antikörper aus dem Kaninchen durchgeführt, der von der Kröger-Gruppe zur Verfügung gestellt wurde und spezifisch an die $\mathrm{N}$-terminale Domäne des Sin1 binden soll. Es handelt sich um ein Antiserum, das neben den Antikörpern einige weitere Proteinbestandteile enthält. Das Western Blot-Protokoll wurde ebenfalls von der Kröger-Gruppe übernommen und unterscheidet sich leicht von dem des Anti-His-Tag-Western Blots. Nach dem Blotting und Färben mit PonceauS wurde die NCM mit $2 \%$ BSA (IgG-frei) geblockt und danach $3 \times 10$ min mit je $30 \mathrm{~mL}$ TBT-Puffer bei RT gewaschen. Die Membran wurde mit $25 \mathrm{~mL}$

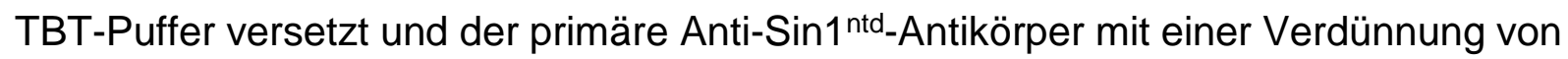
1:10000 zugefügt. Die NCM wurde über Nacht bei $4{ }^{\circ} \mathrm{C}$ inkubiert. Nach dem Waschen mit TBT-Puffer bei RT (3x $10 \mathrm{~min}$ ), wurden erneut $25 \mathrm{~mL}$ TBT-Puffer zur Membran gegeben und der aus Ziegen isolierte sekundäre Antikörper mit HRP-Funktion und Antigenerkennung des Kaninchenantikörpers mit einer Verdünnung von 1:10000 zugefügt. Es wurde $1 \mathrm{~h}$ bei RT inkubiert und anschließend mit TBT-Puffer $3 \times 10 \mathrm{~min}$ bei Raumtemperatur gewaschen. Nach dem Waschen mit Reinstwasser erfolgte die Fotodokumentation wie beim Anti-His-Tag-Western Blot. 
Puffer und Lösungen

Tabelle 3.12: Übersicht der für den Western Blot verwendeten Puffer und Lösungen.

\begin{tabular}{ccc}
\hline Puffer/Lösung & Komponente & Menge \\
\hline Blotting-Puffer & TRIS & $25 \mathrm{mM}$ \\
& Glycin & $192 \mathrm{mM}$ \\
& SDS & $0.1 \%(w / v)$ \\
& Methanol & $20 \%(v / v)$ \\
\hline TBT-Puffer & TRIS/HCl, pH $=7.4$ & $10 \mathrm{mM}$ \\
& $\mathrm{NaCl}$ & $150 \mathrm{mM}$ \\
& Tween 20 & $0.2 \%(v / v)$ \\
\hline ECL1-Lösung & TRIS/HCl, pH $=8.5$ & $100 \mathrm{mM}$ \\
& Luminol (in DMSO) & $2.5 \mathrm{mM}$ \\
& Coumarinsäure (in DMSO) & $396 \mu \mathrm{M}$ \\
\hline ECL2-Lösung & TRIS/ $/ \mathrm{HCl}, \mathrm{pH}=8.5$ & $100 \mathrm{mM}$ \\
& $\mathrm{H}_{2} \mathrm{O}_{2}(30 \%)$ & $0.064 \%(v / v)$ \\
\hline
\end{tabular}

3.3.4 Circulardichroismus-spektroskopische Analyse der sekundären Proteinstruktur

- Teile dieses Kapitels wurden aus der Masterarbeit des Autors übernommen. ${ }^{[16]}$

Das dialysierte $\mathrm{rSin} 1^{-\mathrm{SP}}$ wurde auf seine Sekundärstrukturelementanteile getestet. Dies erfolgte mittels Circulardichroismus (CD)-Spektroskopie. Der Circulardichroismus basiert auf der unterschiedlichen Absorption eines chiralen Moleküls von zirkular polarisiertem Licht.

Licht kann nach dem Prinzip des Welle-Teilchen-Dualismus als Welle beschrieben werden und wird durch einen elektrischen und einen dazu senkrecht stehenden magnetischen Feldvektor charakterisiert. Unpolarisiertes Licht besitzt $\vec{E}$-Feldvektoren, die in alle Raumrichtungen senkrecht zur Ausbreitungsrichtung schwingen können. Mithilfe eines Polarisationsfilters kann linear polarisiertes Licht generiert werden, das lediglich eine Schwingungsebene des $\vec{E}$-Feldvektors besitzt (Abb. 3.10). 

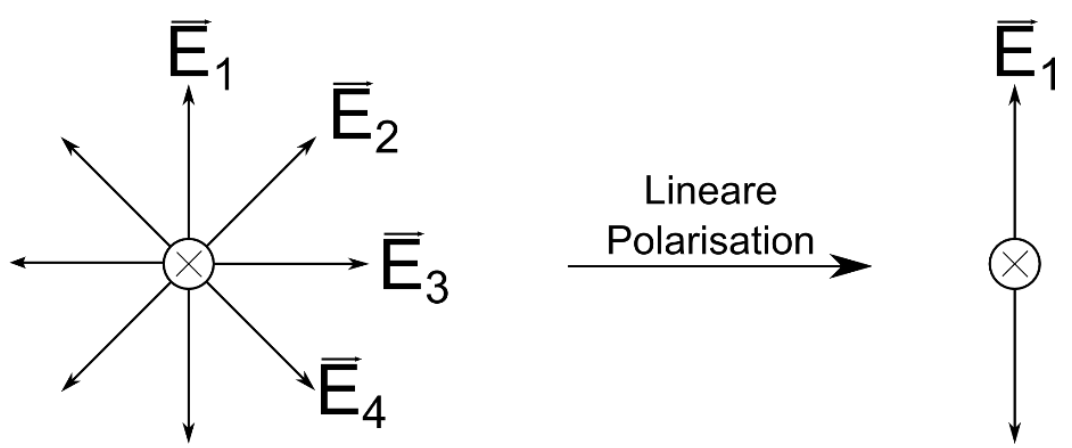

Abbildung 3.10: Unpolarisiertes Licht besitzt $\vec{E}$-Feldvektoren, die in alle Raumrichtungen schwingen. Das Licht breitet sich in die Papierebene hinein aus. Mittels Polarisationsfilter kann linear polarisiertes Licht erhalten werden, das nur in einer Ebene schwingt. ${ }^{[16]}$

Eine weitere polarisierte Form des Lichts ist das zirkular polarisierte Licht, welches rechtsgängig oder linksgängig um die Propagationsachse verlaufen kann (Abb. 3.11A). Der $\vec{E}$-Feldvektor vollzieht dabei eine schraubenförmige Bewegung. Das linear polarisierte Licht kann als Linearkombination zweier gegenläufig um die Propagationsachse rotierender $\vec{E}$-Feldvektoren $\vec{E}_{\mathrm{L}}$ und $\vec{E}_{\mathrm{R}}$ angesehen werden, wobei $\vec{E} \mathrm{~L}$ und $\vec{E}_{\mathrm{R}}$ dieselbe Frequenz und denselben Betrag aufweisen.
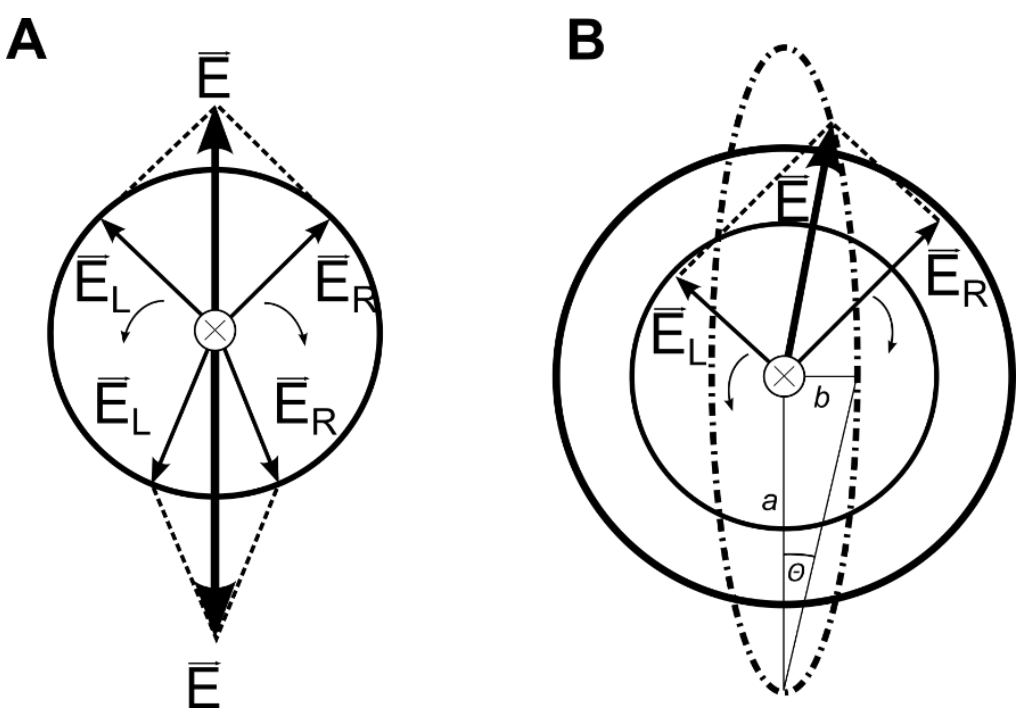

Abbildung 3.11: Zeigerdiagramme polarisierter elektromagnetischer Strahlung. Die Propagationsrichtung des Lichts zeigt in die Papierebene hinein. A: linear polarisiertes Licht dargestellt als Linearkombination von rechts- und links-zirkular polarisiertem Licht mit gleichem Betrag und gleicher Drehfrequenz. B: elliptisch polarisiertes Licht mit einem periodisch ab- und zunehmenden $\vec{E}$-Feldvektor, wenn Amplitude und Phase von $\vec{E}_{\mathrm{L}}$ und $\vec{E}_{\mathrm{R}}$ verschieden sind. 
Die elliptische Polarisierung erfolgt, wenn die $\vec{E}$-Feldkomponenten $\vec{E}_{\mathrm{L}}$ und $\vec{E}_{\mathrm{R}}$ unterschiedliche Amplituden und/oder Phasen aufweisen, sodass der Feldvektor $\vec{E}$ eine Ellipse beschreibt (Abb. 3.11B). Die Elliptizität $\Theta$ ergibt sich dabei als Winkel, der nach Gl. 3.8 mit den Halbachsen $a$ und $b$ der Ellipse zusammenhängt.

$$
\Theta=\tan ^{-1} \frac{b}{a}=\tan ^{-1} \frac{E_{\mathrm{R}}-E_{\mathrm{L}}}{E_{\mathrm{R}}+E_{\mathrm{L}}}
$$

Bei der Wechselwirkung von zirkular polarisiertem Licht mit chiralen - und damit optisch aktiven - Molekülen wird das Licht abhängig von seinem Drehsinn und der Händigkeit des Moleküls unterschiedlich stark absorbiert. Dieses Phänomen wird Circulardichroismus (CD), also zirkulare Zweifarbigkeit, genannt. Der Zusammenhang zwischen verschieden starker Absorption von links- und rechts-zirkular polarisiertem Licht mit dem Lambert-Beerschen Gesetz (GI. 3.6) ist in Gl. 3.9 beschrieben. ${ }^{\text {[91] }}$

$$
\triangle A=A_{\mathrm{L}}-A_{\mathrm{R}}=\varepsilon_{\mathrm{L}} \cdot d \cdot c-\varepsilon_{\mathrm{R}} \cdot d \cdot c
$$

$A_{L}$ und $A_{R}$ bezeichnen die wellenlängenspezifische Absorbanz (Extinktion) von linksoder rechts-zirkular polarisiertem Licht, $\varepsilon_{L}$ bzw. $\varepsilon_{\mathrm{R}}$ die entsprechenden Extinktionskoeffizienten. Die Schichtdicke der Küvette $d$ und die Konzentration $c$ des chiralen Moleküls werden ebenfalls berücksichtigt. Gebräuchlicher als die Differenz der Absorbanz $\Delta A$ ist die absolute Elliptizität, die als $\Theta_{\text {abs }}$ bezeichnet wird. Sie wird typischerweise in der Einheit Milligrad [mdeg] angegeben. Sie hängt nach Gl. 3.10 mit $\Delta A$ numerisch zusammen:[92]

$$
\Theta_{\mathrm{abs}}=\frac{\triangle A}{32.98}
$$

Bei der CD-Spektroskopie von Proteinen wird $\Theta$ normiert, um Proteine unabhängig von ihrer Größe oder Konzentration miteinander vergleichen zu können. Die normierte Größe wird auch Mean Residue Ellipticity (dt. mittlere residuale Elliptizität) genannt und ist definiert als

$$
\Theta=\frac{\Theta_{\mathrm{abb}}[\mathrm{mdeg}]}{c[\mathrm{M}] \cdot d[\mathrm{~cm}] \cdot n \cdot 10}\left[\mathrm{deg} \cdot \mathrm{cm}^{2} \cdot \mathrm{dmol}^{-1}\right]
$$

Auf diese Weise kann der Einfluss der Küvettendicke, der Proteinkonzentration und der Proteinlänge, genauer der Anzahl an Aminosäuren $n$ im Protein, für eine bessere Vergleichbarkeit von $\Theta$ verschiedener Proteine eliminiert werden. 


\section{Aufbau eines CD-Spektrometers}

Ein CD-Spektrometer benötigt einen optischen Aufbau, der nicht nur die lineare Polarisation des Lichts ermöglicht, sondern auch seine Modulation zur Erzeugung zirkular polarisierten Lichts. ${ }^{[93]}$ Als Lichtquelle dient oft eine XenonGasentladungslampe, die ausreichend intensives UV-Licht emittiert. Da dabei die Gefahr besteht, dass durch UV-Strahlung gebildetes Ozon die Optik des Spektrometers angreift, wird das System vor und während des Betriebs mit Stickstoffgas gespült, um den Luftsauerstoff zu verdrängen. Das Licht wird in einem Monochromator auf eine gewünschte Wellenlänge justiert. So kann ein bestimmter Wellenlängenbereich im Verlauf der Spektroskopie Schritt für Schritt abgefahren werden. Zusätzlich zur Monochromatisierung wird das Licht in einem Polarisator linear polarisiert und durch einen folgenden Modulator (z.B. Pockels-Zelle) zu zirkular polarisiertem Licht verändert. Zirkular polarisiertes Licht entsteht durch eine Phasenverschiebung einer der beiden orthogonalen linear polarisierten Lichtwellen um $\lambda / 4$. Der Anteil an links- und rechts- zirkular polarisiertem Licht wird in einer definierten Frequenz moduliert. Das Licht trifft auf die Probe, die rechts- und links-zirkular polarisiertes Licht eventuell unterschiedlich stark absorbiert. Ein Photomultiplier detektiert und verstärkt das Licht, sodass ein $\Theta_{\text {abs-Signal berechnet und ausgegeben }}$ werden kann.

\section{CD-Spektren von Proteinen und Bestimmung der Sekundärstruktur ${ }^{[94]}$}

Im nahen UV-Bereich über $230 \mathrm{~nm}$ absorbieren insbesondere aromatische Aminosäuren wie Tryptophan, Tyrosin und Phenylalanin. Das Absorptionsspektrum hängt dabei aber nicht nur von der Seitengruppe ab, sondern auch von der Umgebung der Aminosäure. Somit können Rückschlüsse auf die tertiäre Struktur eines Proteins gezogen werden ${ }^{[92]}$. Im fernen UV-Bereich zwischen 160 und $240 \mathrm{~nm}$ liegen $n \rightarrow \pi^{*}$ und $\pi \rightarrow \pi^{*}$-Übergänge der Peptidbindungen eines Proteins. Die Sekundärstruktur und damit die chirale Umgebung, in der sich die Peptidbindung befindet, nimmt dabei Einfluss auf diese Absorptionen. Deshalb können CD-Spektren in diesem Wellenlängenbereich im Vergleich mit den Spektren röntgenkristallografisch untersuchter Proteine mit bekannten Sekundärstrukturen Aufschluss über die Sekundärstrukturelementverteilung eines Proteins geben. Winkel und Ausrichtung der Peptidbindungen ändern sich je nach vorliegenden sekundären Strukturmotiven. 
$\Pi \rightarrow \pi^{*}$-Übergänge können sowohl parallel oder senkrecht polarisiert sein, wenn es, z. B. bei $\alpha$-Helices, zu Excitonenkopplungen kommt. Deshalb unterscheiden sich $\alpha-$ Helices von $\beta$-Faltblättern oder Zufallsknäulen (Random Coils). Näherungsweise ergibt die Summe der Motive eine Wechselwirkung mit zirkular polarisiertem Licht, dessen resultierendes CD-Signal wiederum Rückschlüsse auf die Proportionen dieser Motive zulässt.

Die CD-Signale, die aus $\alpha$-Helix, $\beta$-Faltblatt und Zufallsknäuel resultieren, sind in Abb. 3.12 dargestellt. Die $\alpha$-Helix zeigt eine starke positive Bande bei ca. $190 \mathrm{~nm}$ $\left(\pi \rightarrow \pi^{*}\right)$ und zwei schwächere negative Banden bei ca. $208 \mathrm{~nm}\left(\pi \rightarrow \pi^{*}\right)$ und ca. $222 \mathrm{~nm}\left(n \rightarrow \pi^{*}\right)$. Das $\beta$-Faltblatt besitzt eine positive Bande bei ca. $195 \mathrm{~nm}\left(\pi \rightarrow \pi^{*}\right)$ und eine negative Bande bei ungefähr $218 \mathrm{~nm}\left(n \rightarrow \pi^{*}\right)$. Das Zufallsknäuel weist eine starke negative Bande unter $200 \mathrm{~nm}\left(\pi \rightarrow \pi^{*}\right)$ sowie eine schwache positive Bande bei ca. $218 \mathrm{~nm}\left(n \rightarrow \pi^{*}\right)$ auf. $\beta$-Schleifen variieren etwas in der Ausprägung des CDSignals. Ihnen können jedoch grob eine starke positive Bande über $200 \mathrm{~nm}\left(\pi \rightarrow \pi^{*}\right)$ und eine schwache negative Bande bei $225 \mathrm{~nm}\left(n \rightarrow \pi^{*}\right)$ zugeordnet werden. ${ }^{95]}$

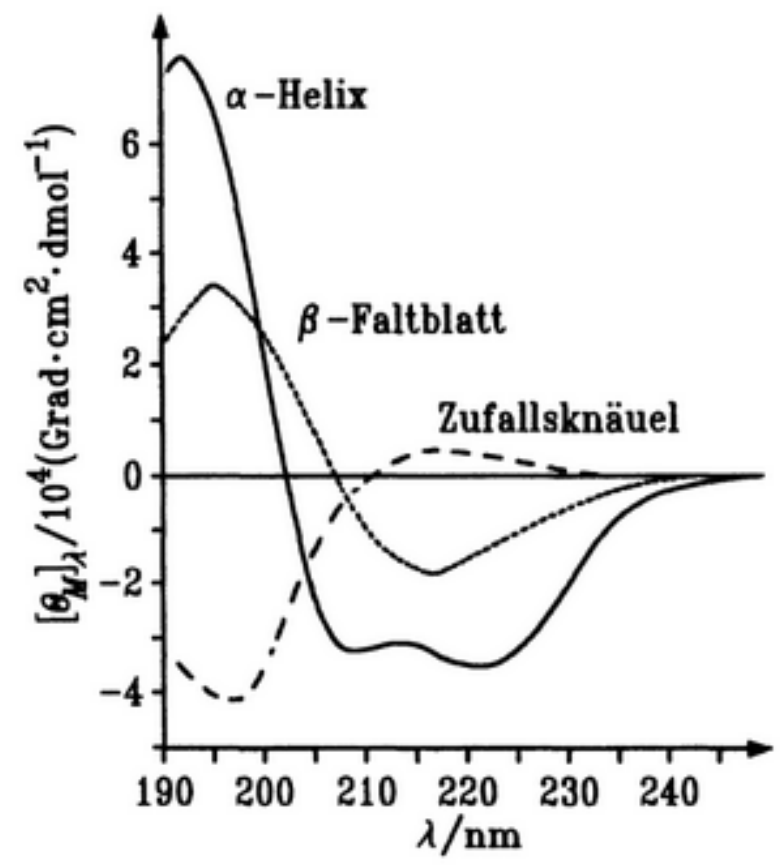

Abbildung 3.12: Darstellung des Einflusses der Sekundärstrukturmotive $\alpha$-Helix, $\beta$-Faltblatt und Zufallsknäuel auf das CD-Signal von Proteinen. ${ }^{[81]}$ 


\section{Durchführung}

Die CD-Messung wurde im fernen UV-Bereich zwischen 190 und $260 \mathrm{~nm}$ durchgeführt. Dazu wurden Quarz-Küvetten mit einer kurzen optischen Weglänge von $d=0.01 \mathrm{~mm}-0.1 \mathrm{~mm}$ verwendet. Pufferbestandteile wie Chlorid, Thiole oder EDTA absorbieren Licht im genannten Wellenlängenbereich. Daher wurde ein niedrigkonzentrierter MOPS-Puffer (Puffer $\mathrm{C}$ ) verwendet, der diese Bestandteile nicht enthält. Die Messungen wurden bei $20^{\circ} \mathrm{C}$ durchgeführt. Die Proteinkonzentration variierte von 3.1 bis $12.7 \mu \mathrm{M}$. Die CD-Spektroskopie erfolgte am Jasco J-1500-CDSpektrophotometer im Arbeistkreis von Prof. Ulf Diederichsen unter Stickstoffstrom, um Ozonbildung zu vermeiden. Die Messparameter sind in Tab. 3.13 angegeben. Die Messung wurde computergestützt über die Software SpectraManager von Jasco gesteuert.

Tabelle 3.13: Parameterübersicht der CD-Messungen.

\begin{tabular}{cc}
\hline Parameter & Wert \\
\hline Sensitivity & $20 \mathrm{mdeg} / 0,5 \mathrm{dOD}$ \\
D.I.T. & $1 \mathrm{~s}$ \\
Band width & $1 \mathrm{~nm}$ \\
Start & $260 \mathrm{~nm}$ \\
End & $190 \mathrm{~nm}$ \\
Data Pitch & $0.1 \mathrm{~nm}$ \\
Start mode & Immediately \\
Scanning mode & Continuous \\
Scanning speed & $10 \mathrm{~nm} / \mathrm{min}$ \\
No. of accumulations & $5 \mathrm{or} 10$ \\
Temperature & $20{ }^{\circ} \mathrm{C}$
\end{tabular}

Es wurden jeweils 5 oder 10 Spektren aufgenommen und im SpectraManager automatisch gemittelt. Die gemittelten Spektren des Puffers und der Proteinlösun wurden anschließend im Unterprogramm SpectraAnalysis voneinander subtrahiert und mit einem Glättungsfaktor 9 geglättet. Die normierte Elliptizität $\Theta$ wurde nach Gl. 3.11 erhalten, indem die abolute Elliptizität durch die optische Weglänge, die Proteinkonzentration sowie die Aminosäureanzahl des Proteins geteilt wurde. 
Die normierten Daten wurde in die Online-Analysesoftware DichroWeb ${ }^{[96]}$ geladen. Dort wurden die Daten mithilfe des CDSSTR-Algorithmus ${ }^{[97,98]}$ mit der Proteindatenbank der Referenzsets ${ }^{[99,98]} 4$ bzw. 7 verglichen und ein Fit berechnet. Die Datenbanken setzen sich aus verschiedenen Proteinen zusammen, deren Sekundärstrukturen mittels Röntgenkristallografie oder NMR bestimmt und mit ihren CD-Spektren in Zusammenhang gebracht wurden. Der berechnete Fit lieferte zugleich die Anteile an regulären und verzerrten $\alpha$-Helices bzw. $\beta$-Faltblättern sowie $\beta$-Schleifen und Zufallsknäueln.

\subsection{Lipidchemische Methoden}

\subsubsection{Verwendete Lipide}

Die Präparation von artifiziellen Membranen erfordert den Einsatz von Lipidmolekülen. Alle verwendeten Lipide sind kommerziell erhaltbar. Für die fluoreszenzmikroskopischen Analysen der Membranen wurden lipidverankerte Fluorophore genutzt.

1,2-Dioleoyl-sn-glycero-3-phosphocholin (DOPC) ist ein Phosphoglycerolipid, das zwei Ölsäurereste enthält, die den hydrophoben Bereich definieren. Als polare Kopgfruppe dient ein an das Phosphoglycerolgerüst gebundenes Cholin (Abb. 3.13). Bei neutralem pH-Wert liegt DOPC zwitterionisch vor. Die Hauptphasenumwandlungstemperatur beträgt $-17^{\circ} \mathrm{C} .{ }^{[100]}$<smiles>CCCCCCCC/C=C\CCCCCCCC(=O)OC[C@H](COP(=O)([O-])OCC[N+](C)(C)C)OC(=O)CCCCCCCCCCCCCC</smiles>

Abbildung 3.13: Struktur von 1,2-Dioleoyl-sn-glycero-3-phosphocholin (DOPC). Molare Masse $M=786 \mathrm{~g} \cdot \mathrm{mol}^{-1}$.

1-Palmitoyl-2-oleoyl-sn-glycero-3-phosphocholin (POPC) enthält im Gegensatz zu DOPC an Position sn-1 einen Palmitinsäurerest (Abb. 3.14). Seine Hauptphasenumwandlungstemperatur liegt bei $-2{ }^{\circ} \mathrm{C} .{ }^{[100]}$ 
<smiles>CCCCCCCC/C=C\CCCCCCCC(=O)OC[C@H](COP(=O)([O-])OCC[N+](C)(C)C)OC(=O)CCCCCCCCCCCCC</smiles>

Abbildung 3.14: Struktur von 1-Palmitoyl-2-oleoyl-sn-glycero-3-phosphocholin (POPC). Molare Masse $M=760 \mathrm{~g} \cdot \mathrm{mol}^{-1}$.

1-Palmitoyl-2-oleoyl-sn-glycero-3-phosphoethanolamin (POPE) hat die gleiche Fettsäurezusammensetzung wie POPC, besitzt als Kopfgruppe jedoch ein Ethanolamin (Abb. 3.15). Es ist somit ebenfalls zwitterionisch im neutralen Milieu. Die Hauptphasenumwandlungstemperatur liegt mit $25^{\circ} \mathrm{C}$ deutlich höher als für POPC.[100]<smiles>CCCCCCCCCCCCCCCC(=O)OC[C@H](COP(=O)([O-])OCC[NH3+])OC(=O)CCCCCCCCCCCC</smiles>

Abbildung 3.15: Struktur von 1-Palmitoyl-2-oleoyl-sn-glycero-3-phosphoethanolamin (POPE). Molare Masse $M=718 \mathrm{~g} \cdot \mathrm{mol}^{-1}$.

1-Palmitoyl-2-oleoyl-sn-glycero-3-phosphoglycerol (POPG) besitzt mit seiner Glycerolgruppe am Kopfende insgesamt eine negative Ladung bei neutralem $\mathrm{pH}$-Wert (Abb. 3.16). Seine Hauptphasenumwandlungstemperatur beträgt wie die von POPC $-2{ }^{\circ} \mathrm{C} \cdot{ }^{[100]}$<smiles>CCCCCCCCCCCCCCCCCCCCCCCCC(=O)OC[C@H](COP(=O)([O-])OCC(O)CO)OC(=O)CCCCCCCCC</smiles>

Abbildung 3.16: Struktur von 1-Palmitoyl-2-oleoyl-sn-glycero-3-phosphoglycerol (POPG). Molare Masse des Na-Salzes $M=771 \mathrm{~g} \cdot \mathrm{mol}^{-1}$. 
Texas Red@-1,2-Dipalmitoyl-sn-glycero-3-phosphoethanolamin (TxR-DPPE) besitzt ein Phosphoethanolamingrundgerüst, an welches zwei Palmitinsäuremoleküle verestert sind. An der Aminfunktion des Ethanolamins ist Sulforhodamin 101, in der Säurechloridform auch bekannt als Texas Red®, gebunden (Abb. 3.17). Es handelt sich hierbei um ein Fluorophor, das eine Anregungswellenlänge von $595 \mathrm{~nm}$ und eine Emissionswellenlänge von $615 \mathrm{~nm}$ besitzt.<smiles>CCCCCCCCCCCCCCCC(=O)OCC(COP(=O)([O-])OCCN[13C](=O)[O-])OC(=O)CCCCCCCCCCCC</smiles>

Abbildung 3.17: Struktur von Texas Red@-1,2-Dipalmitoyl-sn-glycero-3-phosphoethanolamin (TxRDPPE). Molare Masse des Triethylammoniumsalzes $M=1382 \mathrm{~g} \cdot \mathrm{mol}^{-1}$.

Ein weiteres DPPE-gebundenes Fluorophor ist Atto390-1,2-Dipalmitoyl-sn-glycero-3phosphoethanolamin (Atto390-DPPE). Das Fluorophor Atto390 ist ebenfalls kopfgruppenverankert (Abb. 3.18). Die Anregungs- bzw. Emissionswellenlängen des Atto390-Carboxy-Derivats sind 390 und $476 \mathrm{~nm}$.<smiles>CCCCCCCCCCCCCCCCCCCC(=O)OC[C@H](COP(=O)([O-])OCCNC(=O)CCCN1c2cc3oc(=O)cc(C)c3cc2C(C)CC1(C)C)OC(=O)CCCCCCCCCC</smiles>

Abbildung 3.18: Struktur von Atto390-1,2-Dipalmitoyl-sn-glycero-3-phosphoethanolamin (Atto390DPPE). Molare Masse $M=1017 \mathrm{~g} \cdot \mathrm{mol}^{-1}$.

Als Ersatz für das schnell bleichende Atto 390 wurde $\beta$-Bodipy 500/510 $\mathrm{C}_{12}$-PPC verwendet (Abb. 3.19). Der Bodipy-Fluorophor ist hier an der mittleren Fettsäure und 
somit im hydrophoben Bereich des Lipids verbunden. Das Anregungsmaximum liegt bei $500 \mathrm{~nm}$, das Emmissionsmaximum bei $510 \mathrm{~nm}$.

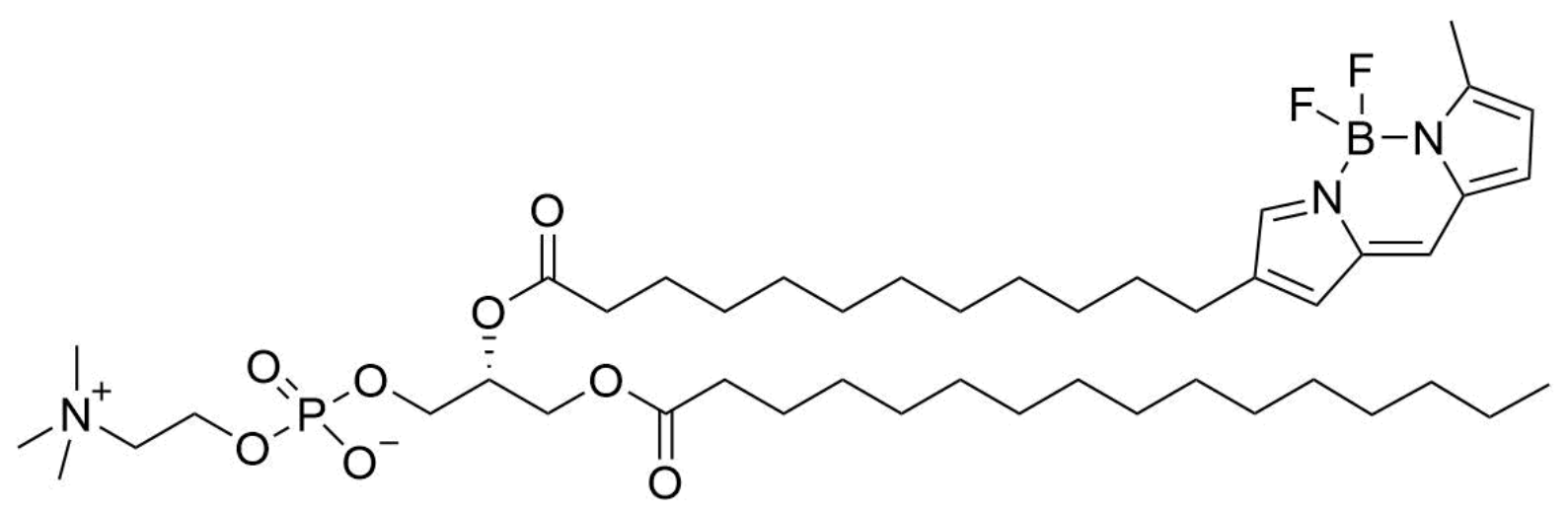

Abbildung 3.19: Struktur von $\beta$-Bodipy $500 / 510 \mathrm{C}_{12}$-PPC. Molare Masse $M=882 \mathrm{~g} \cdot \mathrm{mol}^{-1}$.

\subsubsection{Herstellung von Lipidfilmen und Lipidlösungen}

Es wurden Lipidfilme verschiedener Zusammensetzungen mit einer Gesamtmasse von 0.2 bzw. $0.5 \mathrm{mg}$ hergestellt. Dazu wurden die entsprechenden Volumina der Lipidstammlösungen in Chloroform bzw. Chloroform/Methanol (2:1 (TxR-DPPE) bzw. 4:1 (Atto390-DPPE)) in ein Reagenzglas pipettiert und im Wasserbad bei $30^{\circ} \mathrm{C}$ erwärmt. Das Lösungsmittel wurde dabei im Stickstoffstrom verblasen. Die Filme wurden nach 15 min für $3 \mathrm{~h}$ im Vakuumtrockenschrank bei $30^{\circ} \mathrm{C}$ und unter Vakuum getrocknet. Anschließend wurden die Reagenzgläser mit Parafilm verschlossen und bei $4{ }^{\circ} \mathrm{C}$ für bis zu mehrere Monate gelagert. Lipidfilme, die Fluorophore enthielten wurden mit Aluminiumfolie vor Licht geschützt.

Für das Spreiten eines Lipidmonolayers mittels Langmuir-Blodgett-Technik wurde ein Lipidgemisch in Chloroform auf Eis angesetzt. Das Gesamtvolumen der Lipidlösung betrug $200 \mu \mathrm{L}$. Der Schraubverschluss wurde mit Parafilm abgedichtet und die Lösung bei $-20^{\circ} \mathrm{C}$ gelagert. 


\subsubsection{Präparation von $r \operatorname{Sin} 1^{-\mathrm{SP}}$ enthaltenen Proteoliposomen mittels Comizellisierung}

Comizellisierung ist eine geeignete Methode, um Transmembranproteine in unilamellare Vesikel zu rekonstituieren, sodass sich ihre Transmembrandomäne(n) in die Lipiddoppelschicht des Vesikels einfügt. Dabei werden Detergenzien verwendet, die in Gegenwart von Lipiden und oberhalb der kritischen Mizellenkonzentration ( $\mathrm{cmc}$ ) gemischte Mizellen ausbilden. Werden gemischte Mizellen mittels Größenausschlusschromatographie aufgereinigt, wird die $\mathrm{cmc}$ des Detergens unterschritten und die Detergensmoleküle durch die Chromatographie von sich bildenden unilamellaren Vesikeln getrennt. Diese Vesikel können während ihrer Entstehung Transmembrandomänen von Proteinen insertieren. ${ }^{[101]}$ Abb. 3.20 zeigt eine schmatische Übersicht der Rekonstitution von rSin $1^{-S P}$ in kleine unilamellare Vesikel (SUVs) durch Größenausschlusschromatographie.

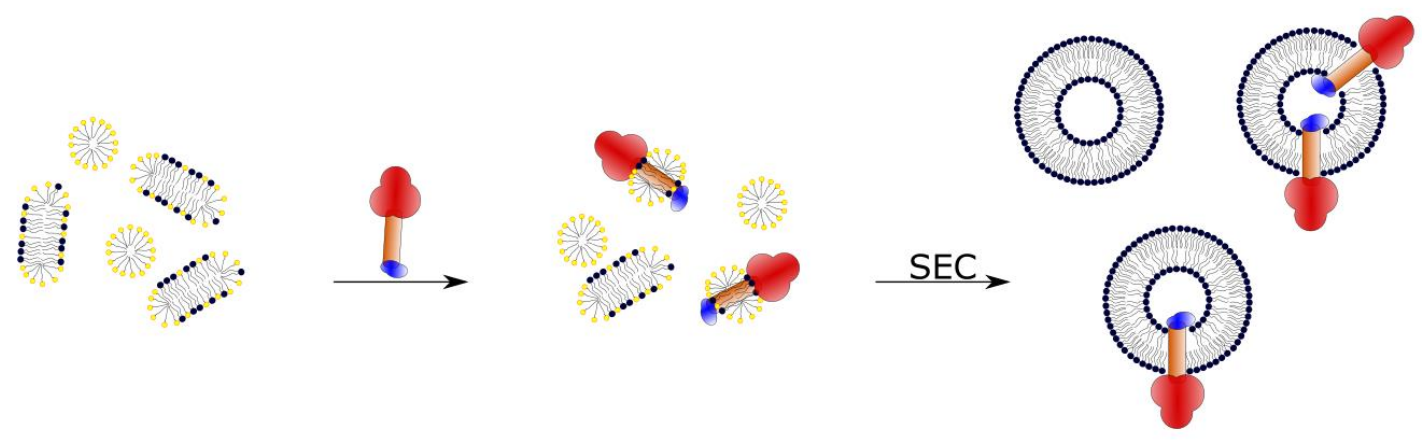

Abbildung 3.20: Schema der Comizellisierung und dadurch resultierender Rekonstitution von rSin1-SP in SUVs nach Gößenausschlusschromatographie (SEC). Detergensmoleküle in gelb, Lipide in schwarz.

Als ungeladenes Detergens wurde $n$-Octyl- $\beta$-D-glucopyranosid (nOG) verwendet, dessen cmc in Wasser bei 20-25 mm bei RT liegt. Es wurde zunächst ein Lipidfilm mit nOG-versetztem Rekonstitutionspuffer (Tab. 3.14) solubilisiert wobei nach einer Inkubation von 30 min bei RT dreimal für $30 \mathrm{~s}$ mit je 5 min Pause gevortext wurde. Diese gemischten Mizellen wurden mit Proteinlösung ( $r \operatorname{Sin} 1^{-\mathrm{SP}}$ ) versetzt, sodass sich ein definiertes nominelles Protein-zu-Lipid-Verhältnis ergab. Es wurde darauf geachtet, dass die nOG-Konzentration nach Proteinzugabe mindestens $40 \mathrm{~mm}$ betrug. 
Nach einer Inkubation von 30 min wurde das Protein-Mizellengemisch auf eine mit Rekonstitutionspuffer äquilibrierte Sephadex G-25-Gelfiltrationssäule gegeben. Beim Eluieren mit Rekonstitutionspuffer wurde $1 \mathrm{~mL}$ Totvolumen verworfen und dann $500 \mu \mathrm{L}$ aufgefangen. Nach einer Aufkonzentrierung des Eluats im Concentrator auf ca. $100 \mu \mathrm{L}$ wurde die Probe erneut auf die gewaschene Säule gegeben und wie zuvor eluiert. Für das Spreiten auf einem Substrat wurden die gesamten $500 \mu \mathrm{L}$ verwendet. Für das Co-Flotationsassay wurden die $500 \mu \mathrm{L}$ erneut auf ca. $150 \mu \mathrm{L}$ aufkonzentriert.

Für Blindexperimente mit Vesikeln ohne Protein wurde statt Proteinlösung das gleiche Volumen Rekonstitutionspuffer eingesetzt.

Tabelle 3.14: Zusammensetzung des Rekonstitutionspuffers.

\begin{tabular}{ccc}
\hline Lösung & Komponente & Menge \\
\hline Rekonstitutionspuffer & MOPS & $10 \mathrm{mM}$ \\
& KCI & $150 \mathrm{mM}$ \\
& & $\mathrm{pH} 7.7(\mathrm{KOH})$ \\
\hline
\end{tabular}

\subsubsection{Phosphattest}

Zur Bestimmung der tatsächlichen Lipidmenge in proteinfreien Vesikeln und Proteoliposomen wurde ein Phosphattest durchgeführt. Dazu wurde eine Eichreihe mit $0,0.25,0.5,1.0,1.5$ und $2.0 \mu \mathrm{g}$ Phosphor aus $\mathrm{NaH}_{2} \mathrm{PO}_{4}$ angesetzt und $60 \mathrm{~min}$ bei $200^{\circ} \mathrm{C}$ eingedampft. Proteoliposomen- und Vesikelproben $(30 \mu \mathrm{L})$ wurden mit Perchlorsäure $(70 \%, 200 \mu \mathrm{L})$ versetzt und $60 \mathrm{~min}$ bei bei $220^{\circ} \mathrm{C}$ zu anorganischem Phosphat verascht. Zu den abgekühlten Proben (einschließlich der Eichreihen) wurde ein Gemisch $(700 \mu \mathrm{L})$ aus $12.6 \%(w / v) \mathrm{HClO}_{4}$ und $0.45 \%(w / v)\left(\mathrm{NH}_{4}\right)_{2} \mathrm{MoO}_{4}$ sowie $700 \mu \mathrm{L} 1.7 \%(w / v)$ Ascorbinsäure gegeben. Alle Proben wurden $10 \mathrm{~min}$ bei $80^{\circ} \mathrm{C}$ erwärmt und dann absorptionsspektroskopisch bei $820 \mathrm{~nm}$ vermessen. Die Proben wurden anhand der Regressiongerade der Eichreihe auf ihren Phosphoranteil untersucht und die Werte gemittelt. ${ }^{[102]}$ 


\subsection{Charakterisierung von Sin1-Aggregaten, Vesikeln und Proteoliposomen}

\subsubsection{Größenbestimmung von Proteinaggregaten und Vesikeln mit dynamischer Lichtstreuung (DLS)}

-Die Arbeit von Kapitel 3.5.1 bezüglich der rSin1-Proben wurde teilweise von Lucia Winkler ausgeführt.-

Die Größe der rSin1-Proteinaggregate in Lösung wurde mittels dynamischer Lichtstreuung (DLS) ermittelt. Bei dieser Technik nutzt man aus, dass unterschiedlich große Moleküle und Aggregate Unterschiede in ihrer Brownschen Molekularbewegung aufweisen. Je leichter und kleiner ein Teilchen, desto schneller bewegt es sich. Diese Bewegung ist zudem von der Temperatur $T$ und der Viskosität des Mediums $\eta$ abhängig. Wird nun monochromatisches, kohärentes Licht auf eine Probe von Teilchen in Lösung gerichtet, wird es zum Teil an den Partikeln gestreut. Ein Detektor in definiertem Winkel zur Einstrahlrichtung misst ein Interferenzmuster dieses Streulichts, da es von vielen Partikeln und somit Streuzentren ausgeht und das Streulicht miteinander interferiert. Die Fluktuationen dieses Streulichtinterferenzmusters geben Aufschluss über die Teilchen in der Lösung. Kleine Partikel bewegen sich schnell und verändern somit auch das Interferenzmuster schneller als etwa schwere Partikel. Aus diesen Fluktuationen wird von einem Computer eine Intensitätskorrelationsfunktion des Streulichts erstellt, die die Ermittelung eines Diffusionskoeffizienten Dermöglicht. Dieser hängt nach der StokesEinstein-Gleichung (Gl. 3.12) von dem hydrodynamischen Radius $r_{H}$ eines sphärischen Teilchens ab.

$$
D=\frac{k_{\mathrm{B}} \cdot T}{6 \pi \cdot \eta \cdot r_{\mathrm{H}}}
$$

Somit können ein oder auch mehrere Partikelradii ermittelt werden. Dies hängt davon ab, ob mehrere verschieden große Makromoleküle oder Aggregate in der Lösung enthalten sind. Mit dieser Technik der Photonen-Korrelationsspektroskopie können in wässrigem Medium Partikelgrößen von $5 \mathrm{~nm}$ bis $5 \mu \mathrm{m}$ bestimmt werden. ${ }^{[81]}$ 
Die DLS-Messungen der rSin1-Proben wurden im Arbeitskreis von Prof. Dr. U. Diederichsen (Institut für Organische und Biomolekulare Chemie, Georg-AugustUniversität Göttingen) an einem Zetasizer Nano S von Malvern Panalytical (Kassel) bei $25^{\circ} \mathrm{C}$ durchgeführt. Der Messwinkel betrug $173^{\circ}$ und die Wellenlänge des Lichts $633 \mathrm{~nm}$. Es wurden Halbmikroküvetten verwendet, die mit je $450 \mu \mathrm{L}$ umgepufferter rSin1-Lösung befüllt wurden (für Umpufferung siehe Ende Kapitel 3.2.5). Die verwendeten Puffer sind in Tab. 3.15 angegeben. Es wurden je 2 Messungen durchgeführt, wobei jede Messung wiederum aus 3 Messläufen bestand. Am Ende wurde über diese gemittelt. Die gerätspezifische Software ermöglichte die direkte Auswertung der Messungen, indem sie Intensitäts- und Massen-Verteilungen der detektierten Partikel ausgab.

Tabelle 3.15: Übersicht der in der DLS-Messung verwendeten Puffer.

\begin{tabular}{ccc}
\hline Lösung & Komponente & Menge \\
\hline $\begin{array}{c}\text { Phosphat-Citrat- } \\
\text { Puffer pH 7.7 }\end{array}$ & $\mathrm{Na}_{3} \mathrm{PO}_{4}$ & $10 \mathrm{mM}$ \\
\hline Phosphat-Citrat- & & $\mathrm{pH} \mathrm{7.7} \mathrm{(Zitronensäure)}$ \\
Puffer pH 5.0 & $\mathrm{Na}_{3} \mathrm{PO}_{4}$ & $10 \mathrm{mM}$ \\
\hline
\end{tabular}

Es wurden zudem DLS-Messungen mit dem gleichen Setup im Arbeitskreis von Prof. Dr. Philipp Vana (Institut für Physikalische Chemie, Georg-August-Universität Göttingen) mit proteinfreien Vesikelproben aus Comizellisierungspräparationen (siehe Kapitel 3.4.3) durchgeführt, um die Größe bzw. die Größenverteilung der erhaltenen Vesikel in Abhängigkeit von ihrer Lipidkomposition zu bestimmen. Die Vesikelproben lagen in Rekonstitutionspuffer ( $\mathrm{pH}$ 7.7, siehe Tab. 3.14) vor. Verglichen wurden die Lipidkompositionen DOPC/POPG/TxR-DPPE=79.5:20:0.5 sowie POPC/POPE/TxR$\mathrm{DPPE}=69.5: 30: 0.5$. Jede Messung bestand aus drei Messläufen, die gemittelt wurden. 


\subsubsection{Rekonstitutionsbestätigung durch Carbonatextraktion}

-Dieses Experiment war Teil der Bachelorarbeit von Alina Schellhase.[103]_

Ein Carbonatexperiment diente dazu zu überprüfen, ob rSin1-SP tatsächlich integral in die Lipidoppelschicht der Liposomen eingebaut wurde. Basische Carbonatlösung öffnet Liposomen zu Membranblättern (membrane sheets) und extrahiert dabei peripher gebundene Membranproteine, während integrale Membranproteine insertiert bleiben. ${ }^{[104]}$

Es wurde die zehnfache Menge an Carbonatlösung (Tab. 3.16) zu Proteoliposomenlösung gegeben und $30 \mathrm{~min}$ auf Eis inkubiert. Durch Ultrazentrifugation (120000 g, $1 \mathrm{~h}, 4^{\circ} \mathrm{C}$ ) wurden Lipidmaterial und integrales Protein im Pellet auf der einen Seite und extrahierte Proteine im Überstand auf der anderen Seite getrennt. Der Überstand wurde abgenommen und mit vier Teilen eines $-20^{\circ} \mathrm{C}$ kalten Aceton-Wasser-Gemischs $(4: 1)$ versetzt, gevortext und $3 \mathrm{~h}$ bei $-20^{\circ} \mathrm{C}$ inkubiert, um vorhandenes Protein auszufällen. Anschließend wurde die Probe zentrifugiert $\left(16000 \mathrm{~g}, 10 \mathrm{~min}, 4^{\circ} \mathrm{C}\right)$, der Überstand abgenommen und das Pellet erneut in Aceton/Wasser (4:1) resuspendiert. Es wurde derart insgesamt dreimal zentrifugiert. Die Proben wurden im Concentrator auf ca. $50 \mu \mathrm{L}$ aufkonzentriert und anschließend mit 2x-Probenpuffer versetzt und denaturiert (Gesamtvolumen ca. $100 \mu \mathrm{L}$ ). Ebenso wurden die ursprünglichen Pellets der Ultrazentrifugation in Probenpuffer resuspendiert und denaturiert (Gesamtvolumen ca. $100 \mu \mathrm{L}$ ). Es wurde schließlich AntiHis-Western Blotting mit den Proben durchgeführt (siehe Kapitel 3.3.3) und die Chemilumineszenzintensität der Protein-Banden mittels ImageJ ausgewertet.

Tabelle 3.16: Verwendete Lösungen für die Carbonatextraktion und Acetonfällung.

\begin{tabular}{ccc}
\hline Lösung & Komponente & Menge \\
\hline Carbonatlösung & $\mathrm{Na}_{2} \mathrm{CO}_{3}$ & $100 \mathrm{mM}$ \\
& EDTA & $1 \mathrm{mM}$ \\
& & $\mathrm{pH} 11.5$ \\
\hline Aceton-Wasser & Aceton $/ \mathrm{H}_{2} \mathbf{O}$ & $4: 1(\mathrm{v} / \mathrm{v})$ \\
\hline
\end{tabular}




\subsubsection{Co-Flotationsassay von Proteoliposomen durch Dichtegradientenzentrifugation}

Die Quantifizierung der Rekonstitutionseffizienz des Comizellisierungsverfahrens wurde mithilfe eines Co-Flotationsassays durchgeführt. Dafür wurden die Proteoliposomen einer Dichtegradientenzentrifugation in Gegenwart von Histodenz (ehemals Nycodenz ${ }^{[105]}$ ) unterzogen. Der sich bildende Dichtegradient aus Histodenz trennt (Proteo-)Liposomen von freiem Protein, da erstere in ihrem Lumen kein Histodenz aufweisen und somit leichter sind und oben flotieren, während sich freies Protein im unteren Bereich des Gradienten befindet (Abb. 3.21).
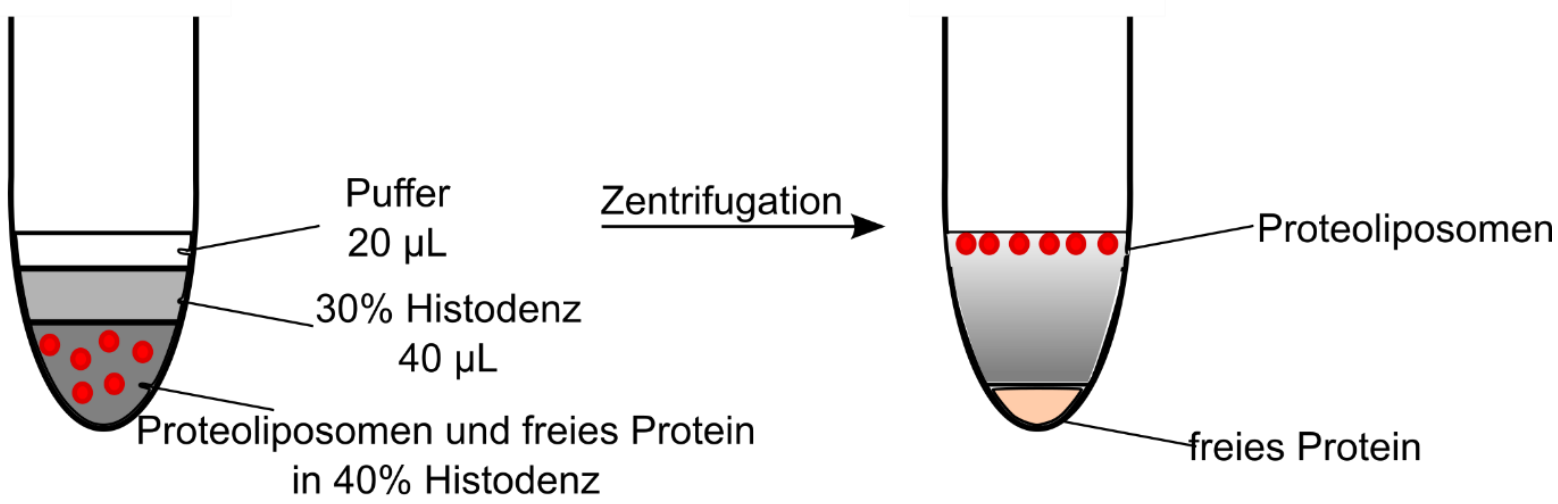

$80 \mu \mathrm{L}$

Abbildung 3.21: Schema des Co-Flotationsassays durch Dichtegradientenzentrifugation. Durch die Ultrazentrifugation werden Proteoliposomen in den oberen Bereich des Gradienten transportiert, während sich freies Protein im unteren Gradientenbereich absetzt.

Es wurde für dieses Assay pro Ultrazentrifugationsröhrchen (UZ-Röhrchen) $40 \mu \mathrm{L}$ Proteoliposomenlösung mit $40 \mu \mathrm{L} 80 \%(w / v)$ Histodenz (in Rekonstitutionspuffer) gemischt und in dem ZU-Röhrchen vorgelegt. Anschließend wurden vorsichtig $40 \mu \mathrm{L}$ $30 \%(w / v)$ Histodenz (in Rekonstitutionspuffer) überschichtet, gefolgt von $20 \mu \mathrm{L}$ Rekonstitutionspuffer. Nach Ultrazentrifugation $\left(350000 \mathrm{~g}, 1.5 \mathrm{~h}, 4{ }^{\circ} \mathrm{C}\right)$ wurden die Proben fraktioniert abpipettiert. Dazu wurden sieben $20 \mu \mathrm{L}-$-Fraktionen erstellt, wobei Fraktion 1 oben und Fraktion 7 unten waren. Die Reihenfolge des Abpipettierens war 1, 2, 7, 6, 3, 5, 4, um ein Durchtragen von Restliposomen von den oberen Fraktionen 
in die unteren zu vermeiden. Die Fraktionen wurden mit je $4 \mu \mathrm{L} 6 \mathrm{x}$-Probenpuffer versetzt, denauturiert $\left(95^{\circ} \mathrm{C}, 10 \mathrm{~min}, 300 \mathrm{rpm}\right)$ und anschließend bei $-20^{\circ} \mathrm{C}$ gelagert. Die Proben wurden schließlich mittels Anti-His-Western Blottings analysiert und am Gelimager fotodokumentiert (siehe Kapitel 3.3.3). Die Graustufenintensität der Banden wurde mit dem Programm Image J ausgewertet und aus den Proportionen die rSin $1^{-S P}{ }_{-}$ Anteile der Fraktionen bestimmt.

\subsubsection{Verdauexperiment zur Bestimmung der Proteinorientierung in Vesikeln}

Das rSin1 konnte theoretisch in zwei möglichen Richtungen in den Vesikeln orientiert sein. Zum einen konnte die große $N$-terminale Domäne in das Lumen des Vesikels zeigen, zum anderen konnte extravesikulär vorliegen, sodass die kurze $C$-terminale Domäne in das Lumen zeigte. Zur Bestimmung dieser Orientierung wurde ein Verdauexperiment durchgeführt bei dem die Proteoliposomen mit der Serinprotease a-Chymotrypsin versetzt wurden, das laut Händler (Sigma) spezifisch Tryptophan, Tyrosin und Phenylalanin und Leucin, aber auch Methionin an den Carboxylenden spaltet. Somit ergäben sich viele kleine Fragmente des $r \operatorname{Sin} 1$. Sollte die $N$-terminale Domäne außerhalb des Vesikels orientiert sein, würde sie komplett fragmentiert werden. Wäre sie im Lumen des Vesikels, wäre sie vor dem Verdau geschützt (Schema, siehe Abb. 4.32).

Es wurde eine rSin1-Proteoliposomenprobe nach dem Protokoll der Comizellisierung präpariert (siehe Kapitel 3.4.3). Die Lipidkomposition war POPC/POPE/TxR-DPPE = 69.5:30:0.5 ( $m=0.5 \mathrm{mg})$ und es wurden $50 \mu \mathrm{L}$ rSin1-Lösung $(c=12.7 \mu \mathrm{M})$ eingesetzt $(P / L$ (nominell) $=1: 1050)$. Analog dazu wurde eine Probe ohne Lipide, aber mit der gleichen Menge rSin1 präpariert. Die Proben wurden nach der zweiten Aufreinigung auf der Sephadexsäule im Concentrator aufkonzentriert und mit Rekonstitutionspuffer so verdünnt, dass ein Gesamtvolumen von $90 \mu \mathrm{L}$ erreicht wurde. Es folgte eine Trennung der Proteoliposomen vom freien Protein mittels Ultradichtezentrifugation mit Histodenz (siehe Kapitel 3.5.3). Die vereinten Fraktionen 1 bis $3(P L)$ wurden zu je $30 \mu \mathrm{L}$ aufgeteilt, eine Verdauprobe und eine Kontrollprobe. Zudem wurde eine weitere Ultrazentrifugationsprobe des freien Proteins ohne Lipide (Sin1) gesamt $(140 \mu \mathrm{L})$ aufgeteilt zu je $70 \mu \mathrm{L}$, eine Sin1-Verdauprobe und eine Sin1-Kontrollprobe. 
Es wurden die PL- bzw. Sin1-Verdauproben mit je $10 \mu \mathrm{L}$ einer wässrigen $\alpha$ Chymotrypsin-Lösung (1.4 mg/mL; $56 \mu \mathrm{M})$ versetzt, durchmischt und $45 \mathrm{~min}$ bei RT inkubiert. Die Kontrollproben wurden mit je $10 \mu \mathrm{L}$ Reinstwasser versetzt. Nach der Inkubation wurde zu allen Proben je $5 \mu \mathrm{L}$ Phenylmethylsulfonylfluorid (PMSF)-Lösung (11.6 mg/mL; $67 \mathrm{~mm}$ in 2-Propanol) gegeben, um Chymotrypsin zu inhibieren. Die Proben wurden mit 6x-Probenpuffer versetzt und im Thermoschüttler denaturiert (95 ${ }^{\circ} \mathrm{C}, 300$ rpm, $10 \mathrm{~min}$ ). Es folgte ein Anti-Sin1-Western Blotting (siehe Kapitel 3.3.3), das das in der $\mathrm{N}$-terminalen Domäne befindliche Epitop nachweist.

\subsubsection{Silicafällung von Proteoliposomen und $\beta$-Silicomolybdattest}

Es sollte die Silicafällungseigenschaft von rSin1 in einer Membranumgebung untersucht werden. Dazu wurden Proteoliposomen mit einem nominellen P/LVerhältnis von 1:630 und einer Lipidkomposition von $\mathrm{POPC} / \mathrm{POPE}=85: 15$ mittels Comizellisierung in Rekonstitutionspuffer $(\mathrm{pH}$ 7.7) präpariert. Blindvesikel wurden analog dazu, jedoch ohne rSin1, hergestellt. Außer dem direkten Vergleich der beiden Vesikelproben wurden Kombinationen mit $0.1 \mathrm{~mm}$ langkettige Polyamin (engl. longchained polyamines, LCPA)-Lösung auf ihre Silicafällung untersucht. Es handelte sich dabei um ein LCPA-Gemisch, das von Fabian Daus und Prof. Dr. Armin Geyer (Fachbereich Chemie, Philipps-Universität Marburg) als Feststoff synthetisiert ${ }^{[106]}$ und zur Verfügung gestellt wurde. Die gemittelte Anzahl an Stickstoffatomen des Gemischs betrug $\mathrm{N}=12$. Die gemittelte molare Masse war $M=813.4 \mathrm{~g} / \mathrm{mol}$. Die Struktur der LCPA entsprach $\mathrm{H}_{3} \mathrm{C}-\mathrm{NH}-\left[\left(\mathrm{CH}_{2}\right)_{3}-\mathrm{N}\left(\mathrm{CH}_{3}\right)-\right]_{n}-\mathrm{H}$. LCPA wurde als $10 \mathrm{~mm}$ Stammlösung in Acetatpuffer (Tab. 3.17) angesetzt. Für die Silicafällung wurde Monokieselsäure $(\mathrm{Si}(\mathrm{OH}) 4,1 \mathrm{M})$ frisch aus Tetramethoxysilan (TMOS, $6.8 \mathrm{M}$ ) und Salzsäure (1 mM) in einem Verhältnis von 3:17 ( $/ v / v)$ angesetzt und $45 \mathrm{~min}$ bei RT inkubiert. Die unterschiedlichen Proben vor $\mathrm{Si}(\mathrm{OH}) 4$-Zugabe setzten sich neben Vesikeln und LCPA nach Tab. 3.18 aus Rekonstitutionspuffer und Acetatpuffer im Verhältnis 1:1 zusammen. Dies ergab eine gemittelte Pufferzusammensetzung (Fällungspuffer) nach Tab. 3.c mit einem neuen pH-Wert von 6.65, der experimentell im größeren Maßstab gemessen wurde. 
Tabelle 3.17: Übersicht der für die Silicafällung verwendeten Puffer.

\begin{tabular}{ccc}
\hline Lösung & Komponente & Menge \\
\hline Rekonstitutionspuffer & MOPS & $10 \mathrm{mM}$ \\
& KCl & $150 \mathrm{mM}$ \\
& & $\mathrm{pH} 7.7(\mathrm{KOH})$ \\
\hline Acetatpuffer & $\mathrm{NaOAC}$ & $40 \mathrm{mM}$ \\
& $\mathrm{KCl}$ & $50 \mathrm{mM}$ \\
\hline Fällungspuffer & & $\mathrm{pH} 5.5(\mathrm{AcOH})$ \\
(Rekonstitutionspuffer & MOPS & $5 \mathrm{mM}$ \\
+ Acetatpuffer = 1:1) & $\mathrm{NaOAC}$ & $20 \mathrm{mM}$ \\
& $\mathrm{KCl}$ & $100 \mathrm{mM}$ \\
& & $\mathrm{pH} \mathrm{6.65}$ \\
\hline
\end{tabular}

Tabelle 3.18: Probenübersicht des Silicafällungsexperiments.

\begin{tabular}{|c|c|c|c|c|c|c|}
\hline in $\mu \mathrm{L}$ & $\mathbf{1}$ & $\mathbf{2}$ & $\mathbf{3}$ & $\mathbf{4}$ & $\mathbf{5}$ & $\mathbf{6}$ \\
\hline Acetatpuffer & 100 & 98 & 100 & 98 & 100 & 98 \\
\hline Rekonstitutionspuffer & 100 & 100 & 0 & 0 & 0 & 0 \\
\hline LCPA (10 mM) & 0 & 2 & 0 & 2 & 0 & 2 \\
\hline $\begin{array}{c}\text { Proteoliposomen } \\
(1 \mathrm{mg} / \mathrm{mL} \text { Lipide; } \\
\text { P/L=1:630) }\end{array}$ & 0 & 0 & 100 & 100 & 0 & 0 \\
\hline $\begin{array}{c}\text { Blindvesikel (1 mg/mL } \\
\text { Lipide) }\end{array}$ & 0 & 0 & 0 & 0 & 100 & 100 \\
\hline
\end{tabular}

Die Proben wurden 25 min bei RT inkubiert, bevor sie mit Si $(O H)_{4}(20 \mu \mathrm{L})$ versetzt und durchmischt wurden. Nach 10 min Inkubationszeit bei RT wurde $1 \mathrm{M} \mathrm{HCl}(20 \mu \mathrm{L})$ zugefügt, um die Silicapolykondensation zu unterbrechen. Die Proben wurden zentrifugiert ( $17000 \mathrm{~g}, 20^{\circ} \mathrm{C}, 5 \mathrm{~min}$ ), die Überstände verworfen und die Pellets $3 \mathrm{x}$ mit je $400 \mu \mathrm{L}$ Reinstwasser gewaschen und zentrifugiert (s.o.). Anschließend wurden die Silicapellets im Concentrator getrocknet.

Die Quantifizierung des gefältten Silicas erfolgte absorptionsphotometrisch mittels modifiziertem $\beta$-Silicomolybdattest. ${ }^{[107]}$ Dabei entsteht aus Kieselsäure und Molybdänsäure ein gelber Silicomolybdänsäure-Komplex, dessen Absorption von Licht der Wellenlänge $370 \mathrm{~nm}$ gemessen wird. Um aus den Silicapellets Kieselsäure 
zu generieren, wurden sie mit $2 \mathrm{M} \mathrm{NaOH}(500 \mu \mathrm{L})$ versetzt, gevortext, ggf. mit Ultraschall behandelt und $60 \mathrm{~min}$ bei RT inkubiert, wobei Silica zu Kieselsäure hydrolisiert wurde. Es wurden zudem zwei Lösungen angesetzt. Die erste Lösung bestand aus $1.35 \mathrm{~mL} \mathrm{HCl}(37 \%)$ und $40.3 \mathrm{~mL}$ Reinstwasser, die zweite aus $774.2 \mathrm{mg}$ [ $\left.\left(\mathrm{NH}_{4}\right)_{6} \mathrm{Mo}_{7} \mathrm{O}_{24} \cdot 4 \mathrm{H}_{2} \mathrm{O}\right]$ in $9.70 \mathrm{~mL}$ Reinstwasser. Beide Lösungen wurden vermischt und der pH-Wert mit $2 \mathrm{M} \mathrm{NaOH}$ auf 1.04 eingestellt (Molybdatlösung). Zu den Silica enthaltenen Proben $(0,20,40 \mu \mathrm{L})$ und einer korrespondierenden Menge $2 \mathrm{M} \mathrm{NaOH}$ (40, 20, $0 \mu \mathrm{L})$ wurden Reinstwasser $(160 \mu \mathrm{L})$ und Molybdatlösung $(800 \mu \mathrm{L})$ gegeben. Die Absorptionsphotometrie erfolgte bei $370 \mathrm{~nm}$. Für die absolute Quantifizierung wurde eine Kalibrationsreihe aus Silicium-Atomabsorptionsspektrometriestandard $(1000 \mu \mathrm{g} / \mathrm{mL}$ in $2 \% \mathrm{NaOH})$ verwendet.

\subsection{Herstellung und Charakterisierung von Sin1-haltigen festkörperunterstützten Membranen}

\subsubsection{Präparation einer festkörperunterstützten Lipideinzelschicht mittels Langmuir-Blodgett-Technik}

Um eine Kontrolle über den Spreitprozess und der mit inm verbundenen finalen Orientierung von rSin1 in der festkörperunterstützten Lipiddoppelschicht zu haben, wurde zunächst eine Lipideinzelschicht auf das hydrophilisierte Substrat gespreitet, um es anschließend durch Vesikelfusion mit Proteoliposomen zu einer Lipiddoppelschicht mit insertiertem Transmembranprotein zu transformieren. Für das Spreiten der Lipideinzelschicht mittels Langmuir-Blodgett-Technik wurde sich an der Arbeit von Kalb et al.[108] orientiert. Dieses Verfahren ermöglicht die Präparation von asymmetrischen Lipiddoppelschichten, wenn die Lipidzusammensetzung der Vesikel sich von der der Lipideinzelschicht unterscheidet.

Als Substrate dienten zugeschnittene $(2.0 \times 0.8 \mathrm{~cm})$ Siliciumwafer, die mit Reinstwasser und $\mathrm{EtOH}$ gespült und am $\mathrm{N}_{2}$-Strom getrocknet wurden. Für die Hydrophilisierung der Substratoberfläche wurde eine Lösung aus Reinstwasser $/ \mathrm{H}_{2} \mathrm{O}_{2}(30 \%) / \mathrm{NH}_{3}(25 \%)=$ 5:1:1 angesetzt, auf $70^{\circ} \mathrm{C}$ erwärmt und die Substrate in einem Teflonhalter in die Lösung gestellt. Die Reaktion wurde nach 25 min abgebrochen, indem der Halter mit 
den Substraten in ein Glas mit Reinstwasser gestellt wurde. Die Substrate wurden mit Reinstwasser gespült und am $\mathrm{N}_{2}$-Strom getrocknet. Zur Aktivierung der Oberfläche wurden die Substrate weiterhin mit $\mathrm{O}_{2}$-Plasma aktiviert (100\% O2, Abpumpdruck 0.15 mbar, Prozessdruck 0.20 mbar, Gaszufuhr 5:30 min, Prozessdauer $30 \mathrm{~s}$, Leistung $60 \%$ ). Die Substrate wurden anschließend mit einer Krokodilklemme und Magnet an einer Eintauchapparatur des Langmuir-Trogs befestigt.

Der aus Teflon bestehende Langmuirtrog fasste $120 \mathrm{~mL}$. Zudem verfügte er über zwei Teflonbarrieren, die mit einem Motor mit Feedbackschleife gesteuert wurden und entweder nach außen oder innen fahren konnten, um die zur Verfügung stehende Flüssigkeitsoberfläche entweder zu vergößern oder zu verkleinern (Expansion vs. Kompression). Als Subphase diente $10 \mathrm{mM}$ Tris-Essigsäure ( $\mathrm{pH}$ 5.0) und die Trogtemperatur wurde mittels Thermostats auf $20^{\circ} \mathrm{C}$ geregelt. Das Mess- und Feedbacksystem wurde kalibriert, indem eine aus einem Streifen Filterpapier bestehende Wilhelmy-Sonde so positioniert wurde, dass sie knapp oberhalb der Flüssigkeit hing und durch sanftes Kippen des Stativs eingetaucht werden konnte und danach in einem Meniskus der Flüssigkeit getaucht blieb. Die gemessene Oberflächenspannung in Flüssigkeit wurde auf $0 \mathrm{mN} / \mathrm{m}$ und die außerhalb der Flüssigkeit auf ca. $72.5 \mathrm{mN} / \mathrm{m}$ eingestellt. Dies entspricht der Oberflächenspannung von Wasser bei $20^{\circ} \mathrm{C}$. Jegliche gemessene Oberflächenspannung stellte somit die Differenz zu dieser Oberflächenspannung von Wasser dar. Das hydrophilisierte Substrat hing vertikal an der motorisierten Eintauchapparatur in die Subphase und im Lot zu den Barrieren getaucht. Es wurde soviel von einer Lipidmischung in Chloroform (siehe Kapitel 3.4.2) mit einer Hamiltonspritze auf die Flüssigkeitsoberfläche gegeben, bis eine stabile Oberflächenspannung von $6-10 \mathrm{mN} / \mathrm{m}$ erreicht war. Dabei wurden die Tropfen möglichst vorsichtig auf die Oberfläche gegeben, um Verwirbelungen und Materialverlust in die Subphase zu vermeiden. Nach einer 10-minütigen Äquilibrierung zum Verdampfen des Chloroforms und einer gleichmäßigen Verteilung der Lipide an der Oberfläche wurden die motorisierten Barrieren langsam zusammengefahren. Als Zielwert galt $32.5 \mathrm{mN} / \mathrm{m}$. Sobald dieser Wert erreicht wurde, stoppten die Barrieren automatisch und hielten diesen Wert im Laufe des weiteren Vorgehens konstant. Nach 30-minütiger Äquilibrierung wurde das Substrat an der Eintauchapparatur langsam (über ca. $2 \mathrm{~h}$ ) aus der Subphase gehoben. Die Barrieren regelten dabei nach und komprimierten, um den Lipidmaterialverlust an das Substrat auszugleichen. Nach der Prozedur wurde das mit einer Lipideinzelschicht versehene Substrat bis zur weiteren 
Verwendung, mindestens aber über Nacht, in einem Glasexsikkator, aber ohne Vakumm, unter Lichtausschluss gelagert.

\subsubsection{Vesikelfusion mit Lipideinzelschicht}

Die Herstellung festkörperunterstützter Membranen kann auf mehreren Wegen erreicht werden. So können Vesikel auf einer hydrophilen Oberfläche spreiten und eine planare Lipiddoppelschicht ausbilden, wobei die polaren Lipidkopfgruppen der unteren Lipidschicht zum Substrat gerichtet sind, während die der oberen Schicht zum flüssigen Medium zeigen. Zwischen diesen polaren Ebenen befindet sich eine unpolare Ebene bestehend aus den Fettsäureketten. Der Spreitprozess war bereits Gegenstand zahlreicher Untersuchungen. So wurde gezeigt, dass eine kritsche Oberflächenbelegung notwendig ist, damit Vesikel in großer Zahl spontan zerreißen (engl. rupture) und somit in eine planare Lipiddoppelschicht überführt werden. ${ }^{\text {109] Die }}$ Kanten der sich bildenden planaren Membran begünstigen dabei die Transformation weiterer Vesikel in eine festkörperunterstützte Membran. Es wurde zudem untersucht, inwiefern es dominante Spreitpfade gibt, die die finale Orientierung der Lipide in der planaren Membran beeinflussen. Es wurde festgestellt, dass Lipide, die in der äußeren Schicht der Vesikel eingebaut waren, nach dem Spreiten mehrheitlich zur Substratseite zeigten. ${ }^{[110]}$ Eine entsprechende Auswirkung auf die Orientierung von Transmembranproteinen ist anzunehmen. Es existieren jedoch auch Publikationen, die die gegenteilige Orientierung beobachtet haben, sodass Transmembranproteindomänen, die in Proteoliposomen nach außen zeigten, in der festkörperunterstützten Membran zum Medium orientiert waren. ${ }^{[111]}$

Eine alternative Methode zur Präparation festkörperunterstützter Membranen aus Proteoliposomen ist die Vesikelfusion mit Lipideinzelschichten. Dabei wird mittels Langmuir-Blodgett-Technik zunächst eine Lipideinzelschicht auf einem hydrophilen Substrat gespreitet und an Luft getrocknet. Der hydrophobe Lipidteil ist dabei der Luft ausgesetzt und ist somit bereits so orientiert wie die untere Lipidschicht in einer festkörperunterstützten Membran. Die Zugabe einer Vesikellösung bewirkt die Fusion der Vesikel mit der Einzelschicht, indem sie auf der Schicht spreiten und eine obere Lipidschicht bilden. ${ }^{[108]}$ Transmembranproteindomänen, die in den Proteoliposomen in das Vesikellumen zeigten, müssen dabei die erste Lipideinzelschicht durchstoßen. Ist 
dies möglich, ist eine Proteinorientierung möglich, in der extravesikuläre Domänen in der festkörperunterstützten Membran ins Medium zeigen. Für t-SNARE-Proteine wurde diese Technik bereits 2001 verwendet. ${ }^{[112]}$

Zur Präparation von festkörperunterstützten Lipiddoppelschichten mit rSin1 als rekonstituiertem Transmembranprotein wurde ein Lipideinzelschicht tragendes Substrat in einen Teflontopf gelegt und mit einem Teflonring fixiert. Anschließend wurde die Proteoliposomen- oder Vesikellösung aus Kapitel 3.4.3 (500 $\mu \mathrm{L}$ ) zusammen mit weiteren $500 \mu \mathrm{L}$ Rekonstitutionspuffer in den Teflontopf pipettiert und so der Fusionsprozess der Vesikel mit der Lipideinzelschicht gestartet. Nach $2 \mathrm{~h}$ bei RT wurde 10x mit je $400 \mu \mathrm{L}$ Rekonstiutionspuffer pipettierend gespült. Alternativ wurden etwa $30 \mathrm{~mL}$ Puffer vorsichtig auf das Substrat gegossen, um einen kompletten Flüssigkeitsaustausch über dem Substrat zu gewährleisten.

\subsubsection{Antikörperanbindung an rSin1 in festkörperunterstützten Membranen}

Zur visuellen Detektion von rSin1 in festkörperunterstützten Membranen wurde die Anbindung von Anti-Sin $1^{\text {ntd }}$-Antikörpern (siehe Kapitel 3.3.3) an die $N$-terminale Domäne des rSin1 ausgenutzt. Dies gewährleistet die Detektion von rSin1-Molekülen, deren große $\mathrm{N}$-terminale Domäne vom Substrat weg in den Messpuffer orientiert ist, während im Fall einer gegenteiligen Orientierung eine Anbindung des Antikörpers an die $C$-terminale Domäne nicht vorkommen sollte. Um die Spezifität der Bindung an das Protein im Vergleich zur Bindung an die Lipide der Membran zu untersuchen, wurden auch festkörperunterstützte Membranen ohne Protein nach demselben Protokoll präpariert und mit Antikörpern versetzt. Sollte Spezifität vorliegen, wären die detektierten Signale für die rSin1-haltige Membran signifikant höher. Um den primären Antikörper (aus Kaninchen, rabbit) detektieren zu können, wurde ein sekundärer Antikörper (Anti-rabbit) aus Ziege verwendet, der ein Alexa Fluor 647-Label trägt, um inn fluoreszenzmikroskopisch detektieren zu können. Es handelte sich bei dem sekundären Antikörper um Goat anti-rabbit IgG $(H+L)$, Superclonal Recombinant Secondary Antibody, Alexa Fluor 647 von Thermo Fisher Scientific mit einer Konzentration von $1 \mathrm{mg} / \mathrm{mL}$. 
Die Inkubation mit Antikörpern erfolgte nach der Präparation der festkörperunterstützten Lipiddoppelschicht. $400 \mu \mathrm{L}$ von insgesamt $1000 \mu \mathrm{L}$ des Puffers oberhalb des Substrats wurden ausgetauscht mit einer Mischung aus $398 \mu \mathrm{L}$ Rekonstitutionspuffer und $2 \mu \mathrm{L}$ primäres Antiserum, sodass eine Verdünnung von 1:500 vorlag. Nach einer Inkubation von 1-2 h bei RT wurde wie in Kapitel 3.6.2 gespült. Es folgte die Inkubation des sekundären Antikörpers und anschließendes Spülen analog zum primären Antiserum.

\subsubsection{Konfokale Laserscanningmikroskopie von festkörperunterstützten Membranen}

- Teile dieses Kapitels wurden aus der Masterarbeit des Autors übernommen.[16]_

Die Untersuchung der präparierten festkörperunterstützten Mebranen erfolgte fluoreszenzmikroskopisch mittels konfokaler Laserscanningmikroskopie (engl. confocal laser scanning microscopy, CLSM). Dabei wurde das Augenmerk auf die Bestätigung des Vorliegens einer kontinuierlichen Lipiddoppelschicht, die Bestimmung der Lipiddiffusion sowie die Detektion von rSin1 gebundenen fluoreszierenden Antikörpern gelegt. Zu diesem Zweck wurden Lipide verwendet, die kovalent mit Fluorophoren verbunden waren. Dazu zählten Atto 390-DPPE, Atto 488-DPPE, Bodipy 500/510 C 12 -PPC und Texas Red-DPPE. Für jedes Fluorophor und in Abhängigkeit der Kombinationen von Fluorophoren wurden unterschiedliche CLSM-Setups gewählt, was die Auswahl der verwendeten Laser, der dichroitischen Spiegel und der Emmissionsfilter betrifft.

\section{Prinzip der Fluoreszenz}

Fluoreszenzmikroskopie nutzt das Prinzip der Anregung und -detektion von fluoreszierenden Molekülen mit elektromagnetischer Strahlung im zumeist sichtbaren Lichtbereich zur visuellen Lokalisation dieser Teilchen. Fluoreszenz entsteht, wenn Elektronen durch Licht mit der passenden Anregungsenergie durch Absorption vom elektronischen Grundzustand $S_{0}$ in einen elektronisch angeregten Zustand $S_{1}$ befördert werden (Abb. 3.22). Dabei werden nach dem Franck-Condon-Prinzip oft höhere Schwingungszustände (z. B. v'=3) besetzt, sodass zunächst vibronische Relaxation stattfindet, indem Schwingungsenergie an umgebende Teilchen 
abgegeben wird und das Elektron so den Schwingungsgrundzustand $v^{t}=0$ von $S_{1}$ erreicht. Anschließend fällt das Elektron unter Lichtemission zurück in den elektronischen Grundzustand So, möglicherweise in einen höheren Schwingungszustand $\left(v^{\prime \prime}>0\right)$, dem wieder vibronische Relaxation folgt. Die emissionsfreie Relaxation hat zur Folge, dass die Emissionsenergie in der Regel kleiner ist als die Anregungsenergie, somit die Anregungswellenlänge $\lambda$ ex kleiner ist als die Emissionswellenlänge $\lambda_{\text {em }}$ (Stokes-Shift).

A

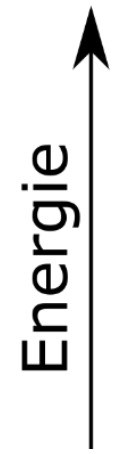

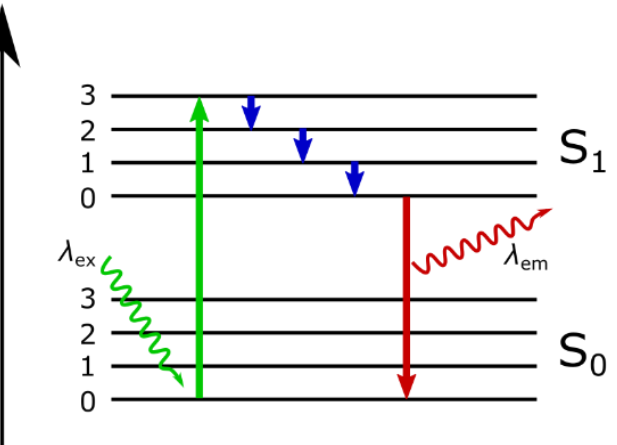

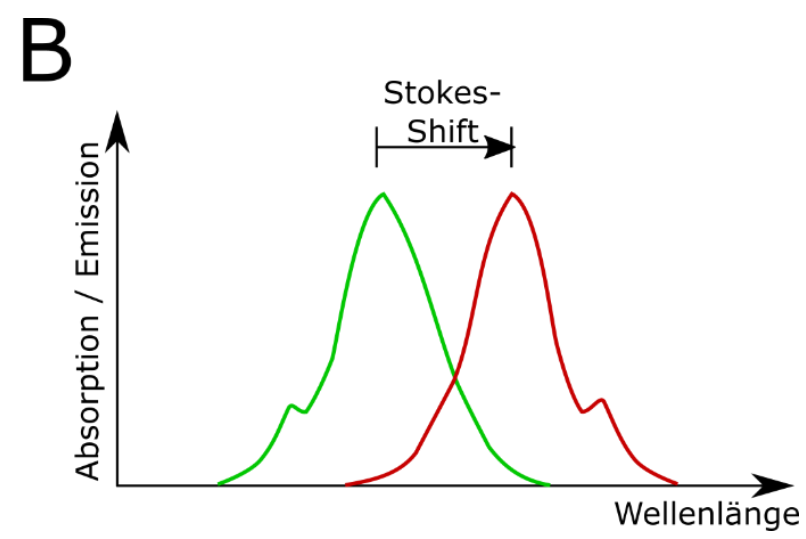

Abbildung 3.22: Prinzip der Fluoreszenz. (A) Ein Elektron im elektronischen Grundzustand So wird durch Licht mit geeigneter Anregungsenergie und -wellenlänge $\lambda_{\mathrm{ex}}$ (grün) in einen höheren Schwingungszustand des elektronisch angeregten Zustands $S_{1}$ befördert. Durch emissionsfreie vibronische Relaxation (blau) fällt das Elektron in den Schwingungsgrundzustand, bevor es unter Lichtemission der Wellenlänge $\lambda_{\text {em }}$ (rot) in den elektronischen Grundzustand $S_{0}$ zurückfällt. (B) Schematische Fluoreszenzanregungs- (grün) und emissionsspektren (rot). Ihre Maxima sind zueinander verschoben, da $\lambda_{\mathrm{em}}>\lambda_{\mathrm{ex}}$ (Stokes-Shift).

\section{Konfokale Laserscanningmikroskopie (CLSM)}

Die konfokale Laserscanningmikroskopie (engl. confocal laser scanning microscopy, CLSM) benutzt ein Setup, das erlaubt eine sehr dünne Fokusebene (mit einer Dicke von ca. $1 \mu \mathrm{m})$ zu betrachten und sämtliches Licht außerhalb dieser Ebene auszublenden (Abb. 3.23). Das Licht eines Lasers wird von einem dichroitischen Spiegel in Richtung der Probe reflektiert, wobei nur bestimmte Wellenlängen reflektiert werden und alle anderen geradewegs passieren. Das Licht wird durch ein Objektiv auf die Probe gebündelt und regt dort Fluorophore an. Diese emittieren Licht, das wiederum zurück auf das Objektiv fällt, gebündelt wird, den dichroitischen Spiegel 
passiert und einen letzten Emissionsfilter passiert, der nur bestimmte Wellenlängenbereiche hindurch lässt, bevor das Licht auf den Detektor trifft. Die Konfokalität wird durch die Lochblende zwischen dichroitischem Spiegel und Emissionsfilter erzeugt. Die Lochblende lässt nur Licht aus der Fokusebene passieren und das Licht anderer Ebenen trifft auf die Lochblendenwand. Da das CLSM ein Scanning- oder Rastermikroskop ist, das in $x$ - und $y$-Richtung linienweise über die Probe scannt, sodass nur ein kleiner Lichtpunkt mit der Probe interagiert und sie so schont, ist ein sensitiver Detektor nötig, der die Einzelsignale erfassen kann.

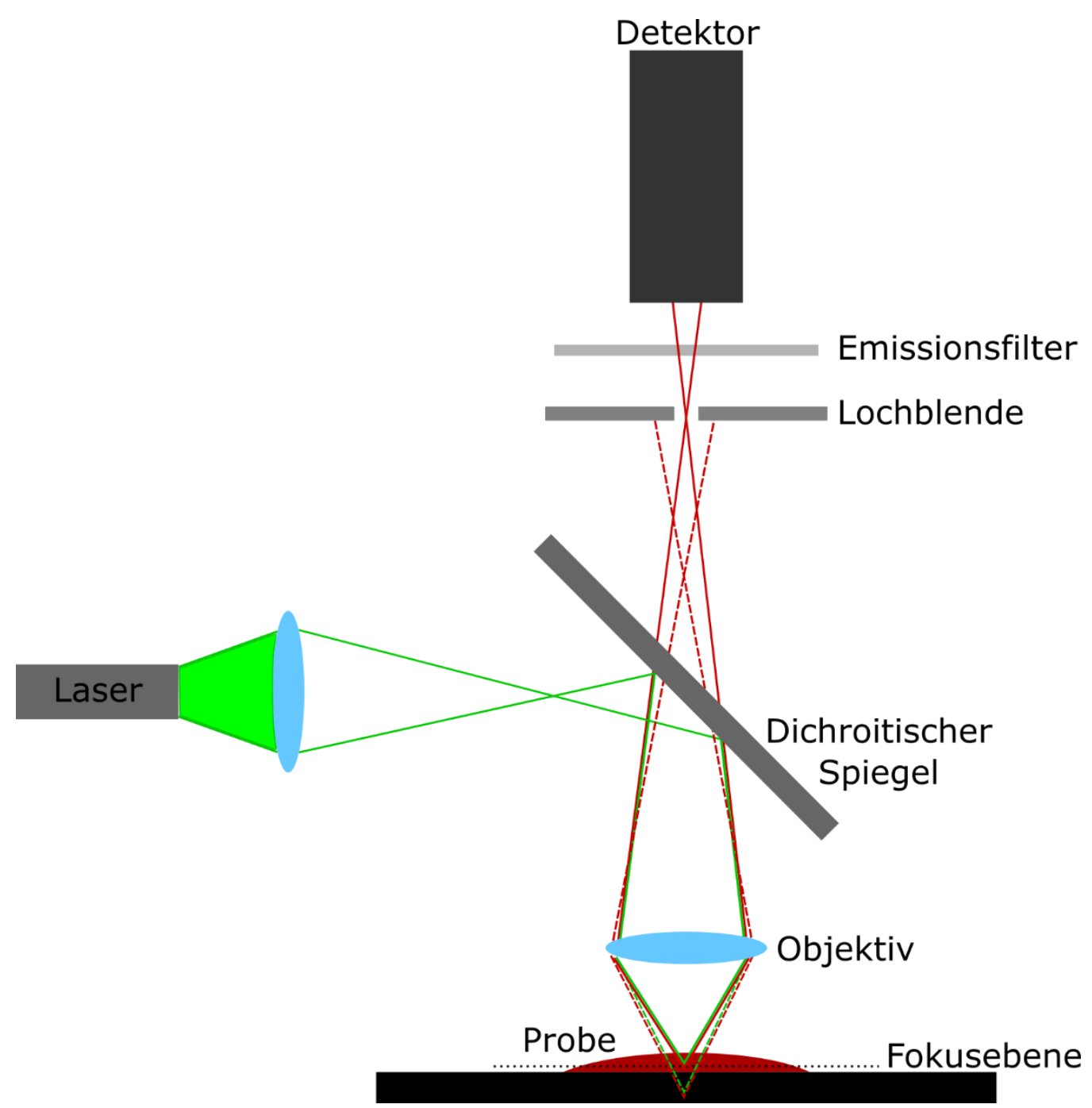

Abbildung 3.23: Schematischer Aufbau eines konfokalen Laserscanningmikroskops (CLSM). Das Anregungslicht (grün) eines Lasers trifft auf die fluoreszierende Probe, dessen emittiertes Fluoreszenzlicht (rot) nur dann eine vor dem Detektor befindliche Lochblende passieren kann, wenn es aus der Fokusebene (schwarz gepunktet) kommt. Licht aus anderen Ebenen trifft auf die Lochblendenwand und wird somit herausgefiltert. 


\section{Fluoreszenzerholung nach Fotobleichung (FRAP)}

Der Erfolg des Spreitens der Lipiddoppelschicht wurde mithilfe eines FRAPExperiments (engl. Fluorescence Recovery after Photobleaching) überprüft. Dabei bleicht ein intensiver Laserpuls einen kreisrunden Bereich der fluoreszenzmarkierten Membran. Durch Diffusion der Lipide und lipidgebundenen Markermoleküle innerhalb der Membran tauschen immer mehr gebleichte Fluoreszenzmarker gegen Lipide mit funktionsfähigem Fluorophor aus und führen so zu einer Regeneration der Fluoreszenz im gebleichten Bereich. Das Experiment wurde in einer Zeitserie dokumentiert. Die resultierende Fluoreszenzintensitätskurve (Abb. 3.24) zeigt eine Regeneration über die Zeit, die jedoch nicht wieder $100 \%$ erreicht, da ein Teil der Membran immobil ist.

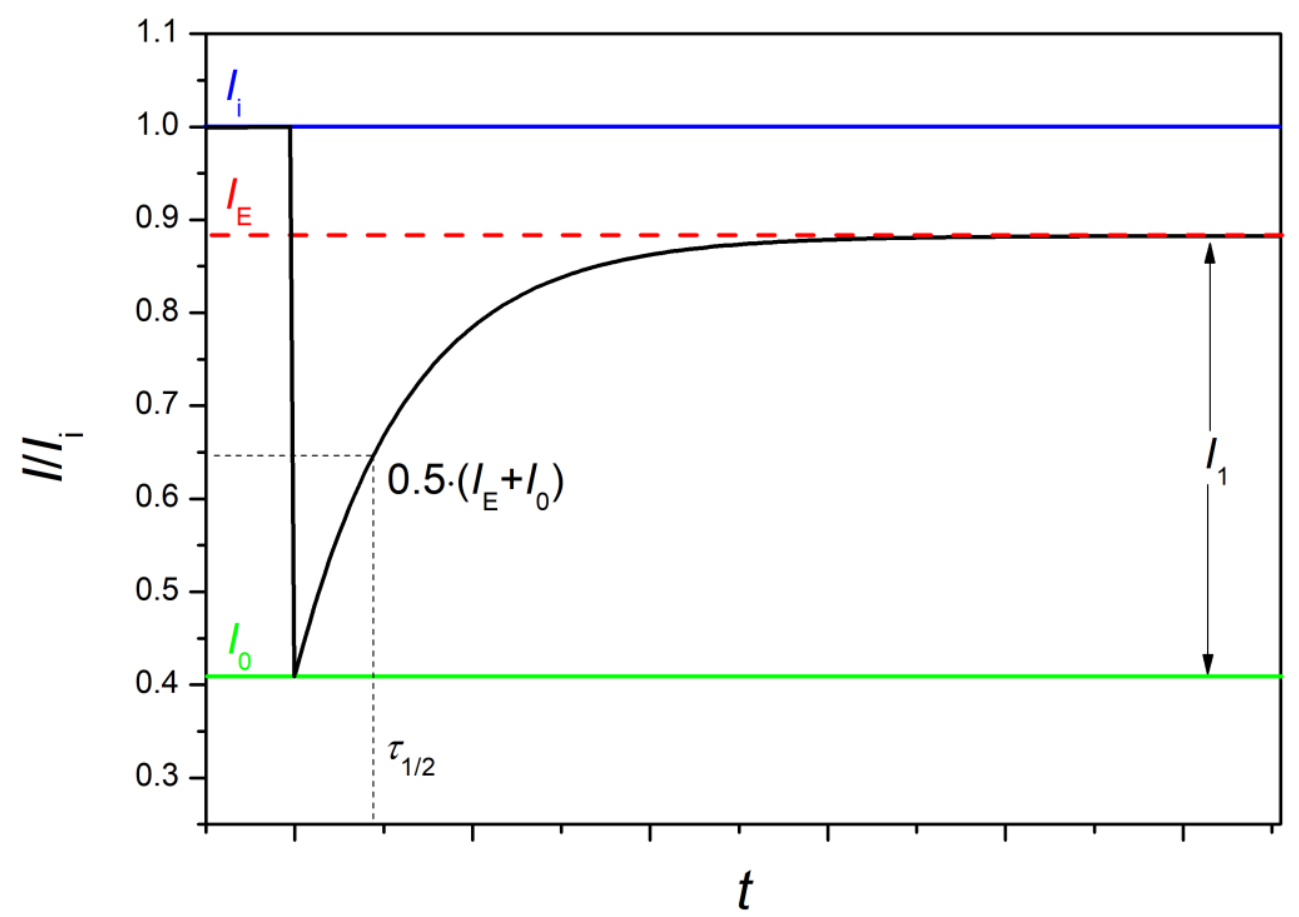

Abbildung 3.24: Zeitliche Auftragung der normierten Fluoreszenzintensität (schwarz). $l_{i}$ (blau) ist die Ausgangsintensität vor dem bleichenden Laserpuls, $I_{0}$ (grün) die niedrigste Intensität direkt nach dem Bleichpuls. Die Fluoreszenzintensität nähert sich für $t=\infty$ dem Wert $l_{E}$ (rot gestrichelt) an. $l_{1}$ ist die Differenz von $l_{E}$ und $l_{0}$ und $\tau_{1 / 2}$ ist die charakteristische Diffusionszeit, bei der der halbe Intensitätswert zwischen $l_{E}$ und $l_{0}$ erreicht ist. ${ }^{[16]}$ 
Die exponentielle Anstiegskurve der Fluoreszenzintensität $I(t)$ mit der Zeit $t$ nach dem Bleichen kann mit der Funktion (Gl. 3.13) ${ }^{[13]}$

$$
I(t)=I_{\mathrm{E}}-I_{1} \cdot \exp ^{\frac{-t}{T_{1}}}
$$

Angepasst werden, wobei $/ E$ die Intensität nach unendlicher Zeit ist. $l_{1}$ ist die Differenz von $I_{E}$ und der Intensität $l_{0}$ zum Zeitpunkt 0 nach dem Bleichen (Gl. 3.14).

$$
I_{1}=I_{\mathrm{E}}-I_{0}
$$

$T_{1}$ hängt mit der charakteristischen Diffusionszeit $\tau_{1 / 2}$ über Gl. 3.15 zusammen.

$$
\tau_{1 / 2}=\ln (0,5) \cdot\left(-T_{1}\right)
$$

Der mobile Anteil der Membran $M$ wird nach GI. 3.16

$$
M=\frac{I_{1}}{I_{\mathrm{i}}-I_{0}}
$$

berechnet und der Diffusionskoeffizient $D$ der lateralen Diffusion ergibt sich aus Gl. 3.17, wobei $\omega$ der Radius des gebleichten Bereichs ist:

$$
D=\frac{\omega^{2}}{4 \cdot \tau_{1 / 2}}
$$

Die so erhaltenen Diffusionskoeffizienten sind oft ungenau. Daher wurde die Auswertung der FRAP-Experimente mithilfe einer Software durchgeführt, die auf einer radialen Mittelung der Umgebung des Bleichspots und einer Hankel-Transformation des Bildes beruht. Diese Methode erfordert radial symmetrische Bilder und Bleichspots, die wesentlich kleiner sind als das Gesamtbild. Dieses Verfahren wurde von Jönsson et al. ${ }^{[14]}$ entwickelt und als Matlab-Software umgesetzt. In dieser Arbeit wurde eine darauf beruhende Matlab-freie Software (von I. Mey und J. Sibold) genutzt. 


\section{Ergebnisse}

\subsection{Lipidanalysen von synchronisierten Thalassiosira pseudonana- Kulturen}

Es wurde untersucht, welche Unterschiede synchronisierte Kulturen von Thalassiosira pseudonana (Tp) zum Zeitpunkt der Zellteilung bei angereicherten ValvenSilicafällungsvesikeln (Tp-div) sowie in G1-Phase (Tp-G1) bezüglich ihrer Lipidkomposition aufweisen. Diese Unterschiede können Hinweise auf die Lipidzusammensetzung von Silicafällungsvesikeln (SDVs) geben, da ihr Anteil in Tpdiv am höchsten ist, sie in Tp-G1 jedoch nicht oder kaum vorkommen. Konkret wurden die Fettsäurezusammensetzungen und die Foldchanges von Lipidklassen analysiert. Die gewonnenen Informationen sollen genutzt werden, um eine vereinfachte aber realtitätsbasierte Modellmembran des SDVs zu erstellen (siehe Kapitel 4.3 und 4.4).

\subsubsection{Fettsäureanalyse des Totallipidextrakts von Thalassiosira pseudonana}

Totallipidextrakte der lyophilisierten Proben von Tp-div und Tp-G1 wurden auf ihre Fettsäurezusammensetzung überprüft, um eventuelle Unterschiede der GesamtFettsäurekompositionen zwischen Tp-div und Tp-G1 festzustellen. Hierfür wurden GCFID-Messungen der Lipidextrakte durchgeführt, und die darin enthaltenen Fettsäureester in Fettsäuremethylester (FAMEs) umgewandelt.

Es wurden insgesamt 16 verschiedene Fettsäuren (FAs) detektiert. Nachweisbar waren 14:0, 15:0, 16:0, 16:1, 16:2, 16:3, 16:4, 18:0, 18:1, 18:2, 18:3, 18:4, 20:5, 22:6, 24:0 und 24:1, wobei für 16:2, 18:1, 18:2 und 18:3 je zwei unterschiedliche Doppelbindungsisomere nachgewiesen werden konnten. Ein exemplarisches Chromatogramm mit Zuordnung der jeweiligen Fettsäuresignale ist in Anhang 8.9 gezeigt. Die absoluten und relativen Fettsäureprofile sind in Abb. 4.1 und 4.2 dargestellt, wobei die oben beschriebenen Doppelbindungsisomere zu einem Wert zusammengefasst wurden. 


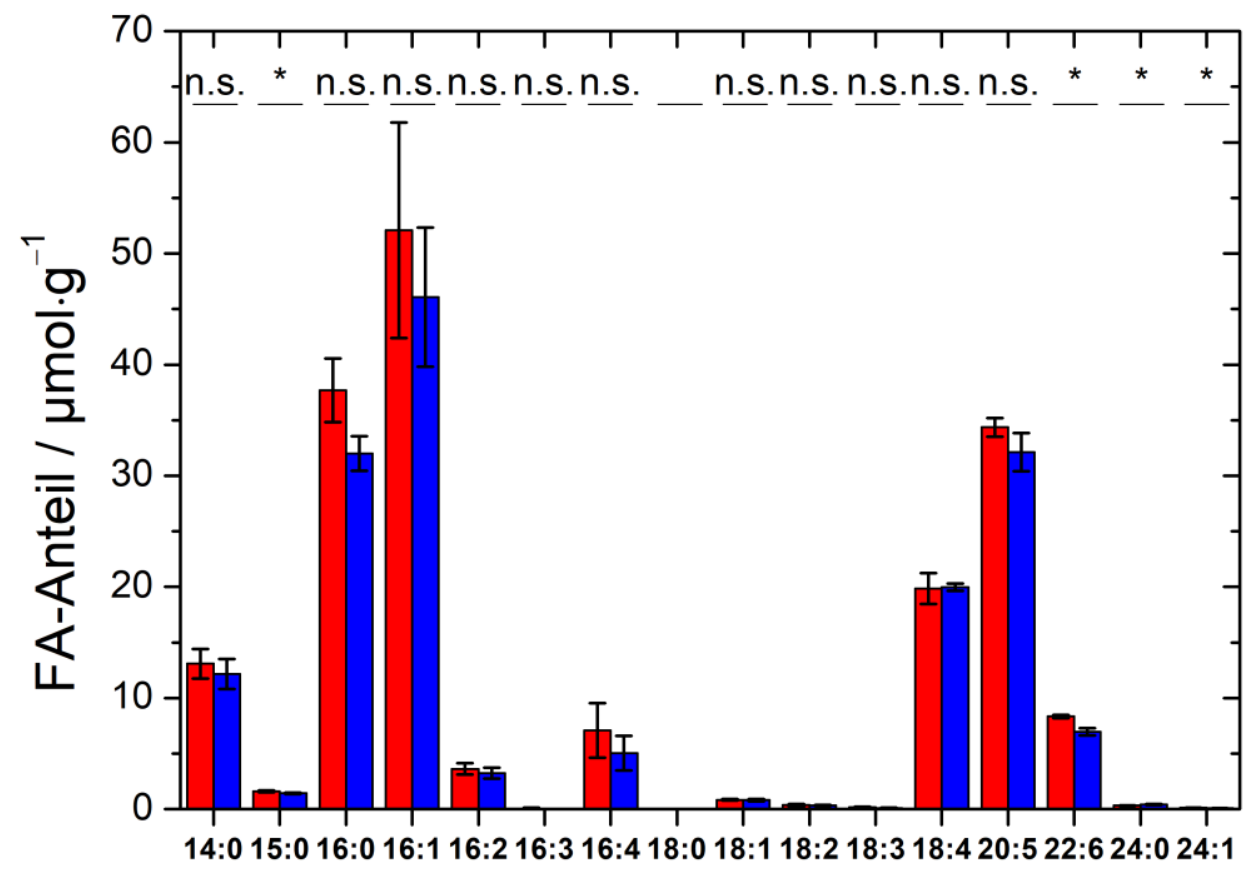

Abbildung 4.1: Absolutes Fettsäureprofil von Tp-div (rot) und Tp-G1 (blau) bezogen auf die Trockenmasse der lyophilisierten Probe. Die Fehlerbalken entsprechen der Standardabweichung des Mittelwerts ( $\mathrm{N}=3$, biologische Replikate). Die statistische Signifikanz wurde mit einem zweiseitigen tTest mit ungleicher Varianz für das Signifikanzniveau $p<0.05\left(^{*}\right)$ berechnet; $n . s .=$ nicht signifikant. 


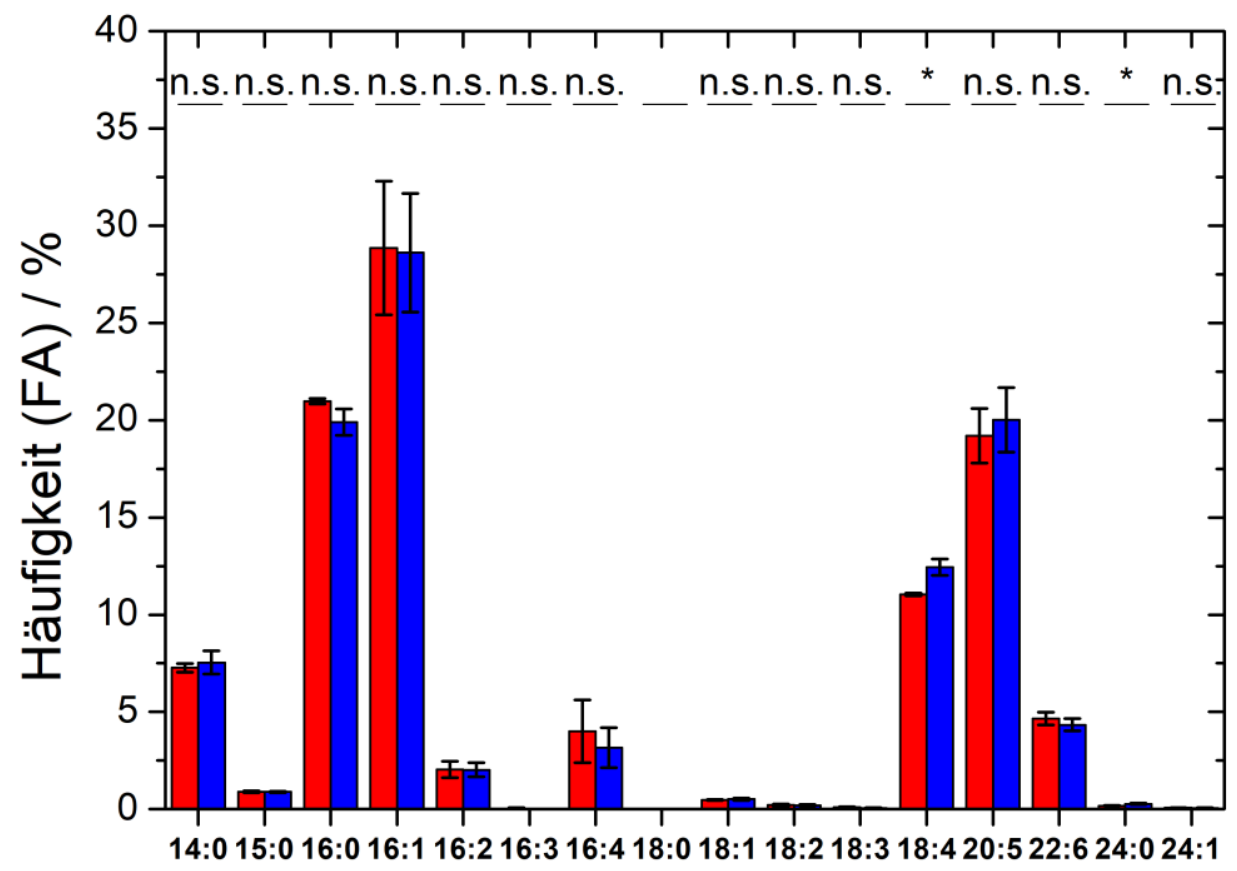

Abbildung 4.2: Relatives Fettsäureprofil von Tp-div (rot) und Tp-G1 (blau). Die Fehlerbalken entsprechen der Standardabweichung des Mittelwerts ( $\mathrm{N}=3$, biologische Replikate). Die statistische Signifikanz wurde mit einem zweiseitigen t-Test mit ungleicher Varianz für das Signifikanzniveau $p<0.05$ (*) berechnet; n.s. = nicht signifikant.

Die Fettsäure (FA)-Gesamtstoffmenge in Tp-div betrug $180 \pm 13 \mu \mathrm{mol} / \mathrm{g}$ Trockengewicht, in Tp-G1 161 $\pm 5 \mu \mathrm{mol} / \mathrm{g}$ Trockengewicht. Für beide Tp-Probentypen ergab sich eine mittlere molare FA-Masse von $271 \mathrm{~g} / \mathrm{mol}$. Die FA-Massen betrugen somit $49 \pm 4$ bzw. $44 \pm 1 \mathrm{mg}$ FA pro g Trockengewicht. Die Unterschiede zwischen beiden Probentypen waren statistisch nicht signifikant ( $\mathrm{N}=3$; zweiseitiger $\mathrm{t}$-Test mit ungleicher Varianz; $\mathrm{p}=0.11$ ). Somit war eine zellzyklusabhängige Veränderung der Gesamtmenge an FAs in T. pseudonana nicht nachweisbar. Die Zellanzahl pro $\mathrm{g}$ Trockengewicht lag für die schon geteilten Tp-G1 bei (17.8 \pm 3.4$) \cdot 10^{9}$.

Die relativen FA-Profile zeigen 16:1 (29 \%), 16:0 (20\%), 20:5 (20\%), 18:4 (12\%) und 14:0 (7\%) als Haupt-FAs für beide Probentypen. Von diesen zeigte lediglich 18:4 eine statistisch signifikante $(p=0.027)$ Erhöhung in Tp-G1 um den Faktor 1.13 gegenüber Tp-div. Insgesamt sind kaum Unterschiede der beiden relativen Profile zu erkennen, 
sodass die Total-FA-Komposition in $T$. pseudonana als unabhängig von den betrachteten Zellzyklusphasen betrachtet werden kann.

\subsubsection{Bestimmung und Quantifizierung der polaren Hauptlipidklassen}

Polare Lipide wie Phosphoglycerolipide und Glycolipide sind als typische Membrankomponenten wichtig für die Kompartimentierung und Funktionalität von Zellen. Eine Quantifizierung der Anteile aller wichtigen polaren Lipidklassen in der gesamten Zelle wurde für Tp bisher nicht veröffentlicht. Auch eventuelle Unterschiede in den Lipiklassenanteilen zwischen Tp-div und Tp-G1 wurden hier untersucht. Die Analyse von Tp-div und Tp-G1 auf ihre Hauptlipidklassenkomposition erfolgte mittels dünnschichtchromatografischer (TLC) Trennung der polaren Lipidklassen mit anschließender GC-FID der in FAMEs umgewandelten FA-Ester sowie der Intensitätsauswertung der primulingefärbten fluoreszierenden Lipidbanden.

Die Primulinfärbung der Lipidbanden (Abb. 4.3) wies fünf Lipide als Hauptlipidklassen aus. Der Retentionsfaktorvergleich $\left(R_{\mathrm{f}}\right)$ mit einem Standardgemisch identifizierte diese Lipidklassen zunächst als PC ( $\left.R_{f}=0.06 \pm 0.01\right)$, SQDG/PS/PI (0.32 \pm 0.02$)$, DGDG $(0.42 \pm 0.05), P G(0.55 \pm 0.03)$ und PA (0.71 \pm 0.02$)$. Die zu erwartende MGDG-Bande lief laut Standard bei $R_{\mathrm{f}}=0.62 \pm 0.03$. Die mittels $\mathrm{CuSO}_{4}$ thermisch angefärbten Standardbanden wurden zudem genutzt, um die Position einer PE-Bande $\left(R_{\mathrm{f}}=\right.$ $0.22 \pm 0.02$ ) abzuschätzen. So wurden PC, PE, SQDG/PS/PI, DGDG, PG, MGDG, PA und DAG als Banden definiert, abgeschabt (Abb. 4.4) und mittels saurer Methanolyse aufbereitet (siehe Kapitel 3.1.3.3). Da DAG sehr nahe an der Laufmittelfront lag und dort eine Überlappung mit TAG möglich war, wurde DAG nicht weiter ausgewertet. 


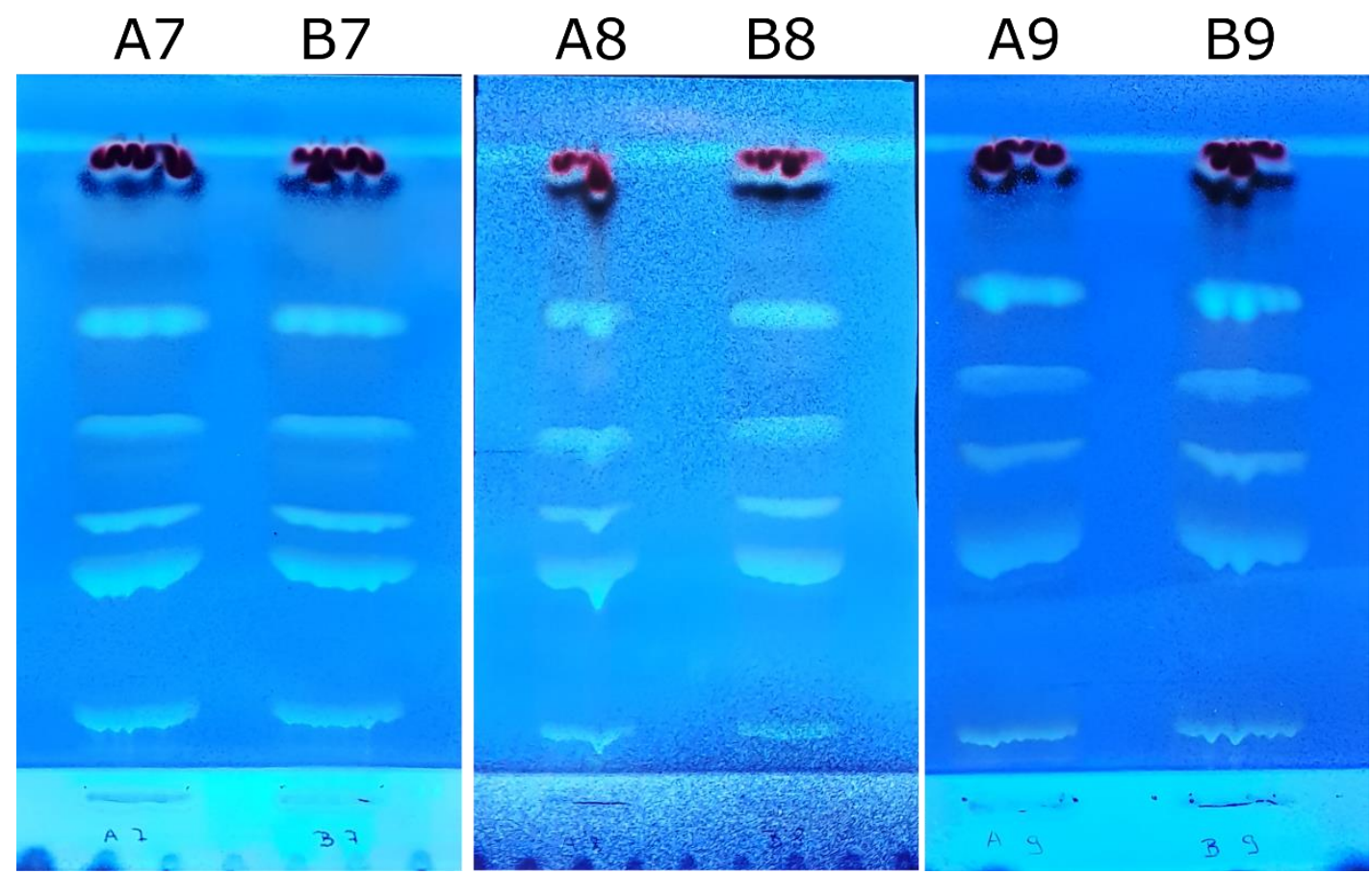

Abbildung 4.3: TLC-Platten nach Primulinanfärbung unter UV-Licht. Es sind fünf Banden erkennbar, sowie Pigmente nahe der Laufmittelfront. $A=T p-\operatorname{div}, B=T p-G 1$.

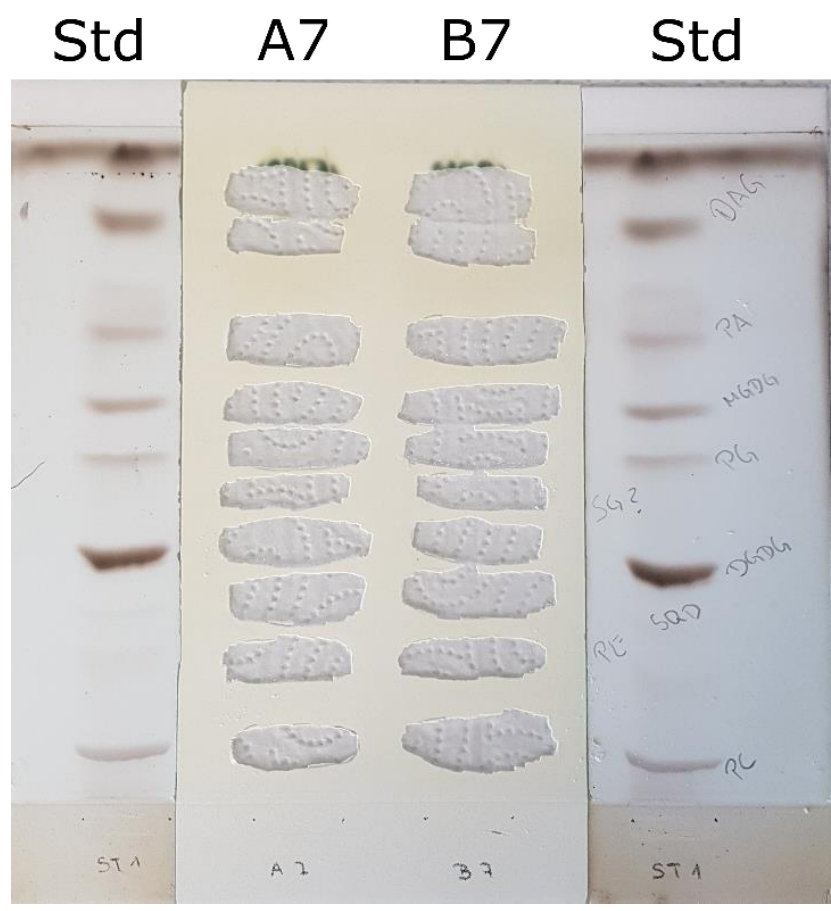

Abbildung 4.4: Exemplarische TLC-Platte nach dem Abschaben von Banden. Links und rechts befinden sich die thermisch mit $\mathrm{CuSO}_{4}$ gefärbten Standardbanden (Std), die zur Identifizierung und Definition der Probenbanden herangezogen wurden. $A=T p-d i v, B=T p-G 1$. 
Aus den GC-FID-Analysen der einzelnen Lipidklassenproben wurden FA-Profile erstellt (siehe Anhang 8.10). Diese wurden mit den FA-Profilen der Lipidklassen verglichen, die aus LC-MS/MS-Messungen erhalten wurden (siehe Anhang 8.11), um die Identität der Lipidkopfgruppen der TLC-Proben zu bestätigen. Die aus der TLCGC-FID resultierenden FA-Profile von PC, DGDG und PG sahen den entsprechenden LC-MS/MS-FA-Profilen sehr ähnlich.

Die SQDG/PS/PI-Fraktion aus der TLC ähnelte vor allem dem SQDG-FA-Profil von Tp-div, sodass davon ausgegangen werden kann, dass die SQDG/PS/PI-Bande vor allem SQDG enthält und PS und PI höchstens in geringen Mengen vorhanden war.

Die Analyse der PE-Bande ergab keine Ähnlichkeit zu dem LC-MS/MS-FA-Profil von PE. Es wird angenommen, dass die sehr geringe Lipidmenge in dieser Bande im Chromatogramm von Hintergrundsignalen wie Weichmachern überlagert wird. So fallen vor allem 16:0, 18:0 und 16:3 mit hohen Anteilen als von den LC-MS/MSMessungen abweichende Fettsäuren auf. Zudem zeigen viele Fettsäuren große Fehlerbereiche. Eine Identifikation eventueller Lipide in der „PE“-Bande mit PE war daher nicht möglich.

Die „MGDG"-Bande zeigte in ihrem FA-Profil keine Ähnlichkeit mit den genannten Lipidmolekülen. Auch hier waren vor allem 16:0, 18:0 und 16:3 mit hohen Anteilen auffällig, sodass von einer Signalüberlagerung mit Weichmachern ausgegangen wird und die Lipidmenge in der Bande sehr gering war.

Die Lipidbande bei dem PA-spezifischen $R_{\mathrm{f}}($,PA“) zeigte ein FA-Profil, dass sehr gut mit dem MGDG-FA-Profil übereinstimmt, während eine Ähnlichkeit zu PA nicht gegeben war. Dies deutet darauf hin, dass es sich hierbei eigentlich um die MGDGBande der Probe handeln könnte. Um dies zu bestätigen wurde erneut eine TLC mit je einer Tp-div- und einer Tp-G1-Probe durchgeführt und nur die „MGDG“- und „PA“Banden ausgekratzt. Es folgte für alle vier Banden eine Analyse via LC-MS/MS der drei häufigsten MGDG- und PA-Lipide, die in vorigen LC-MS/MS-Experimenten bestimmt wurden. Dabei handelte es sich um MGDG-16:3/16:3, MGDG-16:4/16:3 und MGDG-16:4/20:5 sowie PA-16:1/20:5, PA-18:4/20:5 und PA-20:5/22:6. Die Proben wurden vor der PA-Analyse methyliert (siehe Kapitel 3.1.3.1). Die gemessenen Peakflächen (TPA) für MGDG sind in Abb. 4.5 dargestellt, für PA in Abb. 4.6. 


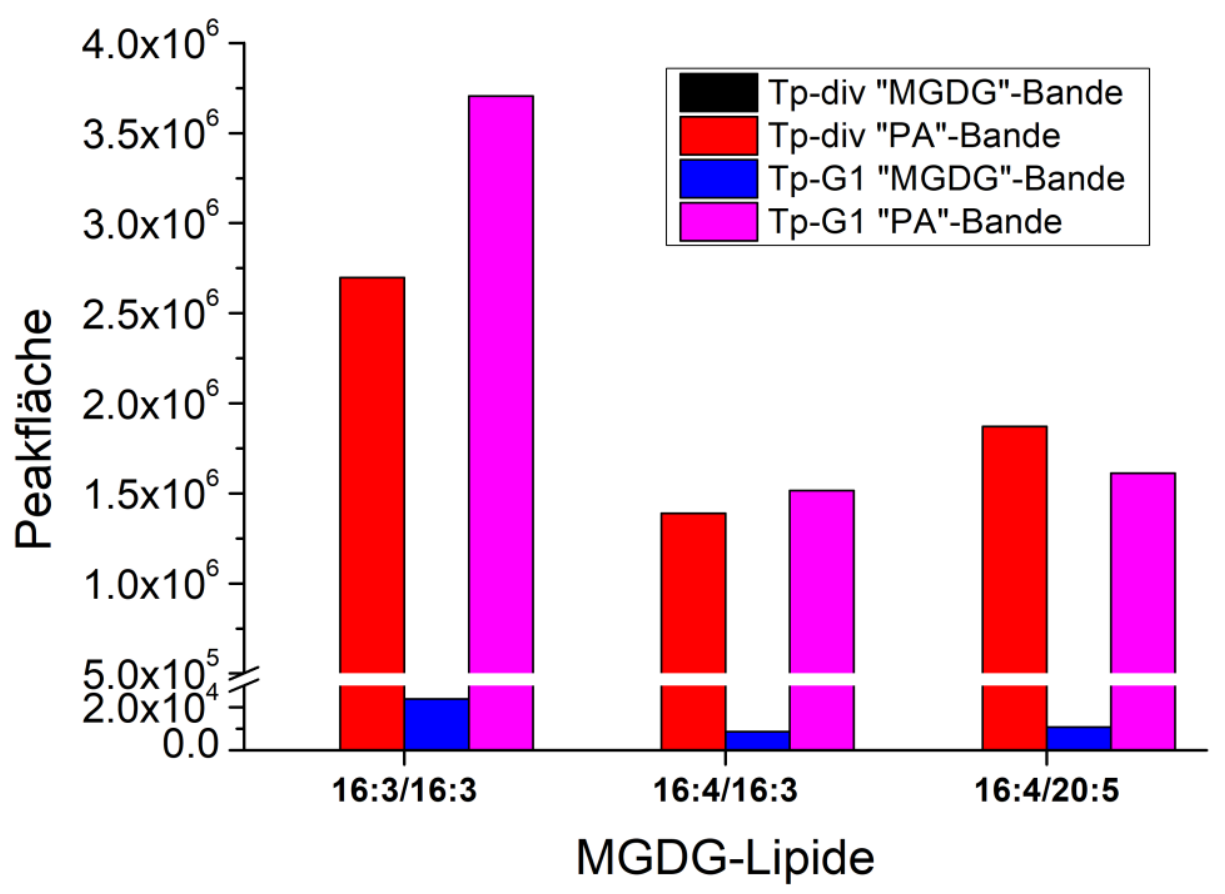

Abbildung 4.5: Gemessene Peakflächen der MGDG-Lipidsignale in der LC-MS/MS der nominellen „MGDG“- und „PA“-Banden.

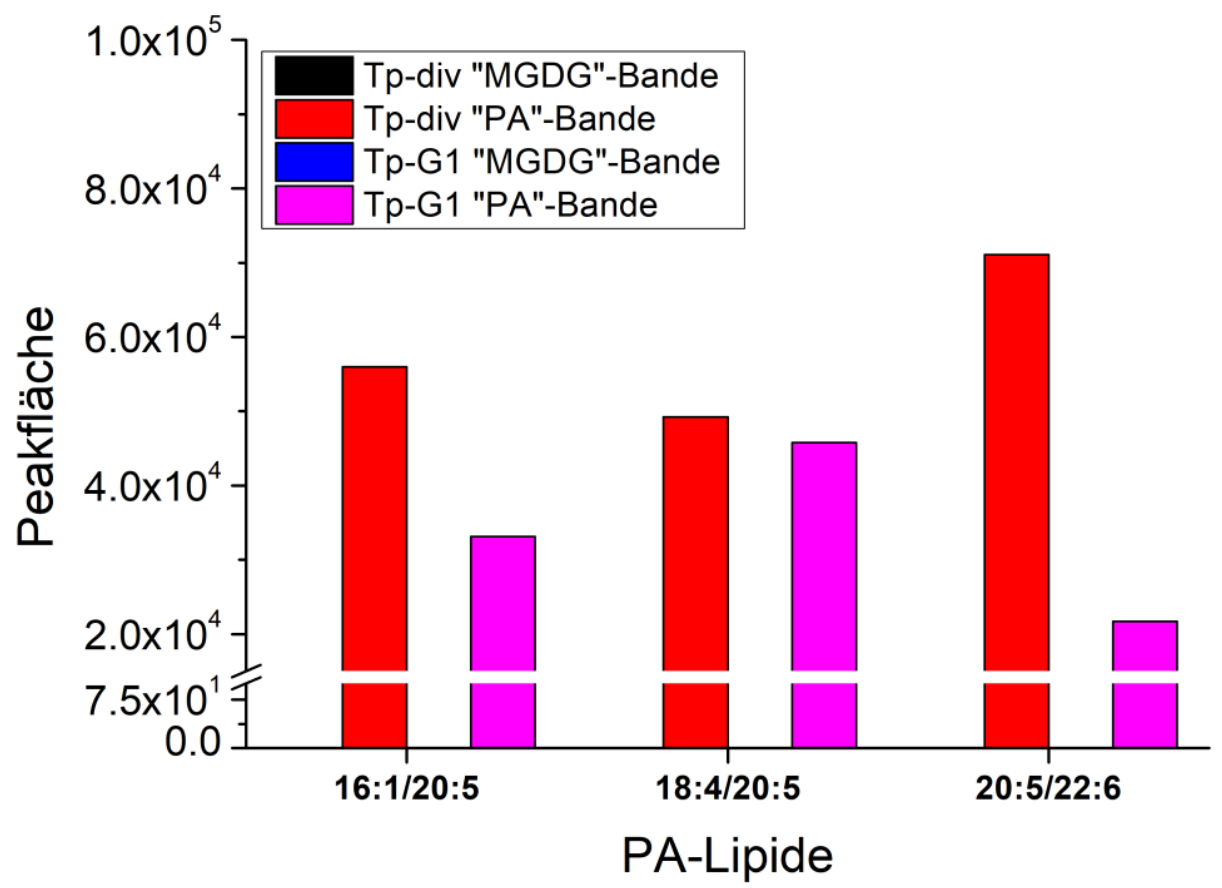

Abbildung 4.6: Gemessene Peakflächen der PA-Lipidsignale in der LC-MS/MS der nominellen „MGDG“- und „PA“-Banden. 
Es wurde festgestellt, dass beide Lipidklassen MGDG und PA fast ausschließlich in der „PA“-Bande nachweisbar waren und dass die „MGDG"-Bande somit als leere Bande gilt. Die Fettsäuresignale dieser Bande in der GC-FID werden daher dem molekularen Hintergrund der Probe zugeordnet. Die „PA“-Bande ist somit die Hauptbande für MGDG und PA. Da das FA-Profil dieser Bande, wie schon erwähnt, nur dem MGDG-FA-Profil der LC-MS/MS-Messungen entspricht, wird angenommen, dass es sich um die MGDG-Bande mit geringen Mengen an PA handelt.

Eine quantitative Abschätzung der Anteile der detektierten polaren Lipidklassen PC, SQDG, DGDG, PG und MGDG war damit möglich, da jede Probe vor der GC-FIDAnalyse mit dem internen Standard Triheptadecanoylglycerol versetzt wurde. Abb. 4.7 zeigt die relative Häufigkeit der polaren Lipidklassen unter Nichtberücksichtigung von DAG und TAG sowie weiterer Lipidklassen. Es ergaben sich keine signifikanten Unterschiede (zweiseitiger t-Test mit ungleichen Varianzen; $p<0.05$ ) zwischen Tp-div und Tp-G1. Die über beide Probentypen gemittelte ( $N=4)$ Lipidklassenzusammensetzung ist in Tab. 4.1 aufgeführt. Es ist zu beachten, dass die Mengen an SQDG und MGDG möglicherweise als leicht überhöht bestimmt wurden, da PS und PI bzw. PA ebenfalls zu der Gesamtfettsäuremenge dieser Banden beitrugen.

Die Auswertung der Intensitäten der primulingefärbten Hauptbanden mit dem Programm ImageJ führte zu einer von Abb. 4.7 abweichenden Lipidklassenverteilung (Abb. 4.8). Auch hier sind keine statistisch signifikanten Unterschiede zwischen Tp-div und Tp-G1 nachweisbar. Die Fehler fielen hier jedoch höher aus. Die über beide Probentypen gemittelten Intensitätsbeiträge $(\mathrm{N}=6)$ sind ebenfalls in Tab. 4.1 dargestellt.

MGDG stellt nach GC-FID-Analyse der TLC-Lipidbanden mit 42.8 $\pm 0.4 \%$ die häufigste polare Lipidklasse dar, während die Primulinfluoreszenzauswertung SQDG mit $26.2 \pm 3.6 \%$ den größten Anteil zuschreibt, dicht gefolgt von MGDG mit $25.5 \pm 5.1 \%$. Im Gegensatz zu MGDG und SQDG zeigen PG, DGDG und PC Anteile von unter $20 \%$, wobei PC für beide Methoden die geringsten Werte um $10 \%$ aufweist.

Es ist zu berücksichtigen, dass hier mehrere Fehlerquellen vorliegen, die die Detektion kleinerer Unterschiede der Probentypen erschweren. Alle Lipidproben zeigten nach der TLC in der GC-FID einen von anderen Molekülen wie Weichmachern geprägten Hintergrund, die die FA-Profile verzerrten. Je geringer der Lipidanteil einer Bande, 
desto stärker der Einfluss des Hintergrunds. Zudem ist eine perfekte Trennung der Lipide unter Ausschluss von Überlagerungen nicht gewiss. Das Einkreisen der Banden nach Augenmaß lässt die Möglichkeit offen entweder Lipidmaterial nicht berücksichtigt oder Fremdlipide eingeschlossen zu haben. Die Qualität der Primulinanfärbung wiederum ist davon abhängig, wie gleichmäßig das Primulin auf die Banden aufgesprüht wurde.

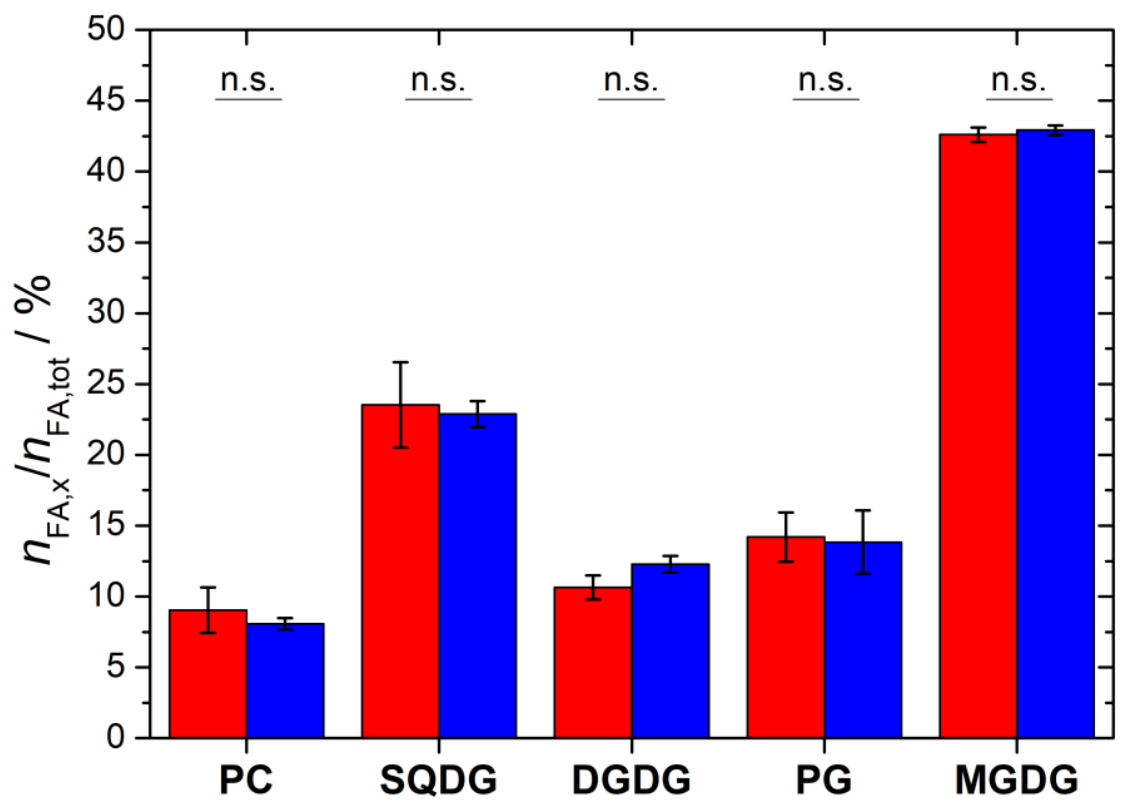

Abbildung 4.7: Relatives Profil polarer Hauptlipidklassen in Tp-div (rot) und Tp-G1 (blau). Standardabweichung des Mittelwerts als Fehlerbalken ( $\mathrm{N}=2$ für beide). Die Unterschiede zwischen Tpdiv und Tp-G1 waren statistisch nicht signifikant (n.s.). 


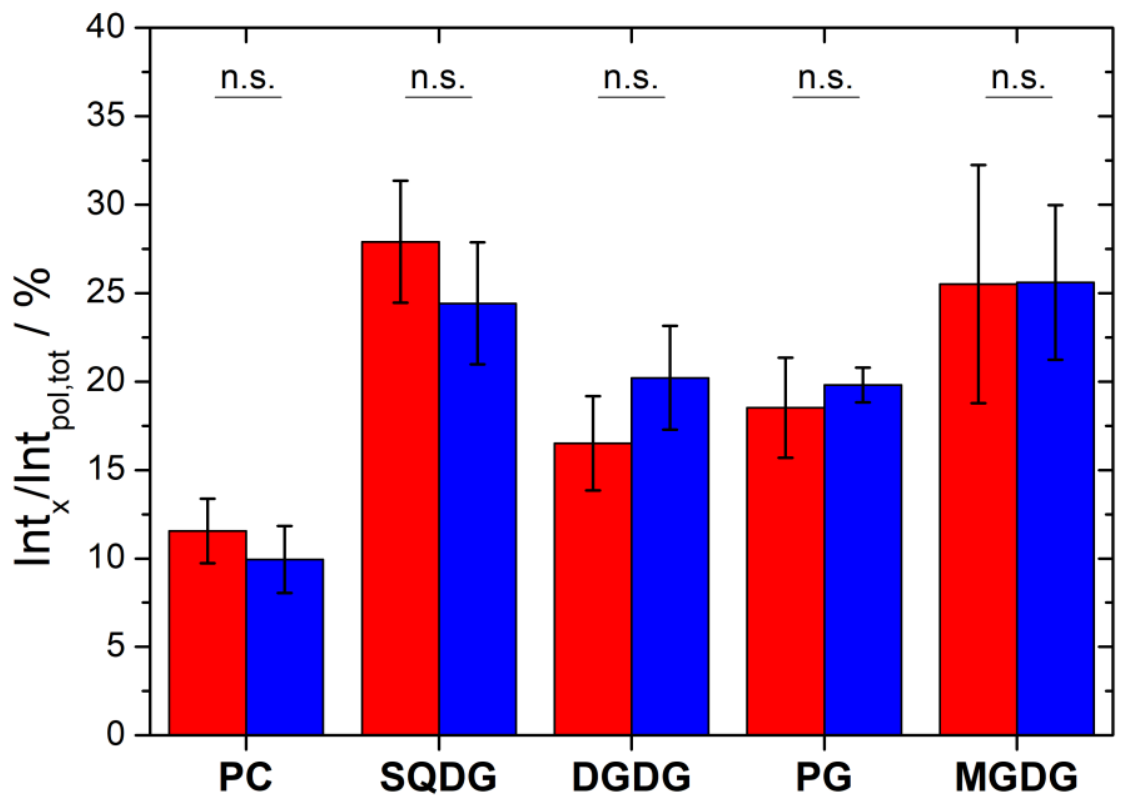

Abbildung 4.8: Primulinintensitätsprofil polarer Hauptlipidklassen in Tp-div (rot) und Tp-G1 (blau). Standardabweichung des Mittelwerts als Fehlerbalken ( $\mathrm{N}=3$ für beide). Die Unterschiede zwischen Tpdiv und Tp-G1 waren statistisch nicht signifikant (n.s.).

Tabelle 4.1: Lipidklassenzusammensetzung nach TLC-Auswertung mittels GC-FID oder Bandenintensität der Primulinfluoreszenz. Tp-div und Tp-G1 wurden zusammengefasst und es wurden nur die fünf detektierten polaren Hauptlipidklassen berücksichtigt. Die Standardabweichungen der Mittelwerte ( $\mathrm{N}=4$ für GC-FID; N=6 für Primulinfluoreszenz) sind als Fehler angegeben.

\begin{tabular}{|l|l|l|}
\hline in $\%$ & Anteil (GC-FID) & Anteil (Primulinfluoreszenz) \\
\hline MGDG & $42.8 \pm 0.4$ & $25.5 \pm 5.1$ \\
\hline SQDG & $23.2 \pm 1.9$ & $26.2 \pm 3.6$ \\
\hline PG & $14.0 \pm 1.6$ & $19.2 \pm 2.0$ \\
\hline DGDG & $11.5 \pm 1.1$ & $18.4 \pm 3.2$ \\
\hline PC & $8.5 \pm 1.1$ & $10.7 \pm 1.9$ \\
\hline
\end{tabular}

\subsubsection{Bestimmung relativer Lipid- und Fettsäureprofile einzelner Lipidklassen}

Die Veränderung von Lipidprofilen und FA-Profilen von Diacylglycero- und Triacylglycerolipiden, ihren Lysoformen sowie Sterolen, Sterolderivaten und 
Sphingolipiden von Tp-div zu Tp-G1 kann Aufschluss darüber geben, welche Lipide im Zellzyklusstadium der Zellteilung (Tp-div) eine größere Rolle spielen und welche an Anteil und Bedeutung verlieren.

Mithilfe der LC-MS/MS wurden die Totallipidextrakte auf die genaue Lipidzusammensetzung einzelner Lipidklassen untersucht. Die Peakflächen der lipidspezifischen Signale wurden für jede analysierte Lipidklasse intern in Relation gesetzt, sodass relative lipidklassenbezogene Lipidprofile erstellt werden konnten. Aus den Lipidprofilen konnten wiederum relative FA-Profile berechnet werden. Ein direkter lipidklassenübergreifender Vergleich war nicht sinnvoll, da jeder Lipidkopfgruppentyp unterschiedlich stark ionisiert wird und damit verschieden hohe Signalintensitäten aufweist. Für alle detektierten Diacylglycerolipide wurden die Lipidprofile über 24 Diacylkombinationen in Abb. 4.9 dargestellt. Es wurden nur die Kombinationen in die grafische Übersicht aufgenommen, die für eine Lipidklasse mindestens $5 \%$ der Gesamtlipide ausmachen. 

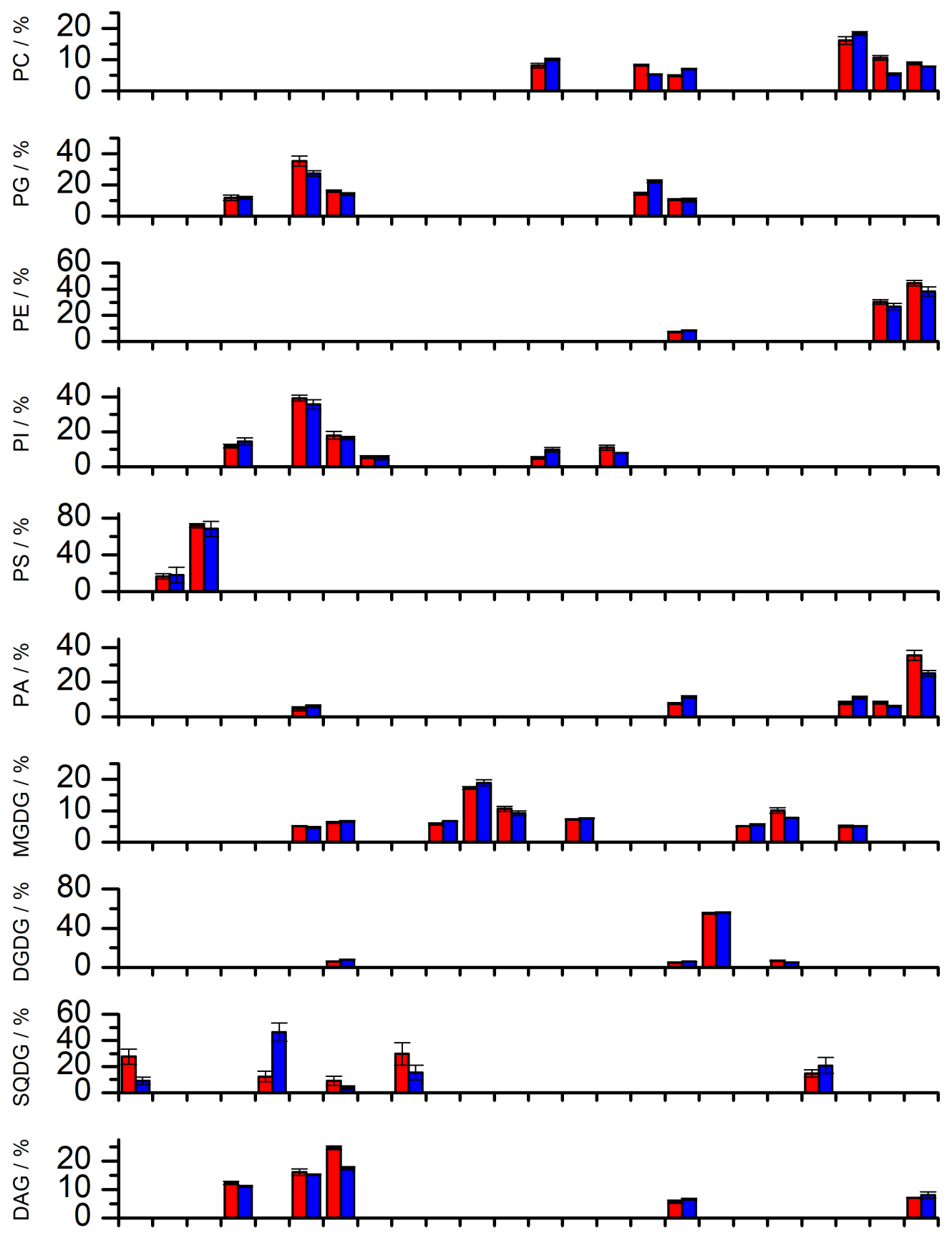

0 莳家官 万亏

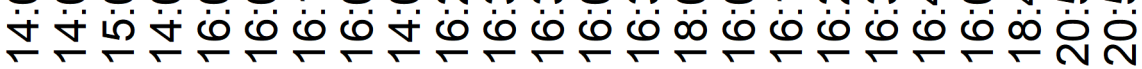

Abbildung 4.9: Übersicht über die häufigsten Fettsäurekombinationen in Diacylglycerolipiden mit mindestens $5 \%$ Anteil an einer Lipidklasse in Tp-div (rot) und Tp-G1 (blau). Standardabweichung des Mittelwerts ( $\mathrm{N}=3$ für beide) als Fehlerbalken. 
Die Übersicht über aus Lipidprofilen berechnete FA-Profile von Diacyl- und Triacylglycerolipiden ist in Abb. 4.10 gezeigt, die analoge Übersicht für Lysolipide (LPC, LPG, usw.) mit nur einer Fettsäure in Abb. 4.11. Für letztere wurden 24:0 und 24:1 nicht aufgeführt, da sie nicht detektiert wurden.
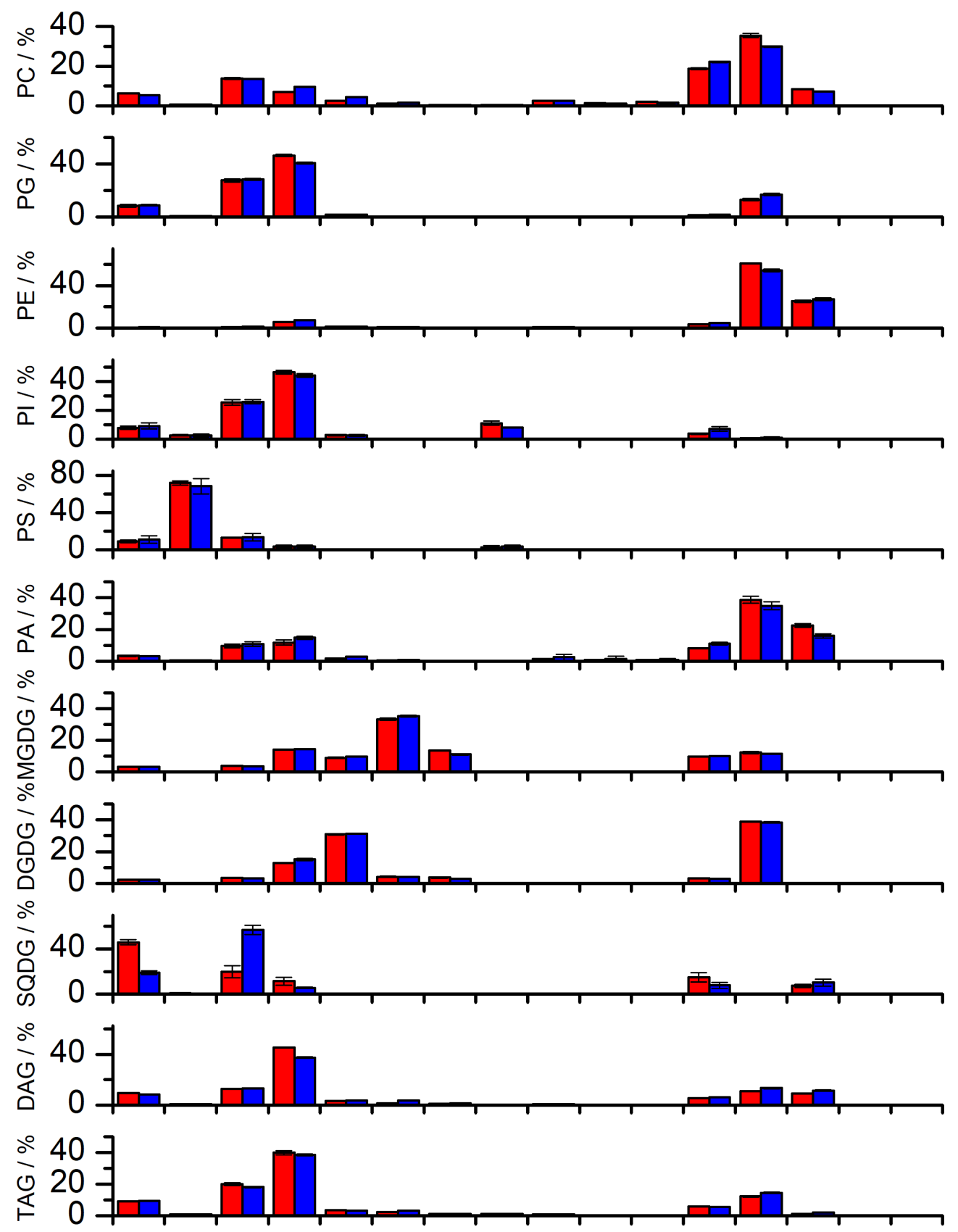

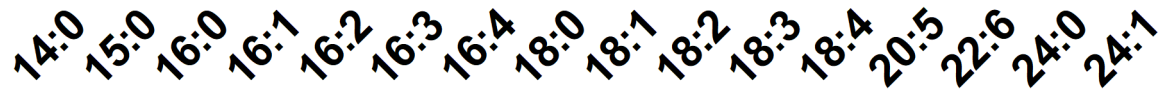

Abbildung 4.10: Übersicht über die FA-Verteilung in Diacyl- und Triacylglycerolipiden in Tp-div (rot) und Tp-G1 (blau). Standardabweichung des Mittelwerts ( $N=3$ für beide) als Fehlerbalken. 

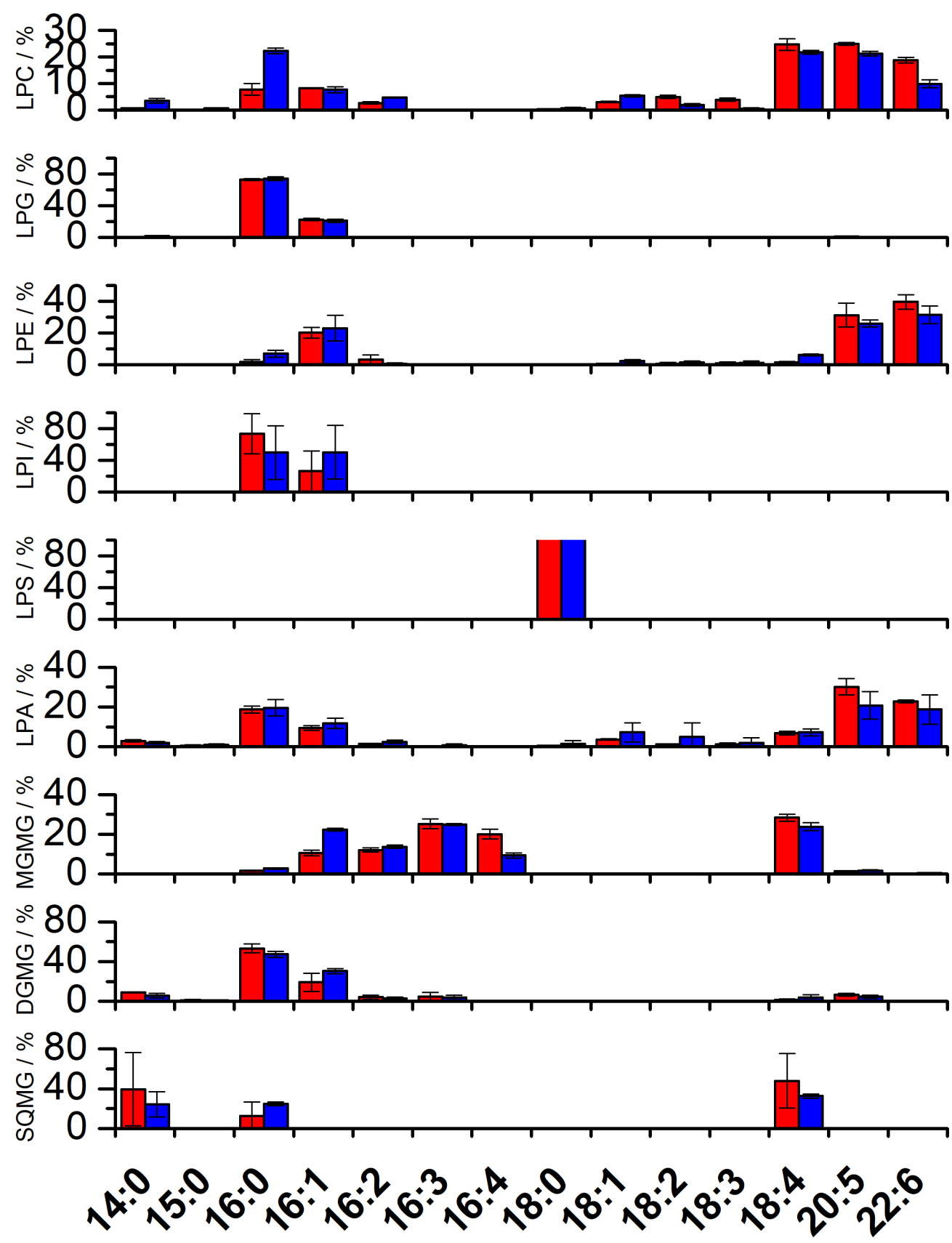

Abbildung 4.11: Übersicht über die FA-Verteilung in Lysolipiden in Tp-div (rot) und Tp-G1 (blau). Standardabweichung des Mittelwerts ( $\mathrm{N}=3$ für beide) als Fehlerbalken.

\subsubsection{Phosphatidylcholine (PC und LPC)}

Die Tp-Zellen wiesen 18:4/20:5 als häufigstes Phosphatidylcholin (PC)-Lipid auf (17\%), gefolgt von 16:0/18:4 (9\%), 20:5/20:5 (8\% gemittelt), 20:5/22:6 (8\%), 
16:0/20:5 (7\%) und 16:1/20:5 (6\%). In diesen Lipiden war jeweils mindestens eine Fettsäure mit zumindest vier Doppelbindungen mehrfach ungesättigt. Tp-div zeigte bezogen auf das relative PC-Lipidprofil Zunahmen für 20:5/20:5 mit dem Faktor 2.0 und für 16:0/20:5 (Faktor 1.6) und eine Abnahme für 16:1/20:5 (Faktor 1.4) gegenüber Tp-G1. Die häufigsten Fettsäuren in PC-Lipiden waren 20:5 (33\% gemittelt), 18:4 (20\%) und 16:0 (14\%). 20:5 erfuhr eine Zunahme, 18:4 eine Abnahme um Faktor 1.2 im Tp-div-Profil ggü. Tp-G1. Die prominentesten Lyso-PC-Spezies (LPC) beinhalteten die FAs 18:4, 20:5 (beide $23 \%$ ), 16:0 (15\% gemittelt) und 22:6 (14\% gemittelt). Tpdiv zeigte dabei eine relative Zunahme von 22:6 um Faktor 1.9 und eine Abnahme von 16:0 um Faktor 2.9 verglichen mit Tp-G1.

\subsubsection{Phosphatidylglycerole (PG und LPG)}

16:1/16:0 war das häufigste Phosphatidylglycerol (PG)-Lipid (31\% gemittelt), für das Tp-div einen 1.3x höheren relativen Anteil an PG-Lipiden zeigte als Tp-G1. 16:0/20:5 folgte (18\% gemittelt), wobei Tp-div eine relative Abnahme um Faktor 1.5 ggü. Tp-G1 zeigte. Es folgten 16:1/16:1 (15\%), 14:0/16:1 (12\%) und 16:1/20:5 (11\%), die für beide Tp-Probentypen gleiche Anteile zeigten. Die häufigsten FAs in PG-Lipiden waren 16:1 (44\% gemittelt), gefolgt von 16:0 (28\%) und 20:5 (15\%). 16:1 zeigte eine kleine Zunahme um Faktor 1.1, 20:5 eine Abnahme um Faktor 1.3 für Tp-div ggü. TpG1. LPG-FAs waren v.a. 16:0 (73\%) und 16:1 (22\%) ohne signifikante Unterschiede zwischen den Tp-Proben.

\subsubsection{Phosphatidylethanolamine (PE und LPE)}

Phosphatidylethanolamin (PE) zeigte als 20:5/22:6 (41\% gemittelt) und 20:5/20:5 (28\%) als häufigste Lipide, ohne statistisch signifikante Unterschiede zwischen den Tp-Proben. Von den detektierten FAs waren 20:5 (58 \% gemittelt) und 22:6 (26 \%) mit herausragend hohen Anteilen versehen, wobei 20:5 eine kleine Zunahme um Faktor 1.1 für Tp-div ggü. Tp-G1 aufwies. FAs in LPE waren am häufigsten 22:6 (36\% gemittelt), 20:5 (29\% gemittelt) und 16:1 (22\%), alle ohne signifikante Unterschiede in ihren Anteilen an den relativen Profilen von Tp-div und Tp-G1. 


\subsubsection{Phosphatidylinositole (PI und LPI)}

Die häufigsten Phosphatidylinositol (PI)-Lipide waren 16:1/16:0 (38\%), 16:1/16:1 (17\%) und 14:0/16:1 (13\%). Bemerkenswert war auch ein Anteil von $9 \%$ (gemittelt) an 18:0/18:0. Diese FA-Kombination kommt in keinem anderen Lipid in so hohem relativen Anteil vor. Der relative FA-Anteil an 18:0 von $9 \%$ ist ebenfalls so hoch wie in keinem anderen Diacylglycerolipid. Die dominanten PI-FAs sind dagegen 16:1 (45 \%) und 16:0 (25\%). 16:0 und 16:1 waren zudem die einzigen für LPI detektierten FAs, zeigten jedoch große Varianz, vermutlich da die LPI-Menge nahe am Detektionslimit war.

\subsubsection{Phosphatidylserine (PS und LPS)}

Phosphatidylserin (PS) zeigte mit dem Lipid 15:0/15:0 (70\%) eine sehr außergewöhnliche FA-Kombination, die in anderen Lipiden nur in Spuren enthalten war. Zudem war das Lipid 14:0/16:0-PS mit 17\% relativem Anteil ebenfalls eine seltene Kombination in anderen Lipidklassen. Die Unterschiede zwischen Tp-div und Tp-G1 waren nicht signifikant. Das resultierende FA-Profil zeigte 15:0 (70 \%), 16:0 (13\%) und 14:0 (10\%) als häufigste FAs. Mehrfach ungesättigte FAs wurden für PS überhaupt nicht detektiert. PS zeigt deutlich höhere Anteile an 15:0 als alle anderen Lipide. Für die Lysospezies LPS wurde ausschließlich 18:0 detektiert, was einen deutlichen Unterschied zu dem PS-Profil bedeutet, das nur $3 \% 18: 0$ aufwies.

\subsubsection{Phosphatidsäuren (PA und LPA)}

Phosphatidsäure (PA)-Lipide waren v.a. 20:5/22:6 (30\% gemittelt) als dominante Spezies mit einer Zunahme um Faktor 1.4 in Tp-div im Vergleich mit Tp-G1 sowie 16:1/20:5 und 18:4/20:5 (beide $10 \%$ gemittelt) mit signifikanten Abnahmen um Faktor 1.5 bzw. 1.4 in Tp-div ggü. Tp-G1. Die FA-Anteile betrugen 20:5 (37\%), 22:6 (19 \% gemittelt), 16:1 (13\%), 16:0 und 18:4 (beide 10\%). 18:4 zeigte eine Abnahme um Faktor 1.3, 22:6 eine Zunahme um Faktor 1.4 in Tp-div verglichen mit Tp-G1. LPA zeigte $20: 5$ (25\% gemittelt), 22:6 (20\% gemittelt), 16:0 (19\%) und 16:1 (11\%) als 
häufigste FAs. Hier traten keine statistisch signifikanten Unterschiede zwischen Tp-div und Tp-G1 auf.

\subsubsection{Monogalactosyldiacyl- und monoacylglycerole (MGDG und MGMG)}

Prominenteste Monogalactosyldiacylglycerol (MGDG)-Lipide waren 16:3/16:3 (18 \%), 16:4/16:3 (10\%), 16:4/20:5 (9\%), 16:3/18:4 (7\%), 16:1/16:1 und 16:3/16:2 (beide $6 \%$ ). 16:3/16:2 zeigte dabei eine Abnahme um Faktor 1.2 und 16:4/20:5 eine Zunahme um Faktor 1.3 in Tp-div im Vergleich zu Tp-G1. Das MGDG-FA-Profil wies 16:3 (34 \%), 16:1 (14\%), 16:4, 20:5 (beide $12 \%$ ) und 18:4 (10\%) als häufigste FAs auf. Kleine signifikante Unterschiede zeigten sich in der Zunahme von 16:4 um Faktor 1.2 und der Abnahme von 16:3 um Faktor 1.1 für Tp-div. Die Lysoform MGMG hatte mit 18:4 (26 \%, Zunahmefaktor 1.2 für Tp-div), 16:3 (25\%), 16:1 (17 \% gemittelt), 16:4 (15\% gemittelt) und 16:2 (13\%) FAs, die im Fall von 16:1 (Abnahmefaktor 2.1 für Tpdiv) und 16:4 (Zunahmefaktor 2.2 für Tp-div) enorme Unterschiede in ihren relativen Anteilen zwischen Tp-div und Tp-G1 zeigten. Die hohen 16:3- und 16:4-Anteile in MGDG und MGMG unterscheiden diese Lipide von anderen Glycerolipidklassen.

\subsubsection{Digalactosyldiacyl- und monoacylglycerole (DGDG und DGMG)}

Digalactosyldiacylglycerol (DGDG) wies als dominante FA-Kombination 16:2/20:5 (56 \%) auf. Das resultierende FA-Profil zeigte 20:5 (39 \%), 16:2 (31\%) und 16:1 (14 \%, Abnahmefaktor 1.2 für Tp-div) als häufigste FAs. Der hohe Anteil von 16:2 in DGDG ist einzigartig unter den analysierten Lipidklassen. Im Gegensatz dazu wurden für DGMG nur geringe Mengen 20:5 (6\%) und 16:2 (4 \%) nachgewiesen, dafür jedoch 16:0 (51\%) und 16:1 (25\% gemittelt).

\subsubsection{Sulfoquinovosyldiacyl- und monoacylglycerole (SQDG und SQMG)}

Die häufigsten Sulfoquinovosyldiacylglycerol (SQDG)-Lipide waren 14:0/18:4 (23\% gemittelt) und 16:0/22:6 (18\% gemittelt), die keine signifikanten Unterschiede 
zwischen Tp-div und Tp-G1 aufwiesen, sowie 14:0/14:0 (18\% gemittelt, Zunahmefaktor 3.1 für Tp-div) und 16:0/16:0 (29\% gemittelt, Abnahmefaktor 3.7 für Tp-div) mit großen Veränderungen zwischen den beiden Probentypen. Resultierend daraus wurden 14:0 (32\% gemittelt, Zunahmefaktor 2.4 für Tp-div), 16:0 (38\% gemittelt, Abnahmefaktor 2.9 für Tp-div) und 18:4 (11\% gemittelt) als dominante FAs identifiziert. Der hohe 14:0-Anteil ist im Vergleich zu anderen Lipidklassen besonders. Für SQMG wurden 14:0, 18:4, 16:0 und 16:1 als FAs detektiert, jedoch mit enormen Varianzen, sodass von insgesamt sehr geringen Mengen nahe am Detektionslimit ausgegangen werden muss.

\subsubsection{Diacylglycerole (DAG)}

Die häufigste Diacylglycerol (DAG)-Lipidspezies war 16:1/16:1 (21\% gemittelt), gefolgt von 16:1/16:0 (16 \%), 14:0/16:1 (12\%) und 20:5/22:6 (8\%). 16:1/16:1 zeigte dabei eine 1.4x Zunahme für Tp-div ggü. Tp-G1. Im FA-Profil dominierte 16:1 (41\% gemittelt) mit einer relativen Zunahme um Faktor 1.2 für Tp-div im Vergleich zu Tp-G1. Es folgten 16:0 (13\%), 20:5 (12\%) und 22:6 (10\%), wobei letztere beide eine schwache Abnahme in Tp-div verzeichneten (Faktor 1.2 bzw 1.3).

\subsubsection{Triacylglycerole (TAG)}

Triacylglycerol (TAG) besteht neben dem Glycerolgrundgerüst aus drei Fettsäureketten. Somit ergeben sich für eine nominelle Lipidmasse viele FAKombinationen, deren Auswertung hier nicht detailliert erfolgte. In Abb. 4.12 ist das Lipidprofil von TAG dargestellt, wobei die Summen der drei FAs gelistet sind, nicht die konkreten FA-Kombinationen. In Summe zeigten 48:2 (16\%) und 48:3 (11\%) die höchsten Anteile. Welche FA-Kombinationen tatsächlich hinter diesen Summen stehen oder wie die Verteilung solcher Kombinationen für eine Summe aussieht, wurde nicht weiter untersucht. Da die Einzelsignale in der LC-MS/MS aufgrund der Spezifität der MRMs (genaue Mutterionen- und Fragmentionenmasse) direkt einer Fettsäure zugeordnet werden können, konnte separat ein konkretes Fettsäureprofil erstellt 
werden (siehe Abb. 4.10 und Anhang 8.11). Die häufigsten FAs in TAG waren 16:1 (39 \%), 16:0 (19\%) und 20:5 (13\%). Damit ähnelte das TAG-FA-Profil dem von DAG.

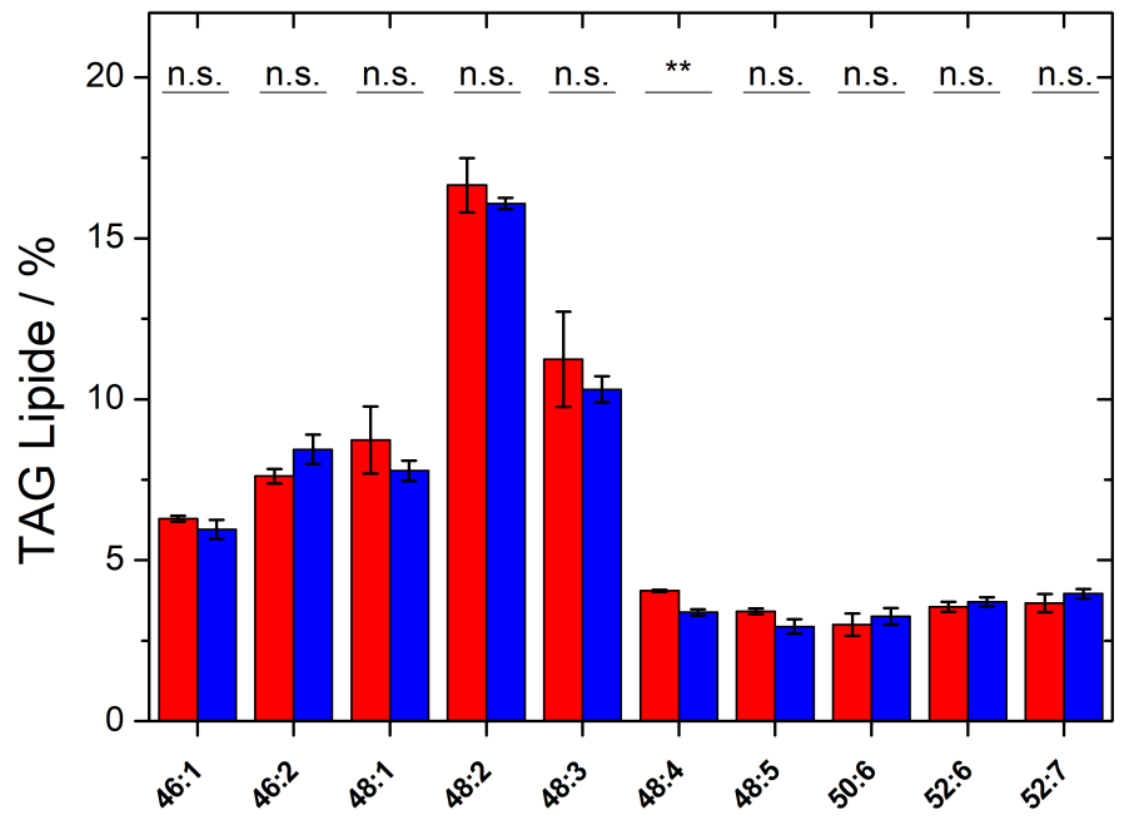

Abbildung 4.12: Lipidprofil von TAG in Tp-div (rot) und Tp-G1 (blau). Gelistet sind die Summen der drei beinhaltenden Fettsäuren. Aufgeführt sind nur Lipide $>3 \%$. Standardabweichung des Mittelwerts als Fehlerbalken ( $\mathrm{N}=3$ für beide). Statistische Signifikanz (zweiseitiger $\mathrm{t}$-Test mit ungleichen Varianzen): $p<0.005\left(^{* *}\right), p<0.05\left(^{*}\right)$, nicht signifikant (n.s.).

\subsubsection{Sphingolipide}

Tp-div und Tp-G1 wurden auf drei Typen von Sphingolipiden untersucht: Ceramide, Glycocerebroside und Diglycocerebroside. Es wurden Ceramide mit dihydroxylierten langkettigen Sphingoidbasen (engl. long chain sphingoid bases, LCB) der Länge C18 gefunden, die entweder einfach, zweifach oder dreifach ungesättigt waren. Die daran gebundene Fettsäure wurde über die Fragmentierung in der LC-MS/MS detektiert. Nachgewiesen wurden 16:0, 24:0, 24:1 oder 26:0-FA (Abb. 4.13). Das häufigste Ceramid mit $50 \%$ (gemittelt, Zunahmefaktor 1.2 für Tp-div) Signalanteil war $\operatorname{Cer}(18: 3 ; 2 / 24: 1 ; 0)$. Zudem wurden $\operatorname{Cer}(18: 2 ; 2 / 24: 1 ; 0,11 \%)$, $\operatorname{Cer}(18: 1 ; 2 / 24: 0 ; 0,10 \%$, Abnahmefaktor 1.2 für Tp-div) und $\operatorname{Cer}(18: 3 ; 2 / 24: 0 ; 0,10 \%$ gemittelt, Abnahmefaktor 1.4 für Tp-div) mit hohem Anteil detektiert. 


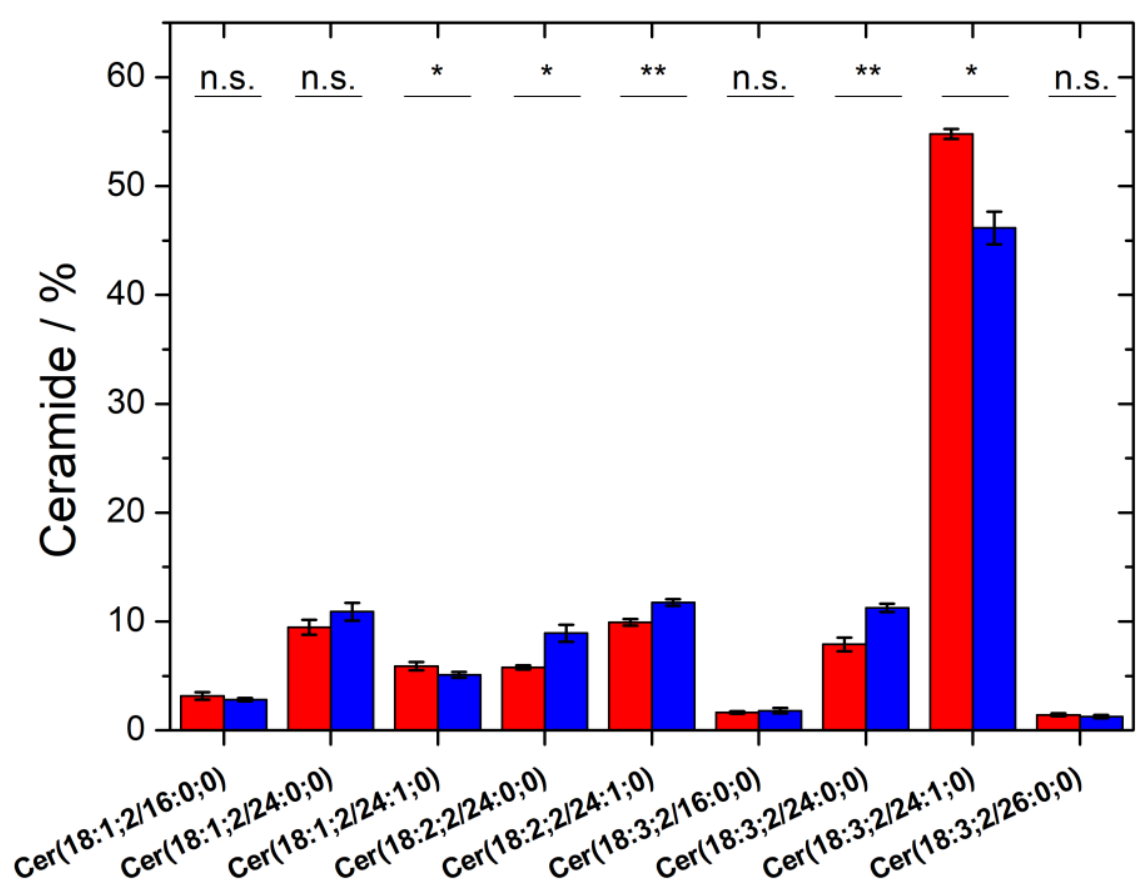

Abbildung 4.13: Lipidprofil der Ceramide in Tp-div (rot) und Tp-G1 (blau). Standardabweichung des Mittelwerts als Fehlerbalken ( $\mathrm{N}=3$ für beide). Statistische Signifikanz (zweiseitiger $\mathrm{t}$-Test mit ungleichen Varianzen): $p<0.005\left(^{* *}\right), p<0.05\left(^{*}\right)$, nicht signifikant (n.s.).

Die detektierten Monoglycocerebroside (HexCer, Abb. 4.14) waren HexCer(18:3;2/24:1;0, $61 \%)$, HexCer(18:1;2/24:0;0, $13 \%)$, HexCer(18:1;2/24:1;0, $11 \%)$, HexCer(18:1;2/16:0;0, $9 \%)$ und HexCer(18:3;2/16:0;0, $7 \%)$. Das HexCerProfil war für beide Tp-Probentypen ohne nennenswerte Unterschiede. Dagegen wurden nur zwei Diglycocerebroside (Hex $2 \mathrm{Cer}$, Abb. 4.15) nachgewiesen, $\mathrm{Hex}_{2} \operatorname{Cer}(18: 3 ; 2 / 24: 1 ; 0,83 \%)$ und $\mathrm{Hex}_{2} \operatorname{Cer}(18: 3 ; 2 / 16: 0 ; 0,17 \%)$. Das Profil war für Tp-div und Tp-G1 gleich. 


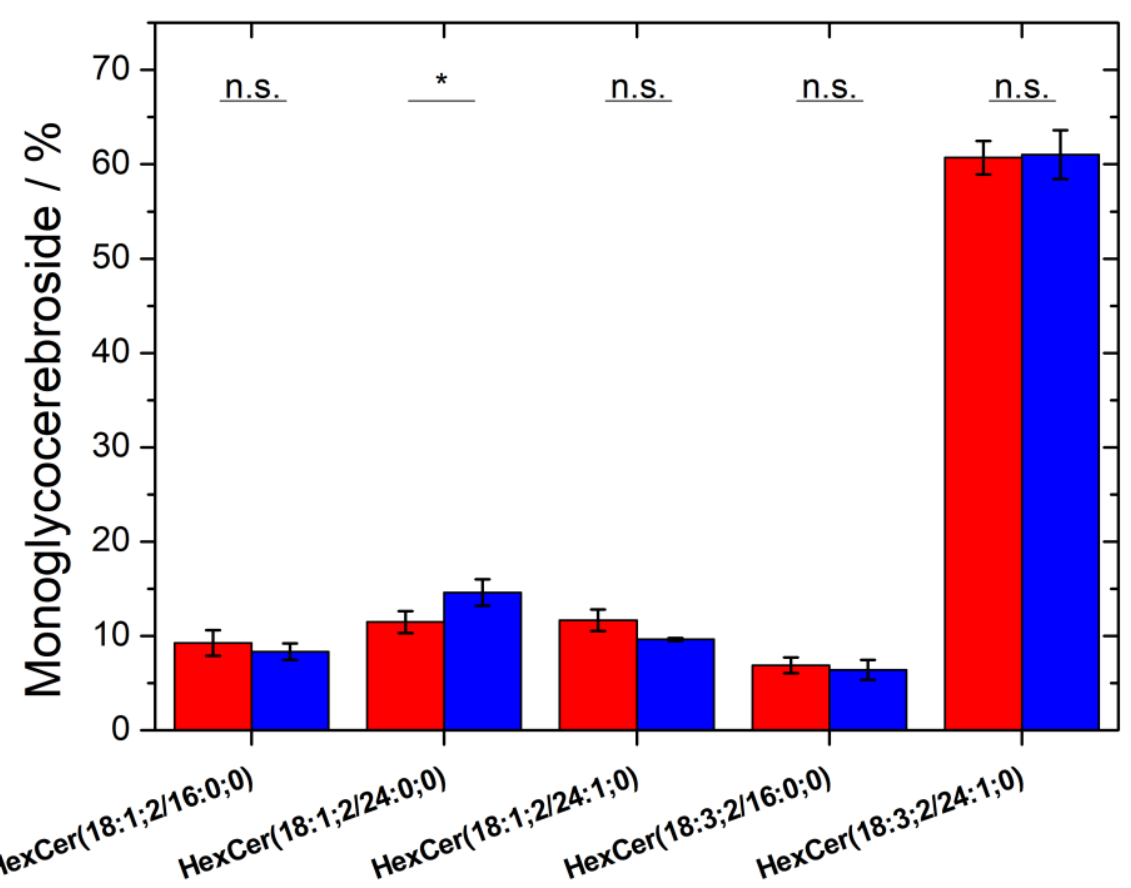

Abbildung 4.14: Lipidprofil der Monoglycocerebroside in Tp-div (rot) und Tp-G1 (blau). Standardabweichung des Mittelwerts als Fehlerbalken ( $\mathrm{N}=3$ für beide). Statistische Signifikanz (zweiseitiger t-Test mit ungleichen Varianzen): $p<0.005\left({ }^{* *}\right), p<0.05\left({ }^{*}\right)$, nicht signifikant (n.s.).

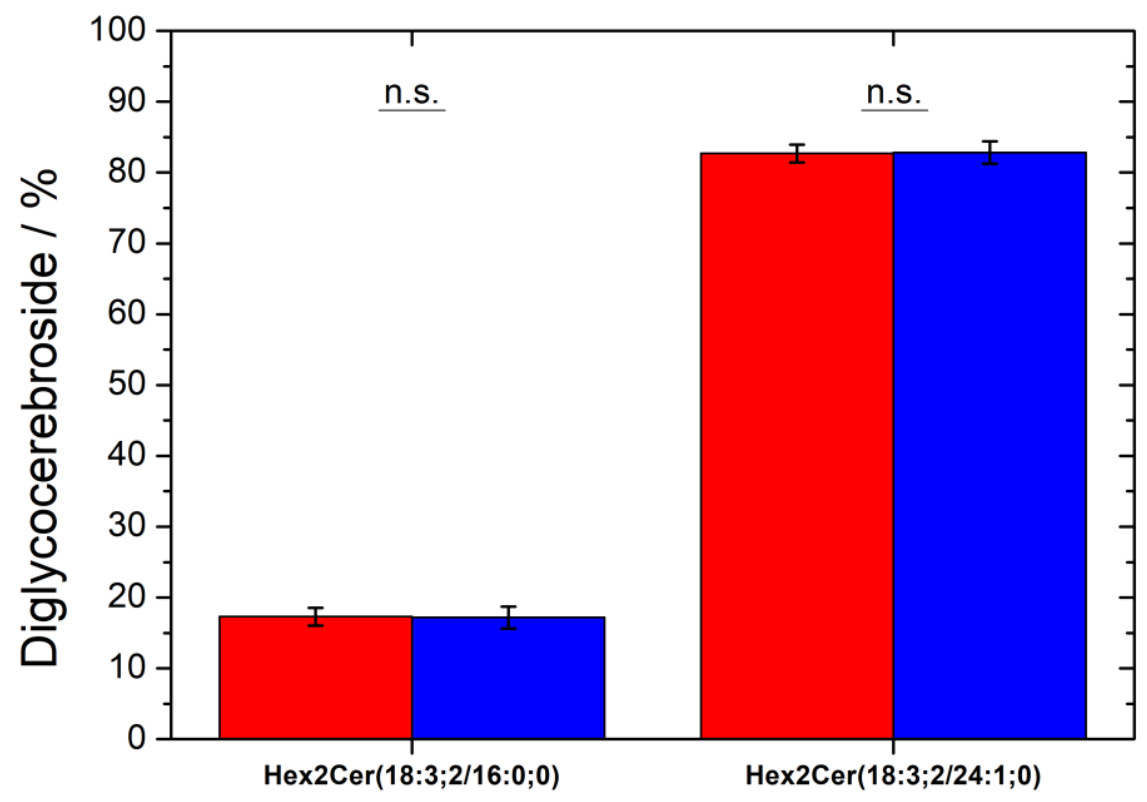

Abbildung 4.15: Lipidprofil der Diglycocerebroside in Tp-div (rot) und Tp-G1 (blau). Standardabweichung des Mittelwerts als Fehlerbalken ( $\mathrm{N}=3$ für beide). Statistische Signifikanz (zweiseitiger t-Test mit ungleichen Varianzen): $p<0.005\left(^{* *}\right), p<0.05\left(^{*}\right)$, nicht signifikant (n.s.). 


\subsubsection{Sterole und Sterolester (SE)}

$94 \%$ Signalanteil der LC-MS/MS-Analyse auf freie Sterole ging auf Moleküle mit der Mutterionenmasse von $458 \mathrm{~g} / \mathrm{mol}$ zurück, aus dem ein Fragmention mit $381 \mathrm{~g} / \mathrm{mol}$ gebildet wurde. Wahrscheinlich handelte es sich hierbei um 24-Methylencholesterol und Brassicasterol, die in dieser Arbeit nicht unterschieden werden und aufgrund der Fragmentionenmasse St381 genannt werden. Ein weiteres detektiertes freies Sterol mit $5 \%$ Signalanteil war St383, bei dem es sich vermutlich um Campesterol handelte. Je unter $1 \%$ zeigten St395 (Fucosterol, Isofucosterol, Stigmasterol) und St397 (Sitosterol). Cholesterol (St369) konnte nicht eindeutig nachgewiesen werden. Die Sterolprofile für Tp-div und Tp-G1 sind in Abb. 4.16 gezeigt.

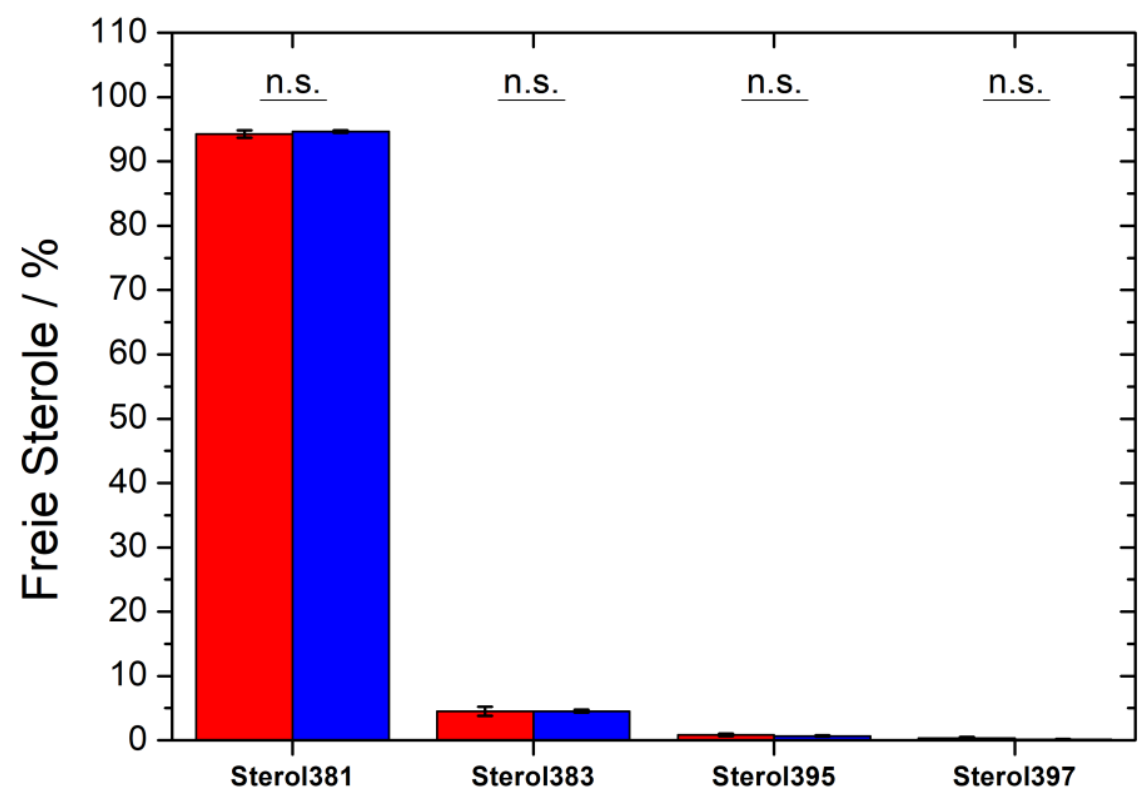

Abbildung 4.16: Relatives Profil der freien Sterole in Tp-div (rot) und Tp-G1 (blau). Standardabweichung des Mittelwerts als Fehlerbalken ( $N=3$ für beide). Statistische Signifikanz (zweiseitiger t-Test mit ungleichen Varianzen): $p<0.005\left(^{* *}\right), p<0.05\left({ }^{*}\right)$, nicht signifikant (n.s.).

Ähnlich wie die freien Sterole zeigte sich für Sterolester (SE) St381 mit $94 \%$ als dominantes Sterolgerüst. Es folgen St395 (3.3\%), St383 (2.5\%) und St369 (0.3\%). In Abb. 4.17 sind Sterolesterprofile der beiden Tp-Zellprobentypen dargestellt. Die häufigsten Sterolester waren St381(18:4) (28\%) und St381(16:4) (24\%), aber auch 
St381(20:5) und St381(16:3) zeigten Anteile $>10 \%$. Die Betrachtung des gesamten Sterolester-FA-Profils in Abb. 4.18 demonstriert die Dominanz der mehrfach ungesättigten Fettsäuren, genauer 18:4 (30\%), 16:4 (26\%), 20:5 (15\% gemittelt) und 16:3 (13\% gemittelt). 20:5 erfuhr eine Zunahme um Faktor 2.1 für Tp-div, 16:3 eine Abnahme um Faktor 1.7.

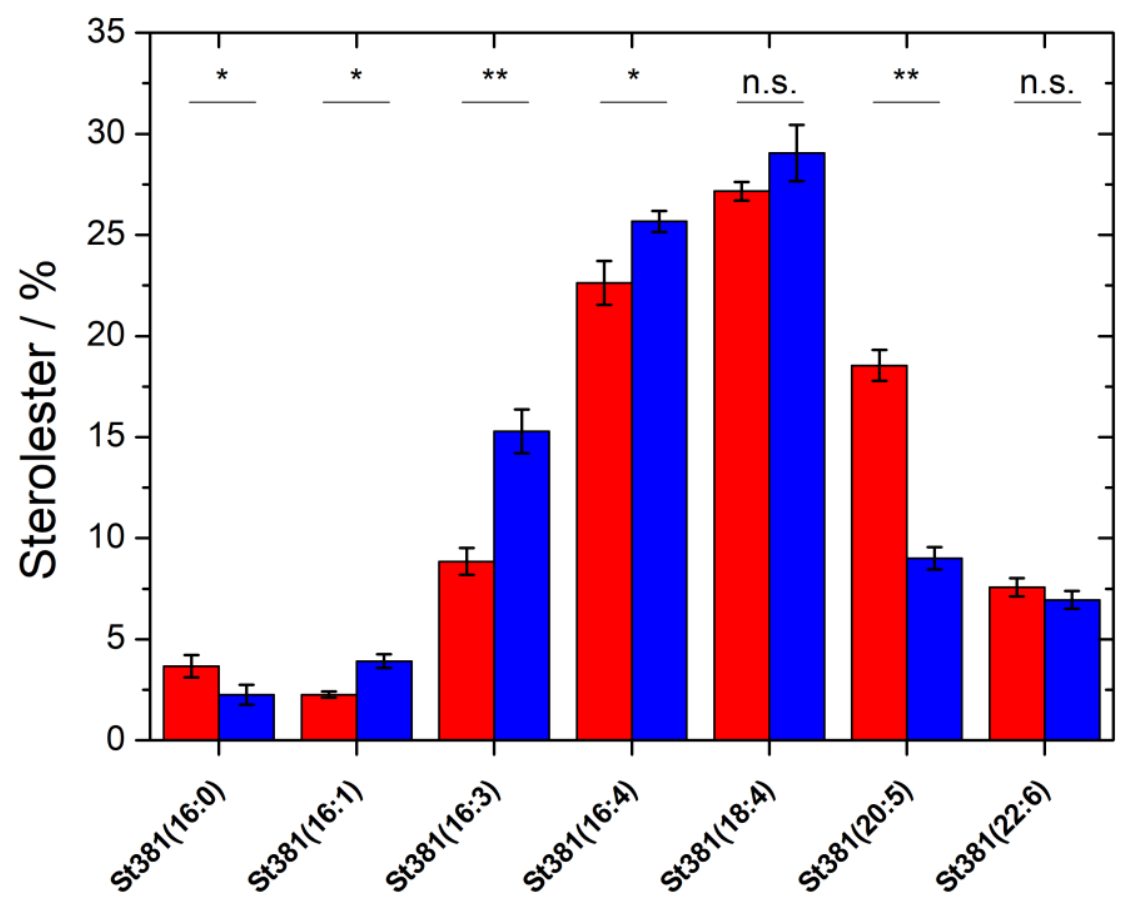

Abbildung 4.17: Relatives Profil der Sterolester in Tp-div (rot) und Tp-G1 (blau). Aufgeführt sind Sterolester $>3 \%$. Standardabweichung des Mittelwerts als Fehlerbalken ( $\mathrm{N}=3$ für beide). Statistische Signifikanz (zweiseitiger t-Test mit ungleichen Varianzen): $\left.p<0.005{ }^{* *}\right), p<0.05\left(^{*}\right)$, nicht signifikant (n.s.). 


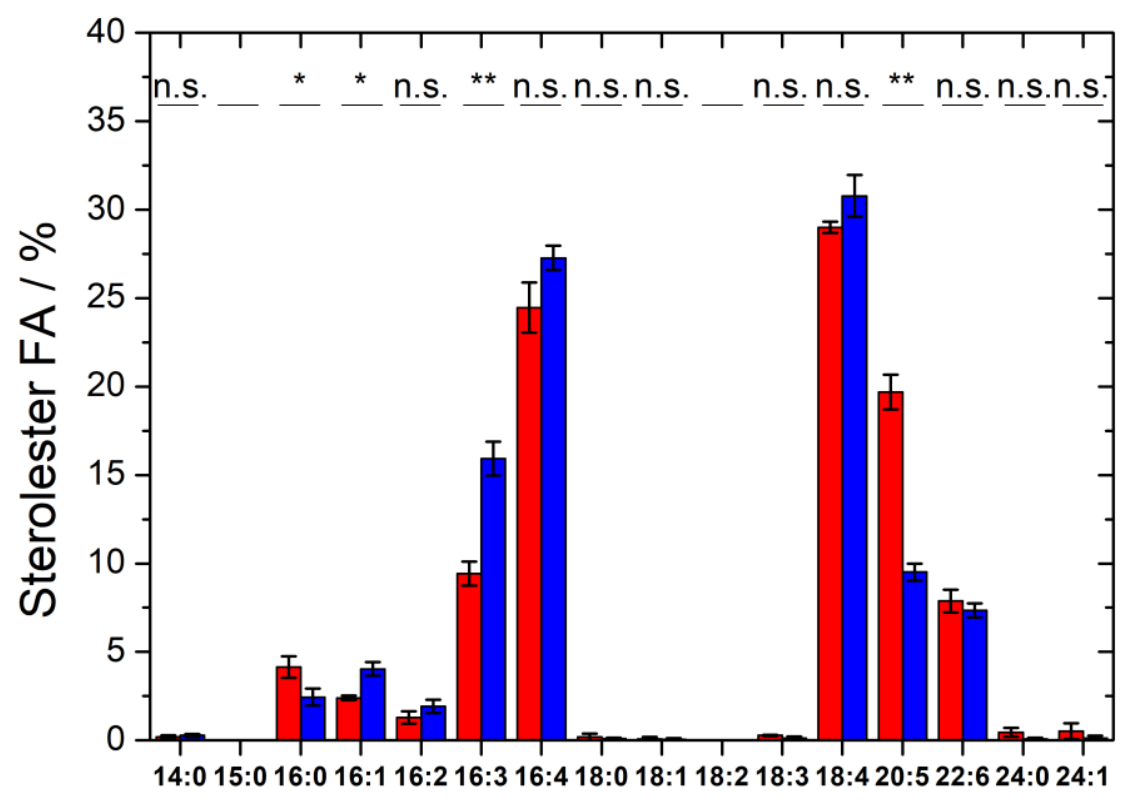

Abbildung 4.18: Relatives FA-Profil der Sterolester in Tp-div (rot) und Tp-G1 (blau). Standardabweichung des Mittelwerts als Fehlerbalken ( $N=3$ für beide). Statistische Signifikanz (zweiseitiger t-Test mit ungleichen Varianzen): $p<0.005\left(^{* *}\right), p<0.05\left({ }^{*}\right)$, nicht signifikant (n.s.).

\subsubsection{Charakterisierung der FA-Zusammensetzung einzelner Lipidklassen nach} FA-Kategorien

Die Kategorisierung von FAs nach Kohlenstoffkettenlänge oder Sättigungsgrad erlaubt einen übersichtlicheren Vergleich der FA-Charakteristika zwischen verschiedenen Lipidklassen bzw. zwischen Tp-div und Tp-G1.

Abb. 4.19 zeigt den Anteil von FAs mit mindestens 20 C-Atomen jeder Lipidklasse (LCMS/MS) und der gesamten Kultur (GC-FID, „Total“). So wird schnell ersichtlich, dass PE (84 \%), LPE (64 \%) und PA (56 \%) einen mehr als doppelt so hohen Anteil an FAs mit mind. 20 C-Atomen im Vergleich zur totalen FA-Komposition der Tp-Zellen (25\%) aufwiesen. Zu diesen FAs gehören 20:5, 22:6, 24:0 und 24:1. LPA (46\%), PC (40\%), DGDG (39\%) und LPC (37\%) zeigten ebenfalls hohe FA(C20+)-Anteile. Auf der anderen Seite besaßen PS, LPS, LPI, SQMG (alle $0 \%$ ) sowie PI (<1\%) und LPG (1\%) keine oder nur geringste Spuren dieser sehr langen FAs. MGMG (2\%), DGMG (6\%) und SQDG (9\%) blieben auch unter $10 \%$. Während der FA(C20+)-Anteil im 
Totallipidom für Tp-div und Tp-G1 keinen Unterschied aufwies, zeigte sich doch für einige Lipidklassen eine Zu- oder Abnahme des relativen Anteils dieser langen FAs für Tp-div ggü. Tp-G1. Eine größere signifikante Zunahme wurde für Sterolester (SE, 1.7x, $\mathrm{p}=0.002$ ) beobachtet, doch auch PC, PE und PA und ihre Lysoformen zeigten leichte Anstiege in ihrem $\mathrm{FA}(\mathrm{C20}+)$-Anteil für Tp-div. Die relative Abnahme dieser FAs wurde dagegen für SQDG (nicht signifikant), $P G, D A G$ und $T A G$ in geringem Maße beobachtet.

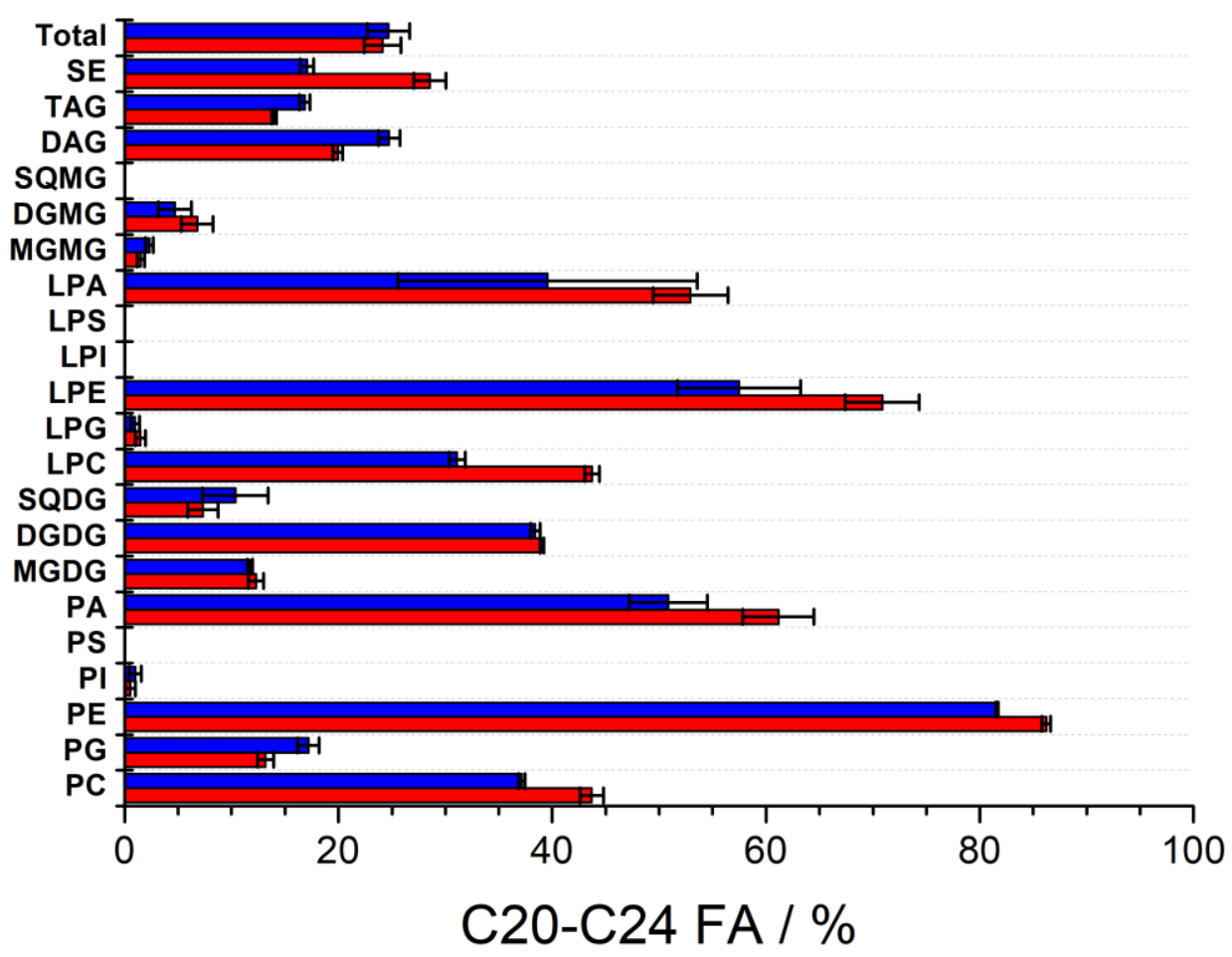

Abbildung 4.19: Anteil von FAs mit mindestens 20 C-Atomen an den Gesamt-FA-Profilen aller untersuchter FA-gebundener Lipidklassen (außer Sphingolipiden) in Tp-div (rot) und Tp-G1 (blau). Total=GC-FID-analysiertes Totallipidextrakt. Standardabweichung des Mittelwerts als Fehlerbalken ( $N=3$ für beide $T p$-Probentypen).

Eine ternäre Übersicht über die Verteilung von FAs mit unterschiedlichen Sättigungsgraden (Abb. 4.20) zeigt, dass relative Anteile von gesättigten und mehrfach ungesättigten FAs über den vollen Bereich verteilt sind, während einfach ungesättigte FAs maximal $50 \%$ des FA-Anteils ausmachen. Die Totallipidom-FAs sind dabei sehr ausgeglichen verteilt (29\% gesättigt (g), $29 \%$ einfach ungesättigt (eu), $42 \%$ mehrfach ungesättigt (mu)) und zeigen keinen nennenswerten Unterschied zwischen Tp-div und 
Tp-G1. Die neutralen Glycerolipide DAG (23 \% g, $42 \%$ eu, $35 \% \mathrm{mu}$ ) und TAG (31\% g, $40 \%$ eu, $29 \% \mathrm{mu}$ ) sind in einem ähnlichen Bereich. PC, PE, PA, MGDG, DGDG sowie Sterolester zeigen eine deutliche Verschiebung zu größeren Mengen an mehrfach ungesättigten FAs (mindestens $68 \% \mathrm{mu}$ ). PI (46 \% g, $45 \%$ eu, $9 \% \mathrm{mu}$ ) und PG (37\% g, $44 \%$ eu, $19 \% \mathrm{mu})$ zeigen dagegen geringere Mengen an mehrfach ungesättigten FAs. SQDG- (71\% g, $9 \%$ eu, $20 \% \mathrm{mu}$ ) und PS-Lipide $(97 \% \mathrm{~g}, 3 \% \mathrm{eu}$, $0 \% \mathrm{mu}$ ) sind hochgradig gesättigt. Statistisch signifikante und dabei nennenswerte Unterschiede zwischen Tp-div und Tp-G1 wurden für Diacyl- und Triacylglycerolipide sowie Sterolester nicht beobachtet.

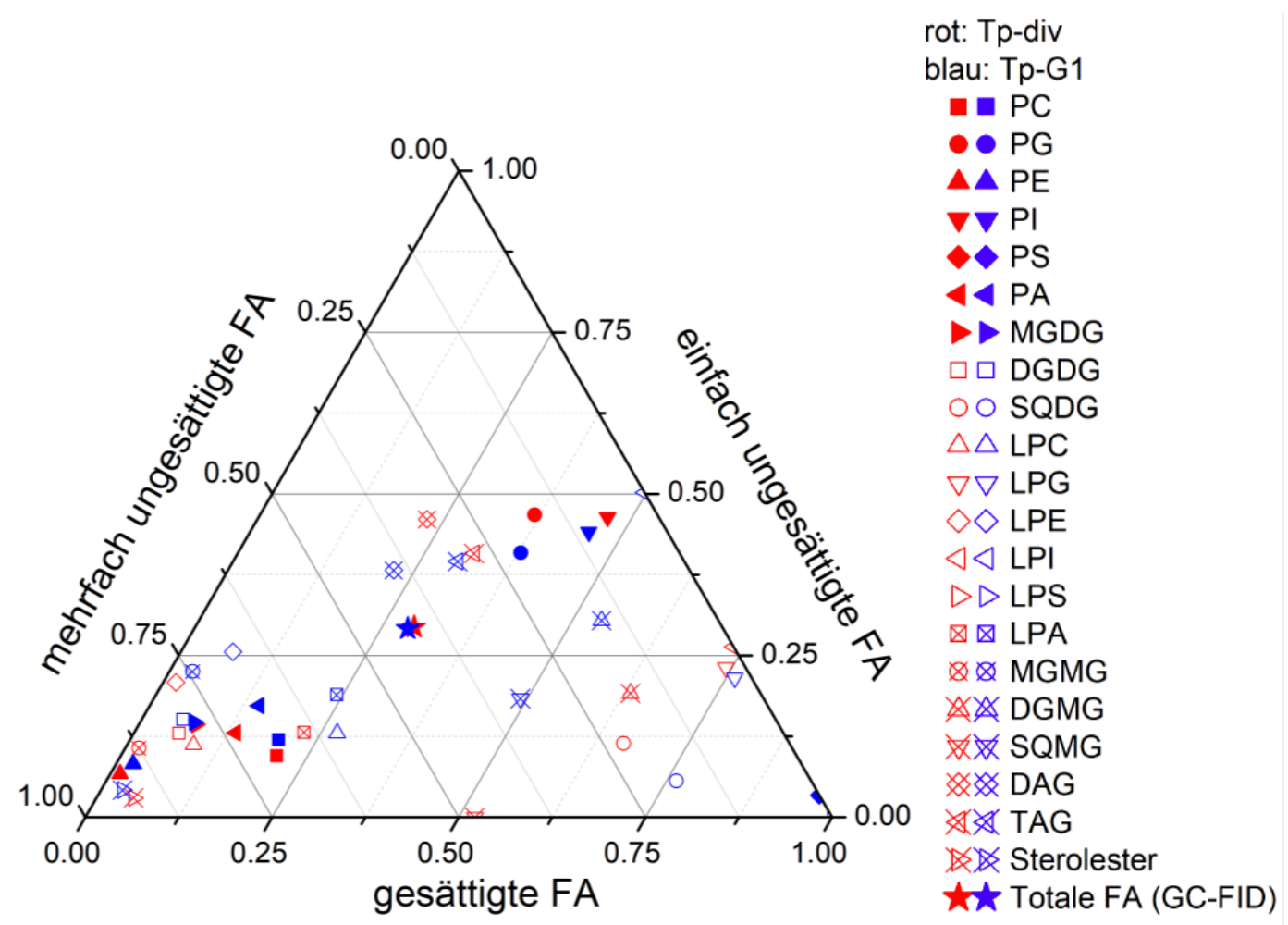

Abbildung 4.20: Dreiecksdiagramm der Anteile gesättigter (g), einfach ungesättigter (eu) und mehrfach ungesättigter (mu) FAs aller untersuchten FA-gebundenen Lipidklassen (außer Sphingolipiden) in Tp$\operatorname{div}$ (rot) und Tp-G1 (blau). Angezeigt sind die Mittelwerte aus N=3.

\subsubsection{Foldchange}

Die Veränderung des Anteils einer Lipidklasse von Tp-div zu Tp-G1 ist ein wichtiges Indiz für die Relevanz, die diese Lipidklasse während eines Stadiums des Zellzyklus besitzt. Daraus kann eine mögliche Funktionalität dieser Lipide oder zumindest ihre Verbindung zu einem zyklusspezifischen Mechanismus abgeleitet werden. 
Die LC-MS/MS-Analyse beruht auf der Detektion von Fragment- und Mutterionen, deren Signalintensität eine Aussage über relative Häufigkeiten innerhalb einer Lipidklasse erlauben. Da die Kopfgruppen jedoch unterschiedlich stark ionisieren, ist ein direkter klassenübergreifender Vergleich nicht möglich.

Die Berechnung des Foldchanges der relativen Anteile einer Lipidklasse an der Totalpeakfläche (engl. total peak area, TPA) aller analysierten Lipidklassen erlaubt eine Aussage über relative $\mathrm{Zu}$ - und Abnahmen bestimmter Klassen in den beiden TpProben. Abb. 4.21 ist eine Übersicht über die TPAs aller detektierten Lipidklassen. MGDG zeigte in Summe die stärksten Signale, die freien Sterole (FS) die schwächsten. Die Tp-G1-Proben zeigten insgesamt eine $2.7 x$ höhere einwaagennormierte TPA als Tp-div. Dieser Faktor konnte mit späteren Proben nicht reproduziert werden und bleibt rätselhaft. Die äquivalenten Proben eines Typs zeigten allerdings sehr ähnliche einwaagennormierte Werte, wie die Fehlerbalken suggerieren, sodass die Auswertung relativer Profile dieser Probentypen legitim war. Für die Foldchangeberechnung wurden einzelne Lipidklassen-TPAs auf die Gesamt-TPA eines Probentyps normiert, also sowohl Tp-div als auch Tp-G1 in Summe auf $100 \%$ gesetzt (Abb. 4.22).

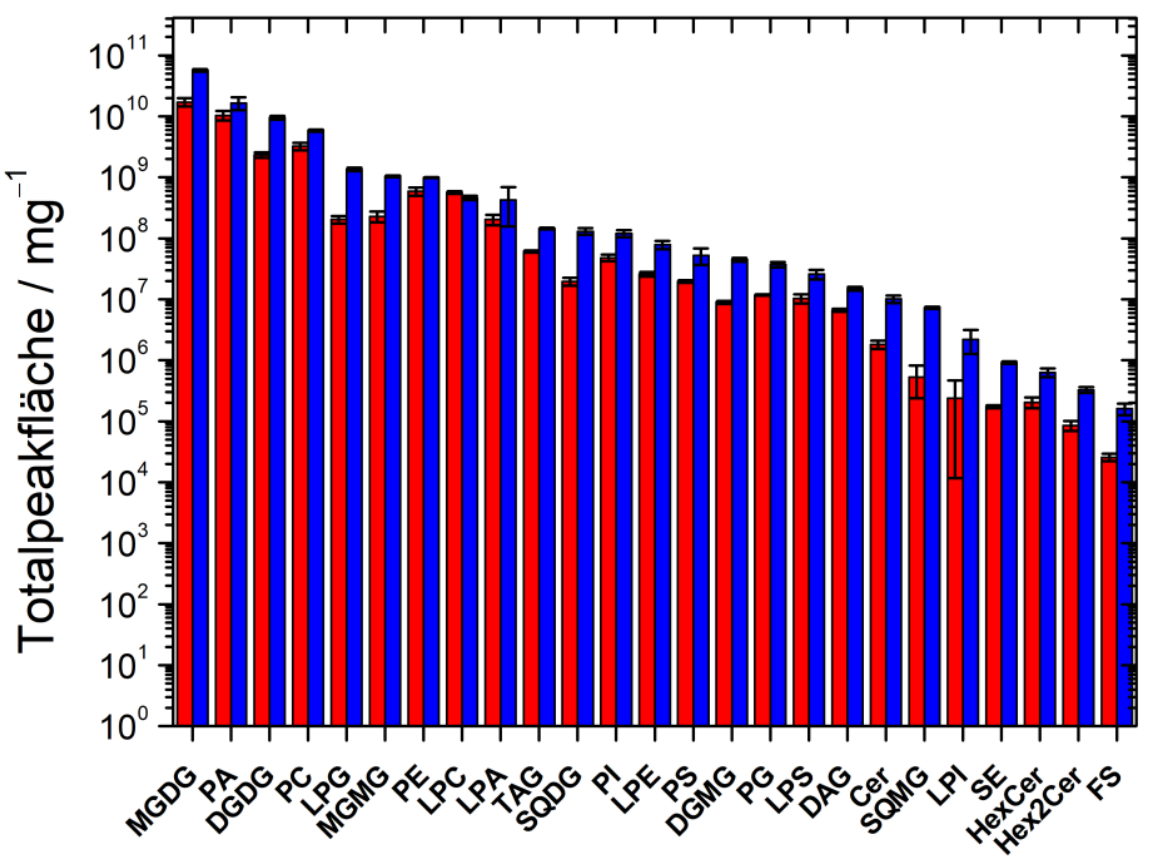

Abbildung 4.21: Einwaagennormierte Totalpeakflächen der LC-MS/MS-Analyse jeder detektierten Lipidklasse für Tp-div (rot) und Tp-G1 (blau). Standardabweichung des Mittelwerts als Fehlerbalken $(\mathrm{N}=3)$. SE=Sterolester; $\mathrm{FS}=$ freie Sterole. 


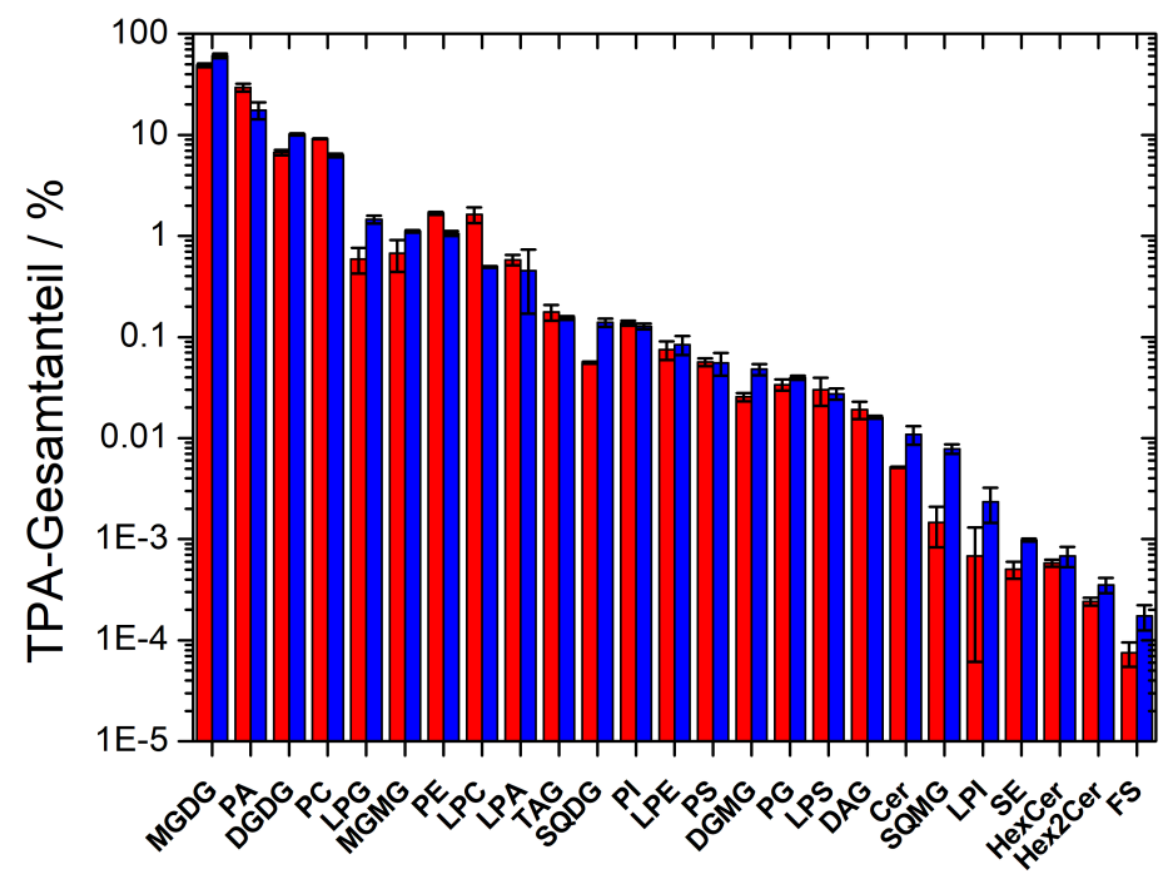

Abbildung 4.22: Relativer Totalpeakflächenanteil jeder detektierten Lipidklasse für Tp-div (rot) und TpG1 (blau). Standardabweichung des Mittelwerts als Fehlerbalken $(\mathrm{N}=3)$. SE=Sterolester; $F S=$ freie Sterole.

Die aus Abb. 4.22 berechneten Foldchanges sind in Abb. 4.23 zusammen mit Fehlern nach der Gaußschen Fehlerfortpflanzung angezeigt. Tp-div zeigte signifikante Zunahmen von PC (1.46 $\pm 0.06, p=0.002), P E(1.58 \pm 0.10, p<0.001), P A(1.68 \pm 0.35$, $\mathrm{p}=0.009)$ und der Lysoform LPC $(3.32 \pm 0.59, p=0.021)$. Statistisch signifikante Abnahmen (Foldchange $<1$ ) in Tp-div wurden für die Glycolipide MGDG $(0.80 \pm 0.06$, $\mathrm{p}=0.009)$, DGDG $(0.66 \pm 0.04, \mathrm{p}=0.001)$ und SQDG $(0.40 \pm 0.04, \mathrm{p}=0.008)$ sowie den Lysolipiden LPG $(0.41 \pm 0.12, p=0.003)$, DGMG $(0.53 \pm 0.08, p=0.014)$ und SQMG $(0.19 \pm 0.08, p<0.001)$ als auch für Sterolester $(0.51 \pm 0.10, p=0.008)$ und Ceramide $(0.47 \pm 0.10, p=0.048)$ gefunden. LPI, MGMG, freie Sterole und Diglycocerebroside zeigten ebenfalls nennenswerte Abnahmen, erreichten jedoch nicht das statistische Signifikanzniveau von 0.05. LPA zeigte dagegen eine Zunahme für Tp-div mit einem beträchtlichen Fehler. PG, PI, PS, LPE, LPS, DAG, TAG und Monoglycocerebroside blieben in ihrem relativen Anteil mehr oder weniger unverändert. 


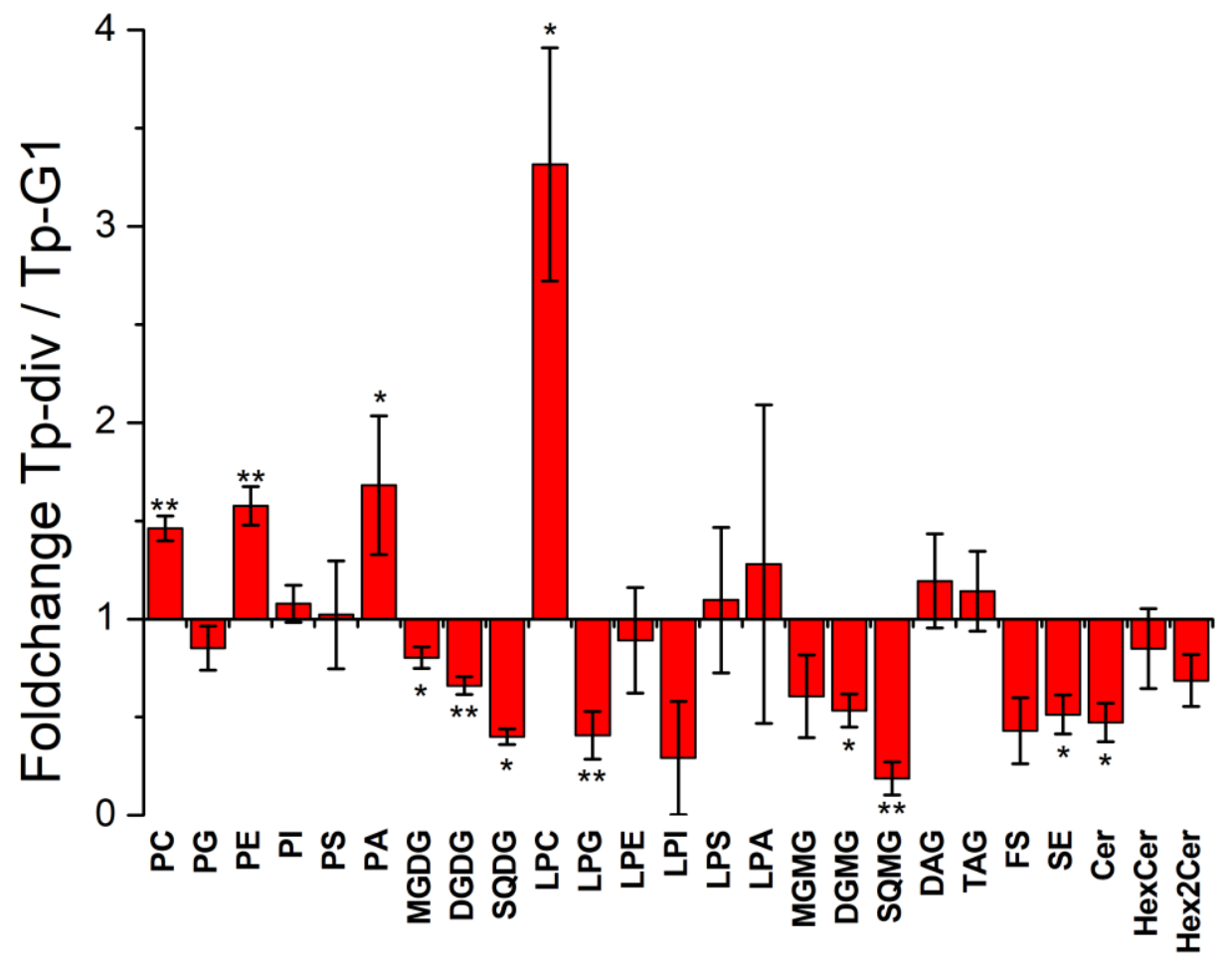

Abbildung 4.23: Foldchanges einzelner Lipidklassen für Tp-div bezogen auf Tp-G1. Die Fehlerbalken entsprechen der Gaußschen Fehlerfortpflanzung der Standardabweichungen aus Abb. 4.22. Statistische Signifikanz (zweiseitiger t-Test mit ungleichen Varianzen): $p<0.005\left(^{* *}\right), p<0.05\left(^{*}\right)$, nicht signifikant $($ kein *). SE=Sterolester; $F S=$ freie Sterole.

\subsection{Charakterisierung von rSin $1^{-\mathrm{SP}}$}

Silicanin-1 (Sin1) ist ein mit SDVs der Spezies Thalassiosira pseudonana assoziiertes Transmembranprotein. Das rekombinante Silicanin-1 ohne Signalpeptid (rSin1-SP) wurde in dieser Arbeit isoliert (siehe dazu die Masterarbeit des Autors ${ }^{[16]}$ ) und in SDVModellmembranen rekonstituiert, um die artifizielle Membran der nativen SDVMembran anzunähern. Vor der Rekonstitution wurde das Protein charakterisiert und mit veröffentlichten Eigenschaften der Sin1-Variante rSin1 1um, die nur aus der löslichen $\mathrm{N}$-terminalen Domäne besteht, verglichen. Auf diese Weise wurde einerseits die korrekte, genauergesagt zu rSin1 ${ }^{\text {lum }}$ analoge, Proteinfaltung überprüft als auch die Selbstaggregationseigenschaften bei erniedrigtem $\mathrm{pH}$-Wert untersucht, die eine Rolle bei der Funktion von Sin1 für die Biomineralisation spielen könnte. 


\subsubsection{Sekundärstrukturanteile in $\mathrm{rSin}^{-\mathrm{SP}}$}

Die Analyse der Sekundärstrukturanteile von rSin1-SP ermöglicht die Einschätzung der korrekten Faltung des Proteins, wobei die native Faltung von Sin1 unbekannt ist. Vergleiche sind daher nur mit r $\operatorname{Sin} 1^{\text {lum }}$ möglich. Eine korrekte Faltung ist unabdingbar, wenn man die natürliche Funktion eines Proteins nachvollziehen möchte.

Die Anteile an Sekundärstrukturelementen in $\mathrm{rSin}^{-\mathrm{SP}}$ wurden mittels Circular Dichroismus-Spektroskopie ermittelt. Dazu wurden gemessene CD-Spektren (beispielhaft in Abb. 4.24) im Onlineprogramm Dichroweb eingelesen und mit dem CDSSTR-Algorithmus und einem Referenzdatenset ausgewertet. Ausgegeben wurden prozentuale Anteile von $\alpha$-Helices, $\beta$-Sheets, $\beta$-Schleifen und Zufallsknäueln. In Tab. 4.2 sind die erhaltenen Werte von sechs $\mathrm{rSin}^{-\mathrm{SP}}{ }_{-}$Proben gezeigt, wobei das Protein entweder in 10 mM MOPS- oder 10 mM Na2HPO4-Puffer (beide pH 7.7) vorlag. Die beiden Puffersubstanzen hatten keinen unterschiedlichen Einfluss auf die Sekundärstrukturanteile.

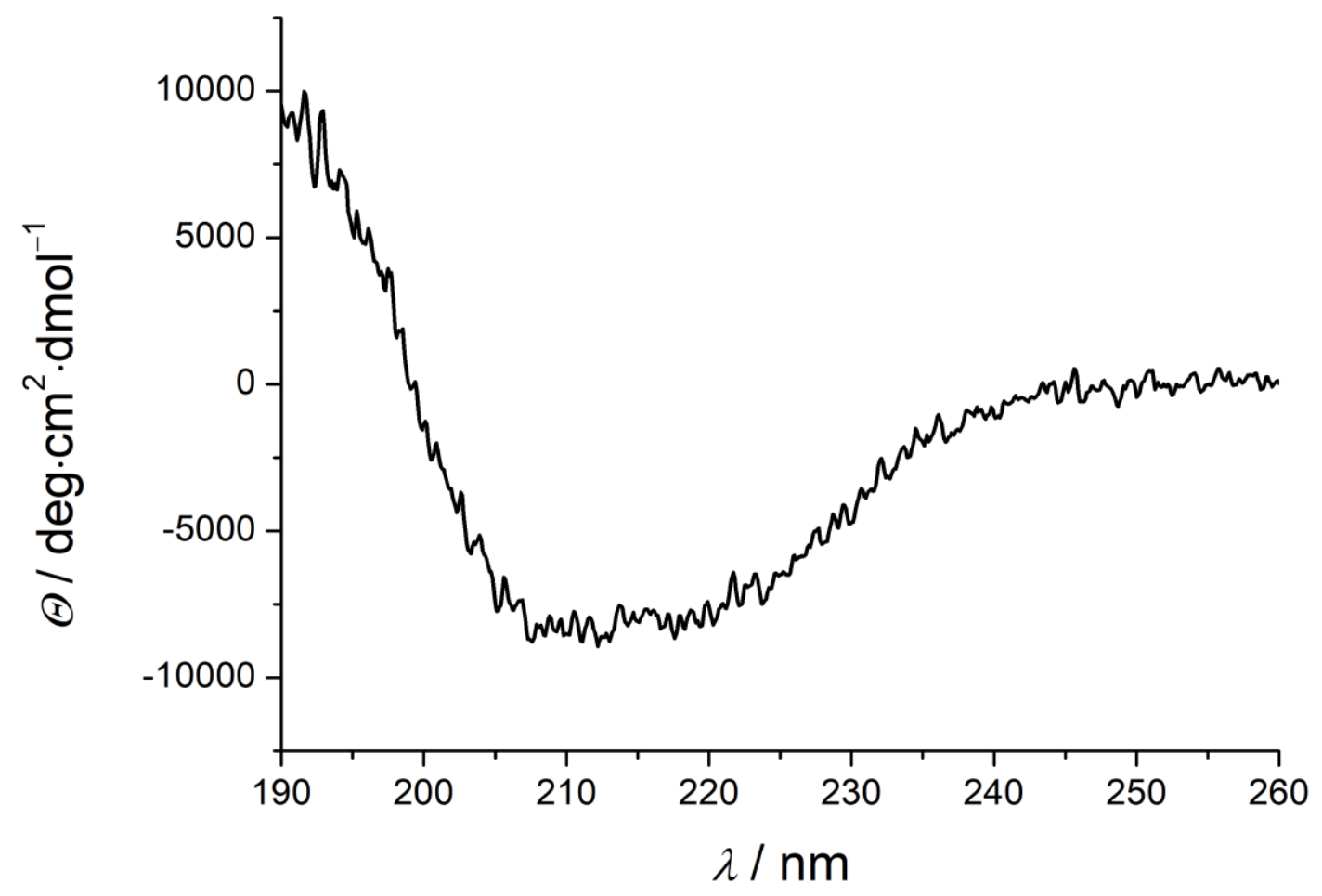

Abbildung 4.24: Beispielhaftes CD-Spektrum einer rSin1-SP-Probe in MOPS-Puffer (10 mM, pH 7.7). 
Tabelle 4.2: Sekundärstrukturelementanteile in rSin1-SP berechnet mit dem CDSSTR-Algorithmus und zwei verschiedenen Referenzsets und aus sechs Proben gemittelt. Als Fehler genannt sind die Standardabweichungen der Mittelwerte.

\begin{tabular}{|l|l|l|l|l|}
\hline Referenzset & $\alpha$-Helix / \% & $\beta$-Faltblatt / \% & $\beta$-Schleifen / \% & Zufallsknäuel / \% \\
\hline $4^{[99,98]}$ & $12 \pm 3$ & $33 \pm 3$ & $23 \pm 1$ & $32 \pm 1$ \\
\hline $7^{[99,98]}$ & $10 \pm 7$ & $30 \pm 4$ & $19 \pm 2$ & $41 \pm 6$ \\
\hline
\end{tabular}

Sowohl Referenzset 4 als auch 7 ergaben für $r \operatorname{Sin} 1^{-S P}$ nach der Dialyse einen $\alpha$ Helixanteil von ca. $10 \%$, einen Anteil an $\beta$-Faltblättern von ca. $30 \%$, einen Anteil von $\beta$-Schleifen von ca. $20 \%$ und 30-40 \% Zufallsknäuel. Eine Lokalisierung dieser Motive in der Aminosäuresequenz ist mit dieser Methode nicht möglich. Da die Proteinproben nach der Dialyse stets ähnliche Strukturanteile ergaben, wurde die Dialyse und die damit verbundene Rückfaltung als reproduzierbar und damit erfolgreich bewertet.

\subsubsection{Bestimmung des Anteils freier Thiole in rSin1-SP}

Sin1 ist ein Protein mit 18 Cysteinresten, die theoretisch vollständig, teilweise oder gar nicht in Disulfidbrücken gebunden vorliegen können. Für diese Verbrückungen existieren eine Vielzahl an Kombinationsmöglichkeiten. Es kann davon ausgegangen werden, dass ein Großteil dieser Kombinationen zu einer Änderung der Proteinfaltung führen würde und somit die Funktion des Proteins ändern könnte. Es wird in der Literatur von kompletter Disulfidverbrückung des rekombinanten rSin1lum nach der Dialyse mit einem Glutathion/Glutathiondisulfid-Redoxpaar berichtet ${ }^{[34]}$, eine Bestimmung der Kombinationen existiert nicht.

Die Detektion des Anteils freier Cysteinreste in $\mathrm{rSin} 1^{\text {-SP }}$ erlaubt die Überprüfung des Disulfidverknüpfens (Reshuffling) während der Dialyse in Gegenwart des Redoxpaars Glutathion/Glutathiondisulfid. Eine massenspektrometrische Analyse von chromatografisch getrennten, nicht-reduzierten rSin1-Fragmenten zur Bestimmung der vorhandenen Kombinationen war aufgrund des unzureichenden Reinheitsgrades des isolierten Proteins jedoch nicht möglich.

Mit Hilfe des Ellman-Assays wurde die Konzentration an freien Thiolen einer rSin1-SP. Probe bestimmt. Damit wurde ermittelt, ob das Reshuffling während der Dialyse vollständig erfolgte. Die Ergebnisse der Messungen der rSin $1^{\text {-SP }}$-Proben bei einer 5,5`- 
Dithiobis-2-nitrobenzoesäure (DTNB)-Konzentration von $111 \mu \mathrm{m}$ sind in Tabelle 4.3 aufgeführt. Aus den gemittelten Absorbanzen und der Kalibrationskurve aus Glutathionmessungen kann eine Sulfhydrylkonzentration $c(\mathrm{SH})$ berechnet werden. Die Anzahl von freien SH-Gruppen pro rSin1-Molekül kann theoretisch maximal 18 betragen, da dies die Anzahl an Cysteinen in diesem Protein ist.

Tabelle 4.3: Resultate der Sulfhydrylquantifizierung in rSin1-SP verschiedener Konzentrationen.

\begin{tabular}{|l|l|l|l|}
\hline $\boldsymbol{c}\left(\mathbf{r S i n} 1^{-S P}\right) / \mu \mathrm{M}$ & $A_{412}$ & $\boldsymbol{c}(\mathrm{SH}) / \boldsymbol{\mu M}$ & $\mathrm{SH}: \mathrm{rSin} 1^{-\mathrm{SP}}$ \\
\hline 250 & $(0.0 \pm 0.6) \cdot 10^{-3}$ & $0.0 \pm 0.4$ & $(0.0 \pm 1.6) \cdot 10^{-3}$ \\
\hline 500 & $(0.3 \pm 4.0) \cdot 10^{-3}$ & $0.2 \pm 2.9$ & $(0.5 \pm 5.7) \cdot 10^{-3}$ \\
\hline 990 & $(-0.3 \pm 0.0) \cdot 10^{-3}$ & $-0.2 \pm 0.0$ & $(-0.2 \pm 0.0) \cdot 10^{-3}$ \\
\hline
\end{tabular}

Es ergibt sich ein gemittelter Wert von freiem Cystein pro rSin $1^{-S P}$-Molekül von $(0.1 \pm 0.4) \cdot 10^{-3}$ und damit nahezu Null. Dies bedeutet, dass kein freies Cystein mehr vorlag, womit alle 18 Cysteinreste in Disulfidbrücken gebunden waren. Das Reshuffling war somit vollständig. Ob diese Disulfidbrücken korrekt (nativ) vorlagen bleibt unklar.

\subsubsection{Aggregatbildung von rSin1 in saurer Lösung}

Die reversible $\mathrm{pH}$-abhängige Selbstaggregation, die für r $\operatorname{Sin} 1$ lum berichtet wird, könnte eine wichtige, wenn auch noch unklare Rolle in der Biomineralisation von Kieselalgen spielen. ${ }^{[34]}$ Daher diente der Test auf Selbstaggregation von rSin1-SP bei pH 5.0 der Überprüfung, ob sich dieses von der $\mathrm{N}$-terminalen (luminalen) Domäne dominierte Protein ähnlich verhält, wie rSin1lum.

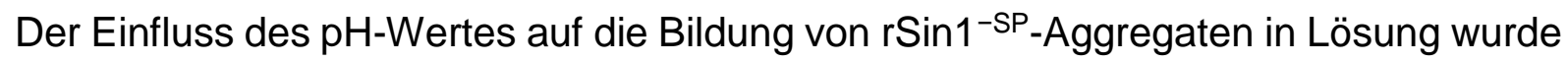
mittels dynamischer Lichtstreuung (DLS) untersucht. Es wurden zwei rSin1-Proben vermessen, die in Phosphat-Citrat-Puffer der Zusammensetzung nach Tab. 3.15 mit den $\mathrm{pH}$-Werten 7.7 bzw. 5.0 vorlagen.

In Abb. 4.25 sind die über alle Messungen gemittelten Intensitäts- und Massenverteilungen der in der DLS detektierten Partikelgrößen für die beiden Pufferbedingungen gezeigt. Es ist deutlich erkennbar, dass in beiden Proben je drei Größenpeaks vorliegen. Für pH 7.7 liegen die Maxima dieser Peaks in der 
Intensitätsverteilung bei Durchmessern von $20 \pm 3, \quad 65 \pm 9$ und $333 \pm 21 \mathrm{~nm}$ (Standardabweichung des Mittelwerts als Fehler, $n=5$ ). Für pH 5.0 wurden die drei Peakmaxima bei $55 \pm 6,149 \pm 40$ und $900 \pm 156 \mathrm{~nm}$ Durchmesser gefunden $(n=6)$. Somit erfolgte durch die Ansäuerung eine deutliche Verschiebung hin zu größeren Durchmessern der detektierten Partikel.

Die Auswertung der Integrale der Größenpeaks in der Massenverteilung erlaubt die Abschätzung der realen Massenanteile dieser Partikel an der Gesamtmasse. Für pH

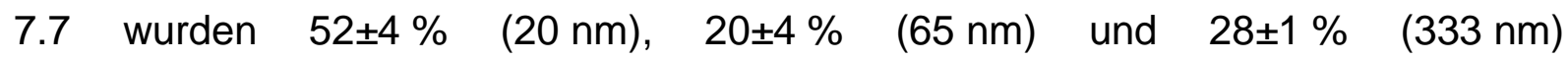
massengewichtete Anteile gefunden. Die kleinsten detektierten Partikel machten also mehr als die Hälfte der Partikelgesamtmasse aus. Im angesäuerten Puffer mit dem $\mathrm{pH}$-Wert 5.0 betrug die Verteilung dagegen $<1 \%(55 \mathrm{~nm}), 3 \pm 1 \%(149 \mathrm{~nm})$ und $97 \pm 1 \%(900 \mathrm{~nm})$. Es lagen somit fast nur die größten detektierten Partikel vor.
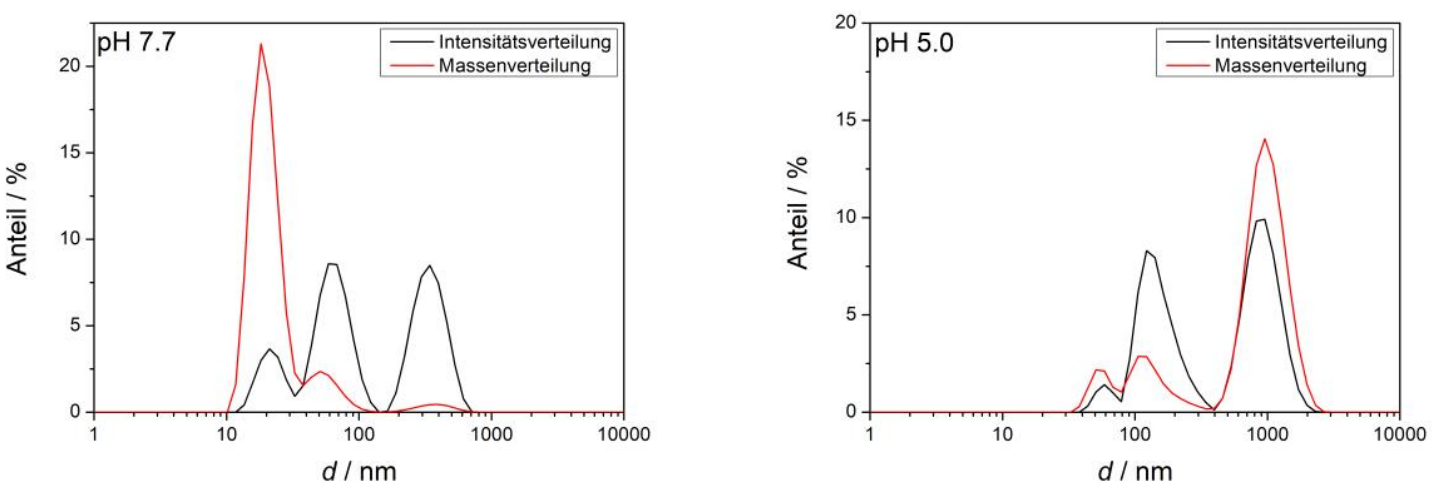

Abbildung 4.25: Gemittelte Intensitäts- (schwarz) und Massenverteilung (rot) der in der DLS-Messung detektierten Partikelgrößen. Verglichen werden die Größenverteilungen von rSin1-SP in Phosphat-CitratPuffer bei pH 7.7 (links; $n=5$ ) und pH 5.0 (rechts; $n=6$ ). Für die Integralauswertung sei auf die logarithmische Darstellung der Durchmesser hingewiesen.

Es bleibt festzuhalten, dass $r \operatorname{Sin} 1^{-\mathrm{SP}}$ deutliche Unterschiede im Aggregationsverhalten zeigt, wenn es von einem neutralen ( $\mathrm{pH} 7.7$ ) in einen sauren ( $\mathrm{pH}$ 5.0) Puffer überführt wird. Im neutralen Bereich liegen zum Großteil entweder Monomere oder kleine Oligomere $(<100 \mathrm{~nm})$ vor, während im sauren Milieu fast ausschließlich sehr große Aggregate mit einem Durchmesser von ca. $1 \mu \mathrm{m}$ gebildet werden. 


\subsection{Charakterisierung von Vesikeln mit rekonstituiertem rSin1}

Vor der Präparation einer planaren SDV-Modellmembran erfolgte zunächst die Herstellung von rSin1-haltigen kleinen unilamellaren Vesikeln. Als Lipide dienten die Phospholipide DOPC, POPC, POPG und POPE, wobei insbesondere die POPC/POPE-Kompositionen den erhöhten Foldchange von PC und PE für Tp-div (siehe Kapitel 4.1.5 und 5.1.4) berücksichtigten.

Die Charakterisierung der Proteoliposomen gab Aufschluss über die Größe der Vesikel und den Erfolg der Rekonstitution des $\mathrm{rSin}^{-\mathrm{SP}}$ in die Lipiddoppelschicht der Liposomen. Zudem wurde die Orientierung des insertierten Proteins analysiert, um eine korrekte Position in der finalen planaren Modellmembran gewährleisten zu können. Die Fähigkeit der Silicafällung wurde für proteinfreie Vesikel und Proteoliposomen bestimmt, sodass zum einen der Einfluss einer Lipidgrenzfläche, zum anderen aber auch des rekonstituierten rSin1, auf die Fällung ermittelt werden konnte.

\subsubsection{Realer Lipidanteil der Proteoliposomen nach Comizellisierung}

Proteoliposomen wurden mittels Comizellisierung hergestellt, wobei eine definierte Menge an Protein sowie Lipiden eingesetzt wurde. Um herauszufinden, welcher Anteil an Lipiden nach der Größenausschlusschromatographie in der eluierten Probe noch enthalten war, wurde ein Phosphattest (siehe Kapitel 3.4.4) mit Proteoliposomen und Vesikeln ohne Protein durchgeführt (POPC/POPE, 85:15), wobei beide Proben nach demselben Comizellisierungsprotokoll (siehe Kapitel 3.4.3) präpariert wurden.

Der auf Absorptionsphotometrie bei $820 \mathrm{~nm}$ basierende Phosphattest zur Lipidquantifizierung zeigte, dass von $663 \mathrm{nmol}$ eingesetzten Phospholipiden $279 \mathrm{nmol}$ in dem Eluat der Proteoliposomen enthalten waren. Dies entspricht $42 \% .58 \%$ des Lipidmaterials gingen somit im Zuge der Proteoliposomenpräparation verloren. Die Vesikel ohne Protein wiesen dagegen $514 \mathrm{nmol}$ und somit $77 \%$ Phospholipide auf. Die Experimente zeigen, dass die Comizellisierung einen Verlust an Lipidmaterial im zweistelligen Prozentbereich mit sich bringt. 


\subsubsection{Größenbestimmung der mittels Comizellisierung präparierten Vesikel}

Die Bestätigung der Bildung von Vesikeln nach der Comizellisierung kann über die Partikelgrößenbestimmung erfolgen. Durchmesser von kleinen unilamellaren Vesikeln liegen im zweistelligen Nanometerbereich (i.d.R. mindestens $20 \mathrm{~nm}$ ) und sind typischerweise deutlich größer als etwa die von Mizellen.

Die Größenverteilung von proteinfreien Vesikeln, die durch Comizellisierung hergestellt wurden, wurde mittels DLS-Messungen bei $\mathrm{pH} 7.7$ und $25^{\circ} \mathrm{C}$ ermittelt. Dabei wurden Vesikel der Lipidkompositionen DOPC/POPG/TxR-DPPE=79.5:20:0.5 sowie POPC/POPE/TxR-DPPE=69.5:30:0.5 verglichen. Die Intensitätsverteilungen der Partikelgrößen der beiden Proben sind in Abb. 4.26 dargestellt. Die PC/PG-Vesikel zeigten einen mittleren Durchmesser von $79 \pm 3 \mathrm{~nm}$ (Standardabweichung des Mittelwerts als Fehler, $n=3)$, die PC/PE-Vesikel 125 \pm 7 nm ( $n=3)$. Die Größe von 79 bzw. $125 \mathrm{~nm}$ zeigt, dass die gebildeten Vesikel formal an der Grenze von kleinen zu großen unilamellaren Vesikeln liegen, die typischerweise mit $100 \mathrm{~nm}$ angegeben wird. Der Einfachheit halber werden die in dieser Arbeit präparierten Vesikel stets als kleine unilamellare Vesikel bezeichnet.

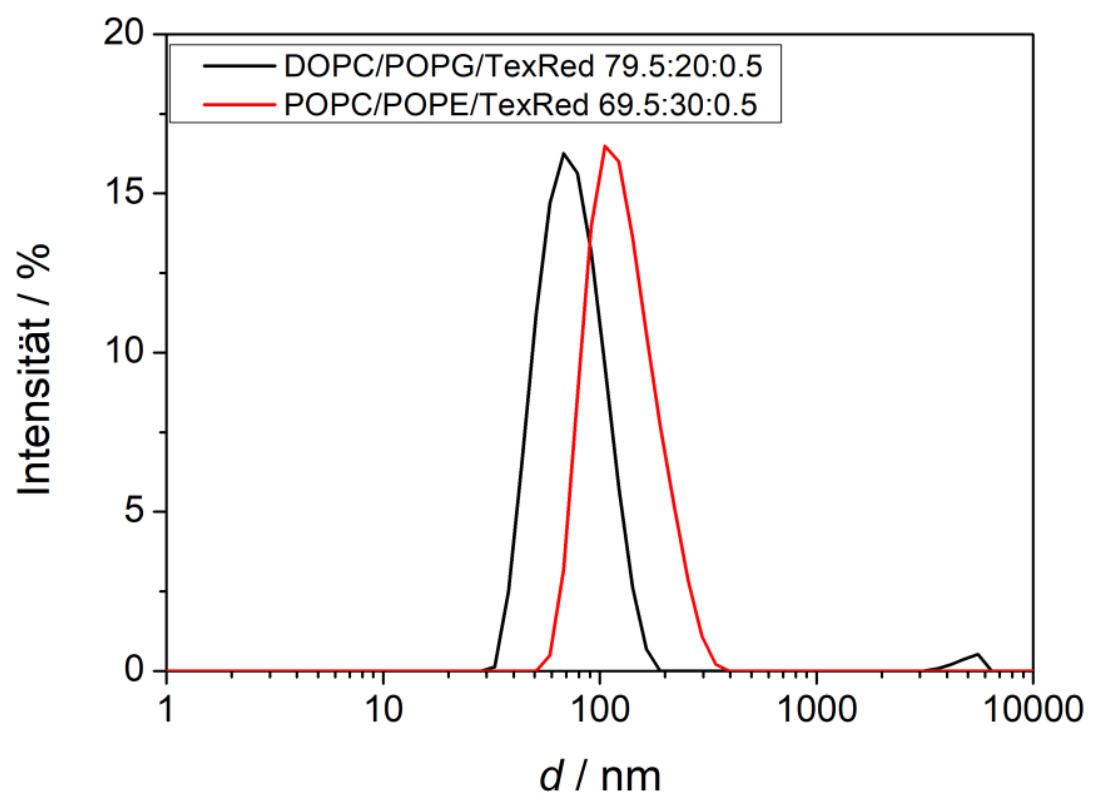

Abbildung 4.26: DLS-Intensitätsverteilung der Partikelgrößen von Vesikelproben der Zusammensetzung DOPC/POPG/TxR-DPPE=79.5:20:0.5 (schwarz) und POPC/POPE/TxRDPPE $=69.5: 30: 0.5$ (rot), die mittels Comizellisierung präpariert wurden. Der Peak bei $5 \mu \mathrm{m}$ ist einem Staubpartikel zuzuordnen. 


\subsubsection{Bestimmung des integral in Proteoliposomen gebundenen rSin1-Anteils}

-Dieses Experiment war Teil der Bachelorarbeit von Alina Schellhase.[103].

Die Einordnung von Sin1 als Transmembranprotein erfolgte nicht nur augfrund von bioinformatischen Vorhersagen, sondern auch aus Carbonatextraktionen von nativem Sin1, das in zellulären Membranen eingebaut war. ${ }^{[34]} \mathrm{Ob}$ nach Expression, Isolierung und Rückfaltung von rSin1-SP seine Transmembrandomäne weiterhin funktionsfähig war, wurder in dieser Arbeit daher mittels Carbonatextraktion untersucht.

Durch Carbonatextraktion sollte nicht-integral gebundenes Protein extrahiert und das Verhältnis aus integralem und nicht-integralem Protein bestimmt werden, um zu überprüfen, ob die Rekonstitution von rSin $1^{-S P}$ durch Comizellisierung erfolgreich war. Die Bestimmung der tatsächlichen Rekonstitutionseffizienz erfolgte mittels HistodenzCoflotationsassays (siehe Kapitel 4.3.4).

Da die Proben des Pellets sowie der Fällungsrückstände des Überstands auf die gleichen Volumina gebracht wurden (je ca. $100 \mu \mathrm{L}$ ), gibt das

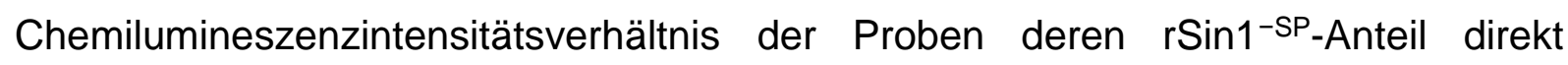
wieder. Abb. 4.27 zeigt die Proben der Pellets sowie des gefällten Proteins aus dem Überstand nach der Ultrazentrifugation. Die Spuren weisen mehrere Proteinbanden auf; neben der Hauptbande von $\mathrm{rSin} 1^{-\mathrm{SP}}$ bei $58 \mathrm{kDa}$ treten weitere Banden bei 18, 80 und $140 \mathrm{kDa}$ auf. Diese Verunreinigungen der Proteinprobe ließen sich mit dem bisherigen Aufreinigungsprotokoll nicht entfernen und sind bekannt. ${ }^{[16]}$ 


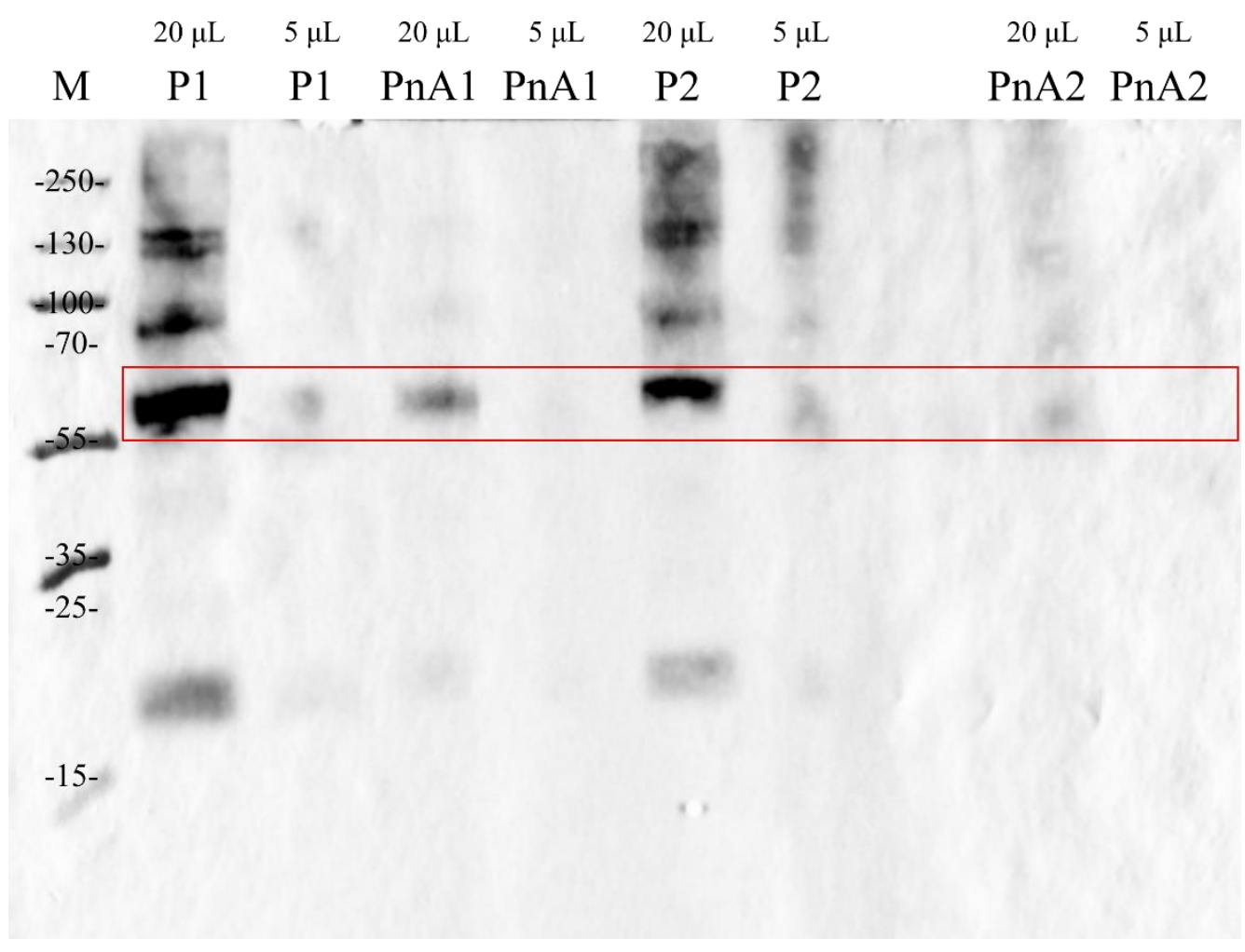

Abbildung 4.27: Chemilumineszenzbild des Anti-His-Western Blots der Carbonatextraktionsproben. Die Markerspur (M) ist keine Chemilumineszenzaufnahme, sondern eine Fotografie, die mit dem Chemilumineszenzbild überlagert wurde. Die Zahlenwerte der Markerbanden entsprechen Proteinmassen in kDa. Die rSin1-Banden sind rot umrandet. Proben 1 wurden hitzedenaturiert, Proben 2 nicht. P1: Pellet der Probe 1 nach Ultrazentrifugation. PnA1: Pellet der Probe 1 nach Acetonfällung des Überstands. P2 und PnA2 sind analog dazu. P/L (nominell) $=1: 1750$. Lipidkomposition: DOPC/POPG/TxR-DPPE $=$ 79.5:20:0.5.

Abb. 4.28 zeigt die Proteinanteile in den Waschfraktionen des acetongefällten Pellets. Ihr Anteil ist beinahe vernachlässigbar gering, sodass schon am Verhältnis von P1 bzw. P2 zu PnA1 bzw. PnA2 zu sehen ist, dass der Großteil des rSin1-SP integral gebunden gewesen sein muss. Die Intensitätsauswertung der $r \operatorname{Sin}_{1}{ }^{-\mathrm{SP}}{ }_{-} \mathrm{H}_{\text {Hauptbande }}$ bei $58 \mathrm{kDa}$ ergibt einen nicht extrahierten Anteil von $72 \%$. Dies bestätigt rSin $1^{\text {-SP }}$ als integrales Membranprotein und die Rekonstitution von $\mathrm{rSin} 1^{-\mathrm{SP}}$ in Liposomen der Zusammensetzung DOPC/POPG/TxR-DPPE $=79.5: 20: 0.5$ bei einem nominellen Protein-zu-Lipidverhältnis von 1:1750 mittels Comizellisierung als erfolgreich. 


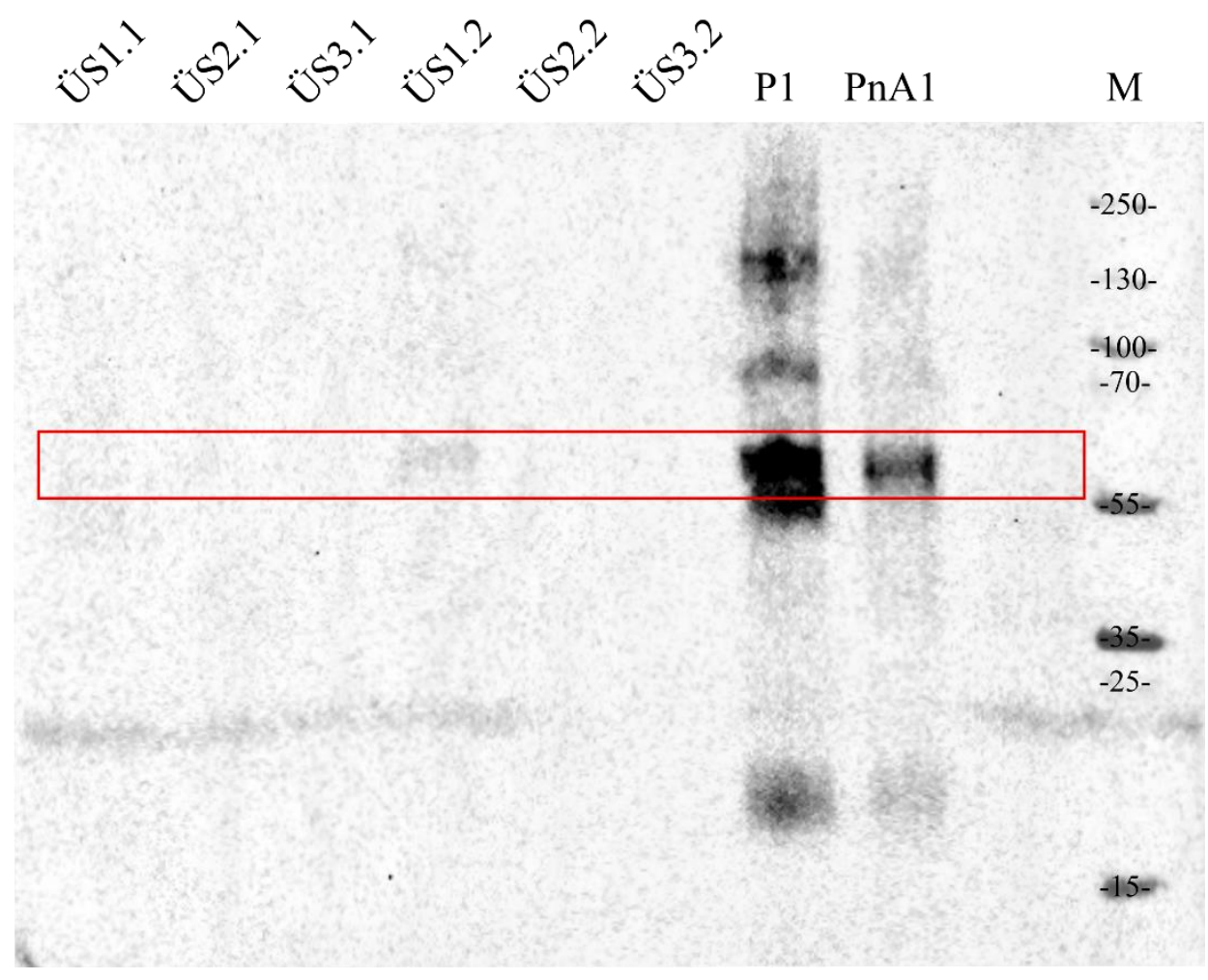

Abbildung 4.28: Chemilumineszenzbild des Anti-His-Western Blots der Carbonatextraktionsproben. Die Markerspur (M) ist keine Chemilumineszenzaufnahme, sondern eine Fotografie, die mit dem Chemilumineszenzbild überlagert wurde. Die Zahlenwerte der Markerbanden entsprechen Proteinmassen in kDa. Die rSin1-Banden sind rot umrandet. Proben 1 wurden hitzedenaturiert, Proben 2 nicht. P1: Pellet der Probe 1 nach Ultrazentrifugation. PnA1: Pellet der Probe 1 nach Acetonfällung des Überstands. ÜS1.1: Waschfraktion 1 der Probe 1, ÜS2.1: Waschfraktion 2 der Probe 1. P/L $($ nominell $)=1: 1750$. Lipidkomposition: DOPC/POPG/TxR-DPPE $=$ 79.5:20:0.5.

\subsubsection{Rekonstitutionseffizienz von $r \operatorname{Sin} 1^{-S P}$ in kleine unilammelare Vesikel}

Die Rekonstitution von rSin $1^{-S P}$ in kleine unilamellare Vesikel erfolgte mittels Comizellisierung. Um zu bestimmen, welcher Anteil des Proteins tatsächlich in die Liposomen rekonstituiert wurde und welcher Anteil am Ende als freies Protein vorlag, wurden Histodenz-Coflotations-Assays durchgeführt. Dabei wurden Proteoliposomen und freies Protein durch Ultradichtezentrifugation räumlich voneinander getrennt und die Proben fraktioniert, um sie mittels Anti-His5-Western Blottings zu analysieren.

Die ersten drei Fraktionen wurden als Proteoliposomenfraktionen definiert, die restlichen vier beinhalteten freies Protein. Es wurden die ersten drei Fraktionen gewählt, da in einigen Fällen noch in der dritten Fraktion mit bloßem Auge eine schwache Pinkfärbung zu erkennen war, falls TexasRed-DPPE als Fluorophor in den 
Proben enthalten war. Ansonsten war diese Färbung in den ersten beiden Fraktionen sichtbar. Ein exemplarischer Anti-His5-Western Blot der sieben Fraktionen ist in Abb. 4.29 gezeigt. Alle sieben Fraktionen zeigen rSin1-Banden bei ca. 60 kDa.

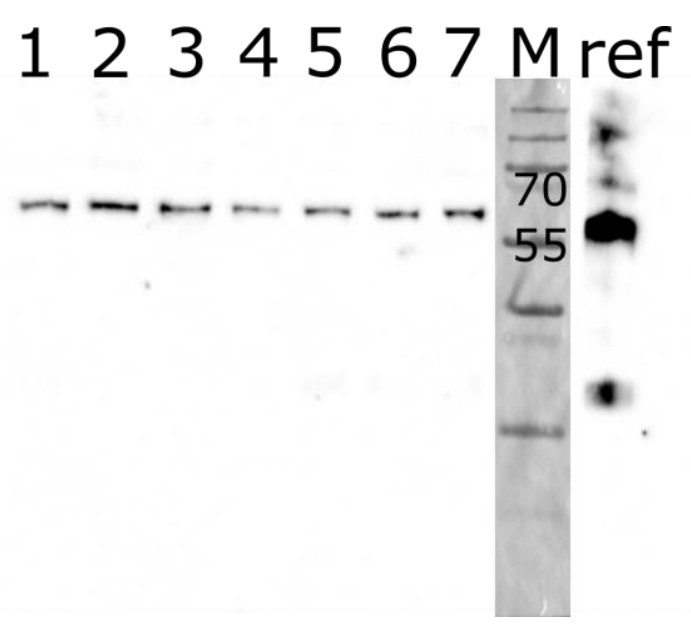

Abbildung 4.29: Exemplarischer Anti-His5-Western Blot der Fraktionen des Histodenz-CoflotationsAssays. 1-7 gibt die $20 \mu \mathrm{L}$-Fraktionen von oben nach unten an, ref ist die rSin1-Referenzprobe. $\mathrm{M}=$ Marker mit Molmassenangaben $(\mathrm{kDa})$ der Markerbanden. Die verwendete Lipidkomposition war POPC/POPE (85:15), das nominelle Verhältnis Protein/Lipid 1:630.

Der Intensitätsvergleich dieser Banden (Abb. 4.30) erlaubt die Berechnung des Anteils von in Vesikeln rekonstituiertem rSin1 (Fraktionen 1 bis 3) an der Gesamtprobe (Fraktionen 1 bis 7). Fraktionen 1 bis 3 umfassen $53 \%$ des gesamtdetektierten rSin 1 , Fraktionen 4 bis $747 \%$. Somit beträgt die Rekonstitutionseffizienz für dieses ausgewählte Beispiel 53 \%. Die Hälfte des rSin1 wurde in die Liposomen eingebaut, die andere Hälfte lag weiterhin als freies Protein vor. 


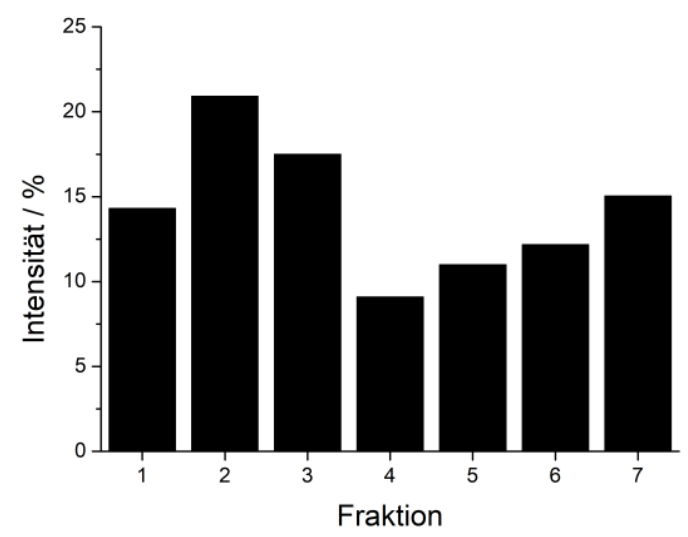

Abbildung 4.30: Darstellung der rSin1-Bandenintensitäten der sieben Fraktionen aus Abb. 4.29 als prozentualer Anteil an der Gesamtprobenintensität. Fraktionen 1-3 umfassen 53 \% des Gesamtproteins der Probe. Die Rekonstitutionseffizienz beträgt somit 53 \% für das gewählte Beispiel.

Der Vergleich der Fraktionsbanden mit der $60 \mathrm{kDa}$-Bande der definierten rSin1Referenzprobe in Abb. 4.29 lässt eine absolute Abschätzung der detektierten Proteinmengen in den Fraktionen zu. Die Referenzprobe entspricht 5.8 pmol rSin1. Die daraus berechnete Gesamtproteinmenge aller sieben Fraktionen wäre dann 7.2 pmol. Theoretisch wurden jedoch 84 pmol rSin1 für die Comizellisierung eingesetzt. Dies entspricht einer rSin1-Ausbeute von nur $8.5 \%$. Mehr als $90 \%$ des Proteins gingen somit im Zuge der Comizellisierung verloren. Betrachtet man die gemittelten Werte aus zwei Histodenz-Coflations-Assays erhält man eine GesamtrSin1-Ausbeute von $11.7 \pm 4.5 \%$ sowie eine Rekonstitutionseffizienz von $46.3 \pm 9.0 \%$. Daraus wiederum folgt, dass $5.2 \pm 1.0 \%$ des eingesetzten $r \operatorname{Sin} 1$ am Ende rekonstituiert in den Vesikeln vorlagen. Diese Ergebnisse können mit den Resultaten des Phosphattests der selben Proben (siehe Kapitel 4.3.1) kombiniert werden. Es wurden $42.1 \pm 0.1 \%$ der ursprünglich eingesetzten Lipidmenge nachgewiesen. Bei einem nominellen Einsatz von Protein/Lipid $(P / L)=1: 630$ ergibt sich zusammengefasst ein reales $P / L$ von 1:5100 in Proteoliposomen.

Im Zuge dieser Arbeit und der in diesem Rahmen angeleiteten Bachelorarbeiten von Marco Niebuhrr ${ }^{115]}$ und Lucia Winkler ${ }^{[116]}$ wurden Rekonstitutionseffizienzen für

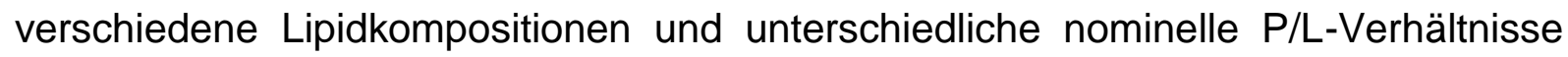
bestimmt (Abb. 4.31). Das PC/PG/TxR-Gemisch nutzte DOPC als PC-Spezies, alle anderen PC-, PG- und PE-Bestandteile waren PO-Phospholipide. Für DOPC/POPG/TxR-DPPE=79.5:20:0.5 ist eine nahezu lineare Steigung der 
Rekonstitutionseffizienz von $50 \%$ auf $80 \%$ im P/L-Bereich von 1:500 bis 1:2000 zu beobachten. Ebenso ist ein P/L-Verhältnis von 1:2000 mit $45 \%$ höher im Vergleich zu $35 \%$ bei $P / L=1: 250$ für die Lipidmischung POPC/POPE/TxR-DPPE=69.5:30:0.5. Die Rekonstitutionseffizienz kann jedoch bei ähnlichen P/L-Verhältnissen (1:500 und 1:630) und Lipidkompositionen (POPC/POPE/Bodipy-PPC=84.5:15:0.5 und $\mathrm{POPC} / \mathrm{POPE}=85: 15)$ auch große Unterschiede (25-55\%) aufweisen und zeigt so, dass diese experimentell bestimmte Effizienz in hohem Maße von der Handhabung des Experimentators abhängt, als auch eine große Varianz in sich hat. Ohne Lipid fand sich etwa $3 \%$ des Proteins in den formalen Proteoliposomenfraktionen.

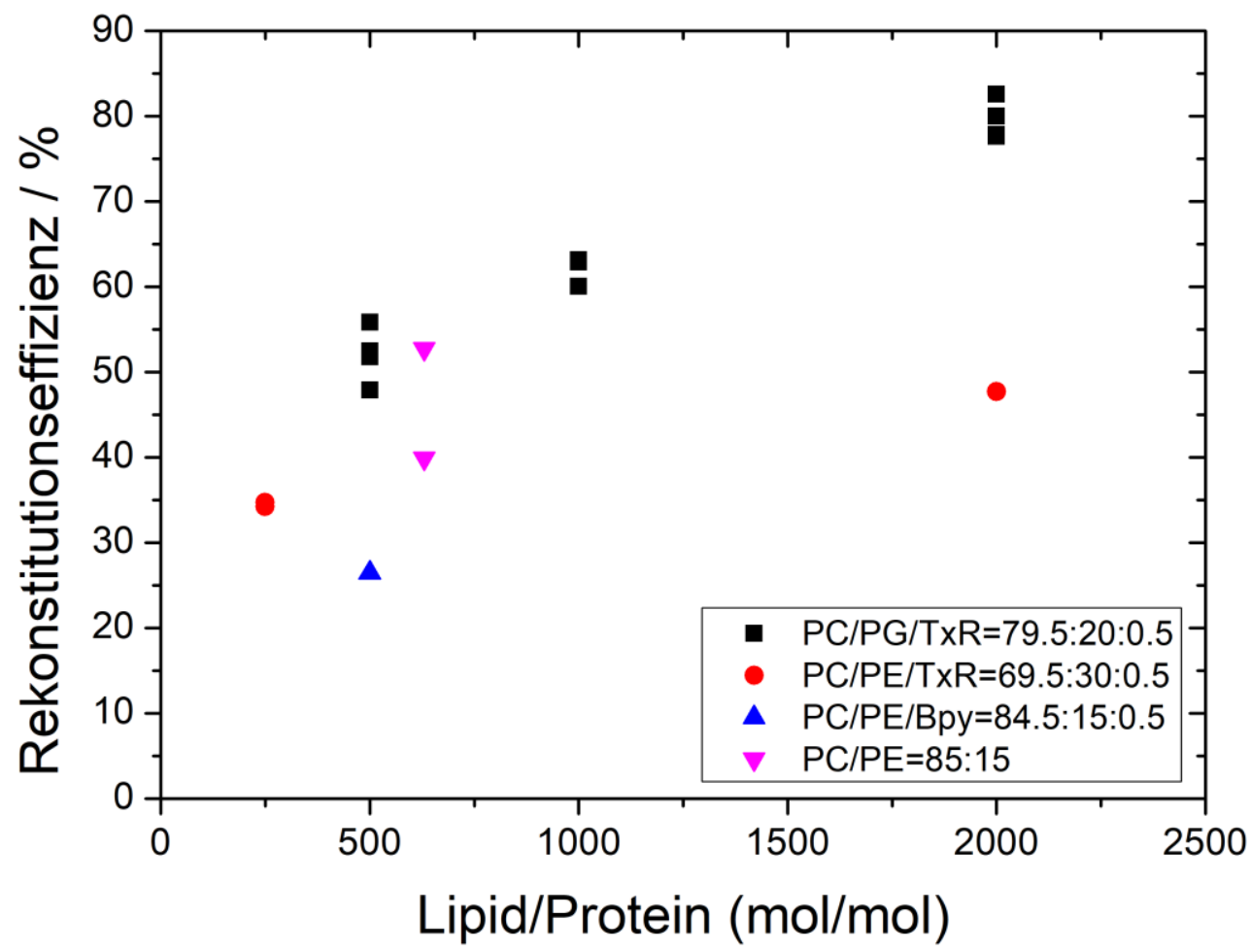

Abbildung 4.31: Übersicht über die Rekonstitutionseffizienzen von $r \operatorname{Sin} 1$ bei verschiedenen Lipidkompositionen und nominellen Lipid-zu-Protein-Verhältnissen.

\subsection{5 rSin1-Orientierung in Vesikeln}

Die Orientierung des in Vesikeln rekontituierten rSin1 spielt eine entscheidende Rolle bei der finalen Ausrichtung der $\mathrm{N}$-terminalen Domäne in der planaren Modellmembran. Diese planare SDV-Modellmembran soll die Lipid-Lumen-Grenzfläche nachbilden und 
daher die $N$-terminale Domäne des rSin1 in Richtung Medium zeigend beinhalten. Nur so ist die planare SDV-Modellmembran für Analysen der Wechselwirkung dieser Domäne mit anderen Biomolekülen geeignet. Da die planare Membran aus dem Spreiten von Proteoliposomen generiert werden soll, ist die rSin1-Orientierung in den Vesikeln bereits fundamental.

Zur Bestimmung der Orientierung des Proteins rSin1 in Proteoliposomen, die mittels Comizellisierung präpariert wurden, wurde ein Verdauexperiment mit a-Chymotrypsin durchgeführt. Dabei waren Proteindomänen innerhalb des Vesikellumens vor dem Verdau geschützt, während Domänen außerhalb der Vesikel von dem Enzym abgebaut wurden (Abb. 4.32).
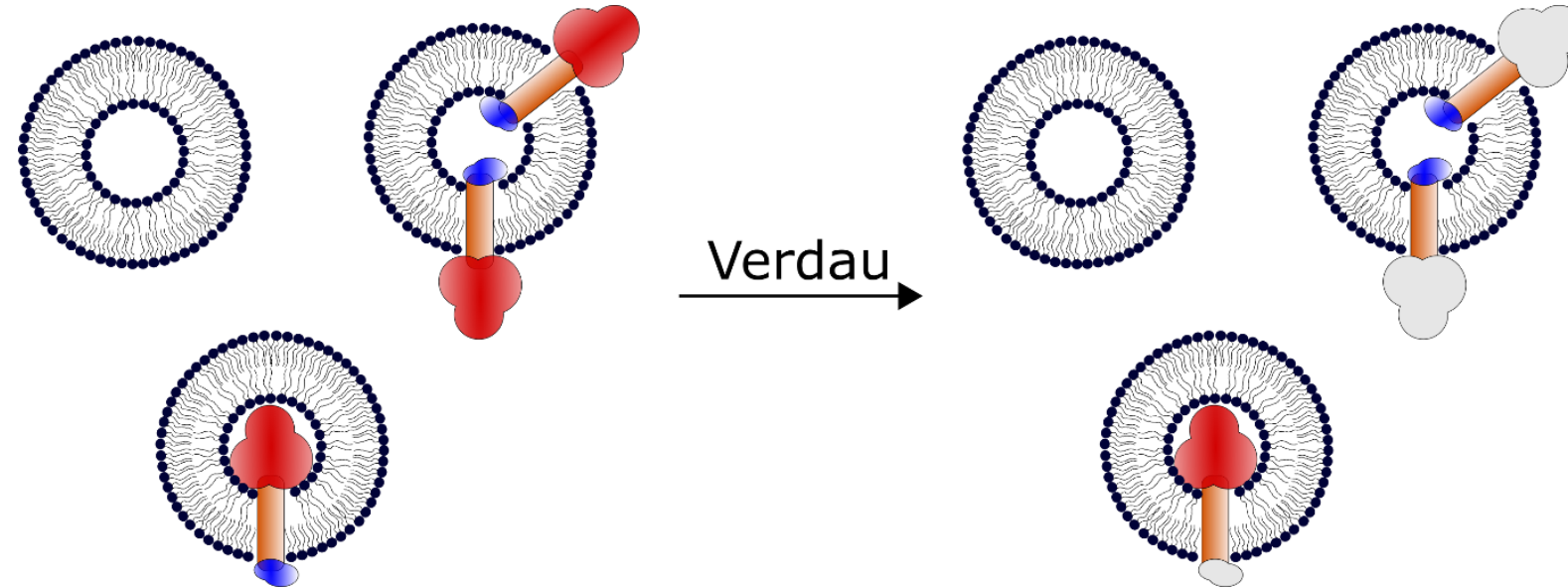

Abbildung 4.32: Schematische Versuchsübersicht des Chymotrypsinverdaus von in Vesikeln rekonstituiertem rSin1. Die ausgegrauten Bereiche werden verdaut, die anderen bleiben durch die Vesikelmembran geschützt.

Abb. 4.33 zeigt das Chemilumineszenzbild der Nitrocellulosemembran eines AntiSin1-Western Blots. Gezeigt sind Proteoliposom- (PL) und Freie-Protein-Proben ohne Lipide (Sin1). Beide sind dabei unterschieden in Verdauproben (Dig.) und Kontrollproben (Ctr.). Für die Massenabschätzung der Proteinbanden wurde ein Markergemisch (PAGE Ruler Plus Prestained Protein Ladder von Thermo Fisher, 10 bis $250 \mathrm{kDa}$ ) verwendet. Die in Abb. 4.33 dargestellte Marker-Spur zeigt keine Chemilumineszenzbanden, sondern farbige Banden einer Fotografie, die im Gelimager aufgenommen wurde und mit dem Chemilumineszenzbild überlagert wurde. 


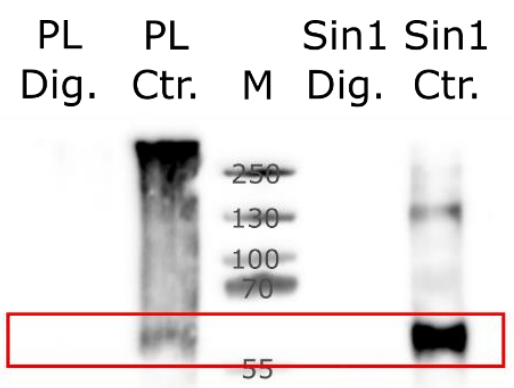

Abbildung 4.33: Chemilumineszenzbild des Anti-Sin1-Western Blots der Proteoliposom- (PL) und Freies-Protein-Proben (Sin1). Neben den Verdauproben (Dig.) sind Kontrollproben (Ctr.) dargestellt. Die rSin1-Banden sind rot umrandet. $M=$ Marker, Markerbanden in kDa.

Die Sin1-Kontrollprobe zeigt die rSin1-Bande bei ca. $58 \mathrm{kDa}$, sowie eine sehr schwache Bande bei etwa $75 \mathrm{kDa}$ und eine weitere Bande bei etwa $130 \mathrm{kDa}$. Bei den beiden letzten handelt es sich wahrscheinlich um rSin1-Aggregate mit dem in SDSPAGE sichtbaren 18 kDa-Fragment.

Die Proteoliposom-Kontrollprobe dagegen zeigt einen sehr verschmierten chemilumineszenten Bereich vom oberen Gelrand bis zur $58 \mathrm{kDa}-B a n d e$. Der intensivste Bereich liegt dabei am oberen Gelrand, was darauf hindeutet, dass die dort detektierten Teilchen erschwert in das Trenngel gelangten, da sie sehr groß waren. Erklärbar wäre dies durch Protein-Lipidaggregate, die als Rest aus den bei der Denaturierung zerstörten Vesikeln übrigblieben. Nichtsdestotrotz zeigt die Bande bei $58 \mathrm{kDa}$, dass rSin1 als Einzelmolekül detektierbar war.

Die Verdauprobe des freien Proteins zeigt lediglich eine Bande im niederen Massenbereich, schätzungsweise $<15 \mathrm{kDa}$. Dieses Fragment, ist das einzige, an das Anti-Sin1-Antikörper des Antiserums gebunden haben. Demnach befindet sich das oder eines der Epitope dieser Antikörper auf diesem Fragment. Dies zeigt, dass der Verdau des Proteins unter den gewählten Bedingungen vollständig funktionierte. Da die Epitope nicht charakterisiert sind, kann nicht vorhergesagt werden, welche Fragmente durch den Anti-Sin1-Western Blot detektierbar sein müssten. Mit der 
Online-Software Expasy Peptide Cutter ${ }^{[117,83]}$ können auftretende Fragmente des Proteins bei einem Verdau durch ein gewähltes Enzym vorhergesagt werden. Dabei kann für das Enzym Chymotrypsin eine Mindestwahrscheinlichkeit der geschätzten Spaltungswahrscheinlichkeiten in der Aminosäuresequenz als Cutoff-Parameter angegeben werden. Für $>50 \%$ Spaltungswahrscheinlichkeit ergeben sich 50 Fragmente, das größte unter innen mit 4.4 kDa (AS 118-157 (40 AS) der 409 AS in der rSin1-SP-Sequenz; siehe Anhang 8.12). Für $>90 \%$ ergeben sich elf Fragmente, das größte mit 9.2 kDa (AS 110-189 (80 AS) der 409 AS in der rSin1-SP-Sequenz; siehe Anhang 8.12). Es bleibt also festzuhalten, dass bei einem vollständigen Chymotrypsinverdau kein rSin1-Fragment größer als $10 \mathrm{kDa}$ wäre. Es ist anzumerken, dass die letztgenannte Bande $<15 \mathrm{kDa}$ eine wesentlich schwächere Chemilumineszenz aufweist als die 58 kDa-Hauptbande der Kontrollprobe.

Die Verdauprobe der Proteoliposomen zeigt dagegen keine einzige Bande. Wäre die $N$-terminale Domäne des Proteins im Lumen der Vesikel vor dem Verdau geschützt gewesen, würde man erwarten eine Bande im Bereich von 40 bis $50 \mathrm{kDa}$ zu detektieren, da nur die kurze $C$-terminale Domäne fragmentiert worden wäre. Im Vergleich dazu würde im Fall einer vollständig außen liegenden $\mathrm{N}$-terminalen Domäne eine solche Bande nicht auftreten, sondern nur Fragmente, die das Epitop der Antikörper tragen. Zu erwarten wäre also auch eine Bande parallel zu der Bande $<15$ kDa der Sin1-Verdauprobe. Dass jedoch keine Bande zu sehen ist, könnte durch die abgeschwächte Intensität der Banden der Proteoliposomenproben im Vergleich zu den Proben des freien Proteins zu erklären sein, insbesondere da die $<15 \mathrm{kDa}$-Bande ebenfalls eine Intensitätsabschwächung gegenüber der Hauptbande in der Kontrollbande zeigte.

Insgesamt zeigt dieses Experiment indirekt, dass rSin1 überwiegend so orientiert sein muss, dass seine $N$-terminale Domäne außerhalb der Vesikel liegt, da in der Proteoliposomenprobe keine Bande mit nur geringfügigem Massenverlust gegenüber der rSin1-Hauptbande detektierbar war. Auch waren Protein-Lipid-Aggregate in dieser Probe nicht erkennbar, was auf den Verdau des Großteils des Proteins und damit der $N$-terminalen Domäne hindeutet. Damit eignen sich auch rSin1-haltige Proteoliposomen für Analysen über die Wechselwirkung der $N$-terminalen Domäne mit Biomolekülen oder z.B. ihrer Silicafällungseigenschaft (siehe Kapitel 4.3.6). 


\subsubsection{Silicafällung von rSin1-haltigen Proteoliposomen}

Sin1 ist ein SDV-assoziiertes Transmembranprotein, dessen Rolle bei der Biomineralisation zwar noch unklar ist, aber dessen Relevanz für diesen Prozess vermutlich gegeben ist, da es ein über viele Kieselalgen konserviertes Protein ist. ${ }^{[34]}$ Für rSin1 1um wurden Silicafällungseigenschaften nachgewiesen, vermutlich aufgrund seiner relativ stark ungeordneten und geladenen Domäne. ${ }^{[34]} \mathrm{Da}$ in Vesikeln rekonstituiertes $r \operatorname{Sin}^{-\mathrm{SP}}$ mit seiner $N$-terminalen Domäne nach außen zeigt, sind diese Proteoliposomen geeignet die Silicafällungseigenschaften der Domäne im Kontext einer Lipiddoppelschicht zu untersuchen.

Die Fähigkeit zur Silicafällung von Proteoliposomen mit rekonstituiertem rSin1 im Vergleich zu reinen Vesikeln sollte mittels Silicafällungstest untersucht werden. Die dabei gefällten und gewaschenen Silicapellets wurden zu Kieselsäure hydrolisiert und absorptionsphotometrisch bei $370 \mathrm{~nm}$ im Zuge des $\beta$-Silicomolybdattests auf ihren Siliciumanteil analysiert.

Silicafällungen wurden nicht nur für rSin1-haltige Proteoliposomen $(P / L=1: 630$, nominell) und Vesikel ohne Protein durchgeführt, sondern auch für Proben, die jeweils $0.1 \mathrm{~mm}$ langkettige Polyamine (LCPA) enthielten. Die Konzentrationen an gefälltem Silicium und damit Silica der verschiedenen Proben sind in Abb. 4.34 gezeigt. Der Fällungspuffer ( $\mathrm{pH}$ 6.65) zeigte mit $0.1 \mathrm{~mm}$ Si eine Fällungsaktivität nahe Null. Vesikel der Lipidkomposition POPC/POPE=85:15 ohne Protein („Blindvesikel“) mit einer nominellen Lipidkonzentration von $0.5 \mathrm{mg} / \mathrm{mL}$ (final $0.175 \mathrm{mg} / \mathrm{mL}$ ) fällten in $10 \mathrm{~min}$ Silica in einer Konzentration von 2.3 $\pm 0.7 \mathrm{~mm}$. Die Fällungsaktivität geht dabei von den Vesikeln bzw. ihrer Oberfläche aus. Proteoliposomen (PL) dagegen enthielten zudem

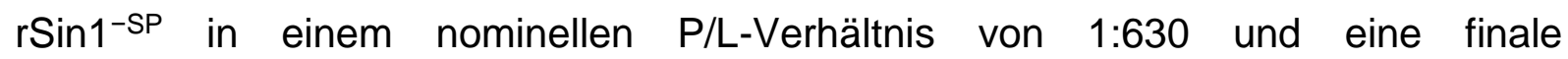
Lipidkonzentration von $0.095 \mathrm{mg} / \mathrm{mL}$. Die PL zeigten eine Fällungsaktivität von $1.8 \pm 0.3 \mathrm{~mm}$ in $10 \mathrm{~min}$. Ein statistischer Signifikanztest (zweiseitiger t-Test mit ungleichen Varianzen, $5 \%$ Signifikanzniveau) ergibt mit $p=0.50$ keine signifikanten Unterschiede zwischen den beiden Proben. Werden die Fällungsmengen mit den mittels Phosphattests quantifizierten Lipidmengen der beiden Proben ins Verhältnis gesetzt, ergeben sich $59 \pm 18 \mathrm{~mm}$ Si pro mg Lipid für Vesikel ohne Protein und 86 $\pm 14 \mathrm{~mm}$ Si pro mg Lipid für Proteoliposomen, doch auch diese Werte sind statistisch 
nicht signifikant verschieden $(p=0.26)$. Die Proteinkonzentration scheint für eine Aussage über eine rSin1-Silicafällungsaktivität ohne LCPA nicht ausreichend.

$0.1 \mathrm{~mm}$ LCPA fällte 6.9 $\pm 0.1 \mathrm{mM}$ Si. Da es sich hierbei um ein LCPA-Gemisch mit einer durchschnittlichen Stickstoffanzahl von $\mathrm{N}=12$ handelt, lag die LCPAStickstoffkonzentration $c\left(„ \mathrm{~N}^{\prime \prime}\right)$ bei $1.2 \mathrm{~mm}$. In Kombination mit Vesikeln ohne Protein oder rSin1-haltigen Proteoliposomen war die Fällungsaktivität leicht gesteigert. Die Proteoliposomen in Gegenwart von LCPA zeigten dabei eine Fällungskonzentration von $8.3 \pm 0.1 \mathrm{mM}$, was etwas weniger als der Summe der einzelnen Fällungsaktivitäten der beiden Komponenten $(8.7 \mathrm{~mm})$ entspricht. Die Blindvesikel-LCPA-Mischung erreichte eine Fällung von $7.5 \pm 0.6 \mathrm{~mm} \mathrm{Si}$ innerhalb von $10 \mathrm{~min}$. Damit bewirkte die Kombination von LCPA und Vesikeln eine Verringerung gegenüber der Summe der Fällungskonzentrationen der Einzelproben $(9.2 \mathrm{mM})$ um $23 \%$ Die Fällungsunterschiede zwischen LCPA-Probe und Vesikeln ohne Protein waren nicht signifikant $(p=0.34)$, die Unterschiede zwischen LCPA-Probe und Proteolipsomen dagegen schon $(p=0.0079)$. Vesikel+LCPA und Proteoliposomen+LCPA zeigten keinen statistisch signifikanten Unterschied zueinander $(p=0.29)$. So gilt auch für die Gegenwart von LCPA, dass für $\mathrm{rSin}^{-\mathrm{SP}}$ keine Silicafällungsaktivität festgestellt werden konnte. Nur die mit der tatsächlichen Lipidmenge ins Verhältnis gesetzten Fällungsmengen für Proteoliposomen+LCPA von $399 \pm 5 \mathrm{mM}$ Si pro mg Lipid bzw. $196 \pm 15 \mathrm{~mm}$ Si pro mg Lipid für Vesikel+LCPA zeigen und einen statistisch signifikanten Unterschied zueinander ( $p=0.017)$ und eine Verdopplung für die Gegenwart von rSin1. Dieser Unterschied könnte dahingehend gedeutet werden, dass das Vorhandensein von rSin1 bei gleichbleibender Lipidmenge in Gegenwart von LCPA eine verstärkende Wirkung auf die Silicafällungsmenge hat. 


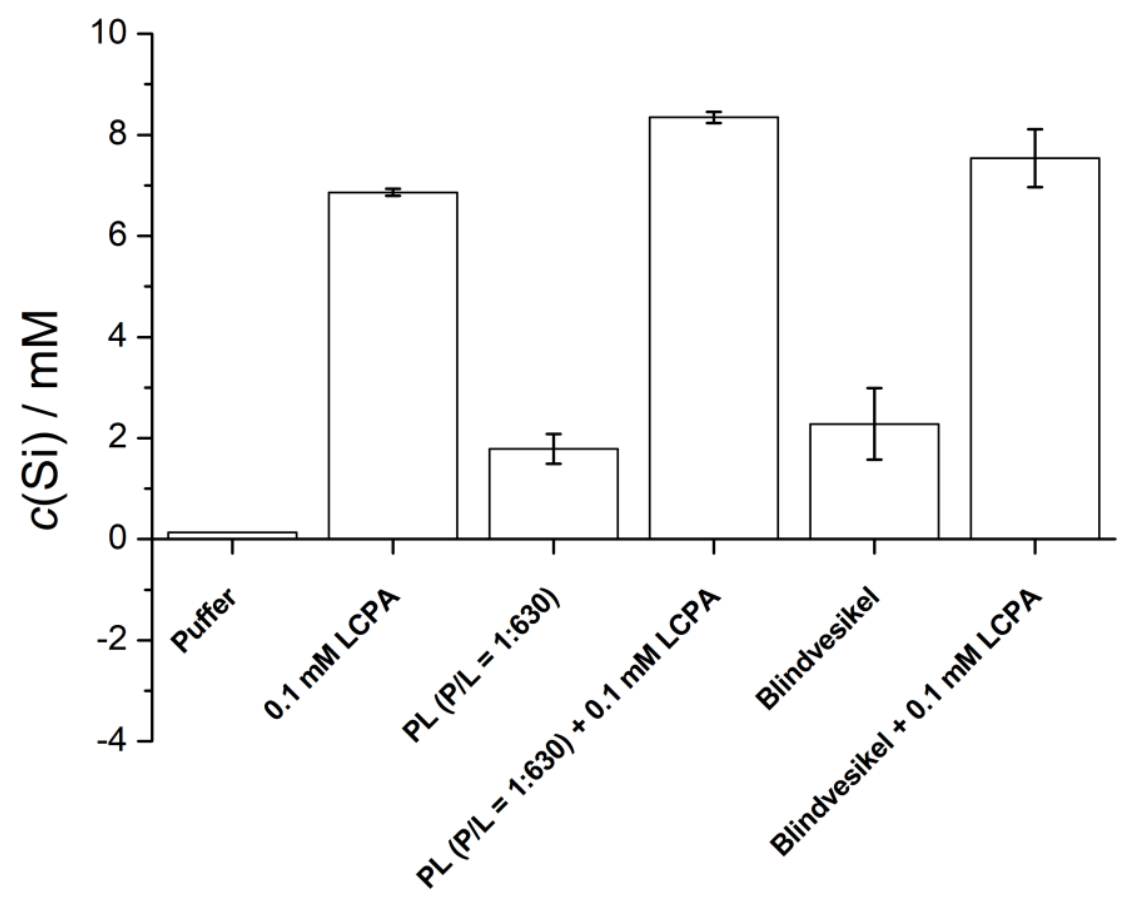

Abbildung 4.34: Ermittelte Siliciumkonzentrationen des gefältten Silicas verschiedener Proben $(n=2$, für Puffer $\mathrm{n}=1$ ). $\mathrm{PL}=$ Proteoliposomen. Fehlerbalken entsprechen der Standardabweichung des Mittelwerts.

\subsection{Charakterisierung rSin1-haltiger festkörperunterstützter Membranen}

Planare Modellmembranen erlauben die Untersuchung von Membranwechselwirkungen mit Substanzen wie Biomolekülen aber auch der biophysikalischen Eigenschaften von Lipiddoppelschichten. In dieser Arbeit wurde eine festkörperunterstützte Membran als SDV-Modellmembran konzipiert (Abb. 4.35), mit der zukünftig in vitro-Analysen der Funktion der Membran im Kontext der Biomineralisation erfolgen können. Die festkörperunterstützte Membran bildet dabei die einfachste artifizielle planare Membran. Porenüberspannende Membranen oder tethered membranes können als Weiterentwicklung auf den Resultaten dieser Arbeit aufbauen. Die Charakterisierung der rSin1-haltigen Modellmembran erfolgte zur Bestätigung einer kontinuierlichen Lipiddoppelschicht, der erwartungsgemäßen Diffusivität der Membranlipide und dem Nachweis von in der Membran befindlichem rSin1. 


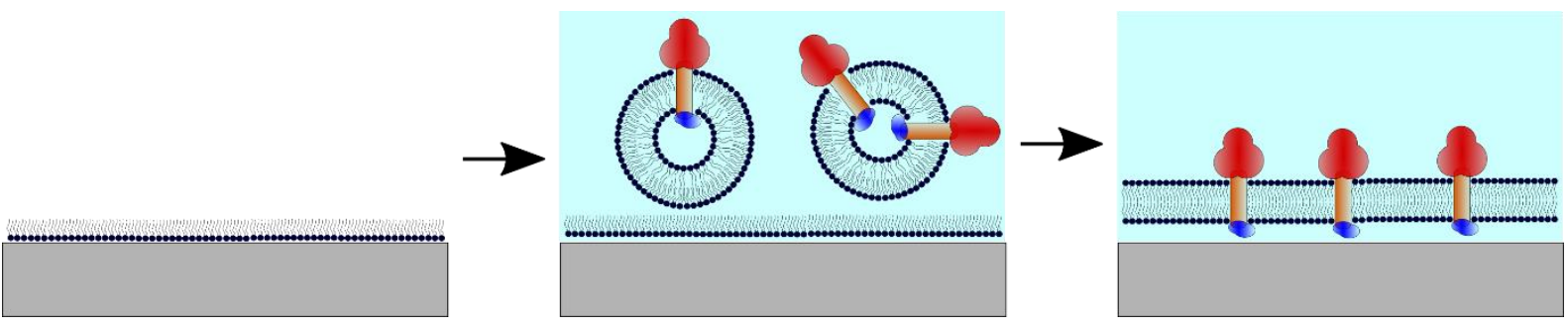

Abbildung 4.35: Schema der Präparation einer rSin1-haltigen festkörperunterstützten Membran durch Spreiten von Proteoliposomen auf einer Lipideinzelschicht.

\subsubsection{Präparation einer Lipideinzelschicht auf einem hydrophilen Substrat}

Für die Präparation einer festkörperunterstützten Membran sollte die Methode der Vesikel-Lipideinzelschicht-Fusion verwendet werden, da auf diese Weise die finale Orientierung der $N$-terminalen rSin1-Domäne zum Medium hinzeigend erfolgen konnte (Abb. 4.35). Dafür musste zunächst eine Lipideinzelschicht auf das hydrophilisierte

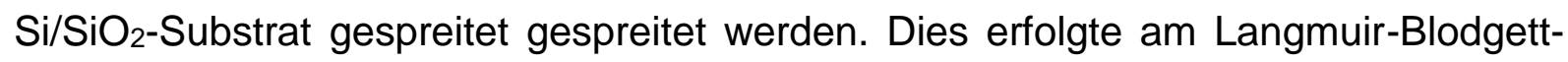
Trog, wobei Teflonbarrieren eine auf der Subphasenoberfläche befindliche Lipidmonoschicht komprimierte, während das Substrat vertikal aus der Subphase gehoben wurde. Der sogenannte Oberflächendruck $\pi$ wurde dabei konstant bei ca. $32.5 \mathrm{mN} / \mathrm{m}$ gehalten. Dies sollte die Lipideinzelschicht in eine Packungsdichte überführen, die der in einer Lipiddoppelschicht entspricht. Phospholipideinzel- und doppelschichten zeigen bei ungefähr $30 \mathrm{mN} / \mathrm{m}$ ähnliches Phasenverhalten. [118]

Abb. 4.36A zeigt exemplarisch die Veränderung von $\pi$ gegen den zeitlichen Verlauf des Übertrags, wobei Start der Lipidkompression, die Äquilibrierung des Systems nach Erreichen des Zielwerts von $32.5 \mathrm{mN} / \mathrm{m}$ und der Start des Anhebens des Substrats aus der Subphase gekennzeichnet sind. Abb. 4.36B stellt die Auftragung $\pi$ gegen die Fläche pro Lipidmolekül in $\AA^{2}\left(10^{-20} \mathrm{~m}^{2}\right)$ dar. Nach dem Erreichen von ca. $68 \AA^{2}$ erfolgte eine scheinbare Reduktion dieser Fläche auf ca. $62 \AA^{2}$, da Lipidmaterial durch das Spreiten mit dem Substrat entfernt wurde. Dieser Lipidverlust wurde dabei jedoch vom Messcomputer nicht berücksichtigt, sondern nur die Verkleinerung der Oberfläche zur Aufrechterhaltung der $32.5 \mathrm{mN} / \mathrm{m}$. Die Fläche pro Molekül sollte in Wirklichkeit konstant bei ca. $68 \AA^{2}$ geblieben sein. Die weitgehend homogene Präparation einer Lipideinzelschicht auf dem hydrophilen Substrat wird als erfolgreich gewertet und wurde mittels Fluoreszenzmikroskopie weiter überprüft (siehe Kapitel 4.4.2). 

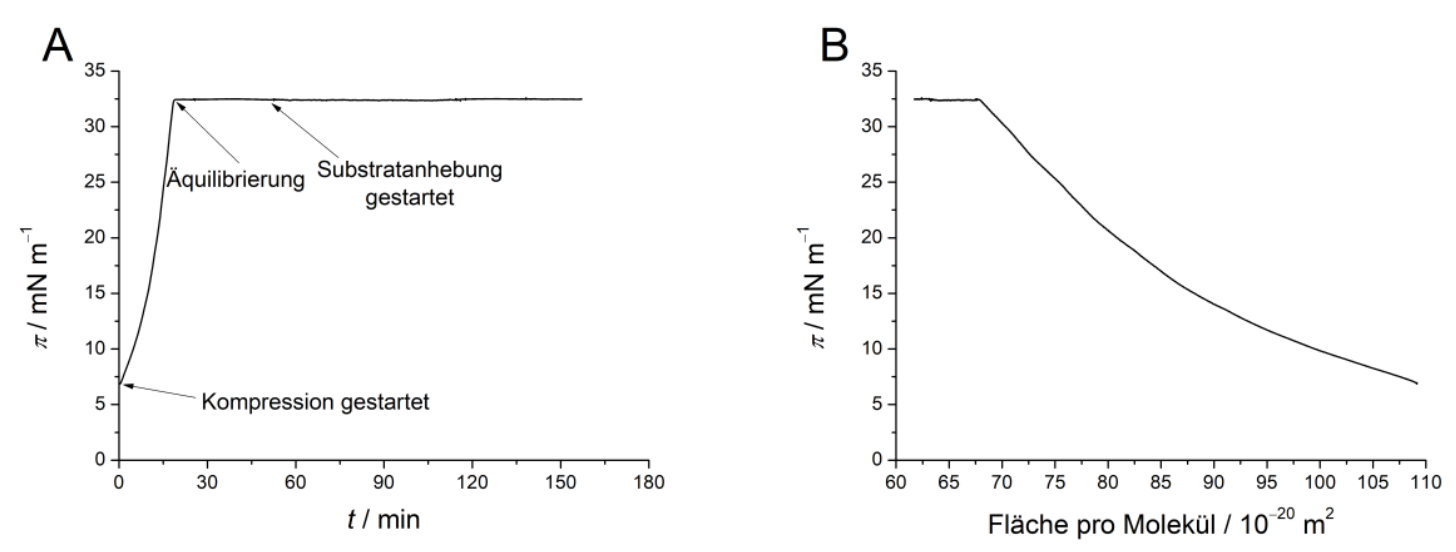

Abbildung 4.36: A: Exemplarischer Oberflächendruckverlauf im zeitlichen Verlauf des Lipideinzelschichtübertrags. Gekennzeichnet sind der Start der Lipidkompression, die Äquilibrierung des Systems nach Erreichen des Zielwerts von $32.5 \mathrm{mN} / \mathrm{m}$ und der Beginn des Anhebens des Substrats aus der Subphase. B: Verlauf des Oberflächendrucks in Abhängigkeit von der Fläche pro Lipidmolekül. Bei $32.5 \mathrm{mN} / \mathrm{m}$ wurde der Verlust an Lipidmaterial an das Substrat als Verkleinerung der Fläche pro Molekül gemessen.

\subsubsection{Charakterisierung der kontinuierlichen Lipiddoppelschicht nach Einzelschicht-Vesikel-Fusion}

Die festkörperunterstützten Membranen wurden mittels Vesikelfusion mit Lipideinzelschichten präpariert. Dabei wurden die Lipideinzelschicht und die Vesikel mit unterschiedlichen fluoreszierenden Lipiden versehen, um eine fluoreszierende asymmetrische Membran zu erzeugen, die mit Hilfe der konfokalen Laserscanningmikroskopie (CLSM) detektiert werden konnte.

Hierfür wurde Texas Red (TxR)-DPPE als Farbstoff der mittels Langmuir-BlodgettTechnik präparierten Lipideinzelschicht verwendet, während Atto 390-DPPE als Vesikelfarbstoff diente. Nach dem Spreitprozess der Vesikel auf der Lipideinzelschicht wurden beide Fluorophore unabhängig angeregt und ihre Emission detektiert. Dabei wurde für beide Farbstoffe eine weitgehend homogene Verteilung beobachtet (Abb. 4.39). 


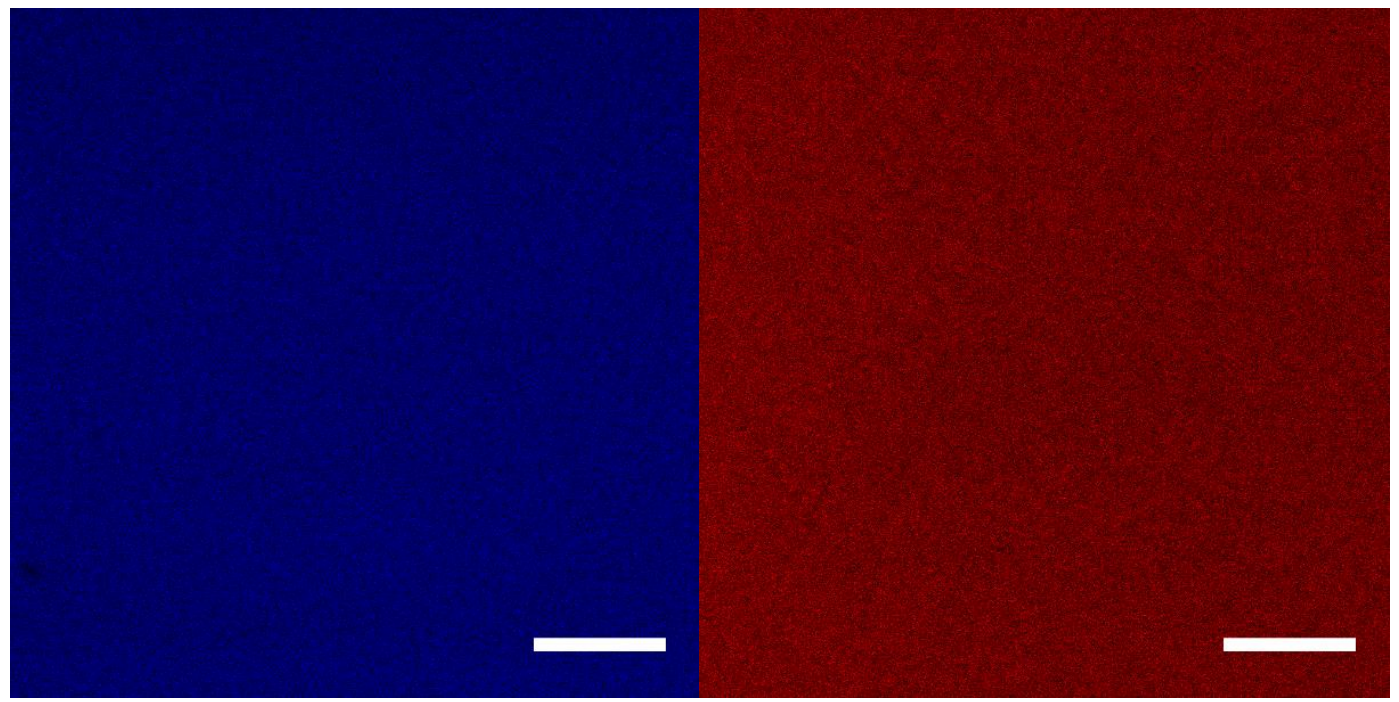

Abbildung 4.37: Fluoreszenzaufnahmen einer festkörperunterstützten Membran. Atto 390-DPPE (links) wurde über die Vesikel in die Membran eingeführt, während Texas Red-DPPE (rechts) in der mittels Langmuir-Blodgett-Technik auf das $\mathrm{Si} / \mathrm{SiO}_{2}$-Substrat gespreiteten Lipideinzelschicht vorlag. Maßstab $=10 \mu \mathrm{m}$.

Um die Kontinuität dieser Membran nachzuweisen wurde die Lipiddiffusion mittels Fluoreszenzerholung nach Photobleichung (FRAP) für beide in der Membran befindlichen Fluorophor gebundenen Lipide untersucht. Es wurde in beiden Fällen Fluoreszenzerholung beobachtet (Abb. 4.38) und mit Hilfe der auf der HankelTransformation beruhenden Software hinsichtlich der resultierenden lateralen Diffusionskonstanten und ihren mobilen Anteil analysiert. 

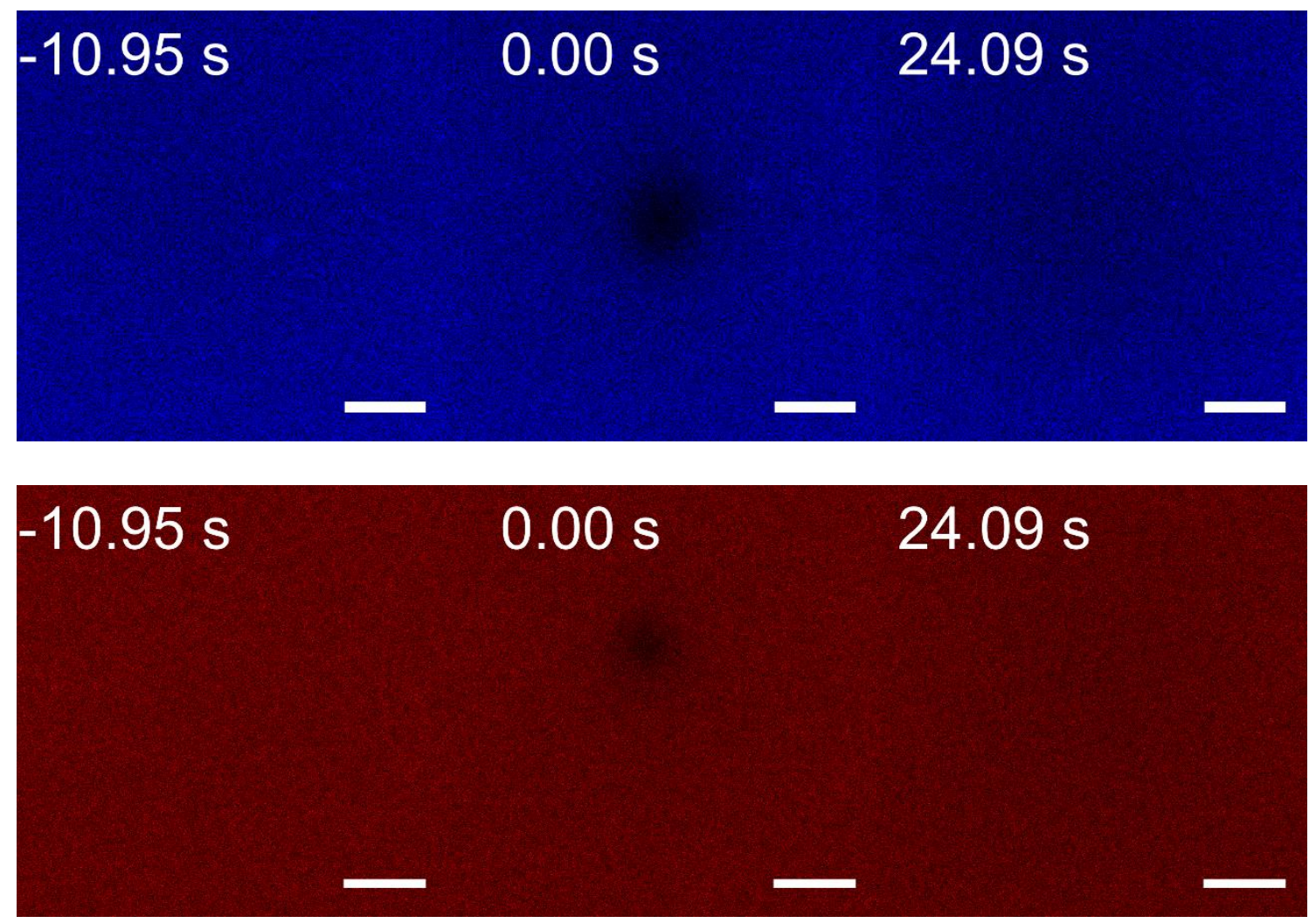

Abbildung 4.38: FRAP-Zeitserien für Atto 390-DPPE (oben) und TxR-DPPE (unten) der festkörperunterstützten Membran. Die Lipidkomposition war POPC/POPE/Atto 390-DPPE=69.8:30:0.2 für Vesikel und POPC/POPE/TxR-DPPE=69.5:30:0.5 für die Lipideinzelschicht. Maßstab $=10 \mu \mathrm{m}$.

Für Atto 390-DPPE, welches über die Vesikel in die Membran gelangt ist, ergab sich eine laterale Diffusionskonstante $D=1.9 \pm 0.7 \mu \mathrm{m}^{2} \cdot \mathrm{s}^{-1}$ (Anzahl an Präparaten $\mathrm{N}=2$, Anzahl an Messungen $\mathrm{n}=4$ ) und ein mobiler Anteil von $M>99 \%$. Für TxR-DPPE wiederum wurden $D=1.7 \pm 0.4 \mu \mathrm{m}^{2} \cdot \mathrm{s}^{-1}(\mathrm{~N}=4, \mathrm{n}=9)$ und $M=95 \pm 3 \%$ berechnet. Die Gegenwart von rSin1 in der Membran hatte dabei keinen Einfluss auf diese Parameter oder auf die Homogenität der Membran. Die Ergebnisse zeigen, dass nach der Vesikel-Einzelschicht-Fusion eine kontinuierliche Lipiddoppelschicht mit mobilen Lipiden vorlag und die Fusiontechnik geeignet war, um eine festkörperunterstützte Membran der Lipidzusammensetzung POPC/POPE/Dye-DPPE = 70-x:30:x $(x($ Atto390 $)=0.2 ; x(T x R)=0.5)$ zu präparieren. Atto 390-DPPE zeigte allerdings in vielen Fällen ein schnelles und intensives Hintergrundbleichen, weshalb auf Atto 390 in späteren Experimenten verzichtet wurde. 


\subsubsection{Nachweis von rSin1 in festkörperunterstützten Membranen}

- Die in Kapitel 4.4.3 gezeigten Ergebnisse beruhen auf Arbeiten von Lucia Winkler. ${ }^{[116]}$

Die visuelle Detektion von rSin1 sollte mit dem Einsatz von Fluorophoren erfolgen. Da eine Markierung über Cystein bindende Fluorophore nicht anwendbar war - rSin1 besitzt 18 Cysteine, die disulfidverbrückt sind - und eine Mehrfachmarkierung des Proteins generell vermieden werden sollte, wurde eine nicht-kovalente Markierungsstrategie verfolgt. Dazu wurde Anti-Sin1-Antiserum (aus Kaninchen) als primärer Antikörper eingesetzt, an den ein sekundärer Anti-Kaninchen-Antikörper band, der kovalent mit einem Alexa Fluor 647-Molekül versehen war. In der festkörperunterstützten Membran eingebautes rSin1, dessen $N$-terminale Domäne zum Medium hin orientiert war, sollte somit indirekt sichtbar gemacht werden (Abb. 4.39).

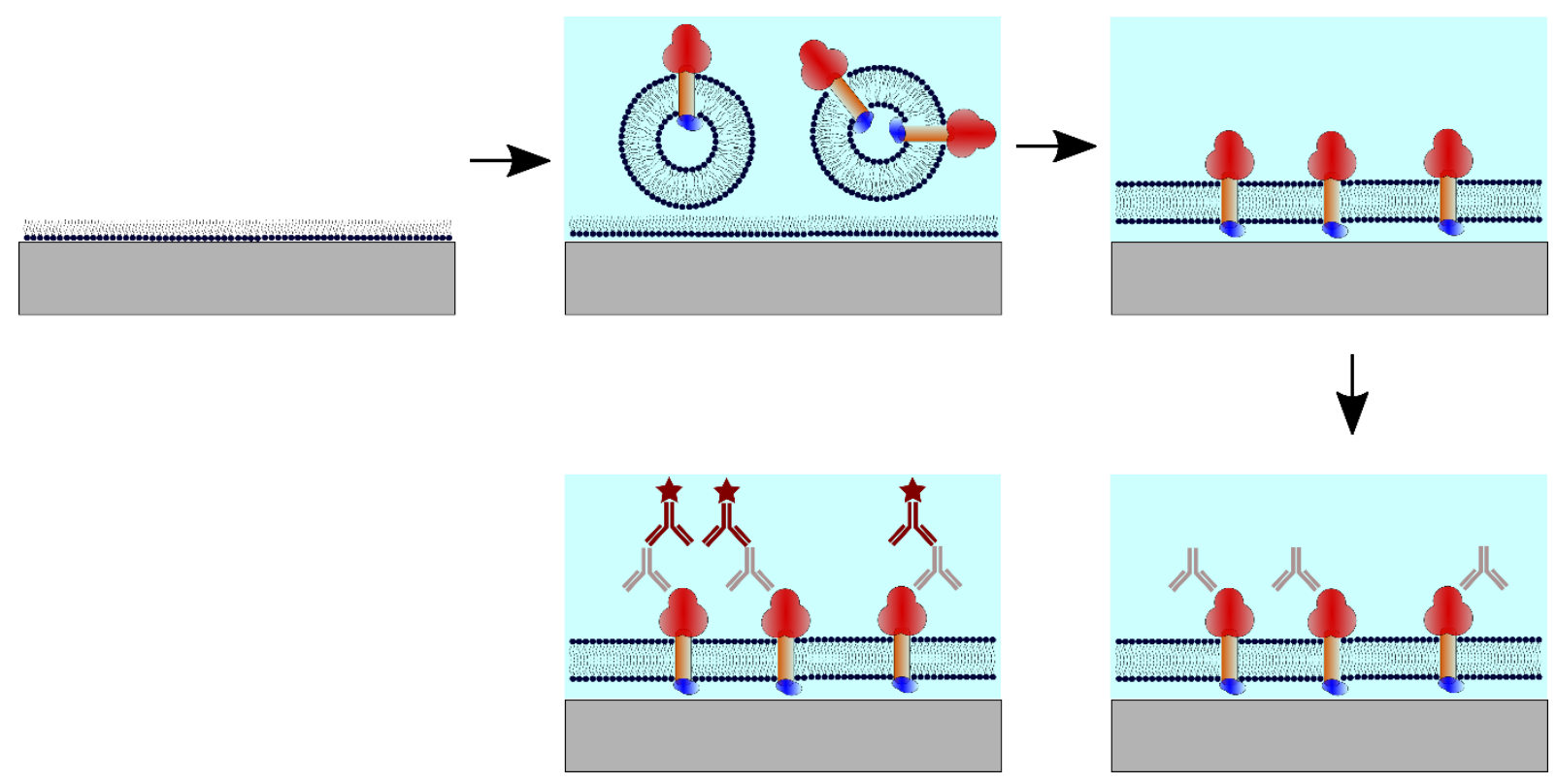

Abbildung 4.39: Schema der Präparation einer rSin1-haltigen festkörperunterstützten Membran durch Vesikelfusion mit einer Lipideinzelschicht sowie die anschließende Anbindung von primären (Anti-Sin1) und sekundären Antikörpern. Der sekundäre Antikörper ist fluoreszenzmarkiert und dient der Detektion mittels Fluoreszenzmikrokopie.

Abb. 4.40 zeigt exemplarisch Fluoreszenzaufnahmen von festkörperunterstützten Membranen, die sich in ihrer Zusammensetzung etwas von den in Kapitel 4.4.2 erwähnten unterscheiden. Die gespreitete Lipideinzelschicht bestand aus $\mathrm{POPC} / \mathrm{POPE}=85: 15$ und verzichtete auf eine Fluoreszenzmarkierung, da die 
Einzelschichtpräparation gut reproduzierbar war. Die Blindvesikel- und Proteoliposomenpräparation erfolgte mit POPC/POPE/Bodipy 500/510 $\mathrm{C}_{12^{-}}$ $\mathrm{PPC}=84.5: 15: 0.5$. Es wurde hier ein Ersatz für Texas Red gewählt, da Alexa Fluor 647 und Texas Red zu starke Fluoreszenzspektrenüberlagerungen aufweisen. Die detektierte Fluoreszenz war weitgehend homogen verteilt, obwohl es einzelne hellere Bereiche gab. Dabei handelte es sich vermutlich um auf der Membran adhärierte Vesikel und Vesikelaggregate.

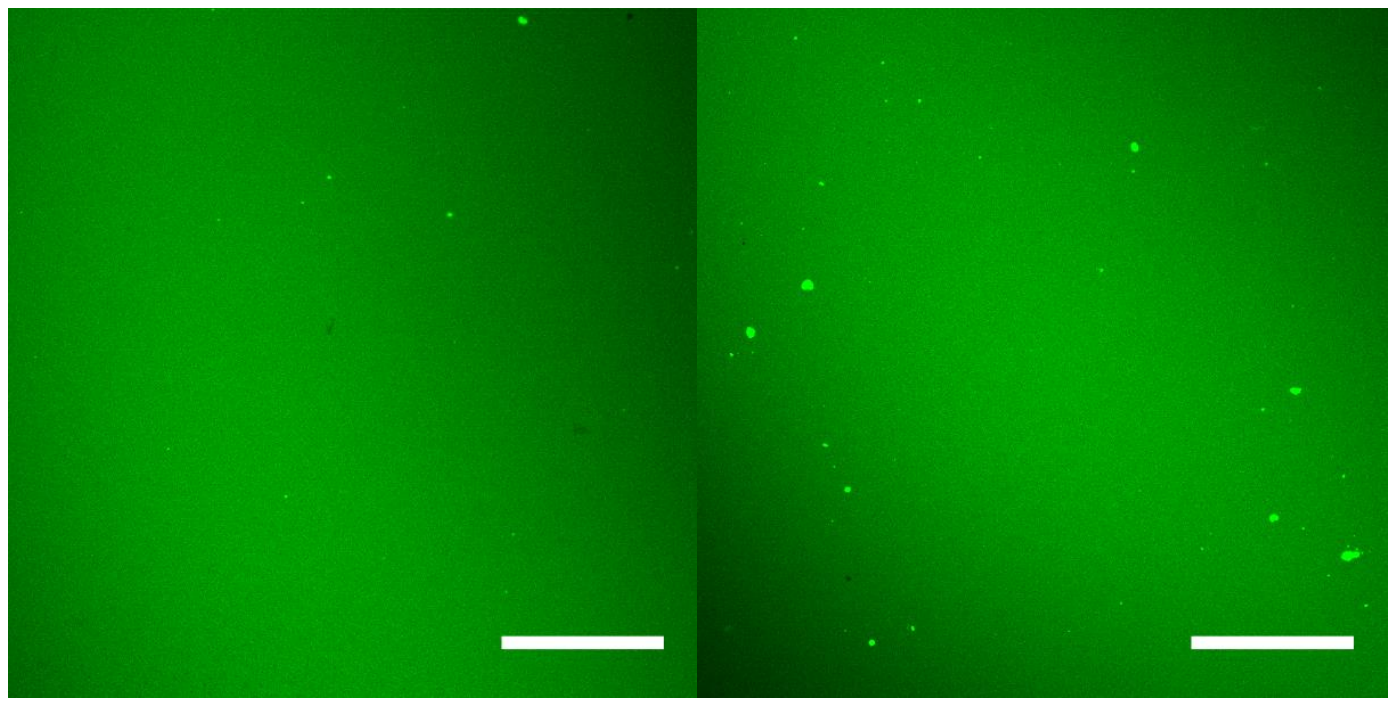

Abbildung 4.40: Fluoreszenzaufnahmen von rSin1-haltigen festkörperunterstützten Membranen im Bodipy 500/510-Kanal bei pH 7.7 (links) und pH 5.0 (rechts) vor Zugabe der Antikörper. Die ungleichmäßige Ausleuchtung resultiert aus einer leicht schrägen Probenebene. Maßstab=50 $\mu \mathrm{m}$.

FRAP-Messungen (Abb. 4.41) zeigten eine Fluoreszenzerholung für Bodipy, was bedeutet, dass die Lipidmembran kontinuierlich und intakt war. Die aus den FRAPMessungen berechnete laterale Diffusionskonstante des Bodipy 500/510 $\mathrm{C}_{12}$-PPC betrug $D=0.8 \pm 0.2 \mu \mathrm{m}^{2} \cdot \mathrm{s}^{-1}(\mathrm{~N}=7, \mathrm{n}=27)$ und die laterale Mobilität $M=90 \pm 9 \%(\mathrm{n}=21)$. 


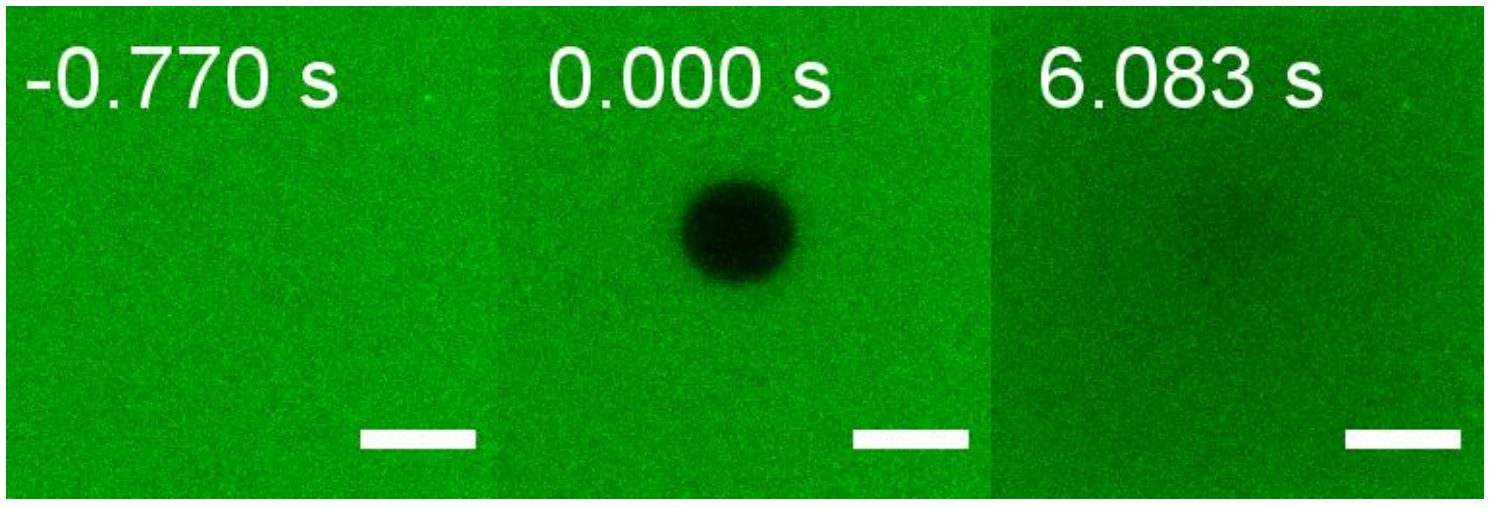

Abbildung 4.41: FRAP-Zeitserien der rSin1-haltigen festkörperunterstützten Membran im Bodipy 500/510-Kanal. Es ist eine Fluoreszenzerholung des geblichenen Bereichs zu beobachten. Maßstab=5 $\mu \mathrm{m}$.

Die Zugabe von primärem Antiserum bewirkte eine Veränderung der Membran (Abb. 4.42). Dabei wurden im Bodipy-Kanal gravierende Unterschiede zwischen den Proben beobachtet, je nachdem ob die Vesikelcomizellisierung und Vesikelfusion bei pH 7.7 oder pH 5.0 erfolgten. Bei $\mathrm{pH} 7.7$ zeigten sich teils streifenartige Fluoreszenzintensitätsunterschiede. Bei pH 5.0 entstanden bis zu $40 \mu \mathrm{m}$ große Bereiche mit Fluoreszenzausschluss. Diese Beobachtungen waren unabhängig von der Anwesenheit von rSin1. 

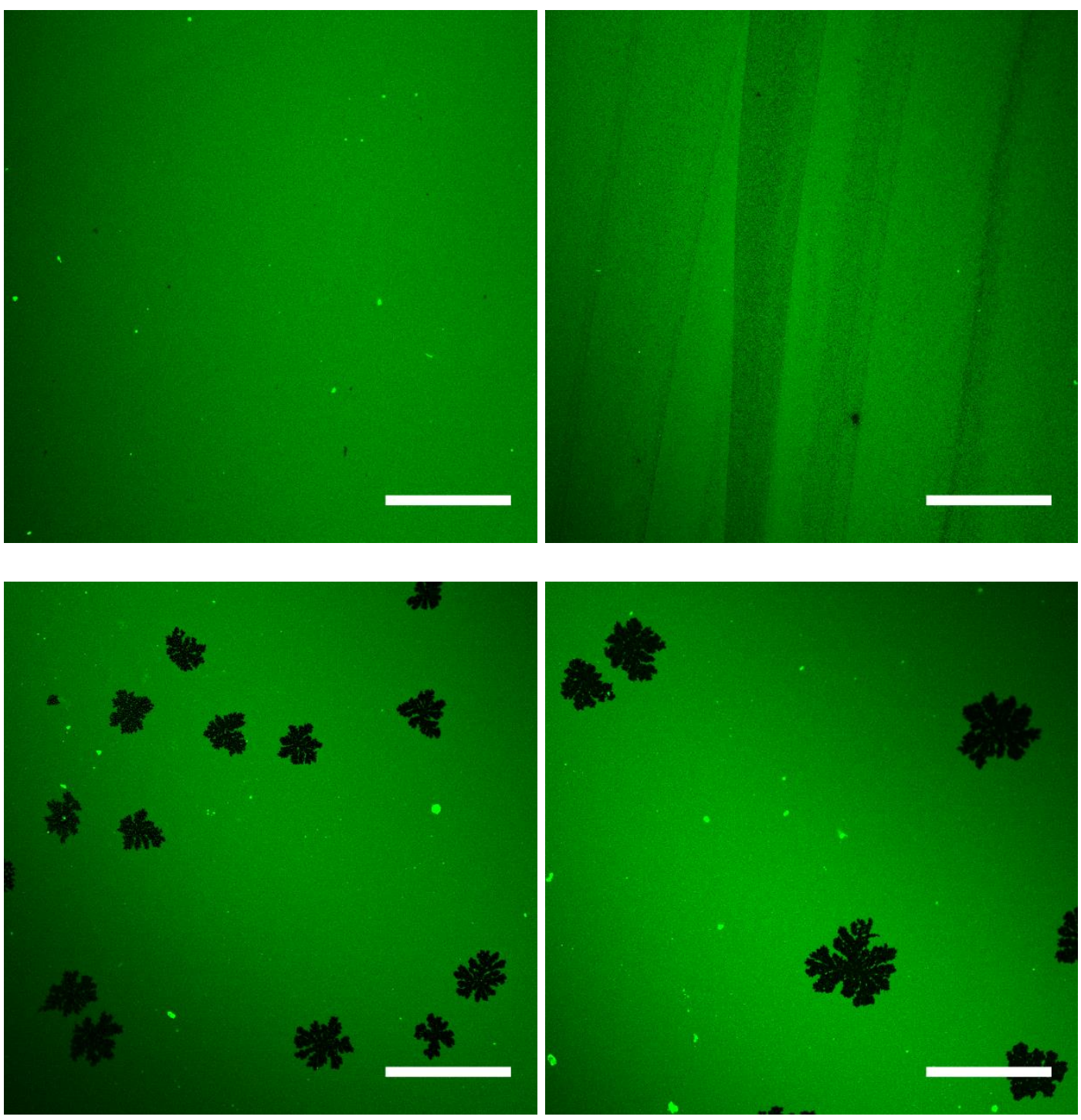

Abbildung 4.42: Exemplarische Bodipy 500/510-Fluoreszenzaufnahmen der festkörperunterstützten Membran nach Zugabe des primären Antiserums bei pH 7.7 (oben) und pH 5.0 (unten). Die ungleichmäßige Ausleuchtung resultiert aus einer leicht schrägen Probenebene. Maßstab=50 $\mu \mathrm{m}$.

Bei Zugabe von sekundärem Alexa Fluor 647-markiertem Antikörper gab es keine weiteren Veränderungen der Membran. Abb. 4.43 zeigt exemplarisch den Unterschied zwischen proteinfreien Membranen und Membranen mit $r \operatorname{Sin} 1$ ( $P / L=1: 500$, nominell). Die Aufnahmen im Alexa-Fluor-647-Kanal zeigen nur schwache Signale, die insbesondere im Fall der proteinfreien Membran dem menschlichen Auge schwarz erscheinen. Die automatische Helligkeits- und Kontrast-Korrektur des Programms ImageJ erlaubt einen zumindest qualitativen Vergleich zwischen den beiden Membranen bezüglich ihres Alexa Fluor 647-Signals. Dabei zeigt sich, dass rSin1- 
haltige Membranen höhere Alexa Fluor 647-Intensitäten aufwiesen. Die sekundären Antikörper sind als heterogen verteilte fluoreszierende Punkte wahrnehmbar.
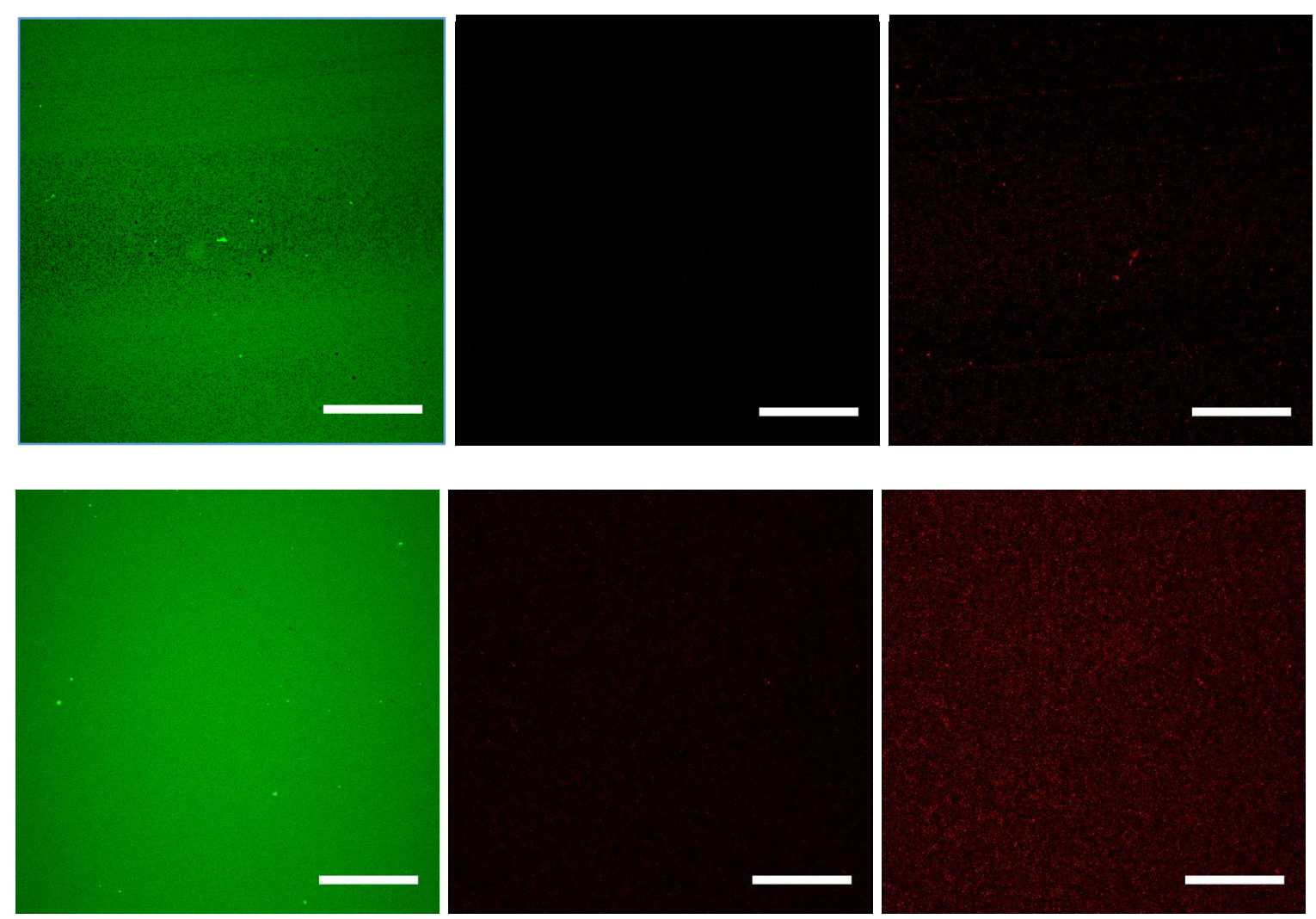

Abbildung 4.43: Exemplarische Fluoreszenzaufnahmen im Bodipy 500/510-Kanal (links) und Alexa Fluor 647-Kanal (mittig) sowie eine Helligkeits-/Kontrast-korrigierte Alexa Fluor 647-Aufnahme (rechts). Oben gezeigt ist eine festkörperunterstützte Membran ohne $r S i n 1^{-S P}$. Unten dargestellt ist eine Membran bei nominellem Einsatz von $r \operatorname{Sin} 1$ von $P / L=1: 500$. Maßstab=50 $\mu \mathrm{m}$.

FRAP-Messungen im Alexa Fluor 647-Kanal nach Zugabe der beiden Antikörper zeigten, dass nach 8 min keinerlei Fluoreszenzerholung beobachtbar war (Abb. 4.44). Der sekundäre Antikörper diffundiert also nicht, sondern bleibt auf seine Position fixiert. $\mathrm{Ob}$ die nicht vorhandene Mobilität ein Resultat der Bindung des Antikörpers an das Protein ist und dabei möglicherweise mehrere Proteine von einem Antikörper verbrückt werden oder ob das rSin1 selbst bereits in kleineren immobilen Aggregaten vorliegt, kann nicht gesagt werden. Auch eine fixierende Bindung der cytosolischen Domäne am Substrat ist vorstellbar. 

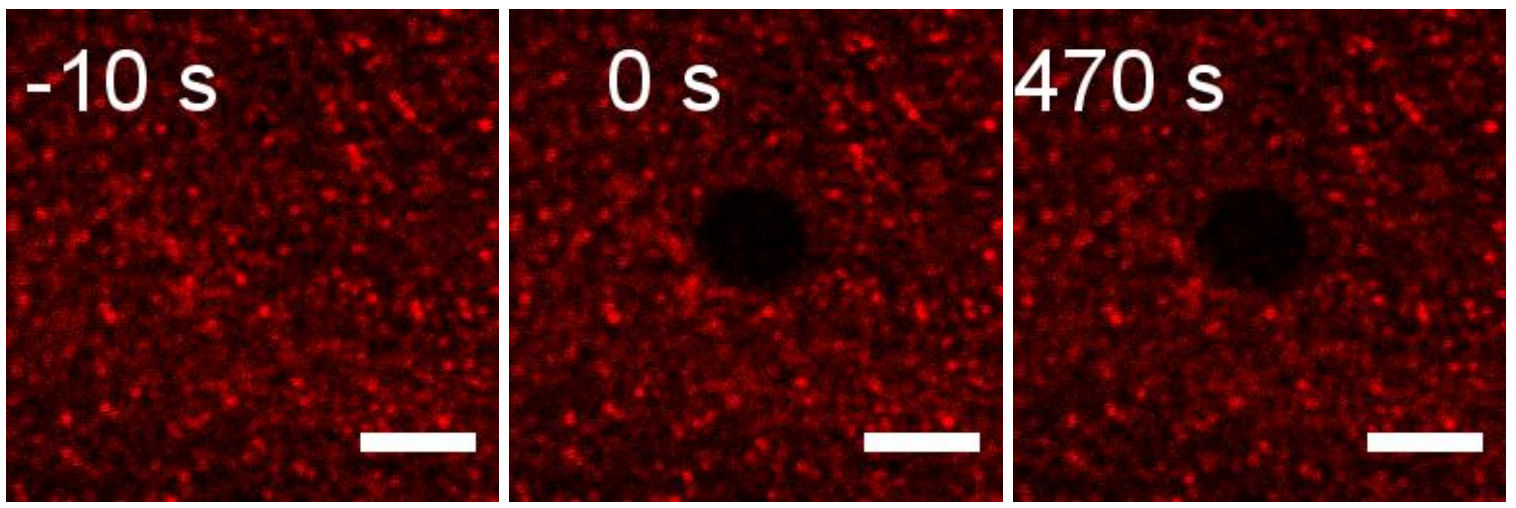

Abbildung 4.44: FRAP-Zeitserien der rSin1-haltigen festkörperunterstützten Membran nach Zugabe von Alexa Fluor 647-gebundenem sekundärem Antikörper. Gezeigt ist der Alexa Fluor 647-Kanal. Es ist keine Fluoreszenzerholung zu beobachten. Die Bilder sind für eine bessere Erkennbarkeit kontrastverstärkt. Maßstab=5 $\mu \mathrm{m}$.

Für eine quantitative Betrachtung der Alexa Fluor 647-Fluoreszenz wurden die Fluoreszenzaufnahmen im Alexa Fluor 647-Kanal mit dem Programm ImageJ auf ihre mittlere Graustufenintensität analysiert und eine Auftragung in Abhängigkeit von dem gewählten Gain (Signalverstärkung) für die beiden verwendeten pH-Werte 7.7 und 5.0 erstellt (Abb. 4.45 und 4.46). Dabei wurden alle Bilder unkorrigiert und unselektiert verwendet, da die Annahme getroffen wurde, dass sich ungleichmäßige Ausleuchtung und das Auftreten von Defekten oder anderer Membranartefakte über alle Probentypen bei An- oder Abwesenheit von rSin1 ungefähr ausgleichen. Laserintensität, Zoomfaktor und Auflösung waren dagegen identisch. 


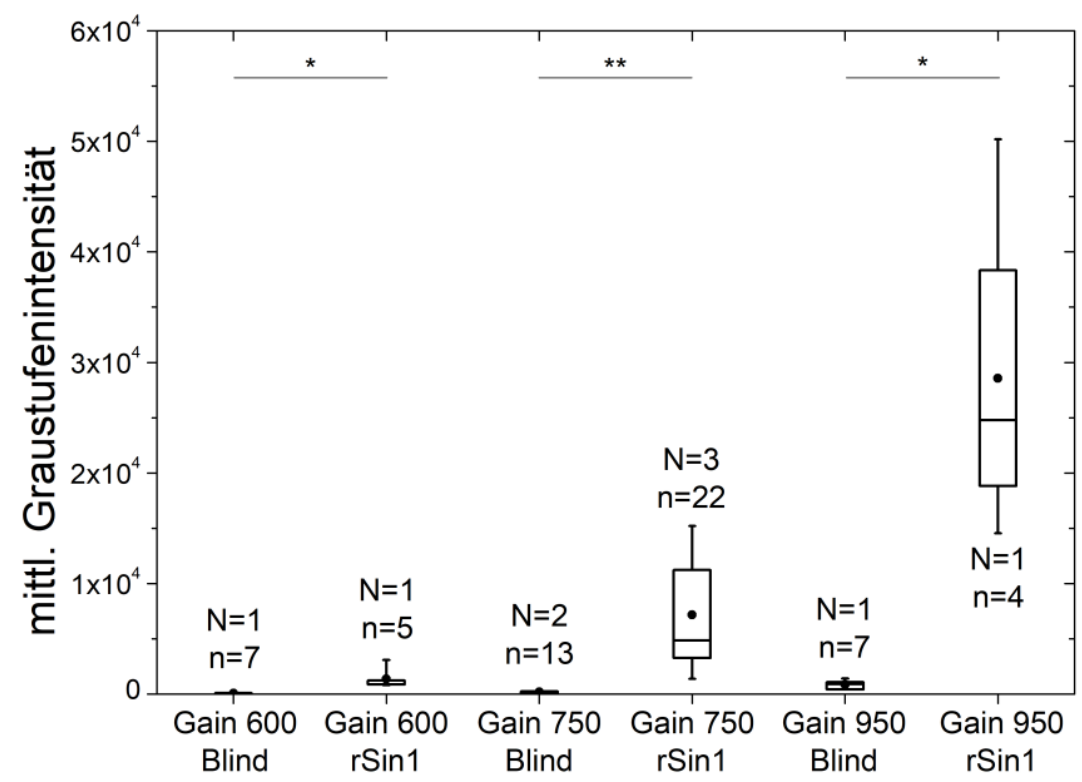

Abbildung 4.45: Box-Diagramm der gemessenen mittleren Graustufenintensität im Alexa Fluor 647Kanal für festkörperunterstützte Membranen $(\mathrm{pH}$ 7.7) in An- und Abwesenheit von rSin1 bei verschiedenen Gains (Signalverstärkungen). Die Box entspricht den Percentilen 25-75\%, der Fehlerbalken den Percentilen 5-95\%. Der schwarze Punkt ist das arithmetische Mittel, der Querstrich der Median der Werte. $\mathrm{N}=$ Anzahl an Proben, $\mathrm{n}=$ Anzahl an Bildern. Statistische Signifikanz wurde nach einem zweiseitigen t-Test mit ungleichen Varianzen berechnet: $p<0.05\left(^{*}\right), p<0.005\left(^{* *}\right)$.

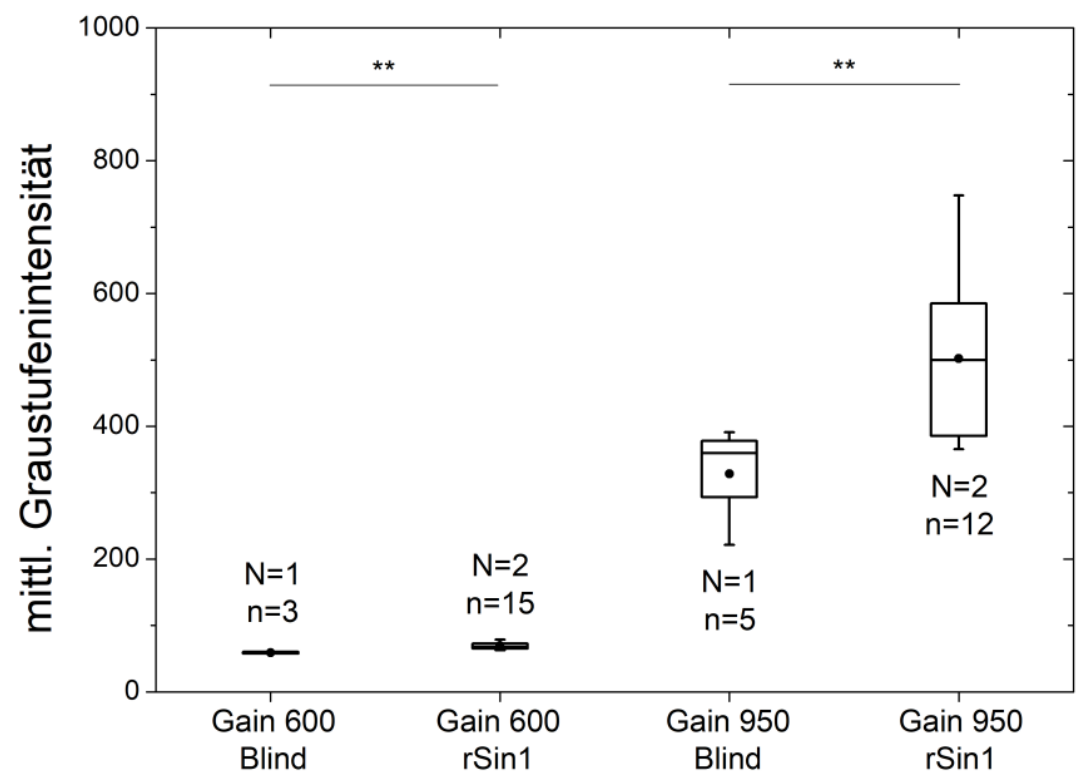

Abbildung 4.46: Box-Diagramm der gemessenen mittleren Graustufenintensität im Alexa Fluor 647Kanal für festkörperunterstützte Membranen $(\mathrm{pH}$ 5.0) in An- und Abwesenheit von rSin1 bei verschiedenen Gains (Signalverstärkungen). Die Box entspricht den Percentilen 25-75\%, der Fehlerbalken den Percentilen 5-95\%. Der schwarze Punkt ist das arithmetische Mittel, der Querstrich der Median der Werte. $\mathrm{N}=$ Anzahl an Proben, $\mathrm{n}=$ Anzahl an Bildern. Statistische Signifikanz wurde nach einem zweiseitigen t-Test mit ungleichen Varianzen berechnet: $p<0.05\left(^{*}\right), p<0.005\left(^{* \star}\right)$. 
Die mittleren Graustufenintensitätsunterschiede zwischen proteinfreien und rSin1haltigen Proben waren durchweg statistisch signifikant. Dies gilt für alle betrachteten Gains von 600, 750 und 950 und beide Präparations- und Mess-pH-Werte 7.7 und 5.0. Dabei war die Alexa Fluor 647-Intensität für rSin1-haltige Membranen stärker als für proteinfreie Membranen. Da sich die Proben in ihrer Zusammensetzung lediglich in der Zugabe des rSin1 unterschieden, ist eine rSin1 induzierte vermehrte Anbindung der Antikörper die logische Erklärung. Somit wurde die Spezifität der Antikörperbindung an rSin1 in festkörperunterstützten Membranen nachgewiesen. Die ermittelten Werte sind in Tab. 4.4 aufgeführt.

Tabelle 4.4: Mittlere Graustufenintensitäten der Alexa Fluor 647-Fluoreszenzaufnahmen von festkörperunterstützten Membranen, präpariert bei pH 7.7 oder pH 5.0 mit oder ohne rSin1-sP $(P / L=1: 500)$. Die angegebenen Werte sind die arithmetischen Mittelwerte sowie die Standardabweichungen.

\begin{tabular}{|c|c|c|c|c|}
\hline $\begin{array}{c}\text { Mittlere Grau- } \\
\text { stufenintensität }\end{array}$ & pH 7.7, blind & pH 7.7, rSin1 & pH 5.0, blind & pH 5.0, rSin1 \\
\hline Gain 600 & $82.0 \pm 13.5$ & $(1.36 \pm 0.97) \cdot 10^{3}$ & $59.2 \pm 1.1$ & $69.3 \pm 5.3$ \\
\hline Gain 750 & $174 \pm 70$ & $(7.16 \pm 5.35) \cdot 10^{3}$ & $/$ & $/$ \\
\hline Gain 950 & $836 \pm 359$ & $(28.6 \pm 15.3) \cdot 10^{3}$ & $329 \pm 71$ & $502 \pm 129$ \\
\hline
\end{tabular}

Werden die zugehörigen Werte von proteinhaltigen und proteinfreien Membranen ins Verhältnis R gesetzt (Tab. 4.5), wird ersichtlich, dass die Präparation und Messung bei pH 5.0 schließlich eine deutlich niedrigere Mehrdetektion von Alexa Fluor 647 (Faktor 1.17 bzw. 1.53) aufwies, als wenn Präparation und Messung bei pH 7.7 erfolgten (Faktor 16.6, 41.2 bzw. 34.2). Wie in Kapitel 4.2.3 gezeigt bildet $r$ Sin1 bei pH 5.0 große Aggregate und es ist zu erwarten, dass die aus Comizellisierung und Größenausschlusschromatografie erhaltene rekonstituierte Proteinmenge deshalb im Vergleich zu pH 7.7 stark reduziert ist. Große freie rSin1-Aggregate werden vermutlich leichter von der präparierten festkörperunterstützten Membran gespült. Wenn also deutlich weniger rSin1 in der festkörperunterstützten Membran vorhanden war, muss auch die Mehrdetektion als Verhältnis $\mathrm{R}$ wesentlich geringer ausfallen als für pH 7.7. Die hohe Mehrdetektion für pH 7.7 zeigt, dass dieser pH-Wert geeignet ist, Alexa Fluor 647-gebundene Antikörper zur indirekten Detektion von rSin1 in festkörperunterstützten Membranen einzusetzen. 
Tabelle 4.5: Verhältnis der mittleren Graustufenintensitäten der Alexa Fluor 647Fluoreszenzaufnahmen von rSin1-haltigen zu proteinfreien Membranen in Abhängigkeit von pH-Wert und gewähltem Gain.

\begin{tabular}{|l|c|c|c|c|c|}
\hline & $\begin{array}{c}\text { pH 7.7, } \\
\text { Gain 600 }\end{array}$ & $\begin{array}{c}\text { pH 7.7, } \\
\text { Gain 750 }\end{array}$ & $\begin{array}{c}\text { pH 7.7, } \\
\text { Gain 950 }\end{array}$ & $\begin{array}{c}\text { pH 5.0, } \\
\text { Gain 600 }\end{array}$ & $\begin{array}{c}\text { pH 5.0, } \\
\text { Gain 950 }\end{array}$ \\
\hline R(rSin1/blind) & 16.6 & 41.2 & 34.2 & 1.17 & 1.53 \\
\hline
\end{tabular}




\section{Diskussion}

\subsection{Lipidkomposition in Tp-div und Tp-G1}

Die Lipidkomposition in synchronisierten Zellen von Thalassiosira pseudonana (Tp) in den Zellzyklusphasen der Zellteilung bei angereichterten Valven-Silicafällungsvesikeln (Tp-div) sowie der G1-Phase (Tp-G1) wurde mittels Gaschromatografie mit Flammenionisationsdetektion (GC-FID) und Ultraperformance-Flüssigchromatografie mit nano-Elektrosprayionisations-Tandemmassenspektrometrie (UPLC-nanoESIMS/MS) analysiert. Die Synchronisierung der Tp-Zellen durch Silicatmangel bewirkte für die meisten Zellen den gleichzeitigen Durchlauf der Phasen des Zellzyklus. Somit zeigte Tp-div, geerntet 2-3 h nach Silicatzugabe, die maximale Konzentration an Valven-Silicafällungsvesikeln (SDVs), während sie in der G1-Phase, $6 \mathrm{~h}$ nach Silicatzugabe, nicht vorhanden waren. Unterschiede in den Lipid- und Fettsäurezusammensetzungen zwischen Tp-div und Tp-G1 können Hinweise auf die Lipidkomposition der Valven-SDVs liefern.

\subsubsection{Totalfettsäurekomposition}

Die im Totallipidextrakt ermittelte Fettsäure (FA)-Menge betrug ca. $170 \mu \mathrm{mol}$ bzw. $46 \mathrm{mg}$ FA pro g Trockengewicht, wobei kein statistisch signifikanter Unterschied zwischen Tp-div und Tp-G1 feststellbar war. Die FA-Masse pro Tp-Zelle wurde auf $2.6 \mathrm{pg}$ berechnet. Dies ist in der Größenordnung der von Volkman et al. ${ }^{[119]}$ genannten $1.0 \mathrm{pg} \mathrm{FA/Zelle} \mathrm{für} \mathrm{Tp.} \mathrm{Tonon} \mathrm{et} \mathrm{al.}{ }^{[120]}$ gaben für eine Tp-Kultur mit einer Wachstumszeit von ungefähr $100 \mathrm{~h}$ (beginnender Übergang der exponentiellen zur stationären Phase) ca. 2 pg FA pro Zelle an. Smith et al. ${ }^{[47]}$ untersuchten die Auswirkungen von Silicatmangel auf Tp-Kulturen und ihre FA-Komposition, wobei sie nach $24 \mathrm{~h}$ Silicatmangel eine auf ca. $170 \mathrm{mg}$ FAME pro g Trockengewicht gesteigerte Lipidmenge nachwiesen. Bezogen auf den FA-Anteil am Trockengewicht ist dies 3.5x mehr als in dieser Arbeit beobachtet. Der Abbau einer großen FA-Menge in 2.5 bis $6 \mathrm{~h}$ ist fraglich. Die von Smith et al. beobachteten FA-Verhältnisse blieben während der Silicatmangelphase ungefähr konstant, die mit der Zeit stark erhöhte FA-Menge jedoch 
deutet auf eine Weiterproduktion von Lipiden bei gleichzeitig geringerem Bedarf an Biomembransynthesen hin. Die während Silicatmangels fortgesetzte Lipidproduktion wurde auch von Coombs et al.[121] für die Kieselalge Navicula pelliculosa beobachtet. Darüberhinaus stellten sie auch fest, dass die Lipidmasse pro Zelle $8 \mathrm{~h}$ Stunden nach Silicatzugabe abnahm. Wie bereits erwähnt, war in dieser Arbeit kein signifikanter Unterschied zwischen Tp-div und Tp-G1 bezüglich des FA-Anteils vorhanden, sodass ein Abbau von Lipiden $6 \mathrm{~h}$ nach der Silicatmangelphase noch nicht erkennbar war.

Das Total-FA-Profil änderte sich ebenfalls unmerklich beim Übergang von Tp-div zu Tp-G1. Als häufigste FAs in Tp wurden 16:1, 16:0 und 20:5 detektiert. Dies ist in Übereinstimmung mit Tonon et al. ${ }^{[122]}$ und Smith et al. ${ }^{[47]}$. Andere Publikationen ${ }^{[119,123-}$ 125] nennen 14:0 als weitere prominente FA, deren Anteil in dieser Arbeit jedoch geringer ausfiel. Die Unterschiede des FA-Profils in Tp für die verschiedenen Arbeiten zeigt, wie sensibel der Organismus schon auf geringe Unterschiede in den Kultivierungsbedingungen reagiert. Abb. 5.1 und 5.2 zeigen die Anteile von FAs mit mindestens 20 C-Atomen einerseits und die ternäre Übersicht über den Sättigungsgrad der FAs im Vergleich zu Literaturwerten für Tp. Eine gute Übereinstimmung wurde mit Tonon et al. (2004 und 2005) ${ }^{[126,122]}$ gefunden. Cook und Hildebrand ${ }^{[124]}$ sowie Zhukova ${ }^{[123]}$ zeigten ungefähr halb so viel FAs mit mindestens 20 C-Atomen. Hier sei explizit erwähnt, dass erstere Tp auch unter Silicatmangel untersuchten. Volkman et al. ${ }^{[119]}$ zeigten etwas geringere Anteile als in dieser Arbeit. Auch diese Vergleiche zeigen den Einfluss von zum Teil geringen Kultivierungsbedingungsunterschieden, wie z.B. die Belichtung. So nutzten Cook und Hildebrand etwa eine konstante Belichtung und keinen Tag/Nacht-Zyklus. Außer Zhukova verwendeten alle hier genannten Veröffentlichungen den gleichen Tp-Klon CCMP1335 (synonym zu CCAP 1085/12 bei Tonon und 3H bei Volkman). Die Unterschiede zu Zhukova sind daher auch genetisch zu erklären. Die Sättigungsgradkomposition der Gesamtheit der detektierten FAs war im Vergleich zu den genannten Quellen ähnlich. 


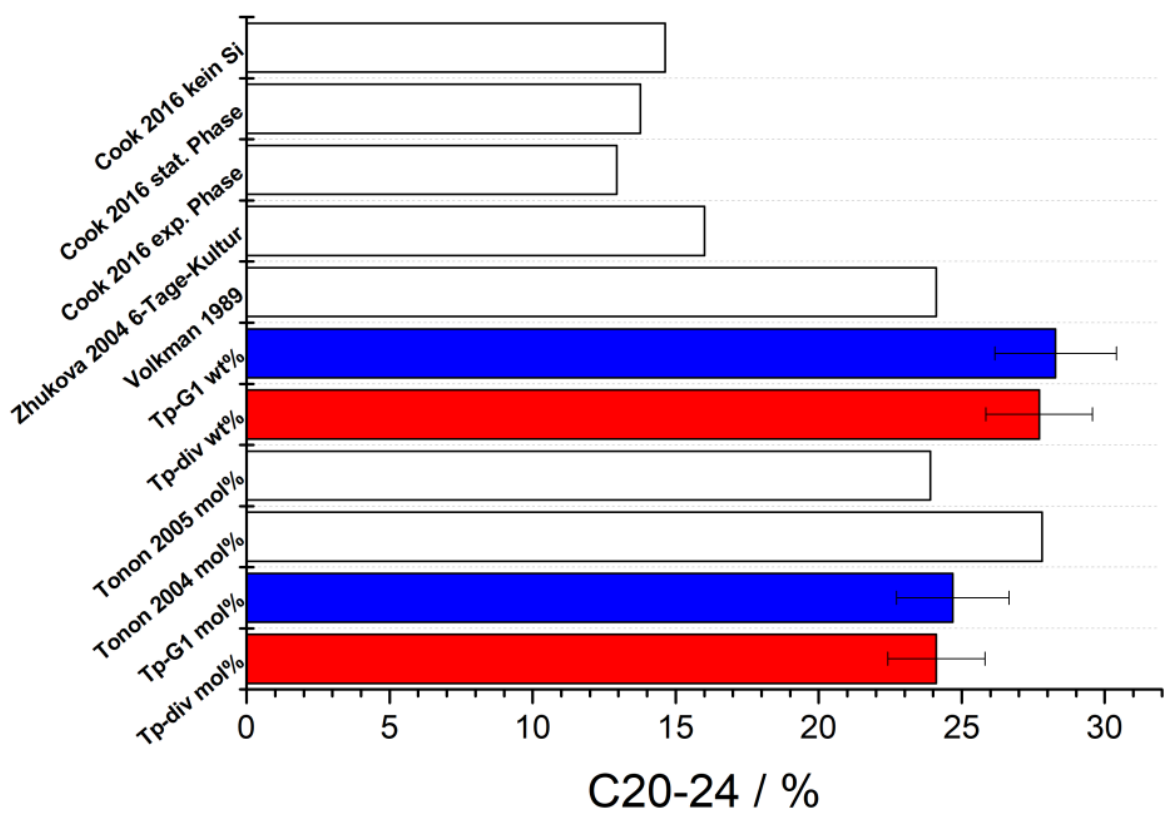

Abbildung 5.1: Vergleich des Anteils von FAs mit mindestens 20 C-Atomen am Gesamt-FA-Profil in Tp-div (rot) und Tp-G1 (blau) mit den Literaturwerten von Cook/Hildebrand, Zhukova, Volkman et al. (alle in wt\%) sowie Tonon et al. (mol\%). ${ }^{[124,123,119,126,122]}$ Gezeigt wird die Standardabweichung des Mittelwerts als Fehlerbalken.

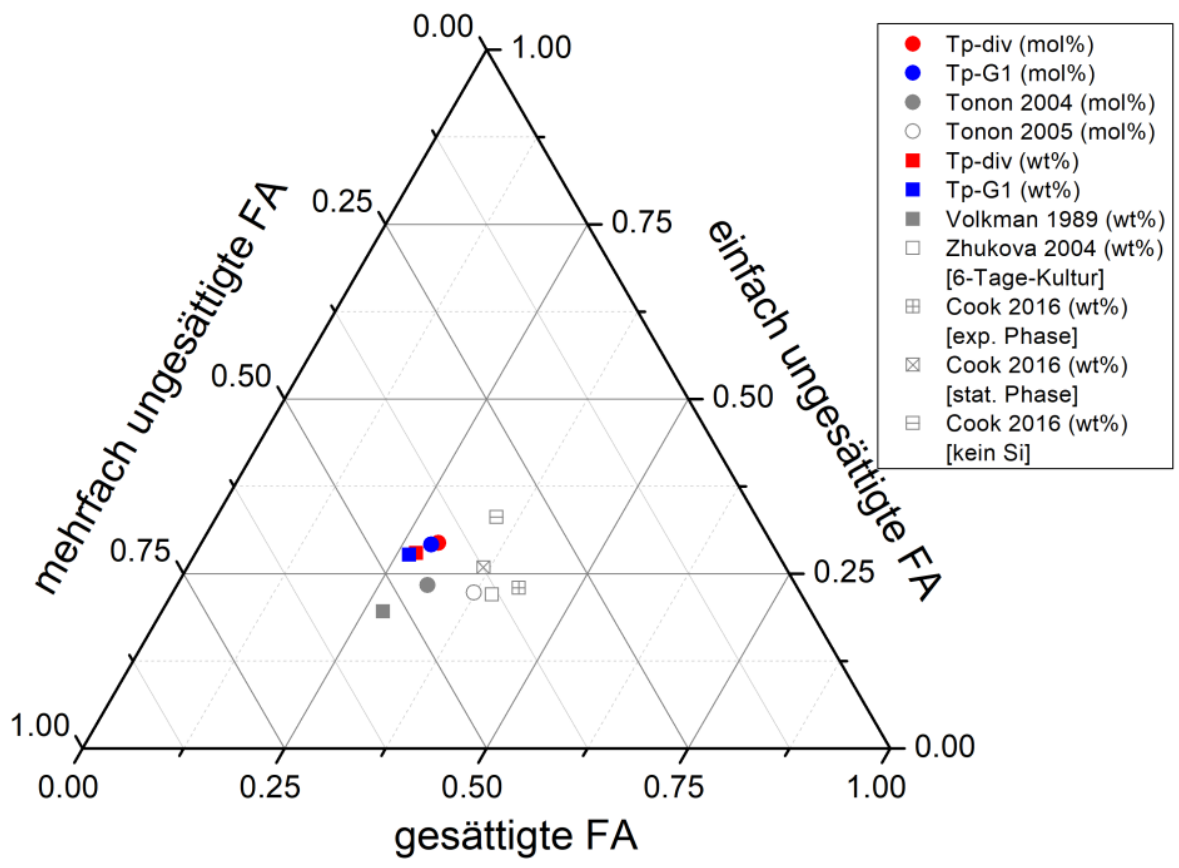

Abbildung 5.2: Vergleich der Sättigungsgradzusammensetzung der FAs in Tp-div und Tp-G1 mit den Literaturwerten von Cook/Hildebrand, Zhukova, Volkman et al. (alle in wt\%) sowie Tonon et al. (mol\%). ${ }^{[124,123,119,126,122]}$ 


\subsubsection{Hauptlipidklassen in Thalassiosira pseudonana}

Die Mengen der polaren Hauptlipidklassen in Tp-div und Tp-G1 wurden mittels Dünnschichtchromatografie (TLC) mit anschließender GC-FID quantifiziert. Es konnten auf diesem Wege die Gehalte für fünf polare Hauptlipidklassen bestimmt werden: die Glycolipide MGDG, DGDG und SQDG sowie die Phosphoglycerolipide PG und PC. Die Bestimmung der jeweiligen Anteile dieser polaren Hauptlipidklassen für $\mathrm{Tp}$ ist bisher noch nie geschehen. Zudem sollten die genannten Anteile zwischen Tpdiv und Tp-G1 verglichen werden, um einen zellzyklusphasenspezifischen Unterschied der Lipidverteilung zu beschreiben. Dies könnte Rückschlüsse auf die Lipidkomposition von Valven-SDVs zulassen.

Die Quantifizerung der lipidklassenspezifischen FA-Mengen nach beiden Methoden ergab, dass MGDG und SQDG über $23 \%$ der polaren Hauptlipide ausmachen, während PG und DGDG Anteile zwischen 11 und $20 \%$ aufweisen. PC zeigte je nach Methode einen Anteil von 8 bis $11 \%$. Für beide Methoden wurde kein statistisch signifikanter Unterschied zwischen Tp-div und Tp-G1 festgestellt, sodass zumindest nach dieser Methodik kein zellzyklusphasenspezifischer Unterschied der polaren Lipidkomposition feststellbar ist.

Ein Literaturwert für das Lipidklassenprofil von $\mathrm{Tp}$ ist nicht bekannt, jedoch zeigten Vieler et al. ${ }^{[127]}$ für die wie Tp zentrische Kieselalge Cyclotella meneghiniana, dass die gleichen polaren Lipidklassen in folgenden Mengen vertreten waren: MGDG (33.7\%), SQDG (24.7\%), DGDG (17.5\%), PG (15.4\%) und PC (8.7\%). Diese Anteile sind qualitativ in guter Übereinstimmung zu den hier gefundenen Werten für Tp (Tab. 5.1). $P C$ ist in beiden Fällen mit $<11 \%$ die am schwächsten vertretene der fünf Lipidklassen. PG und DGDG zeigen einander ähnliche relative Mengen im Bereich zwischen 11 und $20 \%$, während SQDG um $25 \%$ liegt. MGDG wurde hier in Tp je nach Quantifizierungsmethode mit 43 bzw. $26 \%$ beziffert, $C$. meneghiniana liegt mit $33.7 \%$ dazwischen. Die Ähnlichkeit zu den Werten in C. meneghiniana wird dahingehend gedeutet, dass dieses Profil von polaren Hauptlipidklassen speziesübergreifend für die Funktionalität und Lebensfähigkeit von zumindest einigen Kieselalgen notwendig ist. 
Tabelle 5.1: Lipidklassenzusammensetzung nach TLC-Auswertung mittels GC-FID oder Bandenintensität der Primulinfluoreszenz im Vergleich zu den Werten für Cyclotella meneghiniana von Vieler et al.[127]. Die Standardabweichungen der Mittelwerte ( $\mathrm{N}=4$ für $\mathrm{GC}-\mathrm{FID} ; \mathrm{N}=6$ für Primulinfluoreszenz) sind als Fehler angegeben.

\begin{tabular}{|l|l|l|l|}
\hline in $\%$ & Anteil (GC-FID) & Anteil (Primulinfluoreszenz) & C. meneghiniana \\
\hline MGDG & $42.8 \pm 0.4$ & $25.5 \pm 5.1$ & 33.7 \\
\hline SQDG & $23.2 \pm 1.9$ & $26.2 \pm 3.6$ & 24.7 \\
\hline PG & $14.0 \pm 1.6$ & $19.2 \pm 2.0$ & 15.4 \\
\hline DGDG & $11.5 \pm 1.1$ & $18.4 \pm 3.2$ & 17.5 \\
\hline PC & $8.5 \pm 1.1$ & $10.7 \pm 1.9$ & 8.7 \\
\hline
\end{tabular}

Van Mooy et al. ${ }^{[41]}$ zeigten für Tp ohne Phosphatmangel ein Verhältnis von SQDG zu

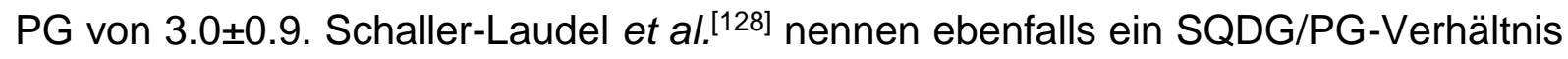
von 2.9 in Thylakoidmembranen von Tp. In dieser Arbeit wurde lediglich ein SQDG/PGVerhältnis von 1.7 bzw. 1.4 nachgewiesen. Ein Grund könnte die 24-stündige Silicatmangelphase sein, deren Einfluss auf die Lipidklassenanteile noch nicht erforscht ist. Schaller-Laudel et al. geben ein MGDG/DGDG-Verhältnis von 2.5 in TpThylakoidmembranen an. Dies liegt zwischen den hier beobachteten Verhältnissen von 3.7 (TLC-GC-FID) und 1.4 (TLC-Primulin). Das von Schaller-Laudel et al. für Tp ermittelte Verhältnis (MGDG+DGDG)/(SQDG+PG)=0.92 ist in guter Übereinstimmung mit den hier aus der Primulinfluoreszenz berechneten 0.97 in Tp. Die GC-FIDQuantifizierung liefert mit 1.43 einen weit davon entfernten Wert. Die vier Lipidklassen sind zwar als typische Thylakoidmembranlipide bekannt, doch ist ihr Auftreten in anderen Membranen und ein daraus resultierendes verändertes Verhältnis möglich.

\subsubsection{Lipid- und Fettsäureprofile einzelner Lipidklassen}

Es wurden relative Lipid- und FA-Profile der einzelnen Lipidklassen mittels UPLCnanoESI-MS/MS (hier verkürzt LC-MS/MS) bestimmt. Es soll hier ein Vergleich mit den von Hunter et al. ${ }^{[48]}$ für Tp ohne Phosphatstress ermittelten Profilen gezogen werden. Sie hatten eine Lipid-Quantifizierung mit Direktinfusion-ESI-MS/MS zusammen mit internen Standards durchgeführt.

Für PC wurden als häufigste Lipide 18:4/20:5 (17\%) und 16:0/18:4 (9\%) gefunden. Tp-div zeigte ca. doppelt so viel 20:5/20:5 wie Tp-G1 (11\% zu $5 \%$ ). Auch 20:5/22:6 
gehörte mit $8 \%$ relativem Anteil zu den prominentesten PC-Lipiden. Hunter et al. fanden ebenfalls 18:4/20:5 und 16:0/18:4 als häufigste PC-Lipide. Auch 20:5/20:5 und 20:5/22:6 lagen bei über $5 \%$ relativem Anteil. Für 16:0/20:5 und 16:1/20:5 zeigten sie höhere Vorkommen als die in dieser Arbeit kalkulierten. Die Übereinstimmung beider Profile ist jedoch insgesamt offensichtlich. Unter Phosphatstress konnten Hunter et al. auch das Betainlipid Diacylglyceryl-3-(O-carboxyhydroxymethylcholin) (DGCC) detektieren und quantifizieren, ohne Phosphatstress jedoch nicht. Auch in dieser Arbeit unter Bedingungen ohne Phosphatstress konnte DGCC nicht detektiert werden. Dass DGCC das Phospholipid PC in Tp unter Phosphatstress ersetzt, ist bereits bekannt. ${ }^{[41]}$ Für PG war 16:1/16:0 mit ca. $30 \%$ die prominenteste FA-Kombination. Auch Hunter et al. zeigten die gleiche Dominanz dieses Lipids. Die vier weiteren hier detektierten Lipide mit mindestens $5 \%$ relativem Anteil wurden ebenso von Hunter et al. gefunden. Die Profilübereinstimmung war sehr gut.

Dominante PE-Lipide waren mit Abstand 20:5/22:6 (ca. $40 \%$ ) und 20:5/20:5 (ca. $30 \%$ ). Diese Reihenfolge wurde auch von Hunter et al. festgestellt, jedoch zeigten dort 20:5/20:5 und 16:1/20:5 ähnliche Anteile, während 16:1/20:5 in dieser Arbeit mit lediglich $8 \%$ deutlich unter 20:5/20:5 lag. Die generelle Übereinstimmung der Profile wird als gut bewertet.

MGDG zeigte mit 16:3/16:3 (18\%), 16:4/16:3 (10\%) und 16:4/20:5 (9\%) als meistvorkommende Lipide einen großen Unterschied zu dem MGDG-Lipidprofil von Hunter et al. Sie nannten in ihrer Publikation gar keine 16:4-beinhaltenden Lipide und 16:3/16:3 wurde für MGDG zwar mit mindestens $5 \%$ angegeben, lag jedoch bezüglich des relativen Anteils nur auf Platz 5 oder 6. Die Lipide mit höchsten Anteilen waren dort 16:1/16:0 (ca. $25 \%$ ), 32:2 (vermutlich 16:1/16:1) sowie 16:1/14:0. Die ersten beiden wurden hier mit 5 bzw. 7 \% quantifiziert. Der Grund für die großen Unterschiede ist unklar.

Das DGDG-Lipidprofil wurde mit über $55 \%$ von 16:2/20:5 dominiert. Die von Hunter et al. genannten häufigsten Lipide sind ebenso wie für MGDG 16:1/16:0 (ca. $40 \%$ ), 32:2 (vermutlich 16:1/16:1) sowie 16:1/14:0. 16:2/20:5 wurde mit mindestens $5 \%$ aufgeführt. Auch hier ist der Grund für die gravierenden Unterschiede unbekannt.

SQDG zeigte für Tp-div und Tp-G1 unterschiedliche Verteilungen der FAKombinationen. Während 14:0/18:4 und 14:0/14:0 mit jeweils über $25 \%$ Anteile in Tp- 
div vorliegen, zeigt Tp-G1 16:0/16:0 als klar dominant (>45 \%), gefolgt von 16:0/22:6 (20\%) und 14:0/18:4 (15\%). Von diesen wurde nur 14:0/14:0 als häufige Kombination von Hunter et al. beobachtet. Diese starke Umstrukturierung von SQDG im Laufe des Zellzyklus könnte mit dem 24-stündigen Silicatmangel zur Synchronisation zusammenhängen. Smith et al! ${ }^{[47]}$ fanden, dass Silicatmangel bereits nach 8 bis $12 \mathrm{~h}$ stärkere Pigmentierungen der Chloroplasten sowie einen Anstieg des nichtphotochemischen Quenchings (NPQ) zur Folge hat. Eine Veränderung der Zusammensetzung der Chloroplasten-lokalisierten Glycolipide könnte im Zuge dieser Anpassungen möglich sein. Die SQDG-Profilunterschiede von Tp-div und Tp-G1 müssten dann aus einer Erholung vom Silicatmangel und Readaption zwischen den beiden Zellernten $3 \mathrm{~h}$ bzw. $6 \mathrm{~h}$ nach Silicatzugabe resultieren. Andererseits ist es auch möglich, dass SQDG mit dem Zellzyklus einen eigenen Zyklus der FA-Komposition durchläuft. Um dies zu untersuchen, müssten Proben mit verschiedenen Erntezeitpunkten auf die SQDG-Zusammensetzung analysiert werden. Die Schwierigkeit besteht darin, dass die Zellen mit zunehmendem Abstand zum Ende der Silicatmangelphase ihre Synchronisation verlieren.

Prominente DAG-Lipide waren 16:1/16:1, 16:1/16:0 und 14:0/16:1. Dieselben Lipide wurden auch von Hunter et al. als häufigste DAG-Lipide aufgeführt. Für TAG wurden 48:2, 48:3, 48:1, 46:2 und 46:1 mit über $5 \%$ relativem Anteil detektiert. Yu et al. [129] kamen für Tp-Kulturen mit Silicatmangel zu einem gleichen Ergebnis, wobei auch noch 48:4, 50:5, 52:6 und 52:7 die $5 \%$-Marke erreichten. Von diesen zeigten 48:4, 52:6 und $52: 7$ in dieser Arbeit zumindest Anteile über $3 \%$. Bezüglich des FA-Profils waren 16:1, 16:0, 20:5 und 14:0 dominant. Diese wurden auch von Tonon et al. ${ }^{[120]}$ als wichtigste TAG-FAs in Tp identifiziert.

Die Lipidklassen mit hohen Anteilen ( $>30 \%$ ) an 20:5 und 22:6 waren PC, PE und PA mitsamt ihren Lysoformen LPC, LPE und LPA sowie DGDG. PE überragte alle anderen Klassen mit einem Anteil von über $80 \%$. PS und PI dagegen zeigten keine oder kaum Anteile von sehr langen FAs mit mindestens 20 C-Atomen.

Die dominanten Sphingolipide der Ceramide, Glycocerebroside und Diglycocerebroside waren 18:3;2/24:1 mit 50, 60 bzw. $80 \%$ relativem Anteil. Dies ist eines der Sphingolipide, das auch Hunter et al. detektiert hatte. Er konnte einen Foldchange von über 6 für dieses und andere Sphingolipide nachweisen, wenn TpKulturen unter Phosphatstress gerieten. ${ }^{[48]}$ In dieser Arbeit konnte für das dominante 
Ceramid ein signifikanter relativer Anstieg um den Faktor 1.2 in Tp-div gegenüber TpG1 festgestellt werden.

Freie Sterole und Sterolderivate wurden ebenfalls in Tp-div und Tp-G1 analysiert. Unter den Derivaten konnten Sterylglycoside und acylierte Sterylglycoside zwar nicht detektiert werden, Sterolester wurden jedoch nachgewiesen. Sowohl freie Sterole als auch Sterolester waren zu $94 \%$ einer Spezies mit der Fragmentionenmasse $381 \mathrm{~g} / \mathrm{mol}$ zuzuordnen. Veron et al. ${ }^{[52]}$ fanden einen Gesamtsterolanteil von $0.88 \mathrm{wt} \%$ am Trockengewicht von $\mathrm{Tp}$, aufgeteilt auf $64.5 \%$ Sterolester, $32 \%$ freie Sterole, $2.5 \%$ Sterylglycoside sowie $1 \%$ acylierte Sterylglycoside. Ein in Frage kommendes Sterol wäre Brassicasterol (24-Methylcholesta-5,22-dien-3ß-ol), dessen Masse ohne die Hydroxygruppe genau der Fragmentmasse von $381 \mathrm{~g} / \mathrm{mol}$ entspräche. Diese Spezies wurde von Veron et al. für freie Sterole auf $7.5 \%$ relativen Anteil quantifiziert. Für Sterolester wurde es jedoch nicht nachgewiesen. Das ebenfalls passende Sterol 24Methylcholesta-5,24(24')-dien-3ß-ol wurde von Veron für freie Sterole und Sterolester mit 31 bzw. $16 \%$ angegeben. Volkman/Hallegraeff ${ }^{[130]}$ dagegen nennen $75 \%$ für diese Spezies in Tp (Klon 3H synonym zu CCMP 1335) und Rampen et al. ${ }^{[131]}$ sogar $85 \%$. Diese Werte entsprechen eher den hier ermittelten Werten. Die Sterolester zeigten mit $92 \%$ einen sehr hohen Anteil an mehrfach ungesättigten FAs.

Insgesamt betrachtet wurden keine größeren Unterschiede in den Fettsäurezusammensetzungen der meisten Lipidklassen zwischen Tp-div und Tp-G1 beobachtet. Tendenziell mag eine Erhöhung des relativen Anteils von 20:5 und 22:6 in den Phospholipiden PC, LPC, PA und PE (nur für 20:5) in Tp-div verglichen mit TpG1 erkannt werden. Sterolester zeigten sogar eine Verdopplung des 20:5-Anteils in Tp-div. Demgegenüber stehen tendenziell geringere relative Anteile von 20:5 und 22:6 in den Neutrallipiden DAG und TAG, sodass auf die gesamte Zelle gerechnet keine signifikanten Unterschiede der 20:5- und 22:6-Anteile zwischen Tp-div und Tp-G1 vorliegen (siehe Kapitel 4.1.1 und 5.1.1). Eine Umverteilung dieser sehr langen mehrfach ungesättigten Fettsäuren von Neutrallipiden, insbesondere dem Energieund Fettsäurespeicher TAG, zu den genannten Phospholipiden wäre daher denkbar. Ein Grund könnte die mit dem hohen Grad an Unsättigung verbundene höhere Unordnung der Fettsäureketten sein, sodass die SDV-Membran phasenseparierte Bereiche mit stark ungeordneten Fettsäuren ausbildet. Wassall und Stillwell beschrieben eine Aversion von membranlokalisiertem 22:6 mit Cholesterol, sodass es zu Phasenseparation und Ausbildung von lipid raft-opponierenden Bereichen kam. ${ }^{[55]}$ 
Solche Bereiche hoher Unordnung könnten eine noch nicht identifizierte Rolle in der Funktion der SDV-Membran spielen.

\subsubsection{Foldchange einzelner Lipidklassen}

Der relative Anteil der LC-MS/MS-Signale einer Lipidklasse an der Gesamtheit der Lipidsignale (siehe Abb. 4.22) wurde zwischen Tp-div und Tp-G1 verglichen und ins Verhältnis gesetzt. Dieser Foldchange (siehe Abb. 4.23) beschreibt die Zunahme (>1) oder Abnahme $(<1)$ des relativen Anteils der betrachteten Lipidklasse am Gesamtlipidom, das mittels LC-MS/MS detektiert wurde. Die Anteilzunahme von Lipidklassen in Tp-div kann bedeuten, dass diese Lipidklasse Bestandteil der Silicafällungsvesikel (SDV)-Membran ist.

Signifikante Zunahmen der relativen Lipidanteile in Tp-div gegenüber Tp-G1 wurden für PC, PE, PA (1.5-1.7x) sowie LPC (3.3x) festgestellt. Die Glycolipide MGDG, DGDG (beide 0.7-0.8x), SQDG und die Lysolipide LPG, DGMG (alle 0.4-0.5x) und SQMG $(0.2 x)$ zeigten statistisch signifikante Abnahmen des relativen Anteils ebenso wie Sterolester und Ceramide (beide 0.5x). Die Neutrallipide DAG und TAG sowie die Phospholipide PG, PI und PS zeigten für Tp-div und Tp-G1 gleiche relative Anteile.

Der Nachweis von Foldchanges der polaren Hauptlipidklassen PC, MGDG, DGDG und SQDG aus den LC-MS/MS-Daten widerspricht den Beobachtungen der TLC-GC-FIDAnalysen, die keine Veränderungen des Lipidklassenprofils zeigten. Dies könnte, wie in Kapitel 5.1.2 diskutiert, mit einer größeren Fehleranfälligkeit der TLC-Methodik zusammenhängen, bei der zum einen Hintergrundsignale mit ausgewertet wurden, zum anderen die korrekte Definition der Lipidbanden aufgrund der nur visuellen Prüfung der Primulinfärbung erschwert war.

Die Zunahme der PC- und PE-Anteile spricht für eine vermehrte Synthese dieser Lipide in Tp-div, vermutlich im Zusammenhang mit dem Aufbau der Valven-SDVMembran. Kennedy und Weiss beschrieben den zugehörigen Syntheseweg in Eukaryoten aus Cholin und Ethanolamin, der als Kennedy-Weg bekannt wurde. [132] Erhöhte Mengen an PC könnten auch die daraus folgenden Produktionen von LPC (mittels Phospholipase A2 im Lands-Zyklus) ${ }^{[133,134]}$ und PA (mittels Phospholipase D) erklären. ${ }^{[135]} \mathrm{PA}$ ist ein Vorläufer von DAG, das im de novo-Syntheseweg (Kennedy- 
Weg) eine Rolle für die PC-Synthese spielt. ${ }^{[134,44]}$ Die Foldchanges $<1$ der Glycolipide wird dahingehend gedeutet, dass die Thylakoidmembransynthese in Tp-div im Vergleich zu Tp-G1 gedrosselt ist. Die Produktion von SDV-Membranen (Silicalemma) ist vermutlich das Hauptziel der Lipidsynthese im Zellzyklusstadium der Zellteilung, wenn Valven-SDVs aufgebaut und neue Silicazellwandbestandteile produziert werden. PA könnte in erster Linie als Ressource für die Phospholipidsynthese dienen oder aber wegen seines hohen Packungsparameters in Bereichen starker Membrankrümmung eingebaut werden. Falls LPC Teil der Membran ist, könnte es aufgrund seines niedrigen Packungsparameters ${ }^{[136,137]}$ ebenfalls in Bereichen starker Krümmung eingebaut werden. Das Valven-SDV wird als pfannkuchenförmiges Vesikel beschrieben ${ }^{[138]}$, dessen Membran eher planar ist. Deshalb und aufgrund der gefundenen Foldchanges wird hier postuliert, dass die SDV-Membran zu großen Teilen aus PC und PE besteht, die als Bestandteile planarer Membranen bekannt sind.

\subsection{Charakterisierung von rSin $1^{-\mathrm{SP}}$}

Ein Ziel dieser Arbeit war die Entwicklung einer Modellmembran für SDVs. Neben einer vereinfachten aber realitätsbasierten Lipidkomposition, sollte sie das Transmembranprotein Silicanin-1 enthalten. Die Analyse der Aminosäuresequenz dieses Proteins zeigte, dass ein Signalpeptid $N$-terminal vorliegt, dass Sin 1 den cotranslationalen Import in das Endoplasmatische Retikulum erlaubt und selber abgespalten wird. ${ }^{[34]}$ Daher wurde in dieser Arbeit das rekombinante Silicanin-1 ohne Signalpeptid $\left(\mathrm{rSin} 1^{-\mathrm{SP}}\right)$ verwendet.

Die Expression dieses Proteins in Escherichia coli bedeutet eine andere Translationsumgebung als in der eukaryotischen Kieselalge Thalassiosira pseudonana. Die native Proteinfaltung von Sin1 ist bisher nicht bekannt, jedoch nannten Kotzsch et al. ${ }^{[34]}$ eine Sekundärstrukturvorhersage mit $28 \%$ a-Helix, $14 \% \beta$ Faltblatt und $58 \%$ ungeordneten Regionen. In derselben Veröffentlichung wurde die rekombinante variante $r \operatorname{Sin} 1$ lum vorgestellt, die nur die $N$-terminale Domäne ohne Signalpeptid, Transmembrandomäne und intrazelluläre $C$-terminale Domäne enthält. Für rSin $1^{\text {lum }}$ wurde dort mittels CD-Spektroskopie eine Sekundärstrukturverteilung bei $25^{\circ} \mathrm{C}$ in $10 \mathrm{~mm}$ Natriumphosphatpuffer $(\mathrm{pH} 7.7)$ von $18 \%$ a-Helix, $22 \% \beta$-Faltblatt, $18 \% \beta$-Schleifen und $43 \%$ ungeordneten Regionen berechnet. Kotzsch et al. nennen 
eine theoretische Strukturvorhersage für natives $\operatorname{Sin} 1$ mit $28 \%$ a-Helix, $14 \% \beta$ Faltblatt und $58 \%$ ungeordneten Bereichen. ${ }^{[34]}$

In dieser Arbeit wurde aus CD-Messungen bei $20^{\circ} \mathrm{C}$ eine Sekundärstrukturverteilung für rSin $1^{\text {-SP }}$ von $10 \pm 7 \% \alpha$-Helix, 30 $\pm 4 \% \beta$-Faltblatt, $19 \pm 2 \% \beta$-Schleifen und $41 \pm 6 \%$ ungeordneten Regionen bestimmt. Dabei wurden keine Unterschiede zwischen $10 \mathrm{~mm}$ Natriumphosphatpuffer ( $\mathrm{pH}$ 7.7) und $10 \mathrm{mM}$ MOPS-Puffer $(\mathrm{pH}$ 7.7) beobachtet. Dieses Ergebnis wurde analog zu den für rSin1 1 lum veröffentlichten Werten mit dem OnlineProgramm Dichroweb, dem Algorithmus CDSSTR sowie dem Referenzdatenset 7 berechnet. Ungeordnete Regionen und $\beta$-Schleifen zeigen für beide Sin1-Varianten unveränderte Anteile. Ein niedrigerer $\alpha$-Helix-Anteil in $r \operatorname{Sin} 1^{-S P}$ war dagegen überraschend, da die vorhandene Transmembrandomäne theoretisch als $\alpha$-Helix vorliegen müsste und damit zu einem eher höheren Gesamtanteil beitragen würde. Möglich ist, dass die Verbindung von $N$-terminaler Domäne zu Transmembrandomäne in rSin $1^{-S P}$ eine zu rSin $1^{\text {lum }}$ veränderte Sekundärstruktur innerhalb der $N$-terminalen Domäne bewirkt, sodass diese effektiv weniger $\alpha$-Helices, aber mehr $\beta$-Faltblätter enthält. Da die Dialysebedingungen für $r \operatorname{Sin} 1^{-S P}$ sehr ähnlich zu denen für rSin $1^{l u m}$ waren, sind Unterschiede zwischen $r \operatorname{Sin} 1^{\text {lum }}$ und $r \operatorname{Sin} 1^{-S P}$ mit den fehlenden bzw. vorhandenen Transmembran- und $C$-terminalen Domänen einerseits, mit noch vorhandenen Verunreinigungen mit Proteinfragmenten in den $\mathrm{rSin}^{-\mathrm{SP}}$-Proben andererseits, zu erklären.

Die Bildung von Disulfidbindungen zwischen zwei Cysteinresten kann einen Einfluss auf die Proteinfaltung haben. Robinson et al. ${ }^{[139]}$ untersuchten für drei verschiedene Proteine die Disulfidbindungsausbildung in vitro entweder nach dem GefaltetenVorläufer-Modell oder dem quasi-stochastischen Modell. Ersteres beschreibt die Proteinfaltung bevor Disulfidbrücken entstehen, während letzteres die Disulfidausbildung vor der Proteinfaltung postuliert. ${ }^{[140]}$ Ihre Ergebnisse indizierten, dass sich ungeordnete Proteinbereiche nach dem quasi-stochastischen Modell verhalten, wobei auch nicht-native Disulfidverbindungen entstehen, während Bereiche mit definierten Sekundärstrukturen dem Gefalteten-Vorläufer-Modell folgen.

Da Sin1 18 Cysteine enthält, wurde bei der Dialyse mit einem Redoxpaar aus Glutathion und Glutathiondisulfid gearbeitet um ein kontrolliertes Ausbilden der Disulfidbindungen zu bewirken. Die Bestimmung freier Thiole in $r S i n 1^{-S P}$ nach der Dialyse zeigte keine ungebundenen Cysteinreste mehr an, womit das Protein 
vollständig cysteinverbrückt vorlag. Dieses Ergebnis stimmt mit den Beobachtungen für rSin $1^{\text {lum }}{ }^{[34]}$ überein, das auf sehr ähnliche Weise bei der Dialyse rückgefaltet und disulfidverbrückt wurde. Eine Aussage darüber, ob korrekte, d.h. native, Disulfidbindungen entstanden, ist nicht möglich, da die Präsenz von Proteinfragmenten in den $\mathrm{rSin}^{-\mathrm{SP}}$-Proben eine massenspektrometrische Analyse von verdautem, unreduziertem $r \operatorname{Sin} 1^{-\mathrm{SP}}$ verhinderte. Da rSin1 ca. $40 \%$ ungeordnete Bereiche enthält, ist es möglich, dass dort eher Zufallsverbindungen zwischen zwei Cysteinen entstanden, während Helices und Faltblätter nach ihrer Ausbildung durch definierte Cysteinkombinationen weiter stabilisiert wurden.

\subsection{Aggregationsverhalten von $\mathrm{rSin} 1^{-\mathrm{SP}}$}

Für die $\mathrm{N}$-terminale Domäne von $\operatorname{Sin} 1$ ( $\mathrm{S} \operatorname{Sin} 1^{\mathrm{lum}}$ ) wurde eine $\mathrm{pH}$-abhängige, reversible Selbstaggregation in vitro nachgewiesen. ${ }^{[34]}$ Das Selbstaggregationsverhalten von rSin $1^{-S P}$ wurde mittels DLS-Messungen bei pH 7.7 und 5.0 untersucht und verglichen. Dabei zeigte sich, dass das Protein bei pH $7.7 \mathrm{zu}$ mehr als $50 \%$ einen hydrodynamischen Durchmesser von $20 \mathrm{~nm}$ aufwies. Weitere $20 \%$ waren $65 \mathrm{~nm}$ im Durchmesser, der Rest zeigte mit $300 \mathrm{~nm}$ bereits große Aggregate. Der kleinste Durchmesser von $20 \mathrm{~nm}$ ist dreimal so groß wie der kleinste Durchmesser von rSin 1 lum bei $\mathrm{pH} 7.7$ von $6.8 \pm 0.6 \mathrm{~nm} \cdot{ }^{[34]}$ Diese als Monomer beschriebene Spezies machte $>99 \%$ der detektierten Partikel aus. Der Größenunterschied zwischen rSin1lum (363 Aminosäuren) und $r \operatorname{Sin} 1^{-S P}$ (409 Aminosäuren) reicht nicht als Erklärung für die Verdreifachung des Durchmessers einer eventuellen monomeren Form aus. Möglicherweise liegt rSin1-SP bereits bei pH 7.7 als Oligomer vor. Dabei könnte die Anwesenheit der Transmembrandomäne durch hydrophobe Wechselwirkungen Oligomerisierung begünstigen.

Bei pH 5.0 wurde in dieser Arbeit für $\mathrm{rSin}^{-\mathrm{SP}}$ eine deutliche Vergrößerung der Aggregate und des Anteils der großen Aggregate im Vergleich zu pH 7.7 nachgewiesen. So machten die Partikel mit dem Peakmaximum bei $900 \mathrm{~nm}$ über $97 \%$ der Partikelmasse aus. Kotzsch et al. wiesen bei pH 5.0 fast ausschließlich Aggregate mit einem Durchmesser von $1806 \pm 316 \mathrm{~nm}$ nach. ${ }^{[34]}$ Sie visualisierten die gebildeten Aggregate zudem mittels Cryo-Elektronenmikroskopie. Die pH-induzierte Selbstaggregation der $\mathrm{N}$-terminalen (luminalen) Domäne wird als wichtiger Bestandteil 
der Funktion von Sin1 angenommen, da das Lumen des Silicafällungsvesikels (SDV) einen sauren pH-Wert um 5 aufweist. ${ }^{[17,141]} \mathrm{Im}$ Unterschied zu Kotzsch et al. wurden die DLS-Proben vor den Messungen nicht zentrifugiert, um bereits vorhandene Aggregate zu sedimentieren. Dies war in dieser Arbeit nicht sinnvoll, da ansonsten alle Aggregate (insbesondere bei $\mathrm{pH}$ 5.0) sedimentiert worden wären, was eine Untersuchung der $\mathrm{pH}$-induzierten Aggregation verhindert hätte. Eine Möglichkeit der exakten Titrierung in der Küvette, wie Kotzsch et al. sie nutzten, lag nicht vor. Ein Grund für die Aggregatgrößenunterschiede bei pH 5.0 könnte die in dieser Arbeit genutzte geringere rSin1-Konzentration von $0.345 \mathrm{mg} / \mathrm{mL}$ (statt $1 \mathrm{mg} / \mathrm{mL}$ ) sein. Dies könnte kleinere Partikel begünstigen, weshalb der Durchmesser von 1806 nm nicht erreicht wurde.

Das rekombinante Protein rSin $^{-\mathrm{SP}}$ besitzt laut dem Onlineprogramm Expasy ProtParam ${ }^{[142,83]}$ einen theoretischen pl-Wert von 4.64. Das Onlineprogramm ProtCalc v3.4[143] gibt einen theoretischen pl von 4.76 an. Für rSin1lum ergeben sich 4.49 bzw. 4.60. Bei diesen Rechnungen ist eine eventuelle Proteinfaltung unberücksichtigt und es wurden nur die formalen pKs-Werte der reinen Aminosäuren in die Berechnung einbezogen. Bei dem neutralen pH-Wert 7.7 lag $\mathrm{rSin} 1^{-\mathrm{SP}}$ demnach bei einer kalkulierten Gesamtladung von -28.4 , bei pH 5.0 bei $-5.7 .{ }^{[143]}$ Die Nettoladung war somit durch Ansäuerung erheblich verringert worden. Die Verringerung der Ladung schwächt repulsive elektrostatische Wechselwirkungen ab und begünstigt daher die Aggregation. Dies wäre eine Erklärung für die Vermehrung und Vergrößerung von rSin1-Aggregaten bei Ansäuerung. Nicht auszuschließen ist eine Veränderung von Sekundär- und Tertiärstruktur bei sauren $\mathrm{pH}$-Werten, die die Oberflächenstruktur des Proteins in Hinsicht auf Ladungen, Dipolen sowie Hydrophobizität beeinflusst. Eine mögliche $\mathrm{pH}$-abhängige Änderung der Sekundärstruktur sollte in Zukunft mittels CDSpektroskopie untersucht werden.

\subsection{Rekonstitution von rSin $1^{-\mathrm{SP}}$ in kleine unilamellare Vesikel}

Die Rekonstitution von $\mathrm{rSin} 1^{-\mathrm{SP}}$ in kleine unilamellare Vesikel ist ein wichtiger Schritt auf dem Weg zur Präparation einer festkörperunterstützten Membran mit insertiertem rSin1. Der prinzipielle Nachweis der Herstellung von Vesikeln mittels Comizellisierung erfolgte durch DLS-Messungen proteinfreier Vesikel, Phosphattests zum Nachweis der 
Phospholipide sowie dem Spreiten der Vesikel auf hydrophilen Substraten mit Lipideinzelschicht.

Die Größe der erhaltenen Vesikel konnte lipidkompositionsabhängig bestimmt werden. DOPC/POPG/TxR-DPPE = 79.5:20:0.5 zeigte mittlere Vesikeldurchmesser von $79 \pm 3 \mathrm{~nm}, \quad P O P C / P O P E / T x R-D P P E=69.5: 30: 0.5125 \pm 7 \mathrm{~nm}$. Damit lagen die Vesikelgrößen im Grenzbereich von kleinen zu großen unilamellaren Vesikeln. Hernandez et al. ${ }^{[144]}$ nutzten Comizellisierung für die Präparation von Synaptobrevin (Syb)-haltigen kleinen unilamellaren Vesikeln und ermittelten einen Proteoliposomenradius von $50 \pm 10 \mathrm{~nm}$ (Vesikeldurchmesser $100 \pm 20 \mathrm{~nm}$ ) mit der Lipidkomposition PC/PE/PS/Chol = 5:2:2:1. Diese Größe ähnelt den in dieser Arbeit beobachteten Vesikelgrößen. Aus zwei Präparationen kann noch keine feste Aussage über den Einfluss der Lipidkomposition auf die finale Vesikelgröße getroffen werden.

Durch einen Phosphattest wurde festgestellt, dass die proteinfreie Vesikelpräparation mittels Comizellisierung zu einem Verlust von 23 \% Lipidmaterial führte. Der Nachweis der verbliebenen $77 \%$ Phospholipide zeigt jedoch, dass genug Lipidmaterial zur Vesikelbildung vorhanden blieb. Für Proteoliposomenpräparationen durch Comizellisierung wurden zwar nur noch $42 \%$ der ursprünglich eingesetzten Phospholipide detektiert, doch auch dieser Anteil reicht prinzipiell für die Vesikelbildung aus. Dies wird ersichtlich, wenn man die theoretische Vesikelzahl $N_{V}$ sehr vereinfacht nach Gl. 5.1 berechnet.

$$
N_{\mathrm{V}}=\frac{N_{\mathrm{L}} \cdot a_{\mathrm{L}}}{\pi d^{2}} \cdot 0.5
$$

Dabei ist $N$ die Gesamtanzahl an Lipidmolekülen, a a die durchschnittliche Fläche pro Lipidmolekül, $d$ der Vesikeldurchmesser und der Faktor 0.5 folgt aus der groben Abschätzung, dass die Vesikel als Lipiddoppelschicht zwei Lipide pro Molekülfläche besitzen. Für $d=100 \mathrm{~nm}$, einer durchschnittlichen Lipidfläche von $62.7 \AA^{2}$ (POPC bei $\left.20{ }^{\circ} \mathrm{C}\right)^{[145]}$ sowie $279 \mathrm{nmol}$ detektierte Phospholipide (entspricht $42 \%$ ) ergibt sich eine Vesikelanzahl von $1.7 \cdot 10^{12}$.

Die Beobachtung von homogenen Membranen nach dem Spreitprozess unter dem Konfokalen Laserscanningmikroskop (CLSM) sind der finale Beweis, dass es sich bei den Proben nach der Comizellisierung und Größenausschlusschromatografie um Vesikel handelte. 
Die erfolgreiche Rekonstitution von $\mathrm{rSin}^{-\mathrm{SP}}$ in kleine unilamellare Vesikel wurde mit Carbonatextraktionsexperimenten sowie Histodenz-Coflotationsassays überprüft. Die Carbonatextraktion von rSin1-haltigen Proteoliposomen zeigte die Extraktion von nur $28 \%$ des Proteins aus dem Lipidmaterial. Kotzsch et al. erhielten eine Extraktion von ca. $50 \%$ für natives Sin1 und folgerten daraus, dass es als Transmembranprotein in die Membran eingebaut vorliegt. ${ }^{[34]}$ Das in dieser Arbeit erhaltene Resultat wird somit dahingehend als Bestätigung von $\mathrm{rSin}^{-\mathrm{SP}}$ als in Vesikel rekonstituiertes Transmembranprotein gedeutet.

Die Rekonstitutionseffizienz wurde mit Coflotationsassays bestimmt und betrug zumeist $30-60 \%$. Dabei zeigte sich die Tendenz, dass je niedriger der nominell eingesetzte Proteinanteil (kleineres $P / L$ ), desto höher wurde die Effizienz. Dies könnte in Zusammenhang mit der Beobachtung der Proteinaggregate bei pH 7.7 stehen. Es ist anzunehmen, dass Proteinoligomere die Rekonstitution in Vesikel behindern. Je geringer die finale Proteinkonzentration, desto eher verschiebt sich das Gleichgewicht zwischen rSin1-Oligomeren und Monomeren in Richtung der Monomere. Dagegen spricht jedoch der Einsatz von Detergensmizellen für die Comizellisierung, der die Oligomerisierung auch bei höheren Proteinkonzentrationen unterbinden müsste. Um dies zu bestätigen, müsste in Zukunft ein DLS-Experiment mit rSin1-Proben bei verschiedenen Detergenskonzentrationen durchgeführt werden. Dabei ist jedoch zu berücksichtigen, dass die Mizellen bei einem Durchmesser von mehreren Nanometern ebenfalls als Partikel erkannt würden und die Proteinmonomerpeaks überlagern könnten.

Es wurde ein Verlust von $88 \%$ des eingesetzten rSin 1 nach der Comizellisierung festgestellt. Verrechnet man dies mit dem erhaltenen Lipidmaterial wurde statt einem Protein-zu-Lipid-Verhältnis $(P / L)$ von 1:630 ein reales $P / L$ von 1:5100 in $r$ Sin1Proteoliposomen ohne freies Protein erhalten. Der Kollege Jan Kuhlmann beschreibt in seiner Dissertation [146] die Rekonstitution von SNARE-Proteinen in große unilamellare Vesikel (engl. large unilamellar vesicles, LUVs), wobei er nach der Rekonstitution lediglich $10 \%$ der anfänglich eingesetzten Synaptobrevin 2 (syb2)Proteinmenge nachweisen konnte. Dies entspricht in etwa dem in dieser Arbeit beobachteten Proteinverlust. Dabei ließ er die Proteoliposomen nach der Größenausschlusschromatografie zu einem Proteo-Lipidfilm trocknen, versetzte sie erneut mit Puffer und generierte schließlich große unilamellare Proteoliposomen durch Extrusion. Diese zusätzlichen Arbeitsschritte können zu der geringen Proteinausbeute 
beigetragen haben. Er beobachtete gleichzeitig einen fast ebenso hohen Lipidverlust für LUVs, sodass das Protein/Lipid-Verhältnis konstant blieb.

Die Orientierung des rekonstituierten $r \operatorname{Sin} 1^{-\mathrm{SP}}$ wurde mittels Chymotrypsinverdaus und folgender Charakterisierung der Anti-Sin1-Western Blot-Banden ermittelt. Es wurde indirekt gezeigt, dass rSin1 mit seiner großen $N$-terminalen Domäne überwiegend vom Vesikellumen wegzeigt, da keine Bande mit geringer Massendifferenz beobachtet wurde. Diese wäre zu erwarten gewesen, wenn ein signifikanter Anteil des Proteins gegensätzlich orientiert gewesen wäre. Da die $C$-terminale Domäne mit der Transmembrandomäne zusammen nur $4.9 \mathrm{kDa}$ Masse ergeben, lief das durch das Vesikellumen geschützte Fragment im genutzten 10\% SDS-PAGE-Gel mit der Laufmittelfront und konnte auch in einem Anti-His-Western Blot nicht visualisiert werden. Die Wiederholung mit einem hochprozentigen Trenngel ist hierfür notwendig.

\subsection{Silicafällungseigenschaften von rSin1 ${ }^{-S P}$-haltigen Proteoliposomen}

Die $N$-terminale Domäne von Sin1 (rSin1lum) zeigte in äquimolarem Verhältnis zu langkettigen Polyaminen (LCPA) eine synergistische Wirkung auf die Silicafällung. ${ }^{[34]}$ Beide Substanzen zusammen fällten somit mehr Silica als die Summe der Einzelkomponenten. In dieser Arbeit wurde untersucht, ob rSin1-SP ebenfalls Silica fällt, wenn es in Vesikeln rekonstituiert ist und inwieweit die Lipiddoppelschicht zur Silicafällung beiträgt.

Die LCPA-Lösung mit umgerechnet $1.2 \mathrm{mM}$ LCPA-Aminogruppen („N“) zeigte eine Fällung von $42 \mu \mathrm{g}$ Silicium in $10 \mathrm{~min}$ bei $\mathrm{pH}$ 6.65. Anja Bernecker konnte in ihrer Dissertation nachweisen, dass das LCPA C3N12 mit $1 \mathrm{mM}$ „N“ bei pH 6.8 in 10 min $14 \mu \mathrm{g}$ Silicium fällte, wenn $30 \mathrm{~mm}$ Phosphat präsent waren. ${ }^{[147]}$ Diese polyvalenten Anionen bewirken eine Verbrückung und verstärkte LCPA-Aggregation, die die Silicafällungseigenschaften maßgeblich erhöhen. ${ }^{[148]} \mathrm{Da}$ in dieser Arbeit keine polyvalenten Anionen, sondern nur Chlorid und Acetat vorhanden waren, ist die hohe Fällungsaktivität von $42 \mu \mathrm{g}$ überraschend. Bernecker zeigte für einen Acetatpuffer $(\mathrm{pH}$ 6.8) ohne Phosphat eine Fällung von nur $3.5 \mu \mathrm{g}$ Silicium in $10 \mathrm{~min}$. Es handelte sich in dieser Arbeit um ein Gemisch aus verschiedenen LCPAs, deren mittlere Stickstoffanzahl $\mathrm{N}=12$ betrug, und die allesamt einfach methyliert waren. Bernecker 
zeigte in zwei Messungen für methylierte LCPA C3N12Me (1 mM „N“) eine verdoppelte Silicafällung von $31 \mu \mathrm{g}$ Silicium statt $14 \mu \mathrm{g}$, allerdings ebenfalls in Anwesenheit von $30 \mathrm{~mm}$ Phosphat. Eine ausreichende Erklärung für die hohe Fällungsaktivität bietet die Methylierung somit nicht. Das Ergebnis dieser Arbeit widerspricht auch der Erkenntnis von Daus et al. ${ }^{[106]}$, die dasselbe LCPA für Silicafällungsexperimente bei pH 5.5 nutzten und eine minimale LCPA-Konzentration von ca. $1.1 \mathrm{~mm}$ feststellten, unter der keine Silicafällung beobachtet werden konnte.

Proteinfreie Vesikel mit einer finalen Lipidkonzentration von $0.175 \mathrm{mg} / \mathrm{mL}(0.46 \mathrm{mM})$ zeigten eine Silicafällungsaktivität von $14 \mu \mathrm{g}$ Silicium. Diese ist auf die Lipidkopfgruppen Phospatidylcholin und Phosphatidylethanolamin zurückzuführen. Die terminalen Aminogruppen wirken dabei in ähnlicher Weise wie die Aminogruppen der LCPAs. Vesikel sind geordnete Molekülaggregate, die eine definierte Grenzfläche zur Umgebung bilden. Diese Grenzfläche ist dabei gekennzeichnet durch eine homogene Kopfgruppenladungsstruktur. Negativ geladenenes Silicat adsorbiert an dieser Grenzfläche aus Aminogruppen und polykondensiert dort zu Silica. Vesikelgrenzflächen wirken wie LCPA-Aggregatgrenzflächen silicafällend. Möglicherweise können LCPAs auch mit den Phosphatgruppen der Phospholipidkopfgruppen wechselwirken und so an den Vesikeloberflächen akkumulieren. Das beobachtete Fällungsverhalten von Vesikeln könnte auch in vivo im Lumen des Silcafällungsvesikels (SDVs) stattfinden, wenn Kieselsäure direkt mit der Lipidmembrangrenzfläche interagiert. Eine Oberflächenbelegung der luminalen Membranseite mit Membranproteinen könnte dagegen eine Separation zwischen Silica und Lipidgrenzschicht bewirken, um eine direkte Silicafällung an der Membran zu verhindern.

Proteoliposomen mit einer finalen Lipidkonzentration von $0.095 \mathrm{mg} / \mathrm{mL}(0.25 \mathrm{~mm})$ fällten $11 \mu \mathrm{g}$ Silica gebundenes Silicium. Da die Lipidkonzentration 1.8x geringer war als für die Vesikelproben ohne Protein kann kein direkter Vergleich zwischen beiden Vesikelproben gezogen werden. Sollte sich die Fällung linear zur Lipidkonzentration verhalten, wären durch die Proteoliposomen bei $0.175 \mathrm{mg} / \mathrm{mL}$ Lipide ca. $20 \mu \mathrm{g}$ Silicium gefällt worden. Sollten weitere Messungen bestätigen, dass die Proteoliposomen unter gleichen Bedingungen mehr Silica fällen als Vesikel ohne Protein, müsste dies auf die Wechselwirkung der extravesikulären $N$-terminalen Domäne der rekonstituierten rSin1-Moleküle zurückzuführen sein. Zudem zeigten die Rekonstitutionsexperimente, 
dass ca. die Hälfte des Proteins frei in Lösung vorlag. Dieses freie Protein kann ebenfalls zur Silicafällung beitragen.

Die Kombination von Vesikeln ohne Protein bzw. Proteoliposomen mit LCPA zeigte keine synergistische Wirkung auf die Silicafällung, sondern eher geringfügige Reduktionen der Präzipitatmengen. Möglicherweise führen schwache Adsorptionen von LCPA an Vesikeloberflächen zu einer effektiv kleineren zur Verfügung stehenden Grenzfläche, an der Silica gefällt wird. Die Adsorption von LCPA an festkörperunterstützte Membranen wurde von Oliver Gräb in seiner Dissertation festgestellt. $\mathrm{Er}$ fand mittels reflektrometrischer Interferenzspektroskopie eine Schichtdickenänderung der artifiziellen Kieselalgenmembran von $0.9 \mathrm{~nm} \cdot{ }^{[149]}$ Zudem entdeckten Gräb et al. ${ }^{[65]}$ LCPA-induzierte Membranstapel. Die Adsorption von LCPA an die Vesikeloberfläche ist daher wahrscheinlich. Wie bereits erwähnt lag rSin1 zur Hälfte nicht rekonstituiert, sondern frei in Lösung vor. Diese Proteinpopulation konnte direkt mit LCPAs interagieren und möglicherweise LCPA-rSin1-Aggregate bilden, die eine Silicafällung begünstigen. Die Betrachtung der Fällungsmenge bezogen auf die Lipidmenge ergab nämlich einen signifikanten Unterschied zwischen Proteoliposomen und Vesikeln ohne Protein, genauer gesagt eine Verdopplung des gefällten Silicas (siehe Kapitel 4.3.6).

Der Unterschied zu den Experimenten von Kotzsch et al. ${ }^{[34]}$ war neben der Präsenz von Vesikeln ein deutlich geringeres Protein-zu-LCPA-Verhältnis. In dieser Arbeit lagen effektiv $0.6 \mu \mathrm{M}$ rSin1-SP gegenüber $100 \mu \mathrm{M}$ LCPA vor, während Kotzsch et al. beide Substanzen mit $25 \mu \mathrm{M}$ verwendeten. Die Beobachtung eines synergistischen Effekts von Faktor fünf bis sieben ist daher und wegen der vermutlichen Maskierung der Vesikel durch LCPA unwahrscheinlich.

\subsection{Visualisierung von rSin $^{-\mathrm{SP}}$ in festkörperunterstützten Membranen}

Aus der Orientierung des rSin1-Proteins in den Proteoliposomen folgte die Notwendigkeit einen Spreitpfad zu nutzen, nach dem die $\mathrm{N}$-terminale Domäne vom Substrat weg in das Medium hinein zeigt. Dazu wurde der Weg der Vesikelfusion mit einer Lipideinzelschicht nach Kalb et al. ${ }^{[108]}$ gewählt. 
Die Bildung kontinuierlicher festkörperunterstützter Membranen nach dieser Methodik konnte mittels CLSM-Mikroskopie bestätigt werden. Präparationen mit den beiden lipidgebundenen Fluorophoren Texas Red (TxR) und Atto 390 zeigten im FRAPExperiment (Fluoreszenzerholung nach Photobleichung) für beide Farbstoffe sehr hohe mobile Anteile mit über $95 \%$. Die lateralen Diffusionskoeffizienten wurden für Atto 390 auf $1.9 \pm 0.7 \mu \mathrm{m}^{2} \cdot \mathrm{s}^{-1}$ und für TxR auf $1.7 \pm 0.4 \mu \mathrm{m}^{2} \cdot \mathrm{s}^{-1}$ bestimmt. Wagner und Tamm ${ }^{[112]}$ ermittelten für POPC/NBD-eggPE $=98: 2$ in der oberen Lipidschicht nach der Vesikelfusionstechnik einen Diffusionskoeffizienten von $0.89 \pm 0.08 \mu \mathrm{m}^{2} \cdot \mathrm{s}^{-1}$. Sie arbeiteten mit einem Glassubstrat und einem tethered polymer (gebundenes Polymer) als Träger der Membran. Die Vesikelfusion mit einer glasunterstützten Lipideinzelschicht ergab $1.32 \pm 0.07 \mu \mathrm{m}^{2} \cdot \mathrm{s}^{-1}$. Das direkte Spreiten von großen unilamellaren Vesikeln (LUVs) auf Glas lieferte Hamai et al. ${ }^{[137]}$ für DOPC/TxR-DPPE = 99.5:0.5 einen Diffusionskoeffizienten von $2.1 \pm 0.1 \mu \mathrm{m}^{2} \cdot \mathrm{s}^{-1}$. Kalb et al. ${ }^{[108]}$ nennen $4.0 \pm 0.5 \mu \mathrm{m}^{2} \cdot \mathrm{s}^{-1}$ für die Vesikelfusion (POPC/NBD-PE = 99.8:0.2) auf einer quartzunterstützten Lipideinzelschicht und $3.5 \pm 0.5 \mu \mathrm{m}^{2} \cdot \mathrm{s}^{-1}$ für das direkte Spreiten der Vesikel auf Quartz. Der Größenbereich der in dieser Arbeit ermittelten Diffusionskoeffizienten ist mit den genannten Beispielen in Übereinstimmung. Unterschiede ergeben sich aus der Membranpräparationsmethode, Lipidkomposition, Pufferzusammensetzung, Fluorophor- und Substratauswahl. Die Lipiddiffusion einer intakten, kontinuierlichen Membran war somit gegeben.

Der etwas geringere Diffusionskoeffizient von TxR könnte darauf zurückzuführen sein, dass TxR der Farbstoff der dem Substrat zugewandten Lipideinzelschicht war und mit der hydrophilen Oberfläche wechselwirkt. Dies kann eine Verlangsamung der Diffusion bewirken. Es wurde jedoch nicht bestimmt, ob Atto 390-DPPE und TxR-DPPE einen Austausch zwischen beiden Lipidschichten eingehen. Dies könnte durch den FlipflopMechanismus geschehen, der kinetisch sehr gehemmt ist. ${ }^{[150]}$

Die Membranen, bei deren Präparation das fluoreszierende Lipid Bodipy 500/510 $\mathrm{C}_{12-}$ PPC verwendet wurde, zeigten in FRAP-Experimenten eine geringere laterale Diffusion von $D=0.8 \pm 0.2 \mu \mathrm{m}^{2} \cdot \mathrm{s}^{-1}$ sowie einem mobilen Anteil von $90 \pm 9 \%$. Przybylo et al. ${ }^{[151]}$ fanden für festkörperunterstützte DOPC-Membranen mit einem C8-Bodipy 500/510 C5-HPC-Anteil von 1:200000 $D=2.7 \pm 0.3 \mu \mathrm{m}^{2} \cdot \mathrm{s}^{-1}$. Als Substrat diente Mica und die Diffusion wurde mittels Z-Scan-FCS ermittelt. Guo et al. ${ }^{[152]}$ zeigten, dass mit Z-Scan-FCS gemessene Diffusionskoeffizienten ca. 2.5x höher waren, als wenn sie mittels FRAP bestimmt wurden. Berücksichtigt man diesen Unterschied zwischen den 
beiden Messmethoden, liegt der in dieser Arbeit beobachtete Diffsusionskoeffizient des Bodipy-Lipids in der Nähe des von Przybylo et al. gefundenen Werts.

Die Visualisierung von in der festkörperunterstützten Membran rekonstituierten rSin1 erfolgte mit fluoreszierenden Antikörpern. Es handelte sich um ein primäres AntiSerum, dessen Antikörper spezifisch an die $\mathrm{N}$-terminale Domäne von Sin1 binden sowie um einen sekundären Antikörper, der an die Kaninchen-Antikörper des Serums band. Der sekundäre Antikörper war an ein Alexa Fluor 647-Fluorophor gebunden und somit mittels CLSM detektierbar. Die Zugabe des Antiserums führte zu einer Veränderung der Bodipy-Verteilung, da sich nicht-fluoreszierende Bereiche der Membran ausbildeten. Für den pH-Wert 7.7 waren diese Fluoreszenzausschlüsse klein und punktförmig, sodass sich ein grobkörniges Bild ergab, während bei pH 5.0 größere rosettenförmige dunkle Bereiche entstanden. Die im Kaninchenserum vorhandenen Komponenten wie Elektrolyte und Proteine, insbesondere Serumalbumin (RSA) ${ }^{[153]}$, könnten für die Fluoreszenzausschlüsse verantwortlich sein. Der Einfluss von RSA auf Membranen dürfte sich von dem von Rinderserumalbumin (BSA) oder humanen Serumalbumin (HSA) kaum unterscheiden, da diese Proteine homolog sind. Law et al. ${ }^{[154]}$ entdeckten, dass BSA unabhängig von pH-Wert oder der Ladungstruktur von Vesikeln an diese adsorbieren, wobei hydrophobe Wechselwirkungen dafür verantwortlich gemacht wurden. Ruggeri et al.[155] fanden eine Reversibilität der Adsorption von BSA an festkörperunterstützten POPCMembranen. Negativ geladene Membranen (POPC/POPG = 75:25) führten dagegen zu einer irreversiblen Adsorption von BSA. Eine elektrostatische Komponente der Wechselwirkungen ist somit nicht auszuschließen. Die Oberflächenbelegung von HSA auf festkörperunterstützten Phosphatidylcholinmembranen, die mittels Spin Coatings präpariert wurden, wurde von Malmsten ${ }^{[156]}$ auf $0.30 \mathrm{mg} / \mathrm{m}^{2}$ beziffert. Galantai und Bardos-Nagy ${ }^{[157]}$ fanden heraus, dass HSA stärker mit kleinen unilamellaren Vesikeln (SUVs) als mit großen unilamellaren Vesikeln (LUVs) interagiert. Die stärkere Krümmung der SUVs wurde hier als Angriffspunkt für Serumalbumin genannt. Diese Krümmung könnte die Penetration der äußeren Lipidschicht durch Serumalbumin begünstigen. Für ein solches Eindringen des Serumalbumins in den hydrophoben Bereich der Lipidschicht spricht zudem die Beobachtung von Lis et al..[158], dass die BSA-Zugabe eine Konformationsänderung der Fettsäuremoleküle in 1,2-Dimyristoylsn-glycero-3-phosphocholin (DMPC)-Membranen verursacht. Unter der Annahme, dass auch RSA in die in dieser Arbeit präparierten festkörperunterstützten Membranen 
eindrang, würden an diesen Stellen Lipide, auch das Bodipy-markierte Phosphatidylcholin, verdrängt. Die Unterschiede zwischen pH 7.7 und 5.0 könnten auf die Ladungsstruktur des RSAs zurückzuführen sein. Seine ausgereifte Form (584 AS, UniProt PRO_0000001078) besitzt laut Expasy Protparam einen pl-Wert von 5.65, sodass der $\mathrm{pH} 5.0$ eine geringere Nettoladung des RSA bewirkt als $\mathrm{pH}$ 7.7. Der hydrophobe Charakter des Proteins wird somit verstärkt und begünstigt die Interaktion mit dem hydrophoben Bereich der Membran. RSA könnte in dem weniger geladenen Zustand auch stärkere Interaktionen zu anderen RSA-Molekülen eingehen und aggregieren. ${ }^{[159]}$ Dies würde die großen Bereiche mit Fluoreszenzaussschluss bei $\mathrm{pH}$ 5.0 gegenüber $\mathrm{pH} 7.7$ erklären. Um die Membranveränderungen (insbesondere bei $\mathrm{pH}$ 5.0) zu unterbinden, wäre der Einsatz von aus dem Antiserum aufgereinigten Antikörpern ohne weitere Serumbestandteile nötig.

Die Detektion von rSin1-SP erfolgte über die Anbindung und Detektion von Antikörpern. Dabei wurde beobachtet, dass die Präparate mit rSin 1 für pH 7.7 und pH 5.0 signifikant stärkere Alexa Fluor 647-Signale zeigten als rSin1-freie Präparate. Dies beweist zum einen, dass das Detektionssystem mit primärem Antiserum und fluoreszierendem sekundärem Antikörper zum Nachweis von rekonstituiertem rSin1 funktioniert, zum anderen, dass tatsächlich erhebliche Mengen an rSin1 in der festkörperunterstützten Membran so oriertiert ist, dass die mit den Antikörpern spezifisch wechselwirkende $\mathrm{N}$ terminale Domäne in das Medium zeigt. Damit war die Präparation einer artifiziellen planaren Membran mit rekonstituiertem und korrekt orientiertem rSin1 erfolgreich. Die deutlich schwächeren Signale bei pH 5.0 ergeben sich aus stark reduzierten rSin1Mengen, die rekonstituiert wurden, da sich das Protein bereits vor der Zugabe auf die Sephadexsäule (Größenausschlusschromatografie) zu großen Aggregaten verband, die selbst im Beisein von Detergensmizellen nicht mehr in die Vesikel eingebaut werden konnten.

\subsection{Ausblick}

Es wurde erfolgreich eine planare SDV-Modellmembran hergestellt, die neben den in Valven-SDVs vermutlich angereicherten PC- und PE-Lipiden die rekombinante Form rSin $1^{-S P}$ des SDV-assoziierten Transmembranproteins Silicanin-1 in sinnvoller Orientierung enthält. Diese Modellmembran kann genutzt werden, um 
Wechselwirkungen der $\mathrm{N}$-terminalen (luminalen) Domäne des Proteins mit anderen Biosilica-assoziierten Biomolekülen wie Silaffinen oder LCPAs zu studieren oder um die Silicafällungseigenschaften der SDV-Membran nachzustellen und zu untersuchen (Abb. 5.3). Die pH-induzierte Selbstaggregation von $r \operatorname{Sin} 1$ in der planaren Membran könnte mittels Rasterkraftmikroskopie visualisiert werden. Sollte die festkörperunterstützte Modellmembran keine Selbstaggregation zulassen ist die Optimierung des Modells, z.B. durch Verwendung eines Abstandshalters in tethered membranes, denkbar.

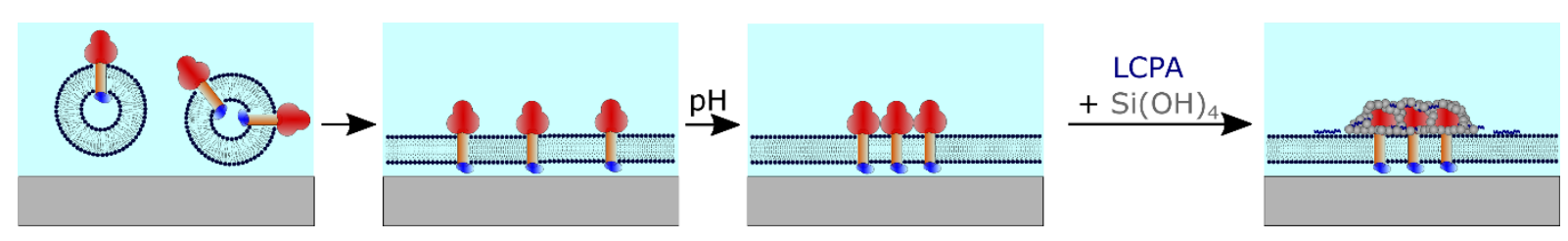

Abbildung 5.3: Schema der in dieser Arbeit erfolgten Präparation der rSin1-haltigen SDVModellmembran (bis einschließlich Bild 2 von links), der pH-induzierten Selbstaggregation von rSin1 in der Membran und der Wechselwirkungs- und Silicafällungsstudien am Beispiel der LCPAs. 


\section{Zusammenfassung}

In dieser Arbeit wurde erfolgreich eine festkörperunterstützte Modellmembran des Valven-Silicafällungsvesikels (SDVs) erstellt, die eine rekombinante Form des SDVassoziierten Transmembranproteins Silicanin-1 (Sin1) enthält.

Die Auswahl an Lipiden für die Modellmembran erfolgte nach intensiver Lipidanalyse der Kieselalgenspezies Thalassiosira pseudonana. Es wurden snychronisierte Kulturen verglichen, die je nach Zellzyklusphase entweder Valven-SDV-angereichert waren oder keine Valven-SDVs enthielten. Die Unterschiede wurden auf die Lipidkomposition der SDVs gedeutet. Zudem wurde erstmalig eine Quantifizierung der relativen Anteile der polaren Hauptlipidklassen MGDG, DGDG, SQDG, PG und PC für die Spezies Thalassiosira pseudonana durchgeführt. Es konnte mittels chromatografischer und massenspektrometrischer Methoden festgestellt werden, dass die Lipidklassen PC, PE, PA und LPC in SDV-angereicherten Kulturen höhere relative Anteile aufweisen als in den Referenzkulturen. PC und PE wurden als wahrscheinliche Hauptkomponenten der SDV-Membran beschrieben. Somit wurden POPC und POPE als Lipide für die SDV-Modellmembran gewählt.

Die rekombinante $\operatorname{Sin} 1$-Form $\operatorname{rSin} 1^{-S P}$ wurde auf seine Funktion als Transmembranprotein untersucht, die mittels Carbonat-Extraktion und HistodenzCoflotationsassay bestätigt werden konnte. Die Rekonstitution des Proteins erfolgte mittels Comizellisierung und die Rekonstitutionseffizienz wurde auf 30-60\% quantifiziert. Die Orientierung des in die vesikuläre Lipiddoppelschicht eingebauten Proteins konnte mit Verdauexperimenten bestimmt werden. Silicafällungsexperimente von Proteoliposomen und Vesikeln ohne Protein in Gegenwart von langkettigen Polyaminen (LCPAs) zeigten keine eindeutige Erhöhung der Menge an gefällten Silicas in Gegenwart von rSin1, möglicherweise, weil die Proteinkonzentration zu gering war. Die silicafällenden Eigenschaften von Vesikeln konnten jedoch beobachtet werden. Die Fällung von Silica an der Membranoberfläche könnte eine Rolle in der nativen Biomineralisierung in Kieselalgen spielen. Es ist auch denkbar, dass die Membran durch Membranproteine von den eigentlichen Orten der Silicafällung separiert wird, um direkte Silicaabscheidung an der Membran zu vermeiden. Es wurde für $r \operatorname{Sin} 1^{-S P}$ in Lösung nachgewiesen, dass es bei pH 5.0 große Protein-Aggregate 
ausbildet. Diese $\mathrm{pH}$-induzierte Selbstaggregation unter SDV-Lumen-physiologischen Bedingungen deutet auf mögliche Clusterbildung des Proteins im SDV hin.

Die Fusion von Proteoliposomen mit festkörperunterstützten Lipideinzelschichten führte zur Ausbildung einer planaren Lipiddoppelschicht mit für gestkörperunterstützte Membranen üblichen Lipiddiffusionskonstanten, wie Experimente zu Fluoreszenzerholung nach Photobleichung (FRAP) zeigten. Die Visualisierung des rSin1 erfolgte mittels Anbindung von Antikörpern, wobei der sekundäre Antikörper fluoreszenzmarkiert war. So konnte gezeigt werden, dass große Mengen rSin1 korrekt orientiert waren und dass die Präparation der Proteoliposomen und der planaren Membran bei pH $7.7 \mathrm{im}$ Vergleich zu pH 5.0 zu bevorzugen ist. Bei letzterem pH-Wert war die Menge an detektiertem rSin1 deutlich geringer.

Mit dieser erfolgreichen Etablierung eines Protokolls zur Herstellung einer Silicanin-1haltigen SDV-Modellmembran können in Zukunft Wechselwirkungen der Membran mit anderen an der Biomineralisation beteiligten Biomolekülen untersucht werden. Diese Systeme könnten dann für Silicafällungsstudien genutzt werden, um die Silicamorphologien und Fällungsdynamiken in SDVs in vitro zu beschreiben. 


\section{Literaturverzeichnis}

[1] N. Kröger, N. Poulsen, Annual review of genetics 2008, 42, 83.

[2] C. B. Field, M. J. Behrenfeld, J. T. Randerson, P. Falkowski, Science (New York, N.Y.) 1998, 281, 237.

[3] W. H. Kooistra, L. K. Medlin, Molecular phylogenetics and evolution 1996, 6, 391.

[4] a) V. Bhardwaj, M. J. Mirliss in Water Encyclopedia (Hrsg.: J. H. Lehr, J. Keeley), John Wiley \& Sons, Inc, Hoboken, NJ, USA, 2005; b) C. H. Sealy, Journal of the Institute of Brewing 1951, 57, 159.

[5] C. E. Hamm, R. Merkel, O. Springer, P. Jurkojc, C. Maier, K. Prechtel, V. Smetacek, Nature 2003, 421, 841.

[6] T. Fuhrmann, S. Landwehr, M. El Rharbi-Kucki, M. Sumper, Applied Physics B 2004, 78, 257.

[7] A. J. Milligan, F. M. M. Morel, Science (New York, N.Y.) 2002, 297, 1848.

[8] N. C. Poulsen, I. Spector, T. P. Spurck, T. F. Schultz, R. Wetherbee, Cell Motility and the Cytoskeleton 1999, 44, 23.

[9] D. Losic, G. Rosengarten, J. G. Mitchell, N. H. Voelcker, Journal of nanoscience and nanotechnology 2006, 6, 982.

[10] a) V. A. Chepurnov, D. G. Mann, K. Sabbe, W. Vyverman in International Review of Cytology, Elsevier, 2004, S. 91-154; b) E. V. Armbrust, Applied and environmental microbiology 1999, 65, 3121.

[11] A. R. Kirkham, P. Richthammer, K. Schmidt, M. Wustmann, Y. Maeda, R. Hedrich, E. Brunner, T. Tanaka, K.-H. van Pée, A. Falciatore et al., The ISME journal 2017, 11, 2452.

[12] M. A. Brzezinski, R. J. Olson, S. W. Chisholm, Marine Ecology Progress Series 1990, 67, 83.

[13] M. Hildebrand, L. G. Frigeri, A. K. Davis, Journal of Phycology 2007, 43, 730.

[14] C. Heintze, P. Formanek, D. Pohl, J. Hauptstein, B. Rellinghaus, N. Kröger, BMC Materials 2020, 2.

[15] M. Hildebrand, S. J. L. Lerch, R. P. Shrestha, Frontiers in Marine Science 2018, 5.

[16] P. Schwarz, Masterarbeit, Georg-August-Universität, Göttingen, 2016.

[17] E. G. Vrieling, W. W. C. Gieskes, T. P. M. Beelen, Journal of Phycology 1999, $35,548$. 
[18] T. L. Simpson, B. E. Volcani, Silicon and Siliceous Structures in Biological Systems, Springer New York, New York, NY, 1981.

[19] T. Coradin, P. J. Lopez, Chembiochem : a European journal of chemical biology 2003, 4, 251.

[20] a) M. Hildebrand, K. Dahlin, B. E. Volcani, Molecular and General Genetics MGG 1998, 260, 480; b) K. Thamatrakoln, M. Hildebrand, Plant physiology 2008, 146, 1397.

[21] R. P. Shrestha, M. Hildebrand, Eukaryotic cell 2015, 14, 29.

[22] Poll, Willem H. van de, E. G. Vrieling, W. W. C. Gieskes, Journal of Phycology 1999, 35, 1044.

[23] N. Kröger, R. Wetherbee, Protist 2000, 151, 263.

[24] S. de Sanctis, M. Wenzler, N. Kroger, W. M. Malloni, M. Sumper, R. Deutzmann, P. Zadravec, E. Brunner, W. Kremer, H. R. Kalbitzer, Structure (London, England : 1993) 2016, 24, 1178.

[25] N. Kröger, S. Lorenz, E. Brunner, M. Sumper, Science (New York, N.Y.) 2002, 298, 584.

[26] N. Kröger, Biospektrum 2013, 19, 12.

[27] M. Sumper, E. Brunner, Chembiochem : a European journal of chemical biology 2008, 9, 1187.

[28] A. Scheffel, N. Poulsen, S. Shian, N. Kroger, Proceedings of the National Academy of Sciences of the United States of America 2011, 108, 3175.

[29] A. Kotzsch, D. Pawolski, A. Milentyev, A. Shevchenko, A. Scheffel, N. Poulsen, N. Kroger, The Journal of biological chemistry 2016, 291, 4982.

[30] M. Sumper, Angewandte Chemie (International ed. in English) 2004, 43, 2251.

[31] M. Hildebrand, E. York, J. I. Kelz, A. K. Davis, L. G. Frigeri, D. P. Allison, M. J. Doktycz, Journal of Materials Research 2006, 21, 2689.

[32] A. M. L. van de Meene, J. D. Pickett-Heaps, Journal of Phycology 2002, 38, 351.

[33] B. Tesson, M. Hildebrand, PloS one 2010, e14300.

[34] A. Kotzsch, P. Gröger, D. Pawolski, P. H. H. Bomans, N. A. J. M. Sommerdijk, M. Schlierf, N. Kröger, BMC Biology 2017, 15, 65.

[35] B. Tesson, S. J. L. Lerch, M. Hildebrand, Scientific reports 2017, 13457.

[36] T. Brembu, M. S. Chauton, P. Winge, A. M. Bones, O. Vadstein, Scientific reports 2017, 4865. 
[37] S. Görlich, D. Pawolski, I. Zlotnikov, N. Kröger, Communications biology 2019, 245.

[38] O. Levitan, J. Dinamarca, G. Hochman, P. G. Falkowski, Trends in biotechnology 2014, 117.

[39] Z. Yi, M. Xu, X. Di, S. Brynjolfsson, W. Fu, Frontiers in Marine Science 2017, 4.

[40] E. Fahy, S. Subramaniam, H. A. Brown, C. K. Glass, A. H. Merrill, R. C. Murphy, C. R. H. Raetz, D. W. Russell, Y. Seyama, W. Shaw et al., Journal of lipid research 2005, 839.

[41] B. A. S. van Mooy, H. F. Fredricks, B. E. Pedler, S. T. Dyhrman, D. M. Karl, M. Koblízek, M. W. Lomas, T. J. Mincer, L. R. Moore, T. Moutin et al., Nature 2009, 458, 69.

[42] R. Anderson, M. Kates, B. E. Volcani, Biochimica et Biophysica Acta (BBA) Lipids and Lipid Metabolism 1978, 528, 89.

[43] N. Mizusawa, H. Wada, Biochimica et biophysica acta 2012, 194.

[44] N. N. Zulu, K. Zienkiewicz, K. Vollheyde, I. Feussner, Progress in lipid research 2018, 70, 1.

[45] Z. Cohen, I. Khozin-Goldberg, D. Adlerstein, C. Bigogno, Biochemical Society transactions 2000, 28, 740.

[46] M. A. Welte, A. P. Gould, Biochimica et biophysica acta. Molecular and cell biology of lipids 2017, 1260.

[47] S. R. Smith, C. Glé, R. M. Abbriano, J. C. Traller, A. Davis, E. Trentacoste, M. Vernet, A. E. Allen, M. Hildebrand, The New phytologist 2016, 210, 890.

[48] J. E. Hunter, J. Brandsma, M. K. Dymond, G. Koster, C. M. Moore, A. D. Postle, R. A. Mills, G. S. Attard, Applied and environmental microbiology 2018, 84.

[49] F. Zhao, J. Xu, J. Chen, X. Yan, C. Zhou, S. Li, X. Xu, F. Ye, Rapid communications in mass spectrometry : RCM 2013, 27, 1535.

[50] M. O. Pata, Y. A. Hannun, C. K.-Y. Ng, The New phytologist 2010, 611.

[51] T. B. Romsdahl, Dissertation, University of Nebraska, 2017.

[52] B. Véron, J.-C. Dauguet, C. Billard, Journal of Phycology 1998, 34, 273.

[53] E. J. Dufourc, Journal of chemical biology 2008, 63.

[54] A. C. Jaramillo-Madrid, J. Ashworth, P. J. Ralph, Journal of Marine Science and Engineering 2020, 8, 85.

[55] S. R. Wassall, W. Stillwell, Biochimica et biophysica acta 2009, 1788, 24. 
[56] a) F. Daboussi, S. Leduc, A. Maréchal, G. Dubois, V. Guyot, C. Perez-Michaut, A. Amato, A. Falciatore, A. Juillerat, M. Beurdeley et al., Nature Communications 2014, 3831; b) Y. Gong, X. Guo, X. Wan, Z. Liang, M. Jiang, Journal of basic microbiology 2011, 666; c) Z.-K. Yang, Y.-F. Niu, Y.-H. Ma, J. Xue, M.-H. Zhang, W.-D. Yang, J.-S. Liu, S.-H. Lu, Y. Guan, H.-Y. Li, Biotechnology for biofuels 2013, 67.

[57] J. M. Berg, J. L. Tymoczko, L. Stryer, G. J. Gatto, Biochemie, 7. Aufl., Springer Spektrum, Berlin, 2014.

[58] S. J. Singer, G. L. Nicolson, Science (New York, N.Y.) 1972, 175, 720.

[59] T. G. Pomorski, A. K. Menon, Progress in lipid research 2016, 69.

[60] J. D. Nickels, S. Chatterjee, C. B. Stanley, S. Qian, X. Cheng, D. A. A. Myles, R. F. Standaert, J. G. Elkins, J. Katsaras, PLoS biology 2017, e2002214.

[61] A. Morshed, B. I. Karawdeniya, Y. M. N. D. Y. Bandara, M. J. Kim, P. Dutta, Electrophoresis 2020, 449.

[62] C. Steinem, A. Janshoff, Chemie in unserer Zeit 2008, 42, 116.

[63] E. Sackmann, Science (New York, N.Y.) 1996, 271, 43.

[64] J. Andersson, I. Köper, Membranes 2016, 6, 30.

[65] O. Gräb, M. Abacilar, F. Daus, A. Geyer, C. Steinem, Langmuir : the ACS journal of surfaces and colloids 2016, 32, 10144.

[66] J. Delasoie, F. Zobi, Pharmaceutics 2019.

[67] R. R. Naik, M. O. Stone, Materials Today 2005, 8, 18.

[68] E. G. Bligh, W. J. Dyer, Canadian journal of biochemistry and physiology 1959, $37,911$.

[69] J. W. Lee, S. Nishiumi, M. Yoshida, E. Fukusaki, T. Bamba, Journal of chromatography. A 2013, 1279, 98.

[70] E. V. Berdyshev, I. A. Gorshkova, J. G. N. Garcia, V. Natarajan, W. C. Hubbard, Analytical Biochemistry 2005, 339, 129.

[71] M. Miquel, J. Browse, The Journal of biological chemistry 1992, 267, 1502.

[72] Z. Wang, C. Benning, Journal of visualized experiments 2011.

[73] a) I. Lang, L. Hodac, T. Friedl, I. Feussner, BMC plant biology 2011, 11, 124; b) B. Steudel, C. Hallmann, M. Lorenz, S. Abrahamczyk, K. Prinz, C. Herrfurth, I. Feussner, J. W. R. Martini, M. Kessler, The New phytologist 2016, 212, 409.

[74] P. Tarazona, K. Feussner, I. Feussner, The Plant journal : for cell and molecular biology 2015, 84, 621. 
[75] K. Yang, X. Han, Metabolites 2011, 1, 21.

[76] "pJexpress 401-406 (T5) Cloning Cassette", zu finden unter https://www.dna20.com/eCommerce/catalog/vectorDatasheet/7.

[77] Invitrogen by life technologies, "Manual - OneShot BL21 (DE3)", zu finden unter https://www.thermofisher.com/document-connect/documentconnect.html?url=https\%3A\%2F\%2Fassets.thermofisher.com\%2FTFSAssets\%2FLSG\%2Fmanuals\%2Foneshotbl21_man.pdf\&title=T25IU2hvdCBCT DIxKERFMyksIE9uZSBTaG90IEJMMjEoREUzKXBMeXNTIGFuZCBPbmUgU2 hvdCBCTDIxKERFMylwTHIzRQ==, 2010.

[78] "S.O.C. Medium", zu finden unter https://www.thermofisher.com/order/catalog/product/15544034.

[79] H. Rehm, T. Letzel, Der Experimentator: Proteinbiochemie/Proteomics, 6. Aufl., Spektrum Akademischer Verlag, Heidelberg, 2010.

[80] "Expression and purification of proteins using 6xHistidine-tag. A comprehensive manual", zu finden unter https://www.iba-lifesciences.com/isotope/2/2-3201010-Manual-6xHistidine-tag.pdf, 2012.

[81] R. Winter, F. Noll, C. Czeslik, Methoden der biophysikalischen Chemie, 2. Aufl., Vieweg + Teubner, Wiesbaden, 2011.

[82] SIB Swiss Institute of Bioinformatics, ExPASy-ProtParam Tool.

[83] E. Gasteiger, C. Hoogland, A. Gattiker, S. Duvaud, M. R. Wilkins, R. D. Appel, A. Bairoch in Methods in Molecular Biology (Hrsg.: J. M. Walker), Humana Press Inc, Totowa, NJ, 2005, S. 571-607.

[84] a) G. L. Ellman, Archives of Biochemistry and Biophysics 1959, 82, 70; b) P. W. Riddles, R. L. Blakeley, B. Zerner, Analytical Biochemistry 1979, 94, 75.

[85] H. R. Maurer, Disk-Elektrophorese: Theorie und Praxis der diskontinuierlichen Polyacrylamidgel-Elektrophorese, de Gruyter, Berlin, 1968.

[86] U. K. LAEMMLI, Nature 1970, 227, 680.

[87] H. Schägger, G. von Jagow, Analytical Biochemistry 1987, 166, 368.

[88] "SDS-PAGE Analysis", zu finden unter http://www.bio-rad.com/dede/applications-technologies/sds-page-analysis.

[89] E. H. White, O. Zafiriou, H. H. Kagi, J. H. M. Hill, Journal of the American Chemical Society 1964, 86, 940.

[90] E. H. White, M. M. Bursey, Journal of the American Chemical Society 1964, 86, 941. 
[91] D. Correa, C. H. I. Ramos, African Journal of Biochemistry Research 2009, 3, 164.

[92] S. M. Kelly, T. J. Jess, N. C. Price, Biochimica et biophysica acta 2005, 1751, 119.

[93] A. F. Drake, Journal of Physics E: Scientific Instruments 1986, 19, 170.

[94] a) W. C. Johnson, Annual review of biophysics and biophysical chemistry 1988, 17, 145; b) J. T. Pelton, L. R. McLean, Analytical Biochemistry 2000, 277, 167.

[95] "Circular Dichroism Spectroscopy-II", zu finden unter http://nptel.ac.in/courses/102103044/module2/lec9/2.html.

[96] a) L. Whitmore, B. A. Wallace, Nucleic acids research 2004, 32, W668-73; b) L. Whitmore, B. A. Wallace, Biopolymers 2008, 89, 392.

[97] W. C. Johnson, Proteins 1999, 35, 307.

[98] N. Sreerama, R. W. Woody, Analytical Biochemistry 2000, 287, 252.

[99] N. Sreerama, S. Y. Venyaminov, R. W. Woody, Analytical Biochemistry 2000, 287, 243.

[100]J. R. Silvius, Thermotropic Phase Transitions of Pure Lipids in Model Membranes and Their Modifications by Membrane Proteins, John Wiley \& Sons, Inc., New York, 1982.

[101] J.-L. Rigaud, D. Lévy in Methods in Enzymology, Elsevier, 2003, S. 65-86.

[102] G. Rouser, S. Fleischer, A. Yamamoto, Lipids 1970, 5, 494.

[103] A. Schellhase, Bachelorarbeit, Georg-August-Universität, Göttingen, 2017.

[104] a) Y. Fujiki, A. L. Hubbard, S. Fowler, P. B. Lazarow, The Journal of cell biology 1982, 93, 97; b) Y. Fujiki, S. Fowler, H. Shio, A. L. Hubbard, P. B. Lazarow, The Journal of cell biology 1982, 93, 103.

[105]D. Rickwood, T. Ford, J. Graham, Analytical Biochemistry 1982, 123, 23.

[106]F. Daus, E. Pfeifer, K. Seipp, N. Hampp, A. Geyer, Organic \& biomolecular chemistry 2020, 18, 700.

[107] a) R. K. Iler, The chemistry of silica. Solubility, polymerization, colloid and surface properties, and biochemistry, Wiley, New York, NY, 1979; b) F. de Smedt, G. Stevens, S. de Gendt, I. Cornelissen, S. Arnauts, M. Meuris, M. M. Heyns, C. Vinckier, Journal of The Electrochemical Society 1999, 146, 1873.

[108] E. Kalb, S. Frey, L. K. Tamm, Biochimica et Biophysica Acta (BBA) Biomembranes 1992, 1103, 307.

[109] E. Reimhult, M. Zäch, F. Höök, B. Kasemo, Langmuir 2006, 22, 3313. 
[110] E. Reimhult, B. Kasemo, F. Höök, International Journal of Molecular Sciences 2009, 10, 1683.

[111]J. Salafsky, J. T. Groves, S. G. Boxer, Biochemistry 1996, 35, 14773.

[112] M. L. Wagner, L. K. Tamm, Biophysical journal 2001, 81, 266.

[113]D. Frese, Dissertation, Georg-August-Universität Göttingen, Göttingen, 2013.

[114] P. Jönsson, M. P. Jonsson, J. O. Tegenfeldt, F. Höök, Biophysical journal 2008, 95, 5334.

[115]M. Niebuhr, Bachelorarbeit, Georg-August-Universität Göttingen, Göttingen, 2018.

[116] L. Winkler, Bachelorarbeit, Georg-August-Universität, Göttingen, 2020.

[117] E. Gasteiger, C. Hoogland, A. Gattiker, S. Duvaud, M. R. Wilkins, R. D. Appel,

A. Bairoch, Expasy Peptide Cutter, Swiss Institute of Bioinformatics, 2005.

[118] A. Blume, Biochimica et Biophysica Acta (BBA) - Biomembranes 1979, 557, 32.

[119]J. K. Volkman, S. W. Jeffrey, P. D. Nichols, G. I. Rogers, C. D. Garland, Journal of Experimental Marine Biology and Ecology 1989, 128, 219.

[120] T. Tonon, D. Harvey, T. R. Larson, I. A. Graham, Phytochemistry 2002, 61, 15.

[121]J. Coombs, W. M. Darley, O. Holm-Hansen, B. E. Volcani, Plant physiology 1967, 42, 1601.

[122] T. Tonon, R. Qing, D. Harvey, Y. Li, T. R. Larson, I. A. Graham, Plant physiology 2005, 138, 402.

[123]N. V. Zhukova, Russian Journal of Plant Physiology 2004, 51, 702.

[124] O. Cook, M. Hildebrand, Journal of Applied Phycology 2016, 28, 897.

[125] A. Sabia, E. Clavero, S. Pancaldi, J. Salvadó Rovira, Applied microbiology and biotechnology 2018, 102, 1945.

[126]T. Tonon, D. Harvey, R. Qing, Y. Li, T. R. Larson, I. A. Graham, FEBS Letters 2004, 563, 28.

[127]A. Vieler, C. Wilhelm, R. Goss, R. Suss, J. Schiller, Chemistry and physics of lipids 2007, 150, 143.

[128] S. Schaller-Laudel, D. Latowski, M. Jemioła-Rzemińska, K. Strzałka, S. Daum, K. Bacia, C. Wilhelm, R. Goss, Physiologia plantarum 2017, 160, 339.

[129] E. T. Yu, F. J. Zendejas, P. D. Lane, S. Gaucher, B. A. Simmons, T. W. Lane, Journal of Applied Phycology 2009, 21, 669.

[130]J. K. Volkman, G. M. Hallegraeff, Phytochemistry 1988, 27, 1389. 
[131]S. W. Rampen, B. A. Abbas, S. Schouten, J. S. Sinninghe Damste, Limnology and Oceanography 2010, 55, 91.

[132] E. P. Kennedy, S. B. Weiss, The Journal of biological chemistry 1956, 222, 193.

[133] W. E. Lands, The Journal of biological chemistry 1958, 231, 883.

[134] C. Moessinger, K. Klizaite, A. Steinhagen, J. Philippou-Massier, A. Shevchenko, M. Hoch, C. S. Ejsing, C. Thiele, BMC cell biology 2014, 15, 43.

[135] F. Gibellini, T. K. Smith, IUBMB life 2010, 62, 414.

[136] V. V. Kumar, Proceedings of the National Academy of Sciences of the United States of America 1991, 88, 444.

[137] C. Hamai, T. Yang, S. Kataoka, P. S. Cremer, S. M. Musser, Biophysical journal 2006, 90, 1241.

[138] F. E. Round, R. M. Crawford, D. G. Mann, The diatoms. Biology \& morphology of the genera, 2007. Aufl., Cambridge University Press, Cambridge, UK, New York, 2007.

[139]P. J. Robinson, S. Kanemura, X. Cao, N. J. Bulleid, The Journal of biological chemistry 2020, 295, 2438.

[140] E. Welker, W. J. Wedemeyer, M. Narayan, H. A. Scheraga, Biochemistry 2001, 40, 9059.

[141]L. M. Mejía, K. Isensee, A. Méndez-Vicente, J. Pisonero, N. Shimizu, C. González, B. Monteleone, H. Stoll, Geochimica et Cosmochimica Acta 2013, 123, 322.

[142] E. Gasteiger, C. Hoogland, A. Gattiker, S. Duvaud, M. R. Wilkins, R. D. Appel, A. Bairoch, Expasy ProtParam, Swiss Institute of Bioinformatics, 2005.

[143] Protein Calculator V3.4., http://protcalc.sourceforge.net/

[144] J. M. Hernandez, A. Stein, E. Behrmann, D. Riedel, A. Cypionka, Z. Farsi, P. J. Walla, S. Raunser, R. Jahn, Science (New York, N.Y.) 2012, 336, 1581.

[145] N. Kučerka, M.-P. Nieh, J. Katsaras, Biochimica et biophysica acta Biomembranes 2011, 1808, 2761.

[146] J. Kuhlmann, Dissertation, Georg-August-Universität, Göttingen, 2017.

[147] A. C. Bernecker, Dissertation, Georg-August-Universität, Göttingen, 2009.

[148]M. Sumper, N. Kröger, J. Mater. Chem. 2004, 14, 2059.

[149] O. Gräb, Dissertation, Georg-August-Universität, Göttingen, 2017.

[150]R. Homan, H. J. Pownall, Biochimica et Biophysica Acta (BBA) - Biomembranes 1988, 938, 155. 
[151] M. Przybylo, J. Sykora, J. Humpolickova, A. Benda, A. Zan, M. Hof, Langmuir : the ACS journal of surfaces and colloids 2006, 22, 9096.

[152] L. Guo, J. Y. Har, J. Sankaran, Y. Hong, B. Kannan, T. Wohland, Chemphyschem : a European journal of chemical physics and physical chemistry 2008, 9, 721.

[153] K. A. Majorek, P. J. Porebski, A. Dayal, M. D. Zimmerman, K. Jablonska, A. J. Stewart, M. Chruszcz, W. Minor, Molecular immunology 2012, 52, 174.

[154] S. L. Law, W. Y. Lo, S. H. Pai, G. W. Teh, F. Y. Kou, International Journal of Pharmaceutics 1986, 32, 237.

[155] F. Ruggeri, F. Zhang, T. Lind, E. D. Bruce, B. L. T. Lau, M. Cárdenas, Soft matter 2013, 9, 4219.

[156] M. Malmsten, Journal of Colloid and Interface Science 1995, 172, 106.

[157] R. Galántai, I. Bárdos-Nagy, International Journal of Pharmaceutics 2000, 195, 207.

[158] L. J. Lis, J. W. Kauffman, D. F. Shriver, Biochimica et Biophysica Acta (BBA) Biomembranes 1976, 436, 513.

[159] V. Vetri, F. Librizzi, M. Leone, V. Militello, European biophysics journal : EBJ 2007, 36, 717. 


\section{Anhang}

\subsection{Abbildungsverzeichnis}

Abbildung 1.1: Schematische Zelldarstellung von Thalassiosira pseudonana aus Gürtelbandperspektive. 14

Abbildung 1.2: Schematische Übersicht über die Reproduktion von Thalassiosira pseudonana durch Zellteilung.

Abbildung 1.3: Schema der Domäneneinteilung von Silicanin-1 (Sin1) und seine rekombinanten Varianten (rSin1) 20

Abbildung 1.4: Auswahl an Glycerolipiden, die in Kieselalgen vorkommen .... 22 Abbildung 1.5: Beispiele für Fettsäuren und ihre in dieser Arbeit verwendete Nomenklatur. 23

Abbildung 3.1: Haworthprojektion des Isopropyl- $\beta$-D-thiogalactopyranosids (IPTG).

Abbildung 3.2: Exemplarische Darstellung des bakteriellen Wachstums von E. coli als Auftragung der optischen Dichte bei $600 \mathrm{~nm} O D_{600}$ gegen die Zeit $t$. 38

Abbildung 3.3: Wechselwirkung zwischen einer an einem Agarosebead gebundenen Ni-NTA-Gruppe und einem Polyhistidin-Tag (His-Tag) 41

Abbildung 3.4: Schematischer Aufbau eines Einstrahl-UV/vis-Spektrometers. 44

Abbildung 3.5: Reaktion von DTNB mit einer freien Thiolgruppe zu einem gemischten Disulfid und $\mathrm{TNB}^{2-}$ 46

Abbildung 3.6: Auftragung des Logarithmus des Molekulargewichts MW von Proteinen gegen ihre Retentionsfaktoren $\mathrm{R}_{\mathrm{f}}$. 49

Abbildung 3.7: Ablauf der Antikörperanbindung während des Western Blots. 53

Abbildung 3.8: Reaktion von Luminol mit dem aus Wasserstoffperoxid generierten Sauerstoff unter Katalyse der Meerrettichperoxidase (HRP). 54

Abbildung 3.9: Schematischer Blottingaufbau. 55

Abbildung 3.10: Unpolarisiertes Licht besitzt $E$-Feldvektoren, die in alle Raumrichtungen schwingen. 58

Abbildung 3.11: Zeigerdiagramme polarisierter elektromagnetischer Strahlung.... 58 Abbildung 3.12: Darstellung des Einflusses der Sekundärstrukturmotive $\alpha$-Helix, $\beta$ Faltblatt und Zufallsknäuel auf das CD-Signal von Proteinen 
Abbildung 3.13: Struktur von 1,2-Dioleoyl-sn-glycero-3-phosphocholin (DOPC).... 63

Abbildung 3.14: Struktur von 1-Palmitoyl-2-oleoyl-sn-glycero-3-phosphocholin. .... 64 Abbildung 3.15: Struktur von 1-Palmitoyl-2-oleoyl-sn-glycero-3-phosphoethanolamin (POPE)...

Abbildung 3.16: Struktur von 1-Palmitoyl-2-oleoyl-sn-glycero-3-phosphoglycerol (POPG).

Abbildung 3.17: Struktur von Texas Red®-1,2-Dipalmitoyl-sn-glycero-3phosphoethanolamin (TxR-DPPE)..

Abbildung 3.18: Struktur von Atto390-1,2-Dipalmitoyl-sn-glycero-3-

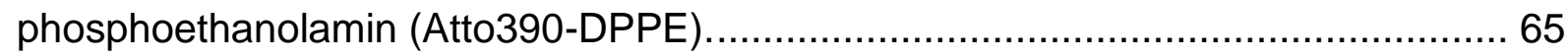

Abbildung 3.19: Struktur von $\beta$-Bodipy 500/510 $\mathrm{C}_{12}$-PPC............................... 66 Abbildung 3.20: Schema der Comizellisierung und dadurch resultierender Rekonstitution von rSin1-SP in SUVs nach Gößenausschlusschromatographie (SEC)

Abbildung 3.21: Schema des Co-Flotationsassays durch

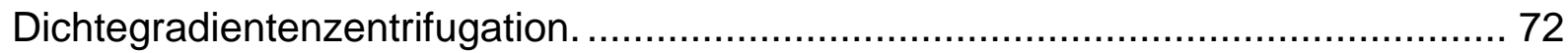

Abbildung 3.22: Prinzip der Fluoreszenz 81

Abbildung 3.23: Schematischer Aufbau eines konfokalen Laserscanningmikroskops (CLSM).

Abbildung 3.24: Zeitliche Auftragung der normierten Fluoreszenzintensität (schwarz).

Abbildung 4.1: Absolutes Fettsäureprofil von Tp-div (rot) und Tp-G1 (blau) bezogen auf die Trockenmasse der lyophilisierten Probe

Abbildung 4.2: Relatives Fettsäureprofil von Tp-div (rot) und Tp-G1 (blau)........... 87

Abbildung 4.3: TLC-Platten nach Primulinanfärbung unter UV-Licht .................... 89

Abbildung 4.4: Exemplarische TLC-Platte nach dem Abschaben von Banden....... 89

Abbildung 4.5: Gemessene Peakflächen der MGDG-Lipidsignale in der LC-MS/MS

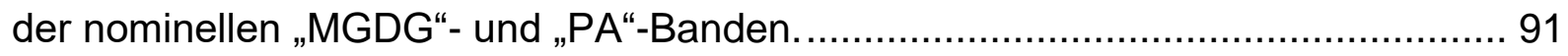

Abbildung 4.6: Gemessene Peakflächen der PA-Lipidsignale in der LC-MS/MS der nominellen „MGDG“- und „PA“-Banden.

Abbildung 4.7: Relatives Profil polarer Hauptlipidklassen in Tp-div (rot) und Tp-G1 (blau). 93

Abbildung 4.8: Primulinintensitätsprofil polarer Hauptlipidklassen in Tp-div (rot) und Tp-G1 (blau). 94 
Abbildung 4.9: Übersicht über die häufigsten Fettsäurekombinationen in Diacylglycerolipiden mit mindestens $5 \%$ Anteil an einer Lipidklasse in Tp-div (rot) und Tp-G1 (blau). 96

Abbildung 4.10: Übersicht über die FA-Verteilung in Diacyl- und Triacylglycerolipiden in Tp-div (rot) und Tp-G1 (blau). 97

Abbildung 4.11: Übersicht über die FA-Verteilung in Lysolipiden in Tp-div (rot) und Tp-G1 (blau). 98

Abbildung 4.12: Lipidprofil von TAG in Tp-div (rot) und Tp-G1 (blau).. 103

Abbildung 4.13: Lipidprofil der Ceramide in Tp-div (rot) und Tp-G1 (blau). 104

Abbildung 4.14: Lipidprofil der Monoglycocerebroside in Tp-div (rot) und Tp-G1 (blau). 105

Abbildung 4.15: Lipidprofil der Diglycocerebroside in Tp-div (rot) und Tp-G1 (blau). 105

Abbildung 4.16: Relatives Profil der freien Sterole in Tp-div (rot) und Tp-G1 (blau). 106

Abbildung 4.17: Relatives Profil der Sterolester in Tp-div (rot) und Tp-G1 (blau). Aufgeführt sind Sterolester $>3 \%$. 107

Abbildung 4.18: Relatives FA-Profil der Sterolester in Tp-div (rot) und Tp-G1 (blau). 108

Abbildung 4.19: Anteil von FAs mit mindestens 20 C-Atomen an den Gesamt-FAProfilen aller untersuchter FA-gebundener Lipidklassen (außer Sphingolipiden) in Tpdiv (rot) und Tp-G1 (blau). 109

Abbildung 4.20: Dreiecksdiagramm der Anteile gesättigter $(\mathrm{g})$, einfach ungesättigter (eu) und mehrfach ungesättigter (mu) FAs aller untersuchten FA-gebundenen Lipidklassen (außer Sphingolipiden) in Tp-div (rot) und Tp-G1 (blau). 110

Abbildung 4.21: Einwaagennormierte Totalpeakflächen der LC-MS/MS-Analyse jeder detektierten Lipidklasse für Tp-div (rot) und Tp-G1 (blau). 111

Abbildung 4.22: Relativer Totalpeakflächenanteil jeder detektierten Lipidklasse für Tp-div (rot) und Tp-G1 (blau) 112

Abbildung 4.23: Foldchanges einzelner Lipidklassen für Tp-div bezogen auf Tp-G1.

Abbildung 4.24: Beispielhaftes CD-Spektrum einer rSin1-SP-Probe in MOPS-Puffer (10 mM, pH 7.7). 114 
Abbildung 4.25: Gemittelte Intensitäts- (schwarz) und Massenverteilung (rot) der in der DLS-Messung detektierten Partikelgrößen.

Abbildung 4.26: DLS-Intensitätsverteilung der Partikelgrößen von Vesikelproben der Zusammensetzung DOPC/POPG/TxR-DPPE=79.5:20:0.5 (schwarz) und POPC/POPE/TxR-DPPE=69.5:30:0.5 (rot), die mittels Comizellisierung präpariert wurden. 119

Abbildung 4.27: Chemilumineszenzbild des Anti-His-Western Blots der Carbonatextraktionsproben. 121

Abbildung 4.28: Chemilumineszenzbild des Anti-His-Western Blots der Carbonatextraktionsproben. 122

Abbildung 4.29: Exemplarischer Anti-His5-Western Blot der Fraktionen des Histodenz-Coflotations-Assays.

Abbildung 4.30: Darstellung der rSin1-Bandenintensitäten der sieben Fraktionen aus Abb. 4.29 als prozentualer Anteil an der Gesamtprobenintensität. 124

Abbildung 4.31: Übersicht über die Rekonstitutionseffizienzen von rSin1 bei verschiedenen Lipidkompositionen und nominellen Lipid-zu-Protein-Verhältnissen.

Abbildung 4.32: Schematische Versuchsübersicht des Chymotrypsinverdaus von in Vesikeln rekonstituiertem rSin1. 126

Abbildung 4.33: Chemilumineszenzbild des Anti-Sin1-Western Blots der Proteoliposom- (PL) und Freies-Protein-Proben (Sin1).

Abbildung 4.34: Ermittelte Siliciumkonzentrationen des gefällten Silicas verschiedener Proben ( $n=2$, für Puffer $n=1)$.. 131

Abbildung 4.35: Schema der Präparation einer rSin1-haltigen festkörperunterstützten Membran durch Spreiten von Proteoliposomen auf einer Lipideinzelschicht. 132 Abbildung 4.36: A: Exemplarischer Oberflächendruckverlauf im zeitlichen Verlauf des Lipideinzelschichtübertrags. B: Verlauf des Oberflächendrucks in Abhängigkeit von der Fläche pro Lipidmolekül 133

Abbildung 4.37: Fluoreszenzaufnahmen einer festkörperunterstützten Membran. 134 Abbildung 4.38: FRAP-Zeitserien für Atto 390-DPPE (oben) und TxR-DPPE (unten) der festkörperunterstützten Membran.

Abbildung 4.39: Schema der Präparation einer rSin1-haltigen festkörperunterstützten Membran durch Vesikelfusion mit einer Lipideinzelschicht sowie die anschließende Anbindung von primären (Anti-Sin1) und sekundären Antikörpern 136 
Abbildung 4.40: Fluoreszenzaufnahmen von rSin1-haltigen festkörperunterstützten Membranen im Bodipy 500/510-Kanal bei pH 7.7 (links) und pH 5.0 (rechts) vor Zugabe der Antikörper.

Abbildung 4.41: FRAP-Zeitserien der rSin1-haltigen festkörperunterstützten Membran im Bodipy 500/510-Kanal. 138

Abbildung 4.42: Exemplarische Bodipy 500/510-Fluoreszenzaufnahmen der festkörperunterstützten Membran nach Zugabe des primären Antiserums bei pH 7.7 (oben) und $\mathrm{pH} 5.0$ (unten).

Abbildung 4.43: Exemplarische Fluoreszenzaufnahmen im Bodipy 500/510-Kanal (links) und Alexa Fluor 647-Kanal (mittig) sowie eine Helligkeits-/Kontrast-korrigierte Alexa Fluor 647-Aufnahme (rechts)

Abbildung 4.44: FRAP-Zeitserien der rSin1-haltigen festkörperunterstützten Membran nach Zugabe von Alexa Fluor 647-gebundenem sekundärem Antikörper. 141

Abbildung 4.45: Box-Diagramm der gemessenen mittleren Graustufenintensität im Alexa Fluor 647-Kanal für festkörperunterstützte Membranen ( $\mathrm{pH} \mathrm{7.7)} \mathrm{in} \mathrm{An-} \mathrm{und}$ Abwesenheit von rSin1 bei verschiedenen Gains (Signalverstärkungen). 142

Abbildung 4.46: Box-Diagramm der gemessenen mittleren Graustufenintensität im Alexa Fluor 647-Kanal für festkörperunterstützte Membranen ( $\mathrm{pH} \mathrm{5.0)} \mathrm{in} \mathrm{An-} \mathrm{und}$ Abwesenheit von rSin1 bei verschiedenen Gains (Signalverstärkungen). 142

Abbildung 5.1: Vergleich des Anteils von FAs mit mindestens 20 C-Atomen am Gesamt-FA-Profil in Tp-div (rot) und Tp-G1 (blau) mit den Literaturwerten von Cook/Hildebrand, Zhukova, Volkman et al. (alle in wt\%) sowie Tonon et al. (mol\%)..

Abbildung 5.2: Vergleich der Sättigungsgradzusammensetzung der FAs in Tp-div und Tp-G1 mit den Literaturwerten von Cook/Hildebrand, Zhukova, Volkman et al. (alle in wt\%) sowie Tonon et al. (mol\%) 147

Abbildung 5.3: Schema der in dieser Arbeit erfolgten Präparation der rSin1-haltigen SDV-Modellmembran (bis einschließlich Bild 2 von links), der pH-induzierten Selbstaggregation von rSin1 in der Membran und der Wechselwirkungs- und Silicafällungsstudien am Beispiel der LCPAs. 166 


\subsection{Tabellenverzeichnis}

Tabelle 3.1: Zusammensetzung des S.O.C-Mediums (Thermo Fisher Scientific).... 36

Tabelle 3.2: Zusammensetzung des LB-Mediums........................................... 36

Tabelle 3.3: Zusammensetzung des Lysepuffers.............................................. 39

Tabelle 3.4: Zusammensetzung der DNase I-Lsg............................................ 40

Tabelle 3.5: Zusammensetzung des Extraktionspuffers. ...................................... 40

Tabelle 3.6: Zusammensetzung des Waschpuffers, Elutionspuffers 1 und Elutionspuffers 2 .

Tabelle 3.7: Übersicht über die Dialysepuffer und -bedingungen zur Proteinrückfaltung und Umknüpfung von Disulfidbrücken.

Tabelle 3.8: Extinktionskoeffizienten $\varepsilon_{280}$ bei $\lambda=280 \mathrm{~nm}$ von $\mathrm{rSin} 1^{-\mathrm{SP}}$ im vollständig reduzierten oder oxidierten Zustand.

Tabelle 3.9: Auftrennungsbereiche von SDS-PAGE-Trenngelen für verschieden große Proteine, je nach Vernetzungsgrad der Gele. 48

Tabelle 3.10: Übersicht über die Zusammensetzung der Schäggergele für die SDSPAGE. 51

Tabelle 3.11: Übersicht der für die SDS-PAGE verwendeten Puffer und Lösungen. 51

Tabelle 3.12: Übersicht der für den Western Blot verwendeten Puffer und Lösungen.

Tabelle 3.13: Parameterübersicht der CD-Messungen....................................... 62

Tabelle 3.14: Zusammensetzung des Rekonstitutionspuffers................................. 68

Tabelle 3.15: Übersicht der in der DLS-Messung verwendeten Puffer. .................. 70

Tabelle 3.16: Verwendete Lösungen für die Carbonatextraktion und Acetonfällung.71

Tabelle 3.17: Übersicht der für die Silicafällung verwendeten Puffer...................... 75

Tabelle 3.18: Probenübersicht des Silicafällungsexperiments. .............................. 75

Tabelle 4.1: Lipidklassenzusammensetzung nach TLC-Auswertung mittels GC-FID oder Bandenintensität der Primulinfluoreszenz 94

Tabelle 4.2: Sekundärstrukturelementanteile in $\mathrm{rSin} 1^{-\mathrm{SP}}$ berechnet mit dem CDSSTRAlgorithmus und zwei verschiedenen Referenzsets und aus sechs Proben gemittelt 115

Tabelle 4.3: Resultate der Sulfhydrylquantifizierung in $r \operatorname{Sin} 1^{-\mathrm{SP}}$ verschiedener Konzentrationen. 116 
Tabelle 4.4: Mittlere Graustufenintensitäten der Alexa Fluor 647Fluoreszenzaufnahmen von festkörperunterstützten Membranen, präpariert bei pH 7.7 oder pH 5.0 mit oder ohne $\mathrm{rSin}^{-\mathrm{SP}}(\mathrm{P} / \mathrm{L}=1: 500)$ 143

Tabelle 4.5: Verhältnis der mittleren Graustufenintensitäten der Alexa Fluor 647Fluoreszenzaufnahmen von rSin1-haltigen zu proteinfreien Membranen in Abhängigkeit von pH-Wert und gewähltem Gain 144

Tabelle 5.1: Lipidklassenzusammensetzung nach TLC-Auswertung mittels GC-FID oder Bandenintensität der Primulinfluoreszenz im Vergleich zu den Werten für Cyclotella meneghiniana von Vieler et al. 149

\subsection{Symbolverzeichnis}

A

$\AA$

a

$b$

c

$\mathrm{cm}$

$D$

$d$

$\operatorname{deg}$

dmol

E

$\vec{E}$

g

h
Absorbanz

Angstrom

Hauptachse einer Ellipse

Nebenachse einer Ellipse

Konzentration

Zentimeter

lateraler Diffusionskoeffizient

optische Schichtdicke; Durchmesser

Grad (degree)

Dezimol

Extinktion

Elektrischer Feldvektor

Gramm; Gewichtskraft

Stunden

Intensität

Ausgangsintensität, Intensität nach dem Photobleichpuls 
$l_{1}$

lE

li

$k_{\mathrm{B}}$

$\mathrm{kDa}$

L

M

m

m

M

$\mathrm{mA}$

mdeg

$\min$

$\mathrm{mL}$

$\mathrm{mm}$

$\mathrm{mM}$

$\mathrm{mN}$

mol\%

MW

N

$\mathrm{n}$

$n$

ng

$\mathrm{nm}$

$O D_{600}$
Differenz aus IE und Io

Intensität nach Fluoreszenzregeneration im FRAP-Experiment

Intensität vor dem Photobleichpuls

Boltzmann-Konstante

Kilodalton

Liter

molare Masse; mobiler Membrananteil

Meter

Masse

molar

Milliampere

Milligrad

Minuten

Milliliter

Millimeter

millimolar

Millinewton

Molprozent

Molekulargewicht

Anzahl an Präparaten; Stickstoff

Anzahl an Messungen

Stoffmenge

Nanogramm

Nanometer

optische Dichte 


\begin{tabular}{|c|c|}
\hline $\mathrm{pH}$ & $\mathrm{pH}-$ Wert \\
\hline pl & isoelektrischer Punkt \\
\hline$R_{f}$ & Retentionsfaktor \\
\hline rpm & Umdrehungen pro Minuten (rounds per minute) \\
\hline$r_{\mathrm{H}}$ & hydrodynamischer Radius \\
\hline S & Sekunden \\
\hline$t$ & Zeit \\
\hline$T$ & Temperatur \\
\hline$T_{1}$ & zeitlicher Parameter der FRAP-Kurve \\
\hline V & Volt \\
\hline$V$ & Volumen \\
\hline$\vec{v}$ & Ausbreitungsgeschwindigkeit des Lichts \\
\hline wt\% & Gewichtsprozent \\
\hline$\alpha$ & Absorptionskoeffizient \\
\hline$\beta$ & Massenkonzentration \\
\hline$\varepsilon$ & molarer dekadischer Extinktionskoeffizient \\
\hline$\eta$ & Viskosität \\
\hline$\Theta$ & Elliptizität, mittlere residuale Elliptizität \\
\hline$\Theta_{\text {abs }}$ & absolute Elliptizität \\
\hline$\lambda$ & Wellenlänge \\
\hline$\mu \mathrm{g}$ & Mikrogramm \\
\hline$\mu \mathrm{L}$ & Mikroliter \\
\hline$\mu \mathrm{M}$ & mikromolar \\
\hline$\tau_{1 / 2}$ & charakteristische Diffusionszeit, Halbwertszeit der \\
\hline & Fluoreszenzregeneration \\
\hline
\end{tabular}


Grad Celsius

\subsection{Abkürzungsverzeichnis}

\begin{tabular}{|c|c|}
\hline Abb. & Abbildung \\
\hline APS & Ammoniumpersulfat \\
\hline ASG & Acyliertes Sterylglycosid \\
\hline BSA & Rinderserumalbumin (bovine serum albumin) \\
\hline CD & Zirkuläre Zweifarbigkeit (circular dichroism) \\
\hline Cer & Ceramid \\
\hline CLSM & Confocal Laser Scanning Microscopy \\
\hline CMC & kritische Mizellenkonzentration (critical micellar concentration) \\
\hline DAG & Diacylglycerol \\
\hline DGCC & Diacylglyceryl-3-O-carboxyhydroxymethylcholin \\
\hline DGDG & Digalactosyldiacylglycerol \\
\hline DGMG & Digalactosylmonoacylglycerol \\
\hline DOPC & 1,2-Dioleoyl-sn-glycero-3-phosphocholin \\
\hline DPPE & 1,2-Dipalmitoyl-sn-glycero-3-phosphoethanolamin \\
\hline DTNB & 5,5`-Dithiobis-2-nitrobenzoesäure \\
\hline DTT & Dithiothreitol \\
\hline EDTA & Ethylendiamintetraessigsäure \\
\hline ER & Endoplasmatisches Retikulum \\
\hline ESI & Elektrosprayionisation \\
\hline et al. & und andere (et alii) \\
\hline
\end{tabular}


FA

FAME

FID

FRAP

FS

GC

GFP

Gl.

HEPES

HexCer/Hex 2 Cer

HSA

IPTG

LC

LCPA

LPC, LPE, ...

lum

LUV

MGDG

MGMG

MOPS

MS

MS/MS

NCM

NTA

PA
Fettsäure (fatty acid)

Fettsäuremethylester (fatty acid methyl ester)

Flammenionisationsdetektion

Fluorescence Recovery after Photobleaching

Freies Sterol

Gaschromatografie

Grünfluoreszierendes Protein

Gleichung

2-(4-(2-Hydroxyethyl)-1-piperazinyl)-ethansulfonsäure

Hexosylceramid/Dihexosylceramid

Humanes Serumalbumin (human serum albumin)

Isopropyl- $\beta$-D-thiogalactopyranosid

Flüssigchromatografie (liquid chromatography)

langkettiges Polyamin (long-chain polyamine)

Lysoformen der Phospholipide (Lysophosphatidylcholin, ...)

luminal

großer unilamellarer Vesikel (large unilamellar vesicle)

Monogalactosyldiacylglycerol

Monogalactosylmonoacylglycerol

3-(N-(Morpholino)propansulfonsäure

Massenspektrometrie

Tandemmassenspektrometrie

Nitrocellulosemembran

Nitrilotriessigsäure

Phosphatidsäure (phosphatidic acid) 
PAGE

Polyacrylamidgelelektrophorese

PC

Phosphatidylcholin

PE

Phosphatidylethanolamin

PG

Phosphatidylglycerol

PI

Phosphatidylinositol

$P / L$

Protein-zu-Lipid-Verhältnis

PL

Proteoliposomen

POPC

1-Palmitoyl-2-oleoyl-sn-glycero-3-phosphocholin

POPE

1-Palmitoyl-2-oleoyl-sn-glycero-3-phosphoethanolamin

POPG

1-Palmitoyl-2-oleoyl-sn-glycero-3-phosphoglycerol

PS

Phosphatidylserin

PTM

post-translationale Modifikation

RSA

Kaninchenserumalbumin (rabbit serum albumin)

$\mathrm{RT}$

Raumtemperatur

SAP

silicalemma associated protein

SDS

Natriumdodecylsulfat (sodium dodecyl sulfate)

SDV

Silicafällungsvesikel (Silica Deposition Vesicle)

SE

Sterolester

SG

Sterylglycosid

Si

Silicium

SiMat

silica matrix-Protein

$\operatorname{Sin} 1$

Silicanin-1

SIT

silicic acid transporter protein

SQDG

Sulfoquinovosyldiacylglycerol

SQMG

Sulfoquinovosylmonoacylglycerol 
SUV

kleiner unilamellarer Vesikel (small unilamellar vesicle)

Tab.

Tabelle

TAG

Triacylglycerol

TEMED

Tetramethylethylendiamin

TLC

Dünnschichtchromatografie (thin layer chromatography)

$\mathrm{Tp}$

Thalassiosira pseudonana

Tp-div

Tp-Kultur zum Zeitpunkt angereicherter Valven-SDVs

Tp-G1

Tp-Kultur zum Zeitpunkt der G1-Phase

TRIS

Tris(hydroxymethyl)-aminomethan

TxR

Texas Red $\circledast$

UPLC

ultraperformance liquid chromatography

UV

Ultraviolett

vis

sichtbar

\subsection{Chemikalien}

Aceton

VWR, Darmstadt

Acrylamidmischung Rotiphorese

Gel 30

Carl Roth $\mathrm{GmbH}$, Karlsruhe

Agar

Carl Roth $\mathrm{GmbH}$, Karlsruhe

Agarose

Carl Roth $\mathrm{GmbH}$, Karlsruhe

Ammoniak (25\%)

Fisher Scientific, Pittsburgh (USA)

Ampicillin (Na-Salz)

Carl Roth GmbH, Karlsruhe

Antikörper (Anti-His-Tag; Maus)

Qiagen, Hilden

Antikörper, Alexa Fluor 647-konj. 
(Ziege; Anti-Kaninchen)

HRP-Antikörper (Ziege; Anti-Maus)

HRP-Antikörper

(Ziege; Anti-Kaninchen)

Antiserum (Anti-Sin1; Kaninchen)

Ammoniumpersulfat (APS)

Atto 390-DPPE

Bodipy 500/510-PPC

Bromphenol

BSA

Chloroform

Coomassie Brilliant Blue R-250

DNase I

DOPC

DTT

ECL Prime Amersham

EDTA ( $\left.\mathrm{Na}_{2} \mathrm{EDTA} \cdot 2 \mathrm{H}_{2} \mathrm{O}\right)$

Essigsäure

Ethanol p. A.

L-Glutathion

L-Glutathiondisulfid

Glycerin

Glycin

Harnstoff

Hefeextrakt
Invitrogen, Bangaluru (Indien)

BD Pharmingen, San Diego (USA)

Santa Cruz Biotechnology, Heidelberg

Arbeitskreis Kröger, Dresden

Sigma Aldrich, Taufkirchen

Atto-tec $\mathrm{GmbH}$, Siegen

Invitrogen, Schwerte

Carl Roth $\mathrm{GmbH}$, Karlsruhe

Carl Roth $\mathrm{GmbH}$, Karlsruhe

VWR, Darmstadt

Fluka, Buchs (Schweiz)

Applichem, Darmstadt

Avanti Polar Lipids, Alabaster (USA)

Sigma Aldrich, Taufkirchen

GE Healthcare, Amersham (UK)

Carl Roth $\mathrm{GmbH}$, Karlsruhe

Fisher Scientific, Loughborough (UK)

Sigma Aldrich, Taufkirchen

Carl Roth $\mathrm{GmbH}$, Karlsruhe

Applichem, Darmstadt

Grüssing, Filsum

Grüssing, Filsum

Applichem, Darmstadt

Carl Roth $\mathrm{GmbH}$, Karlsruhe 
Hellmanex

HEPES

Histodenz

IPTG

Isopropanol

$\mathrm{KCl}$

$\mathrm{KOH}$

Lysozym

$\beta$-Mercaptoethanol

Methanol

$\mathrm{MgCl}_{2} \cdot 6 \mathrm{H}_{2} \mathrm{O}$

Milchpulver

MOPS

Mucasol

Natriumcitrat

$\mathrm{NaCl}$

$\mathrm{Na}_{2} \mathrm{CO}_{3}$

$\mathrm{Na}_{2} \mathrm{HPO}_{4} \cdot 2 \mathrm{H}_{2} \mathrm{O}$

$\mathrm{NaH}_{2} \mathrm{PO}_{4} \cdot \mathrm{H}_{2} \mathrm{O}$

$\mathrm{Na}_{3} \mathrm{PO}_{4}$

$\mathrm{NaN}_{3}$

$\mathrm{NaOH}$

Ni-NTA-Agarose

$\mathrm{NiSO}_{4} \cdot 6 \mathrm{H}_{2} \mathrm{O}$

n-Octylglucosid
Hellma Analytics, Müllheim

Carl Roth $\mathrm{GmbH}$, Karlsruhe

Sigma Aldrich, Taufkirchen

Carl Roth $\mathrm{GmbH}$, Karlsruhe

VWR, Darmstadt

Merck, Darmstadt

Merck, Darmstadt

Sigma Aldrich, Taufkirchen

Sigma Aldrich, Taufkirchen

Honeywell, Seelze

VWR, Darmstadt

Carl Roth $\mathrm{GmbH}$, Karlsruhe

Carl Roth $\mathrm{GmbH}$, Karlsruhe

Brand, Wertheim

Merck, Darmstadt

Sigma Aldrich, Taufkirchen

Grüssing, Filsum

VWR, Darmstadt

Merck, Darmstadt

Merck, Darmstadt

Merck, Darmstadt

J.T. Baker, Center Valley (USA)

Qiagen, Hilden

Riedel de Haen, Seelze

Carl Roth $\mathrm{GmbH}$, Karlsruhe 
PAGE Ruler Plus-PAGE-Marker

Phosphorsäure (konz.)

PonceauS

POPC

POPE

POPG

Roche® Complete Protease-

Inhibitor

Salzsäure (konz.)

SDS

TEMED

Texas Red®-DHPE

Tricin

TRIS

Trypton

Tween $20 \AA$

Wasserstoffperoxid (30\%)

Zitronensäure

\subsection{Materialien}

Celluloseacetat-Filter

(Porengröße: 0,2 $\mu \mathrm{m}$ )

DC-Platte DC Kieselgel 60 mit

Konzentrationszone $2.5 \times 20 \mathrm{~cm}$;
Fisher Scientific, Schwerte

Fisher Scientific, Schwerte

Sigma Aldrich, Taufkirchen

Avanti Polar Lipids, Alabaster (USA)

Avanti Polar Lipids, Alabaster (USA)

Avanti Polar Lipids, Alabaster (USA)

Roche, Grenzach-Wyhlen

VWR, Darmstadt

Applichem, Darmstadt

Sigma Aldrich, Taufkirchen

Santa Cruz Biotechnology, Heidelberg

Carl Roth $\mathrm{GmbH}$, Karlsruhe

Carl Roth $\mathrm{GmbH}$, Karlsruhe

Carl Roth $\mathrm{GmbH}$, Karlsruhe

Carl Roth $\mathrm{GmbH}$, Karlsruhe

Sigma Aldrich, Taufkirchen

Merck, Darmstadt

Sartorius Stedim Biotech GmbH, Göttingen

Merck KGaA, Darmstadt 
$20 \times 20 \mathrm{~cm}$;

Dialyseschlauch 14 kDa VISKING Carl Roth GmbH, Karlsruhe

Dialyseschlauch ZELLUTRANS

MWCO 12000-14000 Carl Roth GmbH, Karlsruhe

Eppendorfgefäße Eppendorf, Hamburg

Eppendorfpipetten Research Eppendorf, Hamburg

Halbmikroküvetten (single-use; PS) Brand, Wertheim

Nitrocellulosemembran

BioRad, Hercules (USA)

Parafilm M

Pechiney Plastic Packaging, Chicago (USA)

Quarzküvette QS $1 \mathrm{~mm}$

Hellma Analytics, Müllheim

Reagenzgläser

VWR, Darmstadt

Sephadexsäule G-25 NAP-10

GE Healthcare, Little Chalfont (UK)

Siliciumwafer $100 \mathrm{~nm} \mathrm{SiO} 2$

active business company $\mathrm{GmbH}$, München

Vivaspin 500/Vivaspin 6

Sartorius Stedim Biotech $\mathrm{GmbH}$, Göttingen

Whatmanpaper

Sigma Aldrich, Taufkirchen

\subsection{Geräte- und Softwareverzeichnis}

\section{Chromatographen}

Gaschromatograph Agilent 6890

Kapillarsystem DB-23 Column

ACQUITY UPLC I-class-System

ACQUITY UPLC HSS T3-Säule
Agilent Technologies, Waldbronn

J\&W Scientific, Agilent Technologies,

Waldbronn

Waters, Milford (USA)

Waters, Milford (USA) 
Spektrometer

Jasco J-1500 (CD)

Jasco Corp., Tokio (Japan)

Nanodrop 2000c

Thermo Fisher Scientific Inc., Waltham (USA)

Varian Cary 50 Scan

Agilent Technologies, Santa Clara (USA)

ESI-QuelleTriVersa Nanomate

Advion, Ithaca (USA)

6500 QTRAP-Tandemmassen-

AB Sciex, Framingham (USA)

spektrometer

Konfokales Laserscanningmikroskop

U-HGLPS

Olympus, Tokio (Japan)

Fluoview FV 1000

Olympus, Tokio (Japan)

BX61WI

Olympus, Tokio (Japan)

LSM 710 Examiner

Carl Zeiss $\mathrm{GmbH}$, Jena

Wasserimmersionsobjektiv 40x/1.0

DIC Vis/IR

Carl Zeiss $\mathrm{GmbH}$, Jena

Waagen

Ohaus Adventurer

Ohaus, Kirchheim

Ohaus Pioneer

Ohaus, Kirchheim

Rührer, Vortexer und Schüttler

Magnetrührer MR 3001 K

Heidolph, Schwabach

Magnetrührer Ikamag RCT

IKA, Staufen

Rollmixer Stuart SRT 6

Bibby Scientific Lim., Stone (England)

Thermomixer Compact

Eppendorf, Hamburg 
Vortexer

Wippschüttler CAT ST5

Zentrifugen

$3 \mathrm{~K} 30$

Allegra X-22R

Centrikon T-1065

Galaxy Mini

Heraeus Fresco 17

Optima L70 UZ mit Rotor SW56Ti

Trockenschränke und Inkubatoren

Orbitalschüttler New Brunswick

Innova 44

Schüttelinkubator TH30/SM30

Vakuumtrockenschrank VD 23

Sonstiges

BioRad Power PAC 200

BioRad Power PAC 1000

BioRad Trans-Blot SD

Concentrator 5301

DLS Zetasizer Nano S

Filmwaage RK1 Standard

Gefriertrockner Alpha 2-4 LD Plus
Heidolph, Schwabach

Cat, Staufen

Sigma, Taufkirchen

Beckmann Coulter, Krefeld

Kontron Instruments, Roßdorf

VWR, Darmstadt

Thermo Fisher Scientific Inc., Waltham (USA)

Beckman Coulter, Krefeld

Eppendorf, Hamburg

Edmund Bühler $\mathrm{GmbH}$, Tübingen

Binder, Tuttlingen

BioRad, Hercules (USA)

BioRad, Hercules (USA)

BioRad, Hercules (USA)

Eppendorf, Hamburg

Malvern Pananalytical, Kassel

Riegler \& Kirstein, Potsdam

Martin Christ Gefriertrocknungsanlagen

$\mathrm{GmbH}$, Osterode am Harz 
Gelapparatur

Gelimager azure c300

Laminar-Flow-Arbeitsbank

HVR 2448

Microfluidizer LM 10

Mikrowelle

$\mathrm{pH} 211$ Microprocessor $\mathrm{pH}-$ Meter

pH-Meter 766 Calimatic

Plasmacleaner ZEPTO

Reinstwasseranlage

MilliQ Gradient A 10

TC10 Automated Cell Counter

Thermobad E11

Tischautoklav $2540 \mathrm{EL}$

Ultraschallbad Bandelin Sonorex

Software

Agilent ChemStation

DichroWeb

ExPASy-PeptideCutter

ExPASy-ProtParam

Frap_analysis

ImageJ
PEQLAB Biotechnologie, Erlangen

azure biosystems, Dublin (USA)

Labotect, Göttingen

Microfluidics, Westwood (USA)

Sharp, Osaka (Japan)

Hanna Instruments, Vöhringen

Knick, Berlin

Diener electric, Ebhausen

Millipore, Eschborn

BioRad, Hercules (USA)

Dinkelberg Analytics, Gablingen

Tuttnauer, Breda

Bandelin, Berlin
Agilent Technologies, Waldbronn

L. Whitmore, B. A. Wallace

SIB Swiss Institute of Bioinformatics, Lausanne (Schweiz)

SIB Swiss Institute of Bioinformatics, Lausanne (Schweiz) Höök und Mitarbeiter Open Source 
Inkscape

IrfanView

MultiQuant

Office 2016

Origin Pro 8.5G

ProtCalc

ZEN Black
Open Source

Freeware

AB Sciex, Framingham (USA)

Microsoft Corp., Redmond (USA)

OriginLab Corp., Northhampton (USA)

Open Access

Zeiss, Oberkochen

\subsection{Proteinsequenzen}

Silicanin-1 (Sin1):

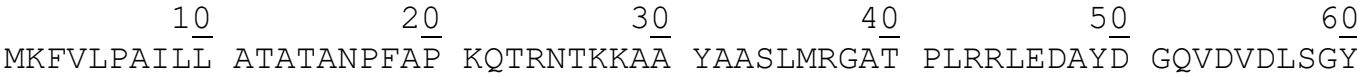

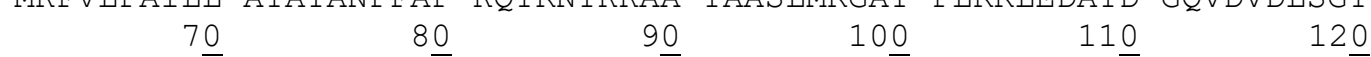

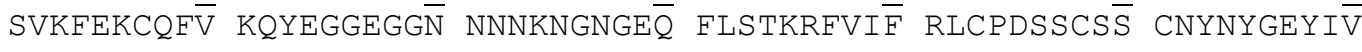

$\begin{array}{llllll}13 \underline{0} & 14 \underline{0} & 15 \underline{0} & 16 \underline{0} & 17 \underline{0} & 18 \underline{0}\end{array}$

DMDTYLESTL QYKQEEQETY CQSCQQCVEM QANANNGDA $\bar{N}$ DDQNNDNAWM CNNIDTSTCY

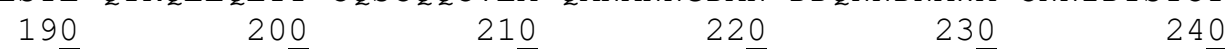

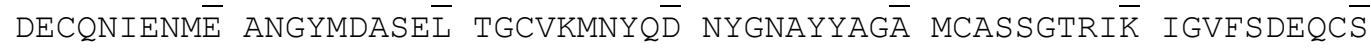

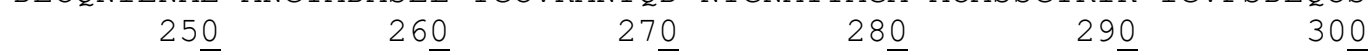

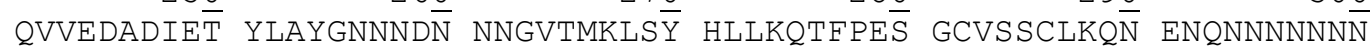

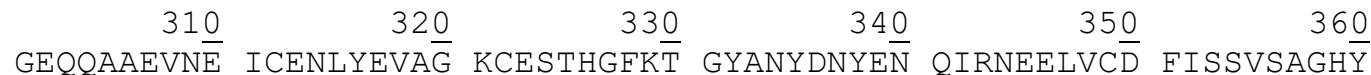

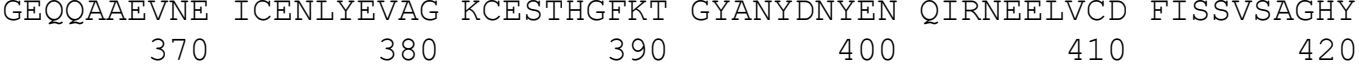

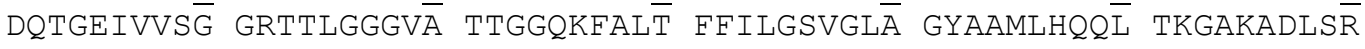
QGGAMA

rSin $1^{\text {lum: }}$

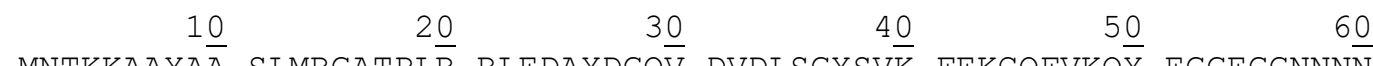

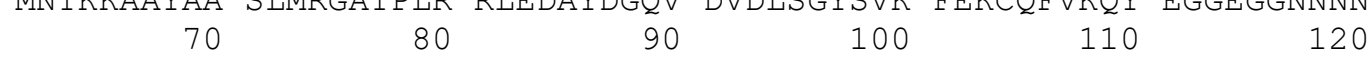
KNGNGEQFL $\bar{S}$ TKRFVIFRL $\bar{C}$ PDSSCSSCNY NYGEYIVDMD TYLESTLQYK QEEQETYCQ $\overline{\mathrm{S}}$

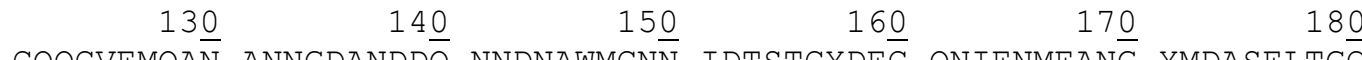

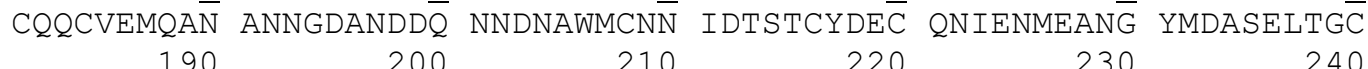
VKMNYQDNYG NAYYAGAMC $\bar{A}$ SSGTRIKIGV FSDEQCSQVV EDADIETYLA YGNNNDNNNG $25 \underline{0} \quad 26 \underline{0} \quad 27 \underline{0} \quad 28 \underline{0} \quad 29 \underline{0} \quad 30 \underline{0}$

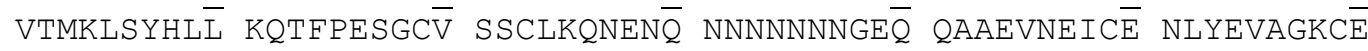
$\begin{array}{llllll}31 \underline{0} & 32 \underline{0} & 33 \underline{0} & 34 \underline{0} & 35 \underline{0} & 36 \underline{0}\end{array}$

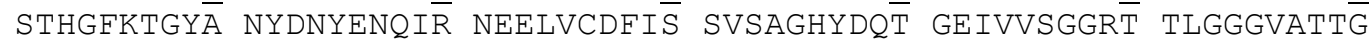
HHHHHH 
rSin $1^{-S P}$ :

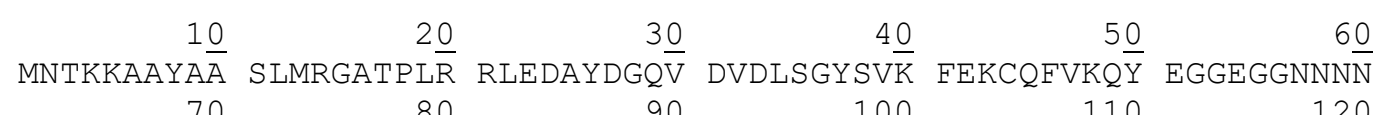

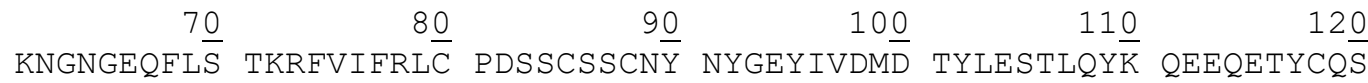
$\begin{array}{llllll}13 \underline{0} & 14 \underline{0} & 15 \underline{0} & 16 \underline{0} & 17 \underline{0} & 18 \underline{0}\end{array}$ CQQCVEMQAN ANNGDANDD $\bar{Q}$ NNDNAWMCNN IDTSTCYDEC QNIENMEANG YMDASELTG $\bar{C}$ $\begin{array}{llllll}19 \underline{0} & 20 \underline{0} & 21 \underline{0} & 22 \underline{0} & 23 \underline{0} & 24 \underline{0}\end{array}$ VKMNYQDNYG NAYYAGAMC $\bar{A}$ SSGTRIKIGV FSDEQCSQVV EDADIETYLA YGNNNDNNNG

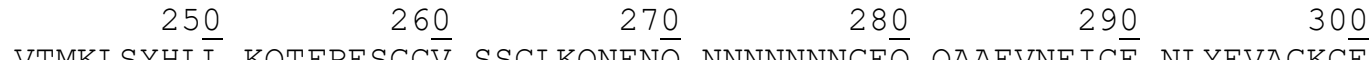

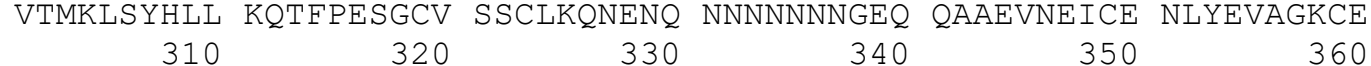
STHGFKTGYA NYDNYENQI $\bar{R}$ NEELVCDFI $\bar{S}$ SVSAGHYDQT GEIVVSGGRT TLGGGVATT $\bar{T}$ $\begin{array}{rrrr}370 & 380 & 390 & 400 \\ \text { GQKFALTFFI LGSVLAGYA } & \text { AMLHQQLTKG AKADLSRQGG AMAHHHHHH }\end{array}$

\subsection{Exemplarisches Chromatogramm der GC-FID von PC}

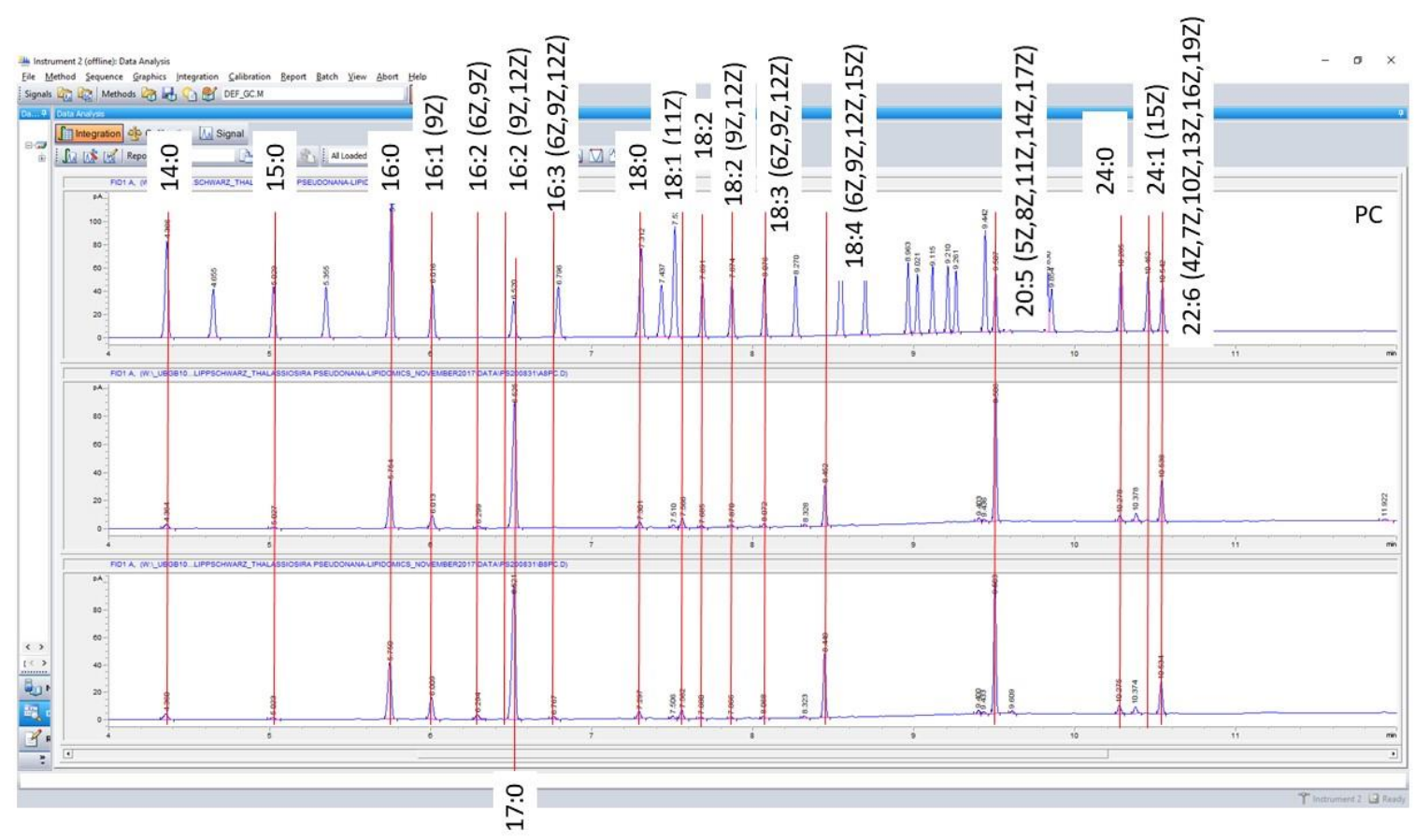

\subsection{Relative FA-Profile aus der TLC-GC-FID}

Die nachfolgenden relativen FA-Profile wurden mittels GC-FID aus dünnschichtchromatografisch getrennten Lipidklassen für Tp-div (rot) und Tp-G1 (blau) ermittelt. 

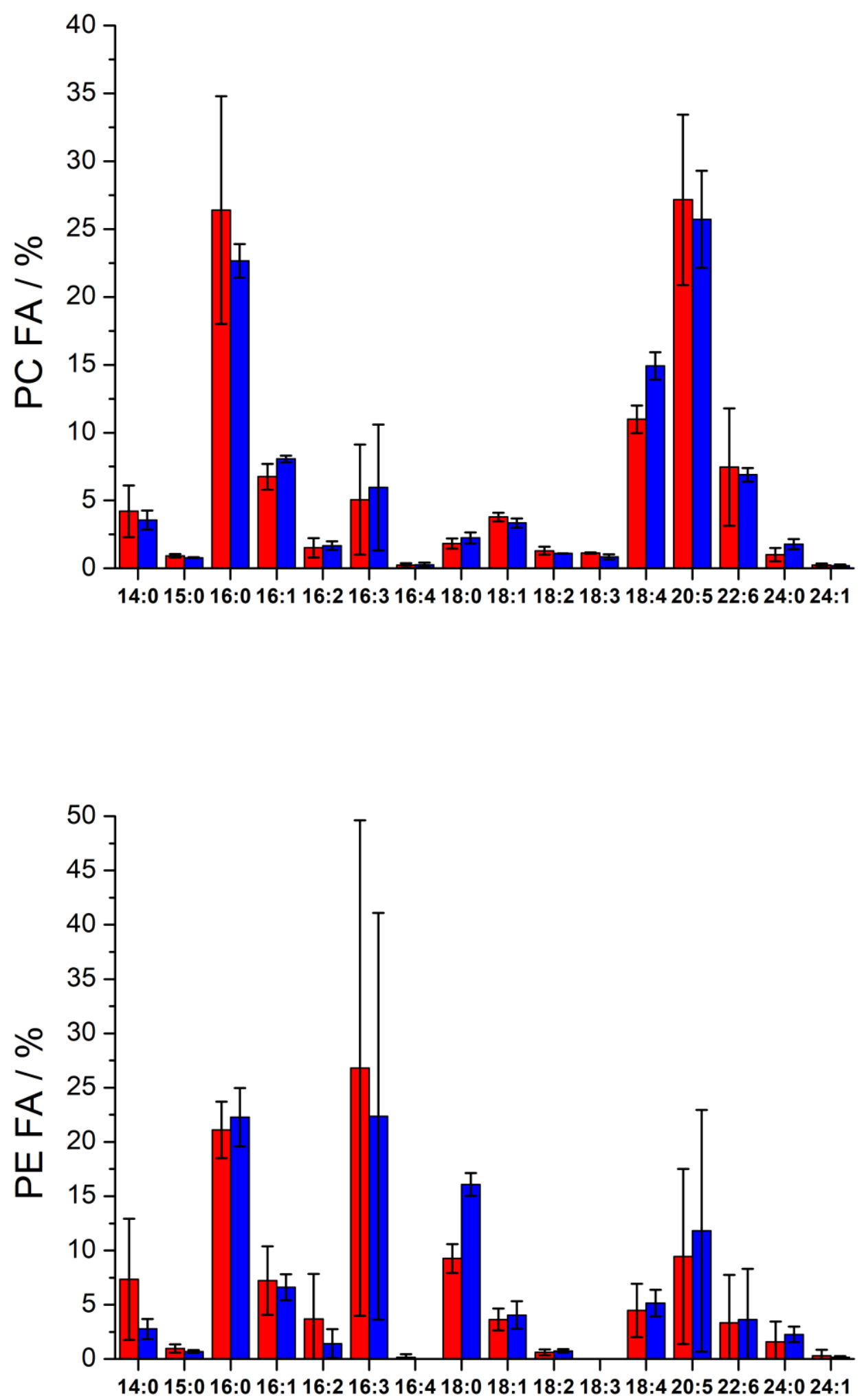

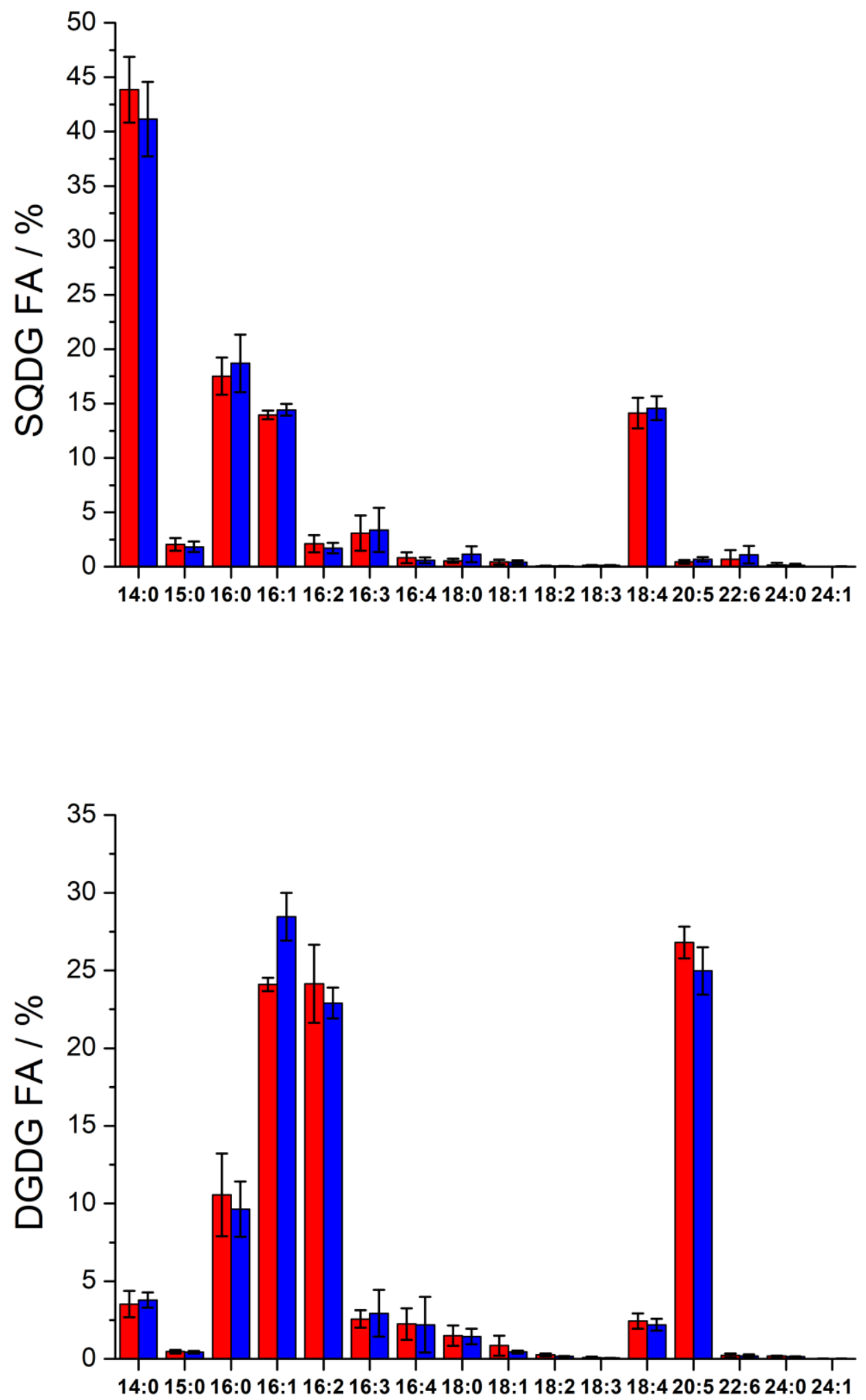

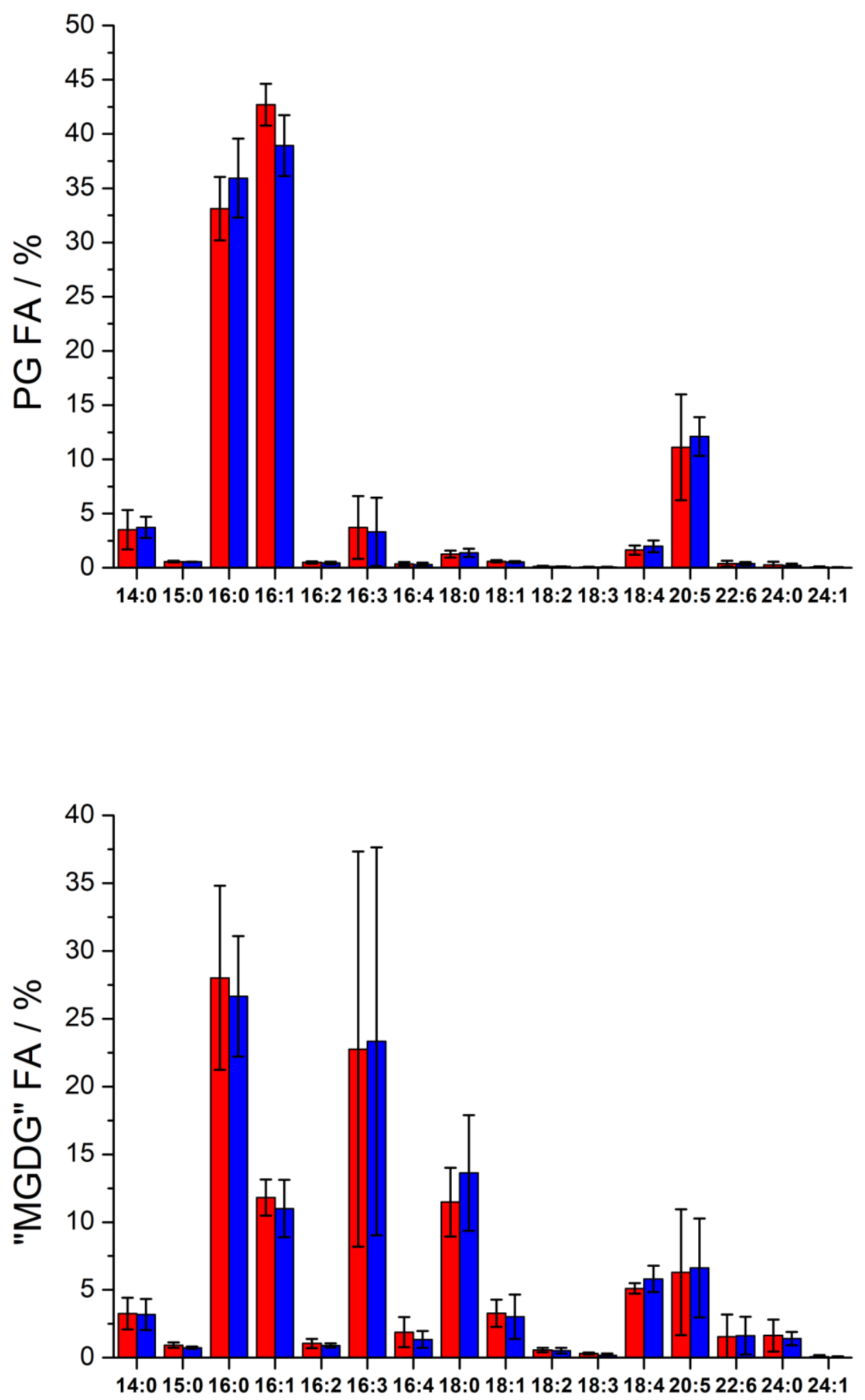


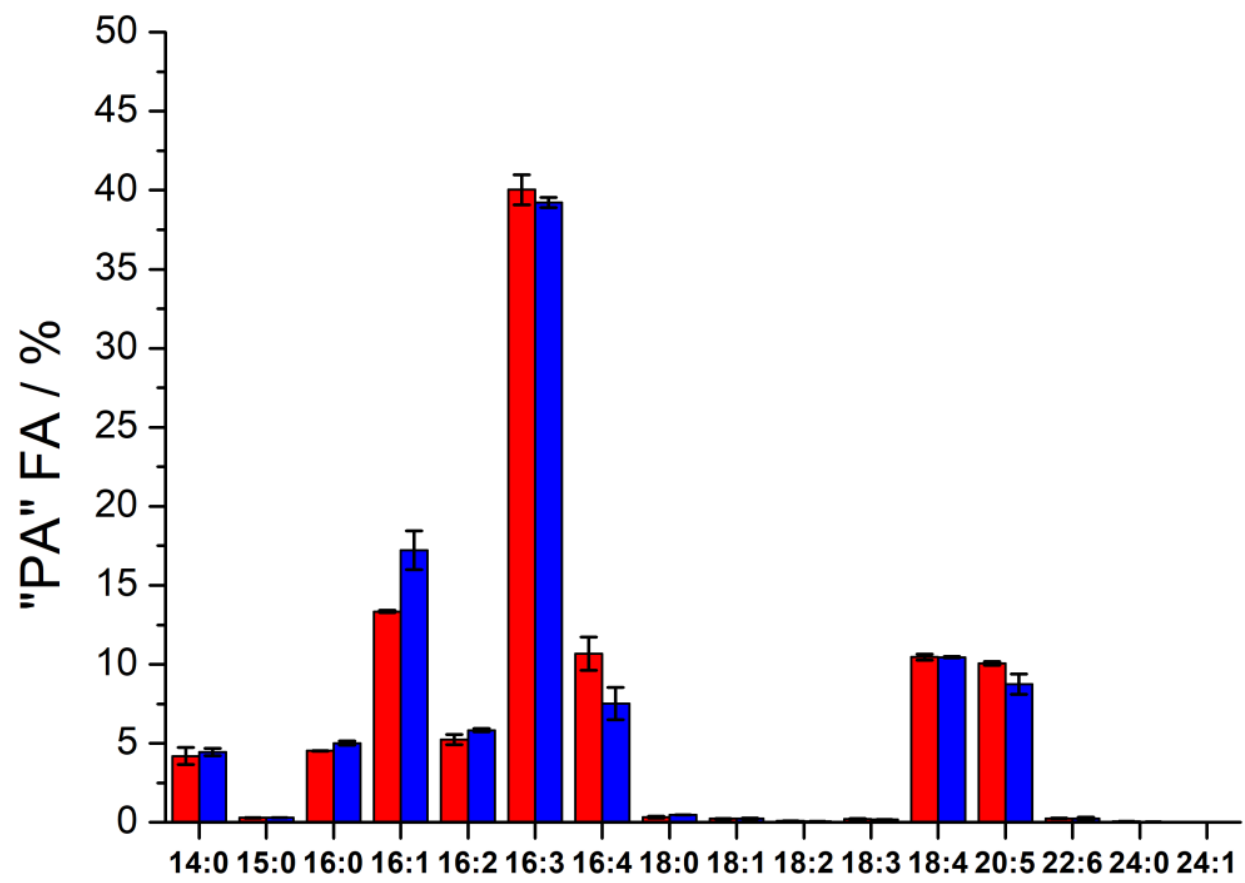

\subsection{Relative Lipid- und FA-Profile aus der LC-MS/MS}

Die nachfolgenden relativen Lipid- und FA-Profile einzelner Lipidklassen für Tp-div (rot) und Tp-G1 (blau) wurden aus UPLC-nanoESI-MS/MS-Messungen ermittelt. Die Standardabweichung des Mittelwerts dient als Fehlerbalken. Zweiseitige t-Tests mit ungleichen Varianzen wurden zur Überprüfung der statistischen Signifikanz

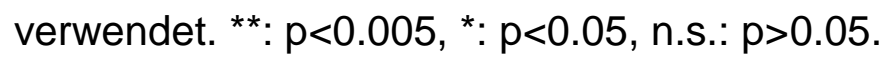



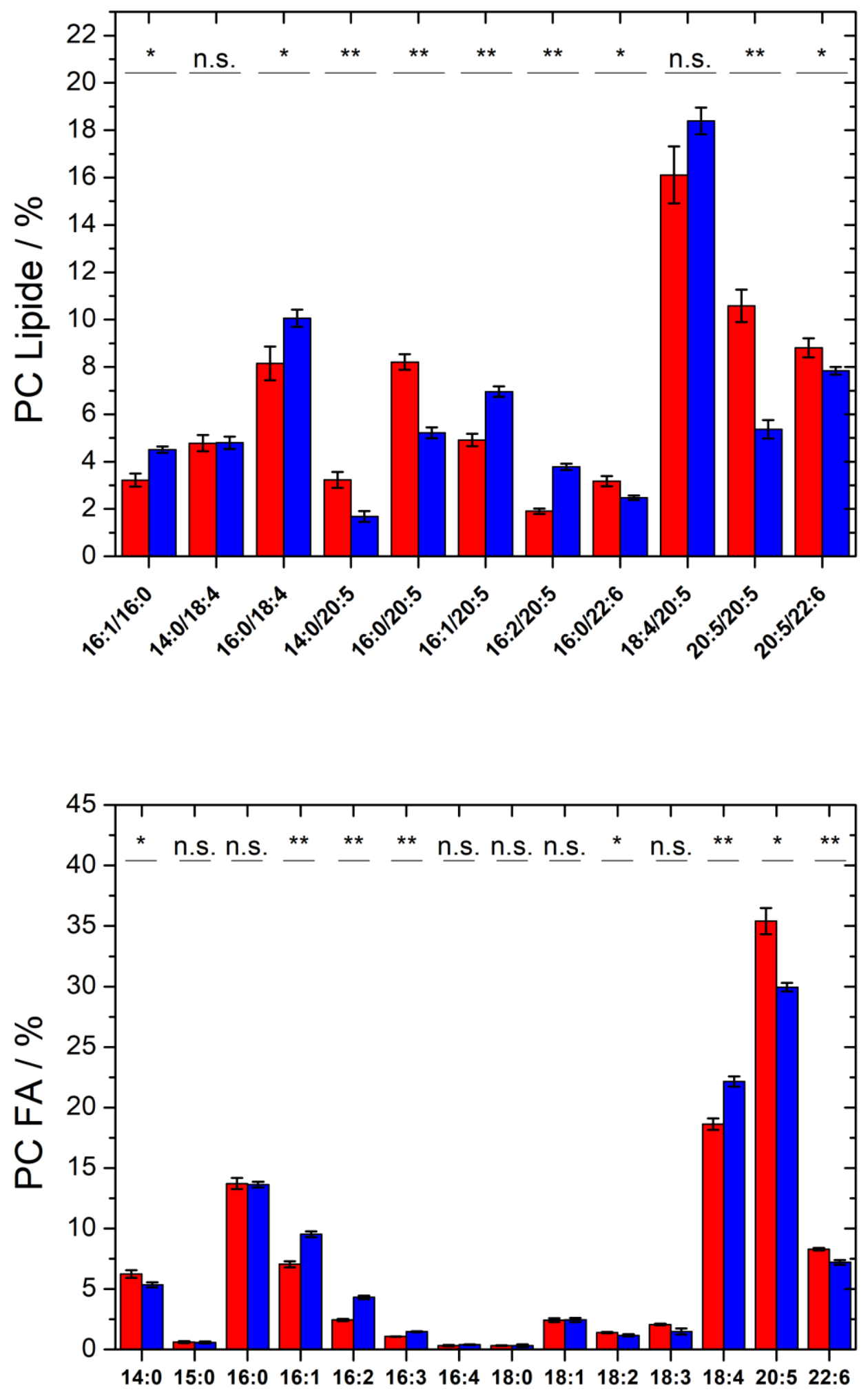

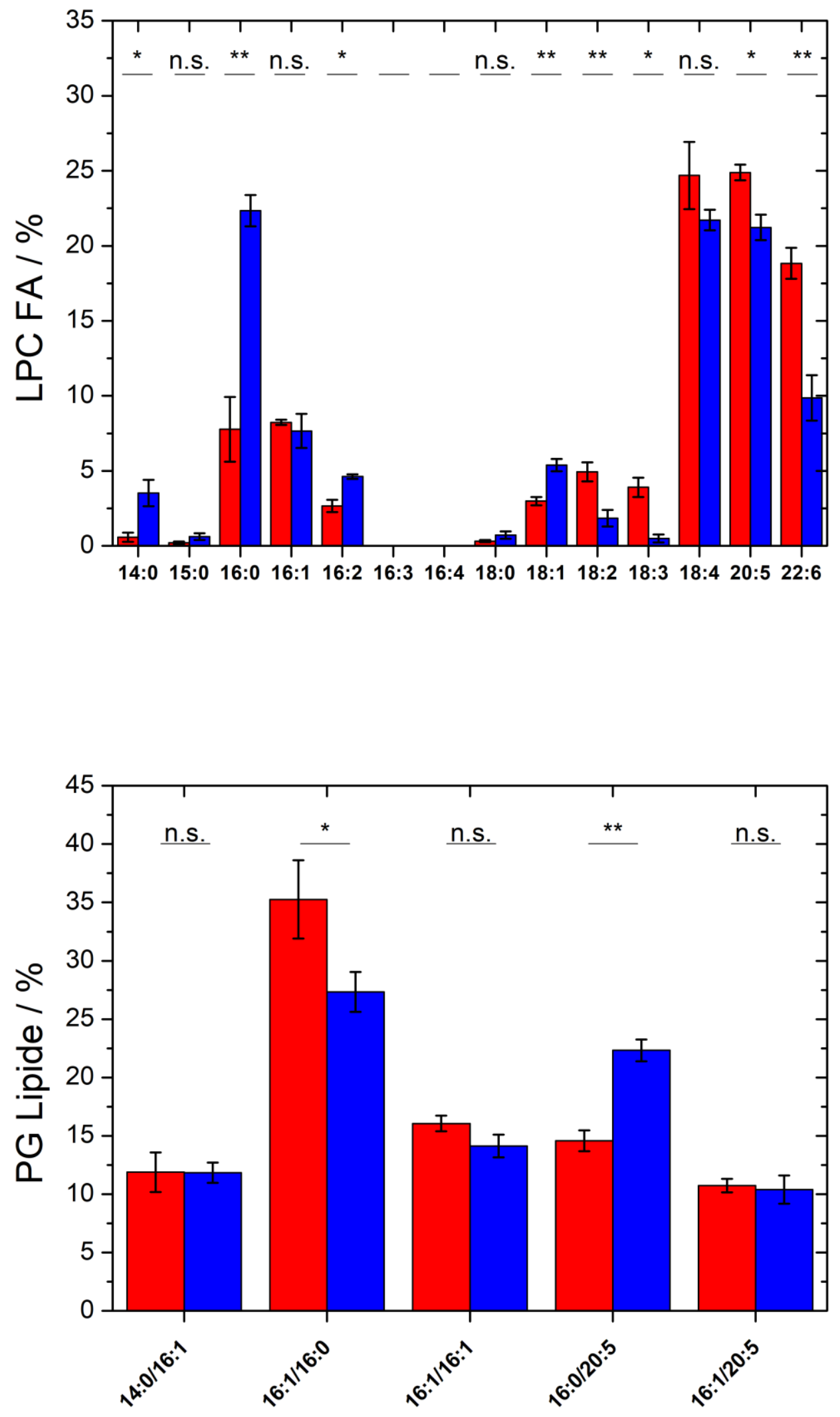

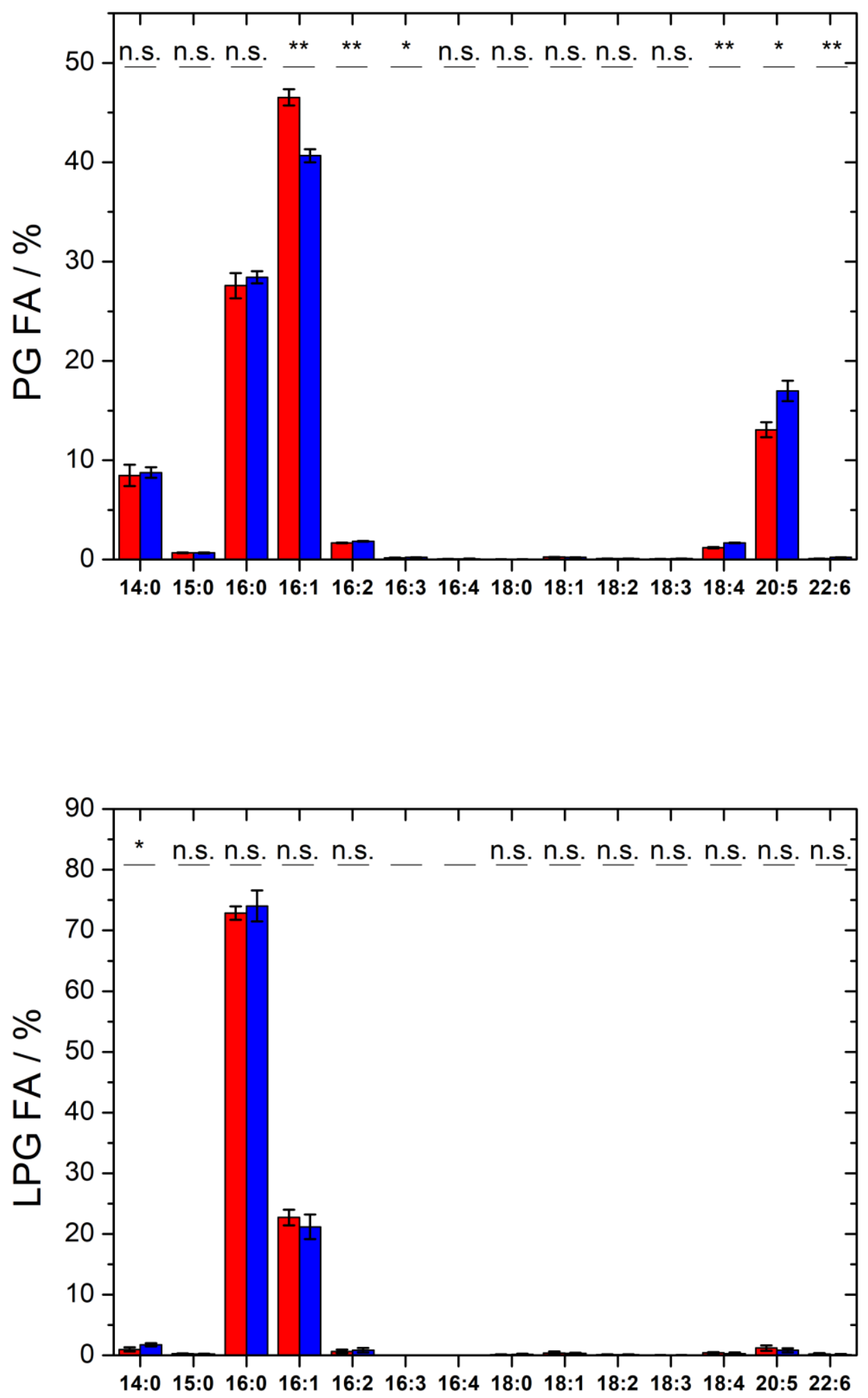

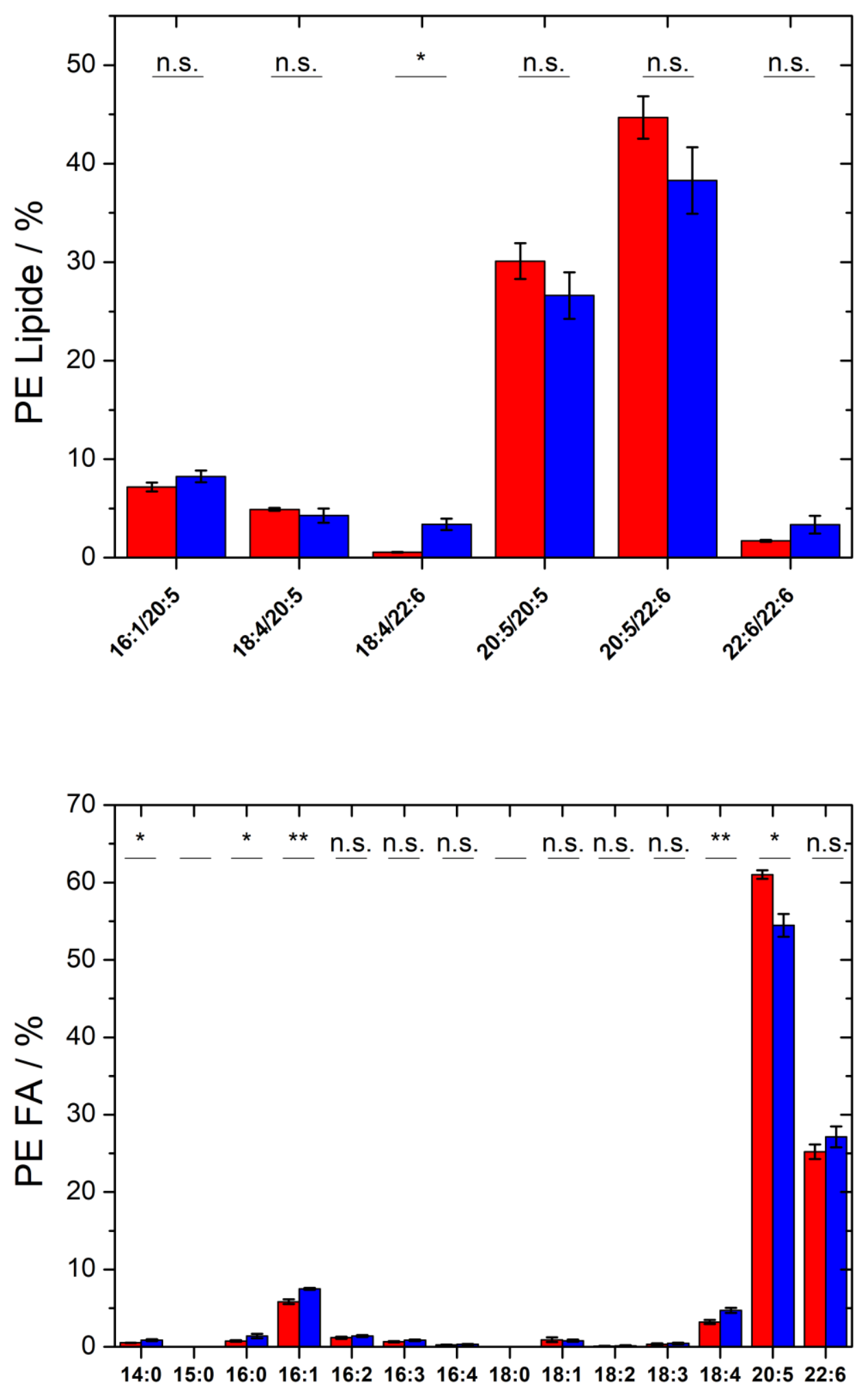

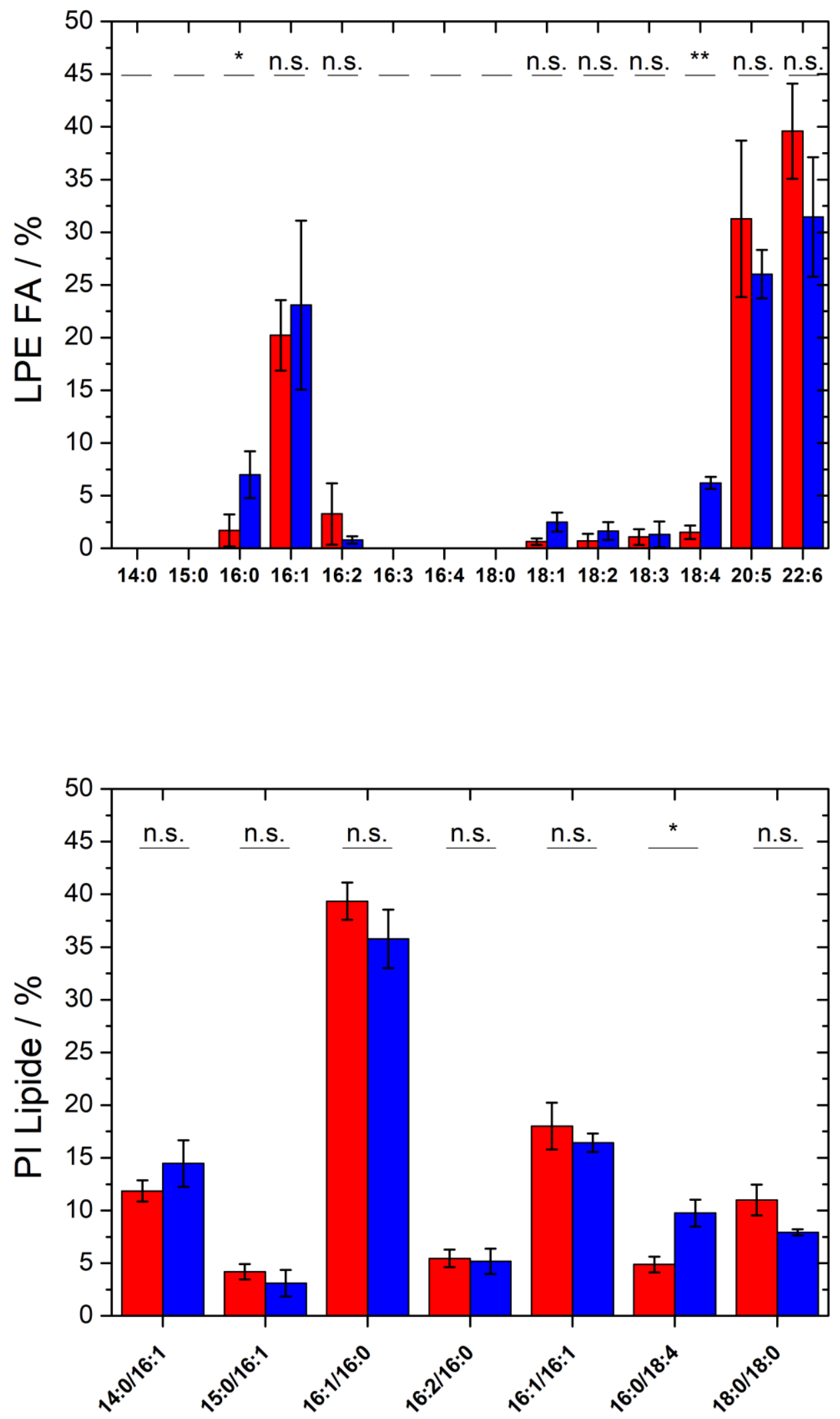

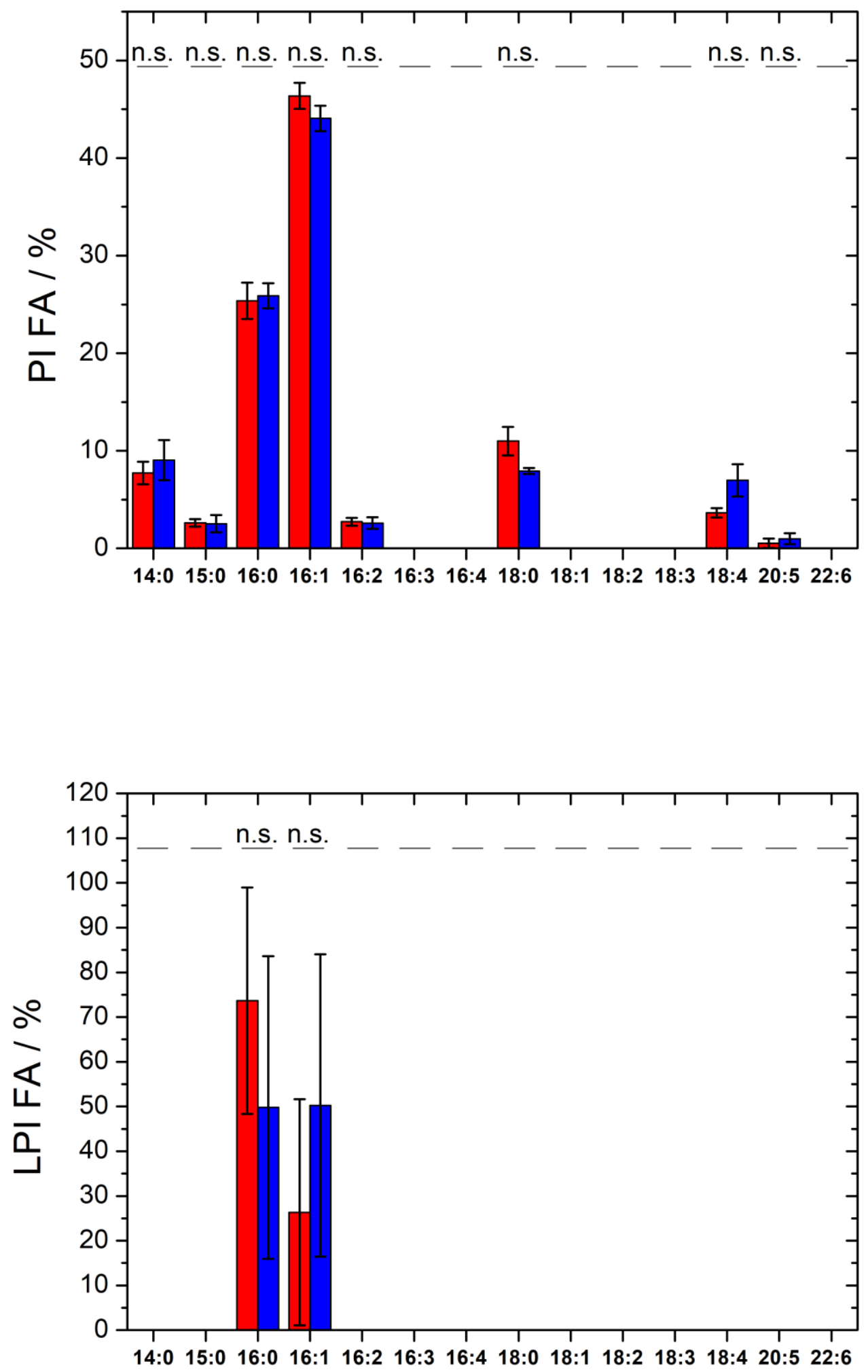

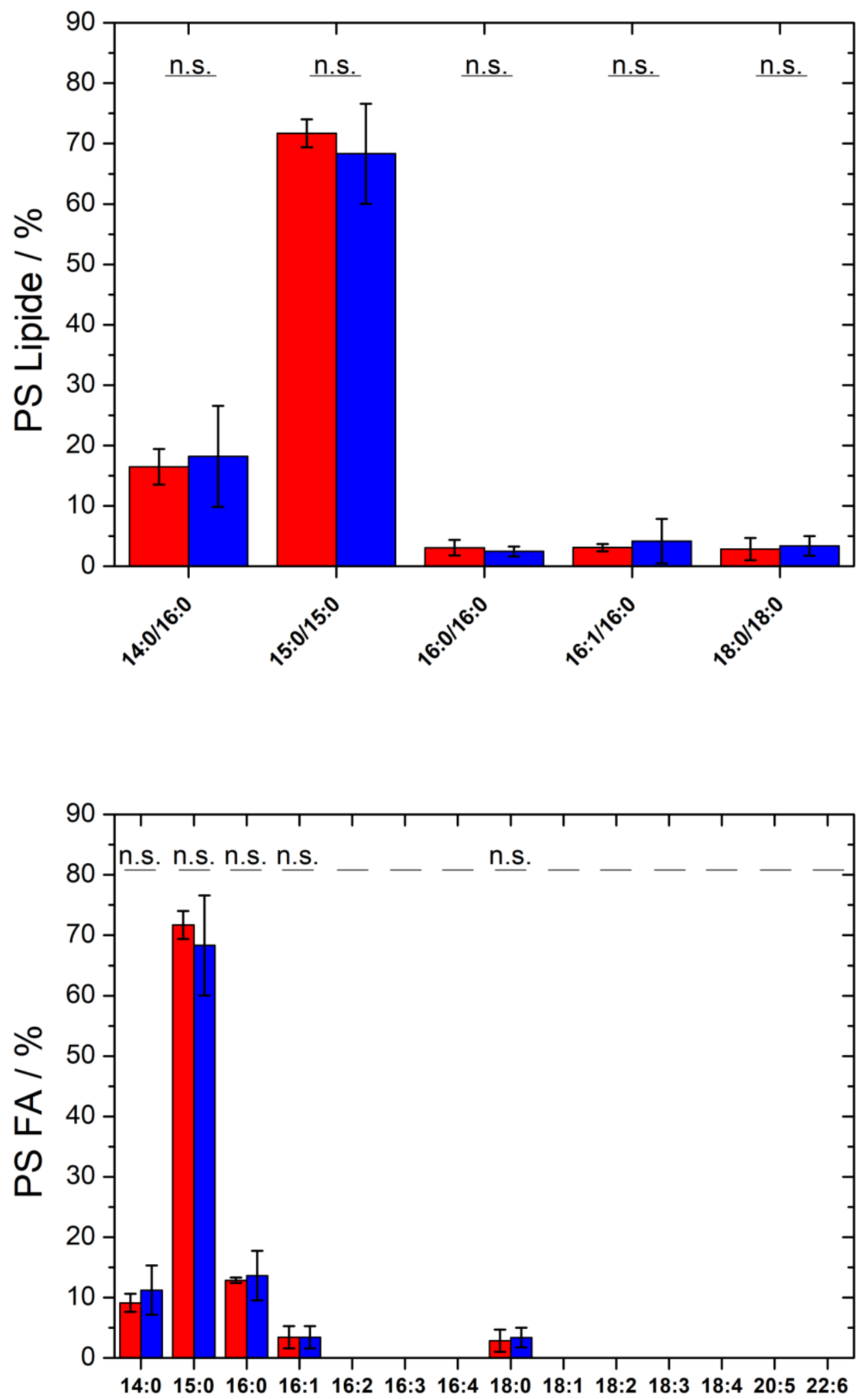

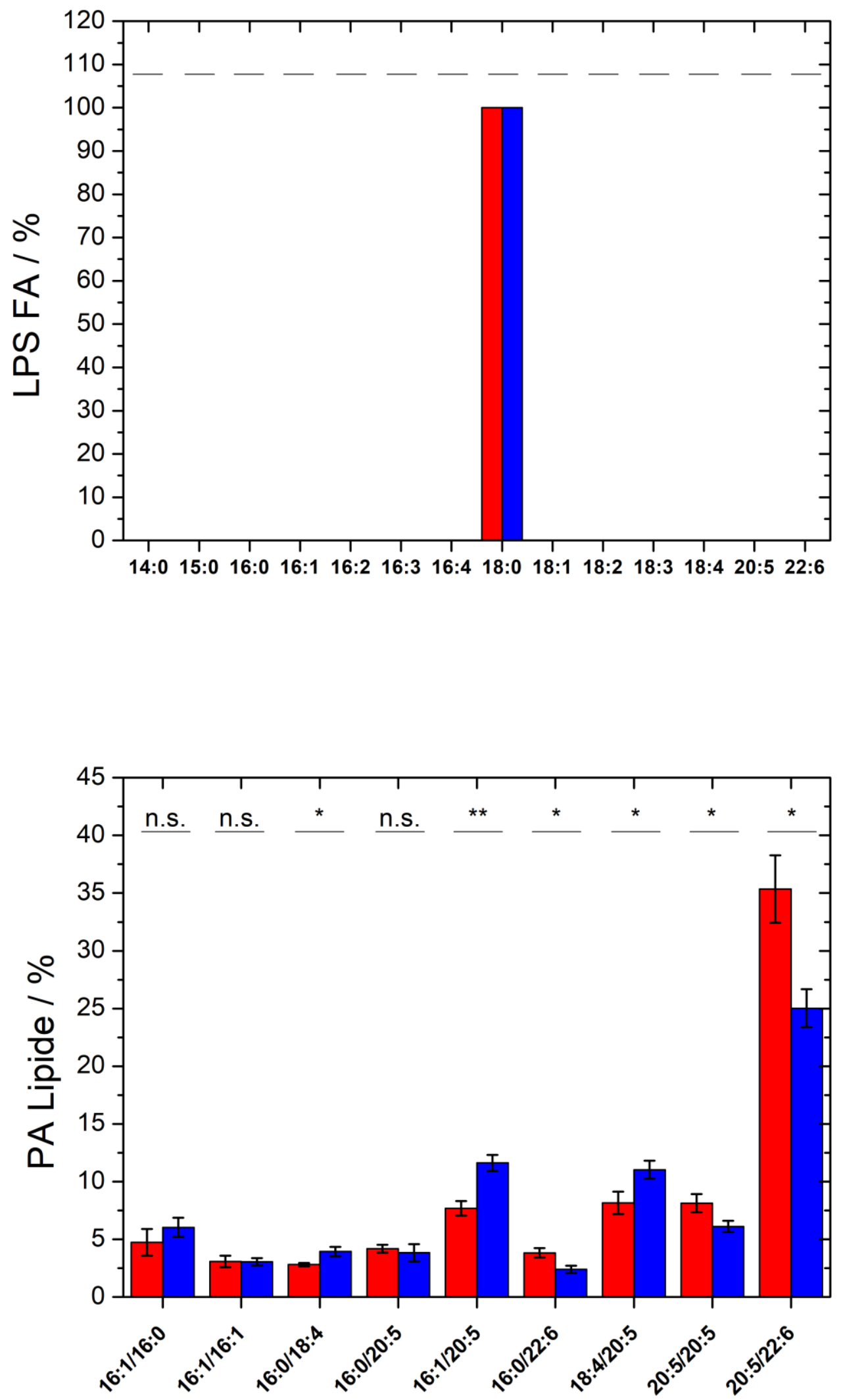

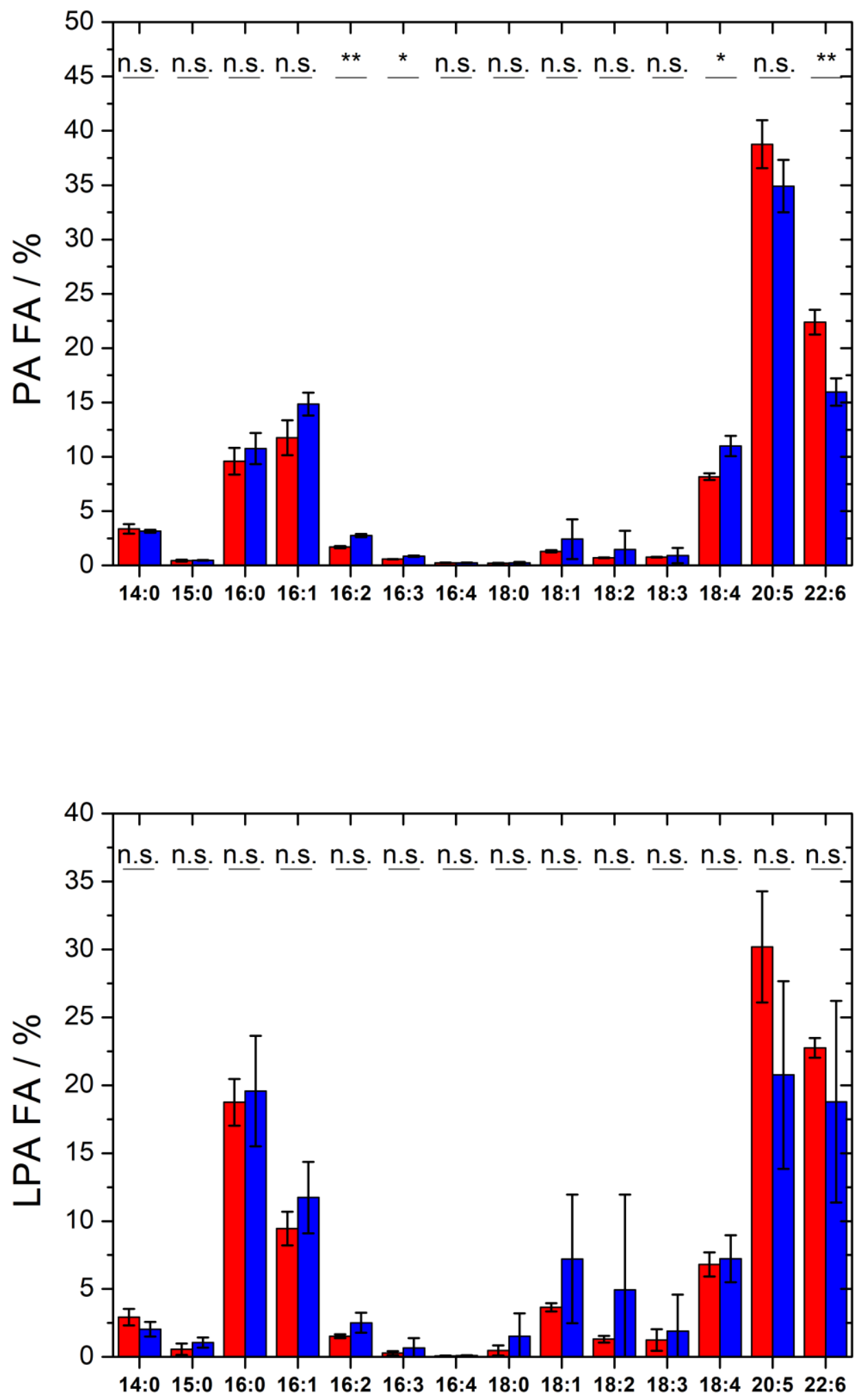

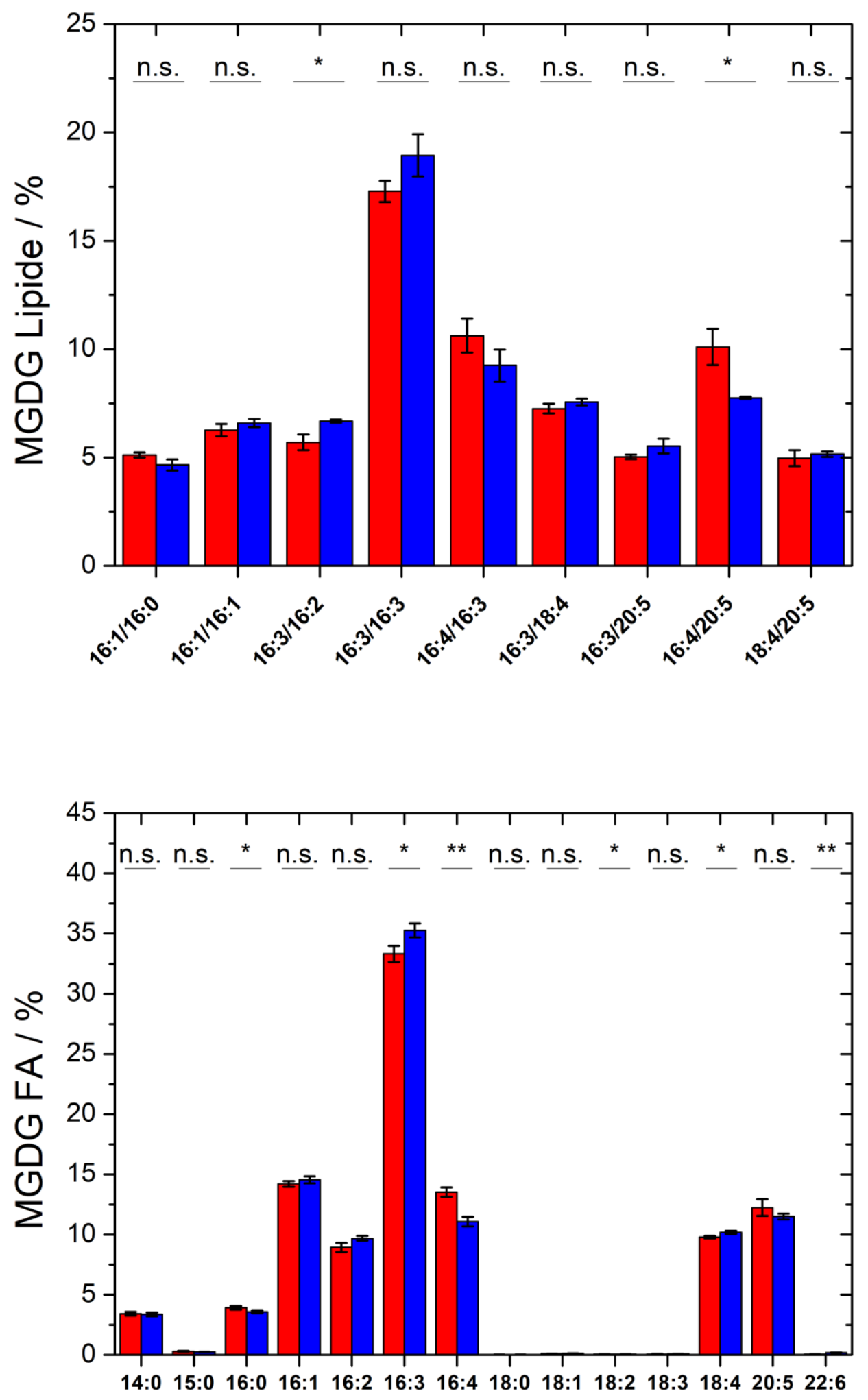

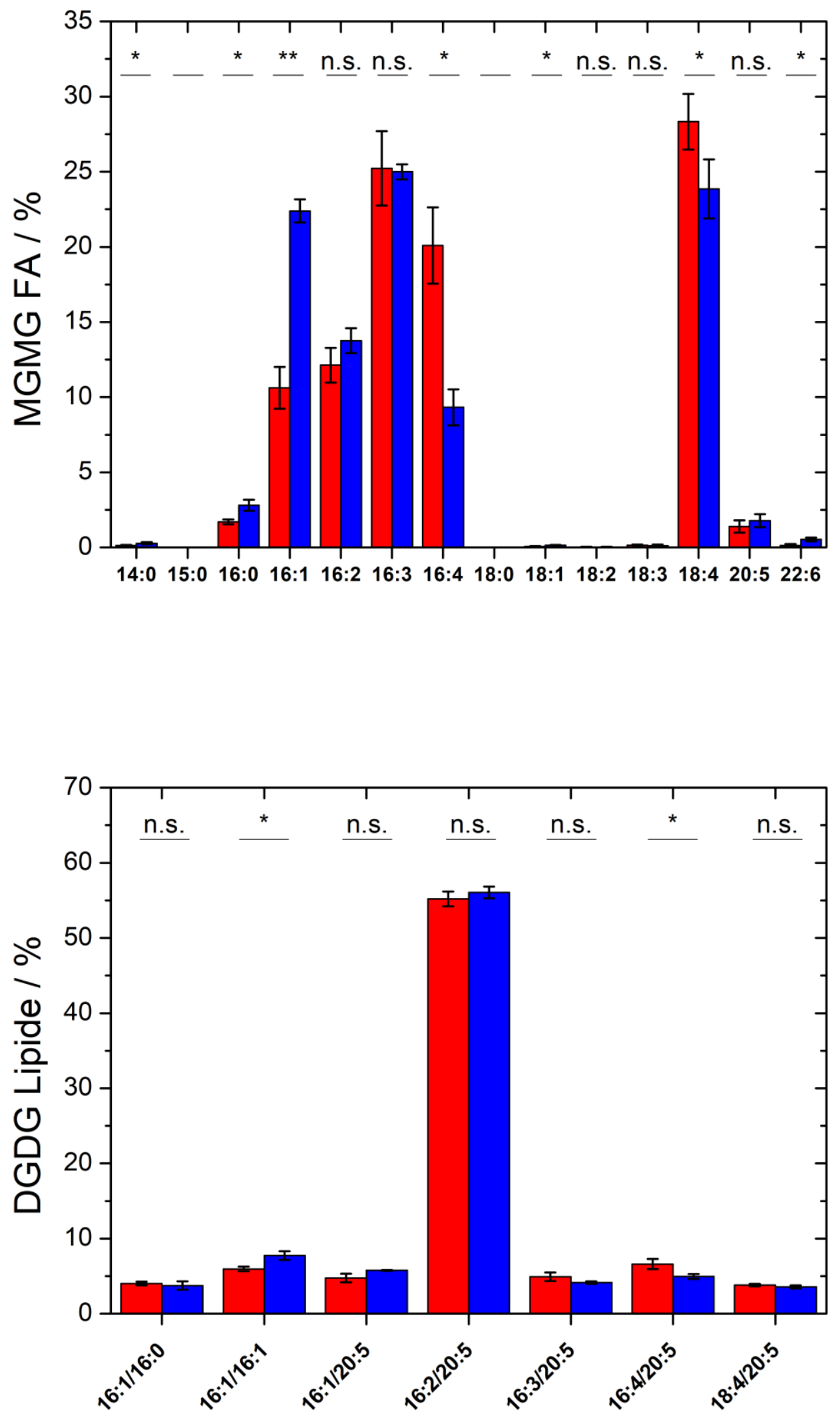

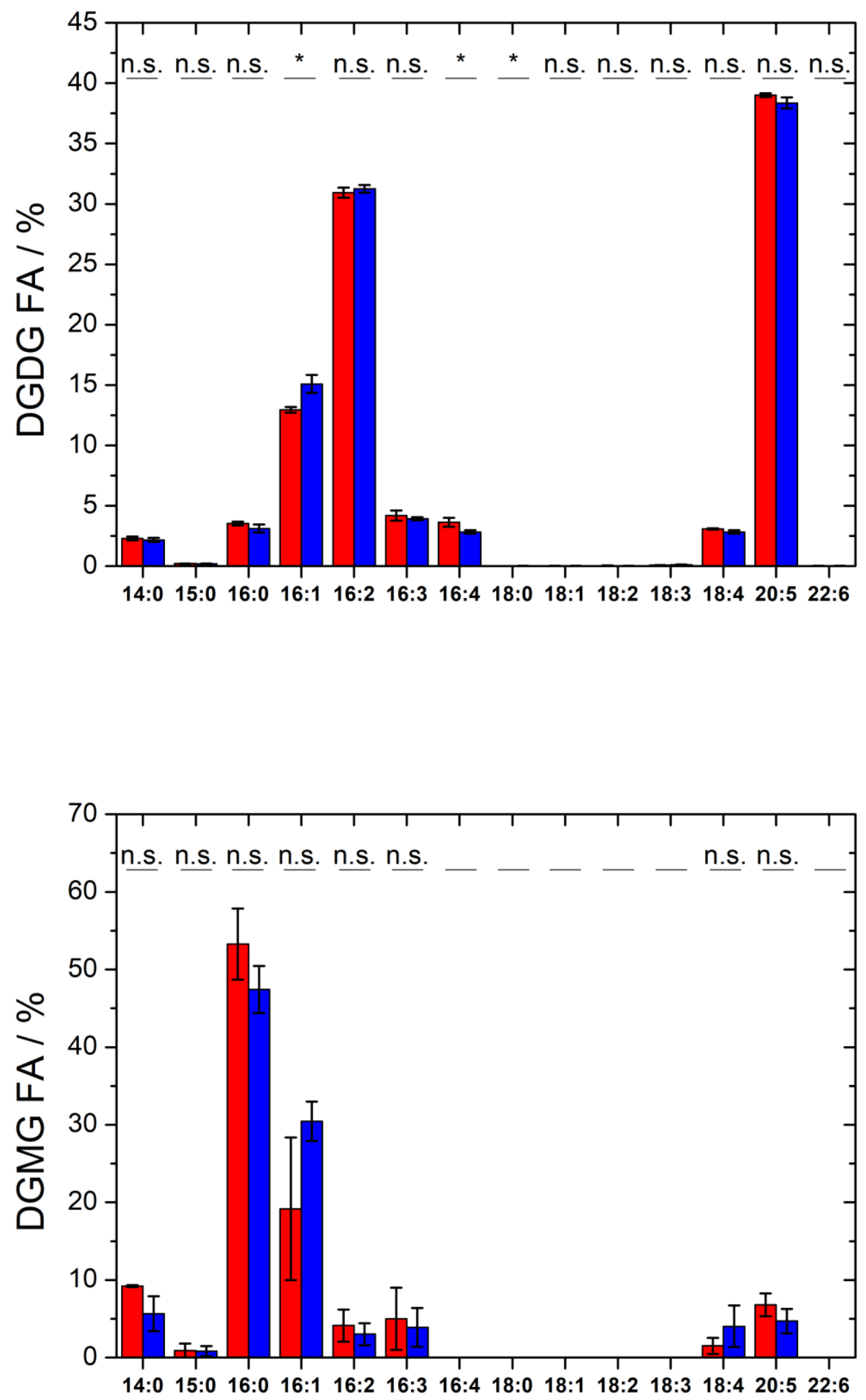

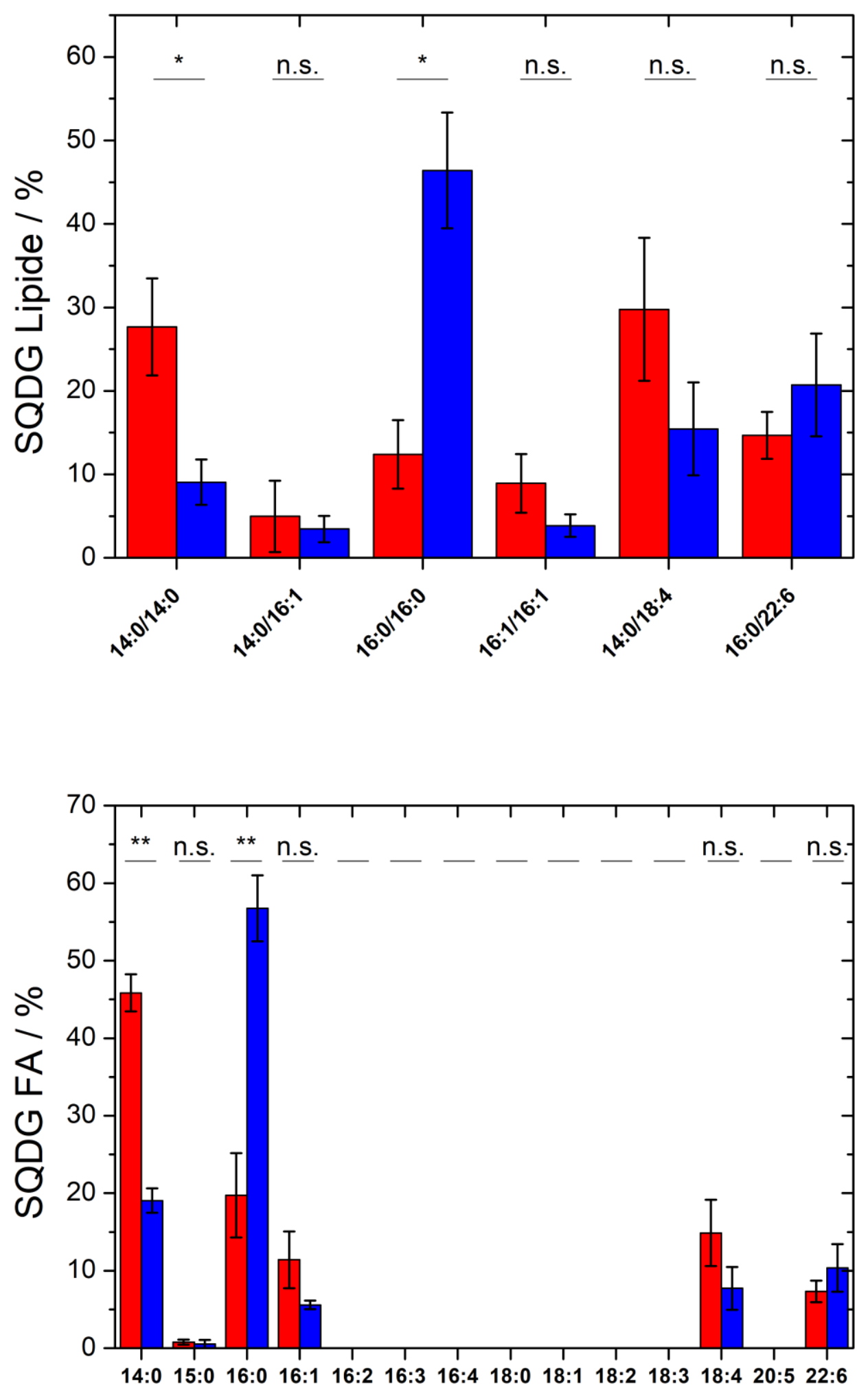

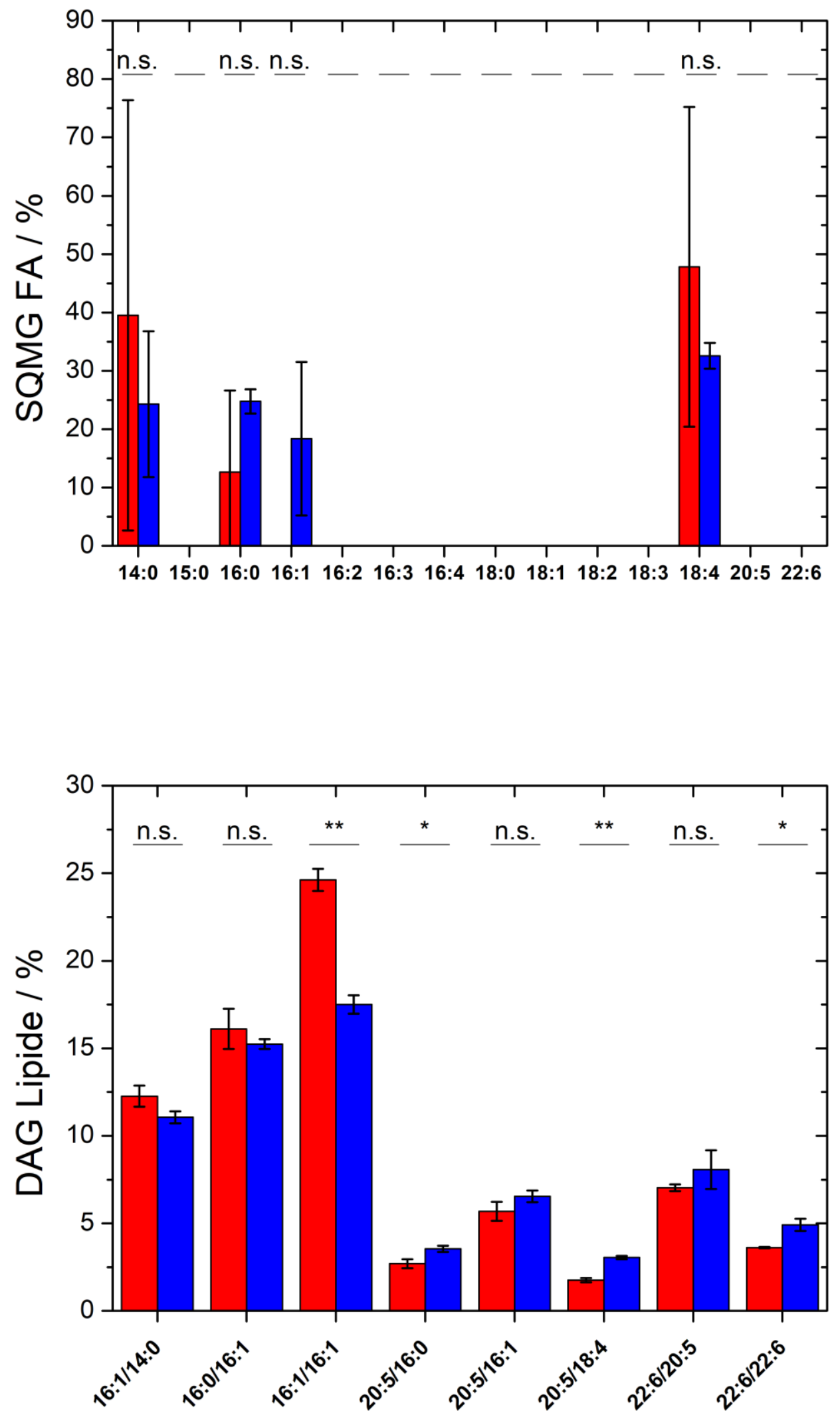

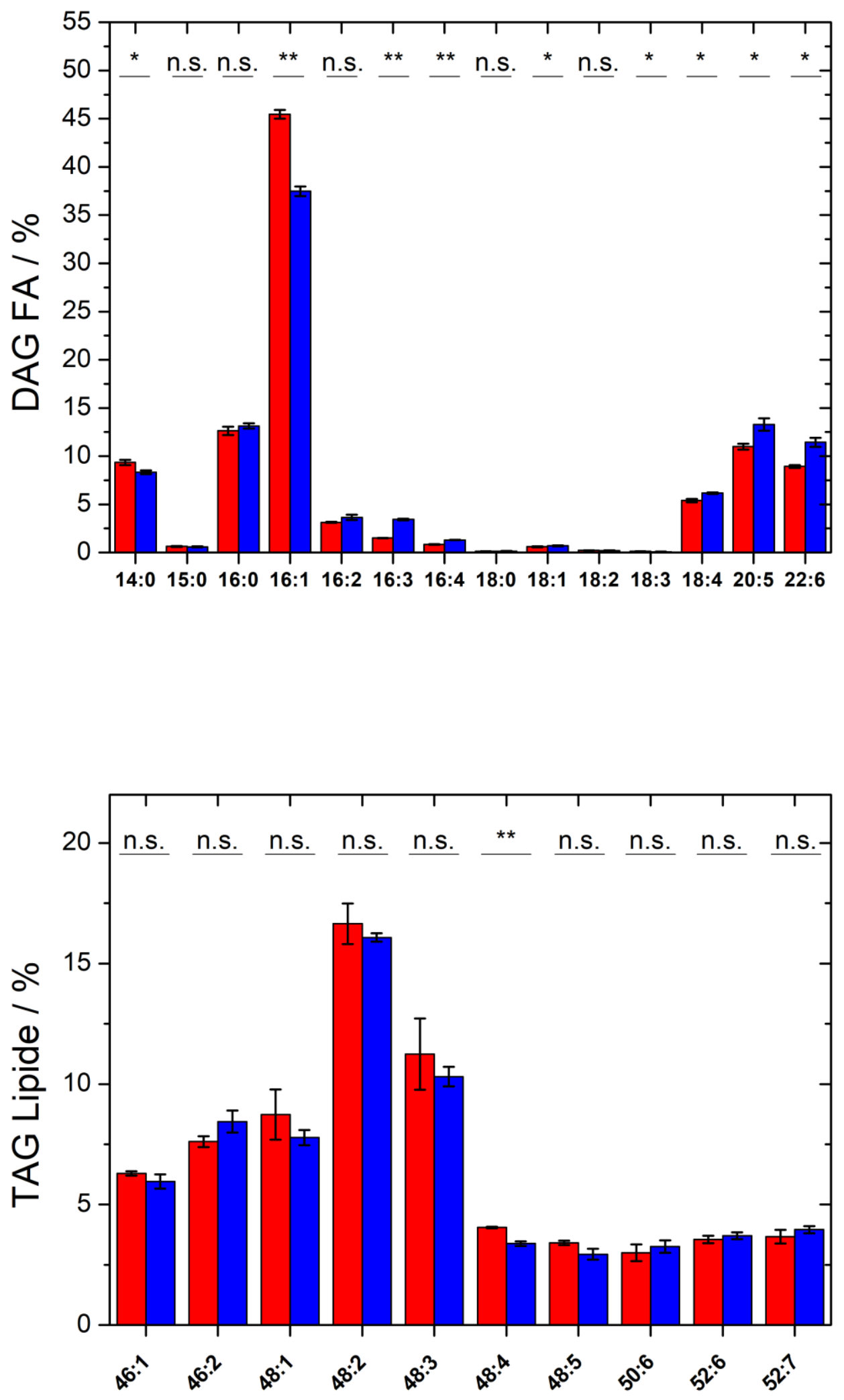

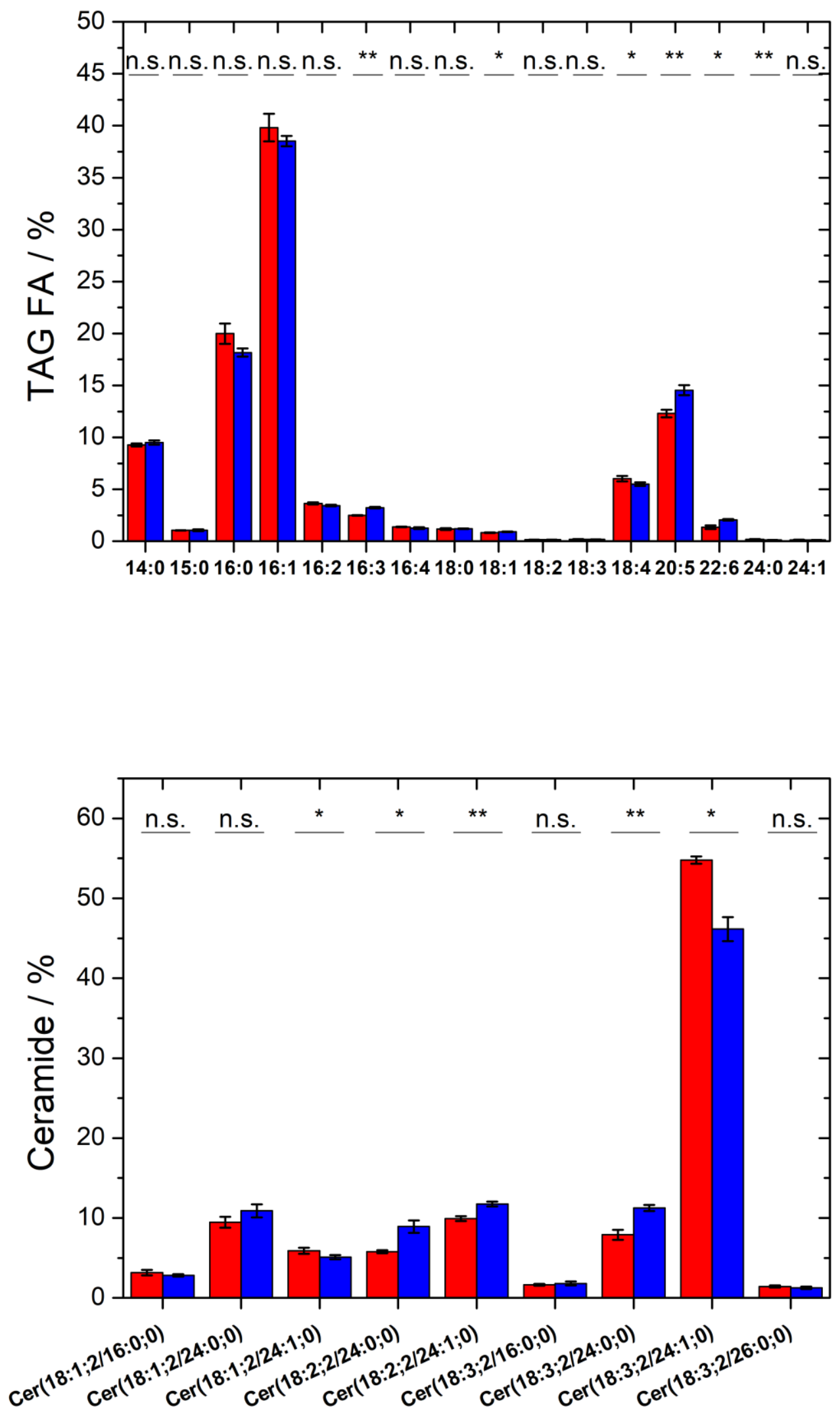

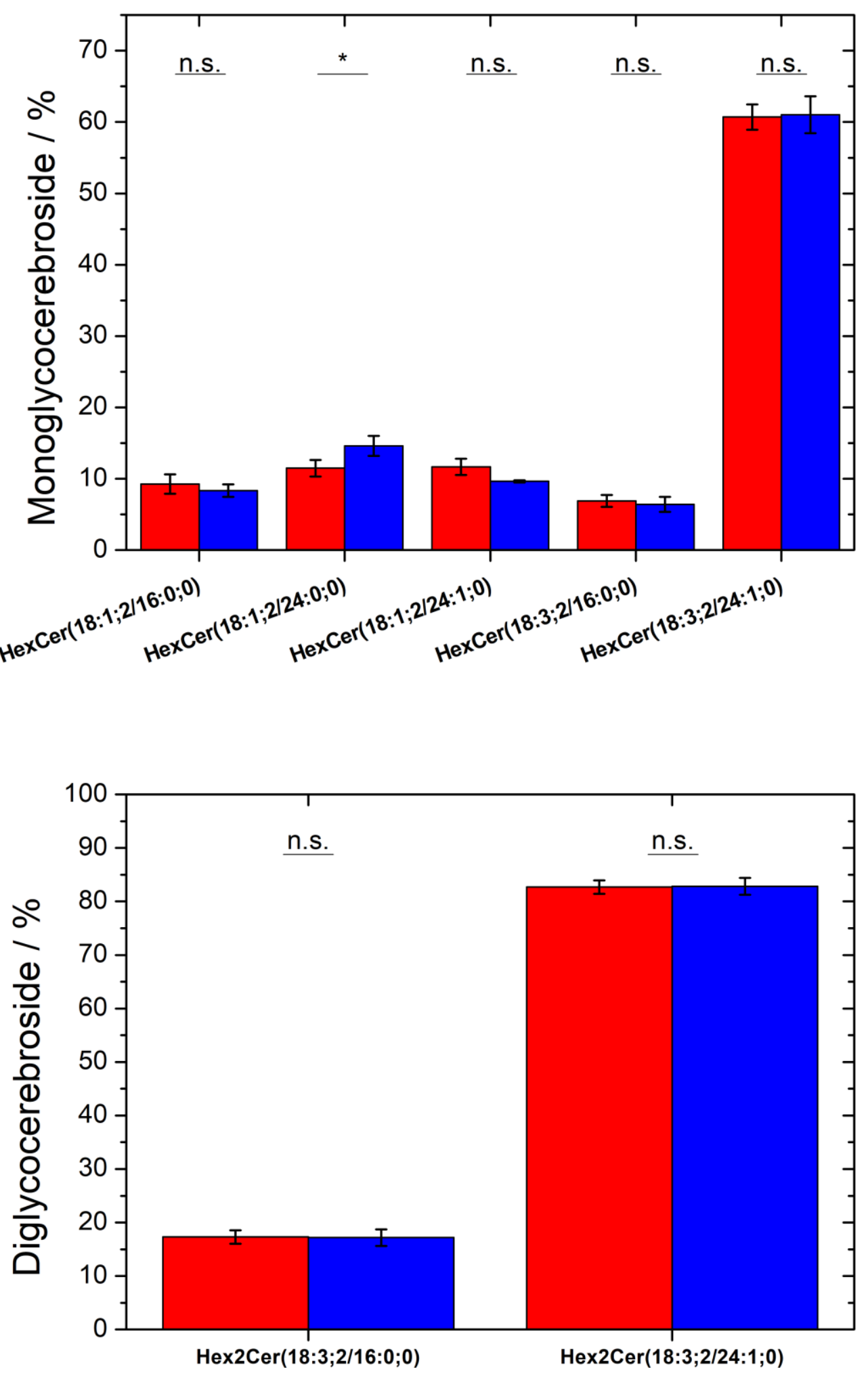

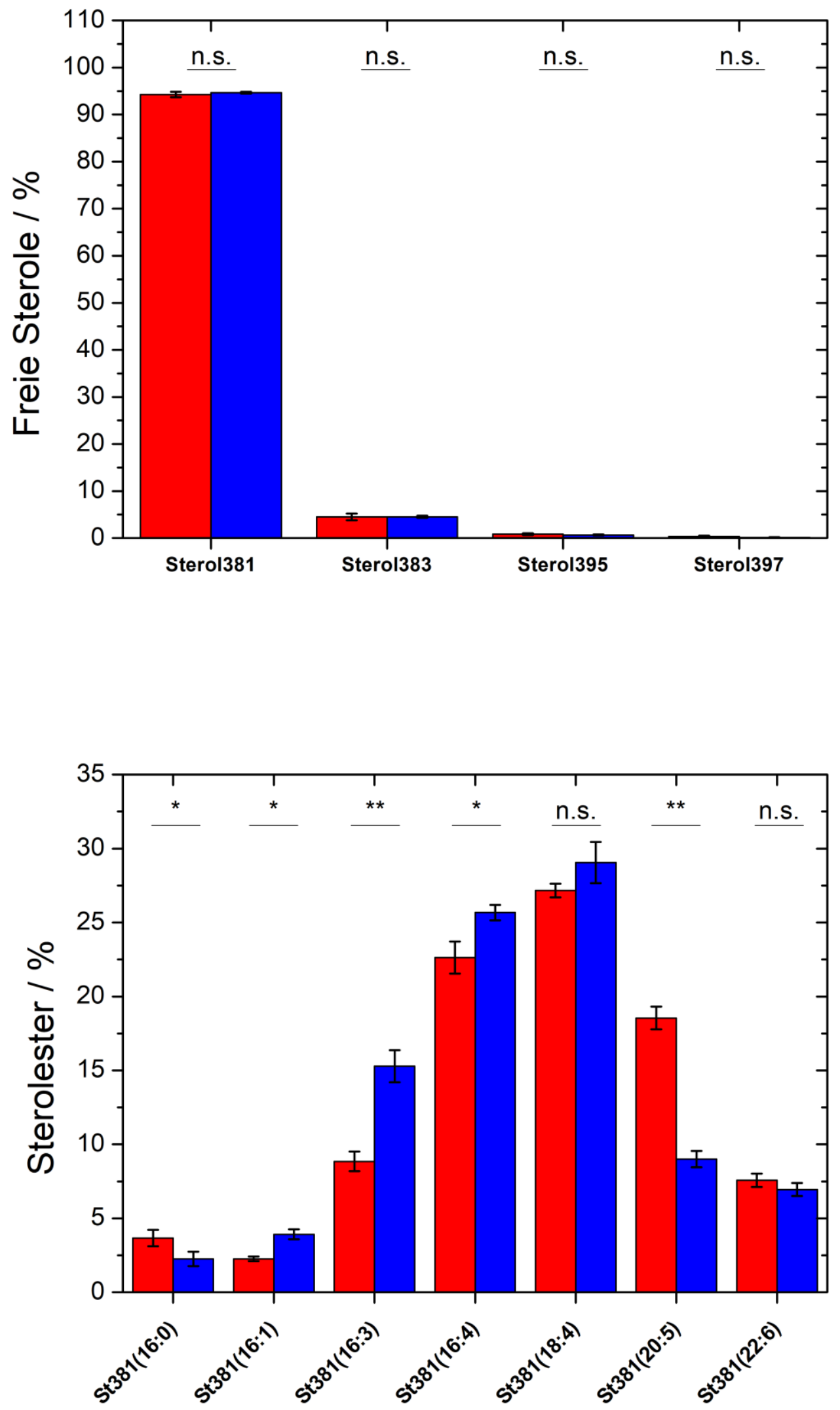


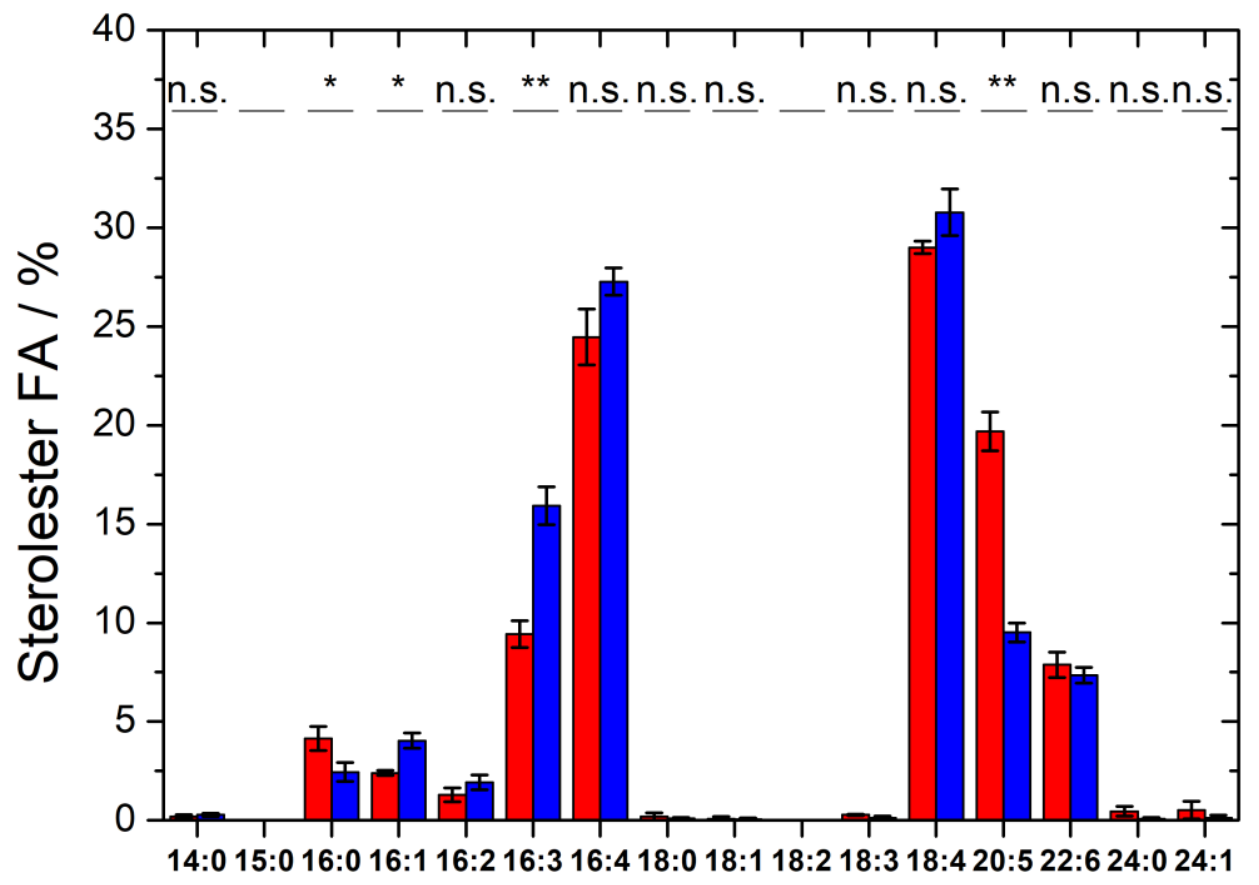

\subsection{Verdauvorhersage für rSin $1^{-\mathrm{SP}}$ durch Chymotrypsin}

Vorhersage der Verdau-Schnittstellen in $\mathrm{SSin}^{-\mathrm{SP}}$ durch Chymotrypsin von dem OnlineTool Expasy Peptide Cutter.[117,83]

Mindestwahrscheinlichkeit $50 \%$ :

\begin{tabular}{ccl}
$\begin{array}{c}\text { Position } \\
\text { of } \\
\text { cleavage } \\
\text { site }\end{array}$ & $\begin{array}{c}\text { Name of } \\
\text { cleaving } \\
\text { enzyme(s) }\end{array}$ & Resulting peptide sequence \\
8 & Chymotrypsin & MNTKKAAY \\
12 & Chymotrypsin & AASL \\
19 & Chymotrypsin & MRGATPL \\
26 & Chymotrypsin & RRLEDAY \\
34 & Chymotrypsin & DGQVDVDL \\
37 & Chymotrypsin & SGY \\
41 & Chymotrypsin & SVKF \\
46 & Chymotrypsin & EKCQF \\
50 & Chymotrypsin & VKQY \\
68 & Chymotrypsin & EGGEGGNNNNKNGNGEQF \\
69 & Chymotrypsin & L \\
& & \\
\hline
\end{tabular}

$\begin{array}{ccc}\begin{array}{c}\text { Peptide } \\ \text { length } \\ \text { [aa] }\end{array} & \begin{array}{c}\text { Peptide } \\ \text { mass } \\ \text { [Da] }\end{array} & \begin{array}{c}\text { Cleavage } \\ \text { probability }\end{array} \\ 8 & 926.099 & 91.8 \% \\ 4 & 360.410 & 53.5 \% \\ 7 & 744.907 & 75.9 \% \\ 7 & 922.009 & 83.8 \% \\ 8 & 859.888 & 62.5 \% \\ 3 & 325.321 & 94.1 \% \\ 4 & 479.577 & 80.8 \% \\ 5 & 653.751 & 72.6 \% \\ 4 & 536.629 & 86.3 \% \\ 18 & 1835.777 & 67.8 \% \\ 1 & 131.175 & 62.5 \%\end{array}$




\begin{tabular}{|c|c|c|c|c|}
\hline Chymotrypsin & STKRF & 5 & 637.737 & $72.6 \%$ \\
\hline Chymotrypsin & VIF & 3 & 377.484 & $82.1 \%$ \\
\hline Chymotrypsin & $\mathrm{RL}$ & 2 & 287.362 & $65.2 \%$ \\
\hline Chymotrypsin & CPDSSCSSCNY & 11 & 1165.230 & $82.7 \%$ \\
\hline Chymotrypsin & NY & 2 & 295.295 & $90.3 \%$ \\
\hline Chymotrypsin & GEY & 3 & 367.359 & $85.4 \%$ \\
\hline Chymotrypsin & IVDMDTY & 7 & 855.958 & $82.3 \%$ \\
\hline Chymotrypsin & LESTLQY & 7 & 852.940 & $100 \%$ \\
\hline Chymotrypsin & KQEEQETY & 8 & 1054.078 & $81.9 \%$ \\
\hline Chymotrypsin & CQSCQQCVEMQANANNGDANDDQNNDNAWMCNNIDTSTCY & 40 & 4447.656 & $83.8 \%$ \\
\hline Chymotrypsin & DECQNIENMEANGY & 14 & 1629.690 & $82.2 \%$ \\
\hline Chymotrypsin & MDASEL & 6 & 664.728 & $54 \%$ \\
\hline Chymotrypsin & TGCVKMNY & 8 & 915.090 & $89.1 \%$ \\
\hline Chymotrypsin & QDNY & 4 & 538.514 & $90.3 \%$ \\
\hline Chymotrypsin & GNAYY & 5 & 586.602 & $91.8 \%$ \\
\hline Chymotrypsin & AGAMCASSGTRIKIGVF & 17 & 1668.990 & $72.5 \%$ \\
\hline Chymotrypsin & SDEQCSQVVEDADIETY & 17 & 1930.969 & $82.3 \%$ \\
\hline Chymotrypsin & $\mathrm{L}$ & 1 & 131.175 & $54.5 \%$ \\
\hline Chymotrypsin & $\mathrm{AY}$ & 2 & 252.270 & $90.3 \%$ \\
\hline Chymotrypsin & GNNNDNNNGVTM & 12 & 1263.261 & $59.7 \%$ \\
\hline Chymotrypsin & $\mathrm{KL}$ & 2 & 259.349 & $62.5 \%$ \\
\hline Chymotrypsin & SY & 2 & 268.269 & $70 \%$ \\
\hline Chymotrypsin & HLL & 3 & 381.475 & $66.9 \%$ \\
\hline Chymotrypsin & KQTFPESGCVSSCL & 14 & 1485.690 & $66.9 \%$ \\
\hline Chymotrypsin & KQNENQNNNNNNNGEQQAAEVNEICENLY & 29 & 3350.407 & $86.3 \%$ \\
\hline Chymotrypsin & EVAGKCESTHGF & 12 & 1264.375 & $85 \%$ \\
\hline Chymotrypsin & KTGY & 4 & 467.522 & $91.8 \%$ \\
\hline Chymotrypsin & ANY & 3 & 366.374 & $83.8 \%$ \\
\hline Chymotrypsin & DNY & 3 & 410.384 & $86.3 \%$ \\
\hline Chymotrypsin & ENQIRNEEL & 9 & 1144.206 & $55.2 \%$ \\
\hline Chymotrypsin & VCDFISSVSAGHY & 13 & 1384.526 & $83.8 \%$ \\
\hline Chymotrypsin & DQTGEIVVSGGRTTLGGGVATTGGQKF & 27 & 2593.833 & $94.7 \%$ \\
\hline Chymotrypsin & AL & 2 & 202.253 & $54 \%$ \\
\hline Chymotrypsin & $\mathrm{TF}$ & 2 & 266.297 & $59.4 \%$ \\
\hline Chymotrypsin & FILGSVGL & 8 & 804.985 & $54.5 \%$ \\
\hline Chymotrypsin & AGY & 3 & 309.322 & $91.8 \%$ \\
\hline Chymotrypsin & AAMLHQQL & 8 & 911.087 & $54 \%$ \\
\hline Chymotrypsin & TKGAKADL & 8 & 802.926 & $62.5 \%$ \\
\hline $\begin{array}{l}\text { end } \\
\text { sequence }\end{array}$ & f SRQGGAMAнннннн & 14 & 1599.712 & - \\
\hline
\end{tabular}

\section{Mindestwahrscheinlichkeit $90 \%$ :}
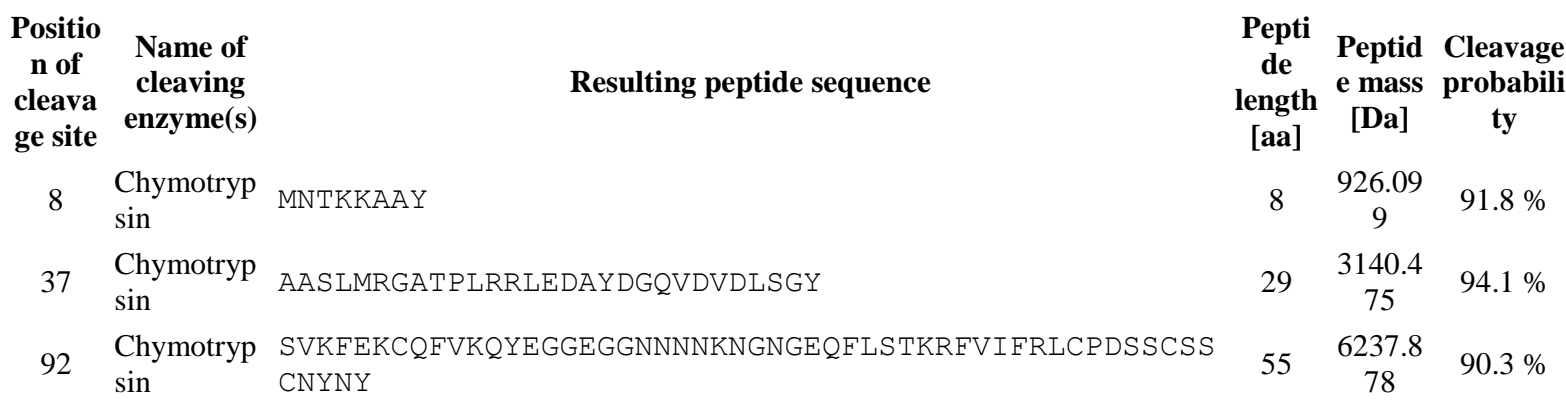
Anhang

\begin{tabular}{|c|c|c|c|c|}
\hline $\begin{array}{l}\text { Chymotryp } \\
\sin \end{array}$ & GEYIVDMDTYLESTLQY & 17 & $\begin{array}{c}2040.2 \\
26\end{array}$ & $100 \%$ \\
\hline $\begin{array}{l}\text { Chymotryp } \\
\sin \end{array}$ & $\begin{array}{l}\text { KQEEQETYCQSCQQCVEMQANANNGDANDDQNNDNAWMCNNIDTSTCYDE } \\
\text { CQNIENMEA } \\
\text { NGYMDASELTGCVKMNYQDNY }\end{array}$ & 80 & $\begin{array}{c}9159.6 \\
80\end{array}$ & $90.3 \%$ \\
\hline $\begin{array}{l}\text { Chymotryp } \\
\text { sin }\end{array}$ & GNAYY & 5 & $\begin{array}{l}586.60 \\
2\end{array}$ & $91.8 \%$ \\
\hline $\begin{array}{l}\text { Chymotryp } \\
\sin \end{array}$ & AGAMCASSGTRIKIGVFSDEQCSQVVEDADIETYLAY & 37 & $\begin{array}{c}3929.3 \\
57\end{array}$ & $90.3 \%$ \\
\hline $\begin{array}{l}\text { Chymotryp } \\
\sin \end{array}$ & $\begin{array}{l}\text { GNNNDNNNGVTMKLSYHLLKQTEPESGCVSSCLKQNENQNNNNNNNGEQQ } \\
\text { AAEVNEICE } \\
\text { NLYEVAGKCESTHGEKTGY }\end{array}$ & 78 & $\begin{array}{c}8614.2 \\
42\end{array}$ & $91.8 \%$ \\
\hline $\begin{array}{l}\text { Chymotryp } \\
\sin \end{array}$ & $\begin{array}{l}\text { ANYDNYENQIRNEELVCDFISSVSAGHYDQTGEIVVSGGRTTLGGGVATT } \\
\text { GGQKF }\end{array}$ & 55 & $\begin{array}{c}5827.2 \\
62\end{array}$ & $94.7 \%$ \\
\hline $\begin{array}{l}\text { Chymotryp } \\
\text { sin }\end{array}$ & ALTFFILGSVGLAGY & 15 & $\begin{array}{c}1528.8 \\
11\end{array}$ & $91.8 \%$ \\
\hline $\begin{array}{l}\text { end of } \\
\text { sequence }\end{array}$ & AAMLHQQLTKGAKADLSRQGGAMAHHHHHH & 30 & $\begin{array}{l}3277.6 \\
95\end{array}$ & - \\
\hline
\end{tabular}




\section{Danksagung}

Zu allererst möchte ich Prof. Dr. Claudia Steinem für die Gelegenheit und das Vertrauen danken, eine Dissertation in ihrem Arbeitskreis anzufertigen. Vielen Dank für die lehrreiche Zeit, die gute Anleitung und Impulsgebung und die gesamte Betreuung!

Prof. Dr. Ivo Feußner danke ich für die Bereitschaft als Koreferent meine Dissertation zu begleiten und für wertvolle Impulse. Außerdem danke ich für die Bereitschaft und das Vertrauen, einen wichtigen Teil meiner Arbeit in seiner Abteilung ausführen zu dürfen. So hatte ich die Möglichkeit die Welt der Lipidanalysen kennenzulernen.

Dr. Cornelia Herrfurth danke ich für die engagierte Betreuung und Anleitung der lipidanalytischen Arbeiten, für das Korrekturlesen und für deine freundliche Art!

Ich danke Ingo für Auswertungsimpulse, seine ermutigenden Worte und für die nötigen Sticheleien, damit es auch nicht langweilig wird.

Danke an Jutta für die tatkräftige Unterstützung durch vielerlei Präparationen und Messungen, für ihre eiserne Hand im Kampf für Sauberkeit und Ordnung im Labor und die zahlreichen Gespräche.

Danken möchte ich auch Micha sowie Sabine Freitag für Hilfestellung und Vorbereitungen bei der Laborarbeit.

Ich danke Olli, Rapha, Miri, Stefan, Johannes, Jerry und Nodumo für das Zeigen und Beibringen wichtiger Techniken. Gut möglich, dass ich hierbei jemanden vergessen habe.

Vielen Dank an Melanie, Marianne und Dana für all die Hilfe mit Formularen, Verträgen, etc. Danke für die freundlichen Gespräche!

Danke an den ganzen AK Steinem für die tolle Zeit, die herausfordernd und frustrierend sein konnte, aber auch gesellig und lustig! Danke für offene Ohren, helfende Hände, ein Witz hier, ein Lachen da! Ohne euch wäre die Zeit nur halb so schön gewesen.

Ein herzlicher Dank geht an Lydia und meine Familie. Ihr wart für mich da, wenn es wirklich schwer wurde, habt mich ermutigt und aufgebaut und euch mit mir gefreut, wenn es gut lief. Danke für eure Unterstützung und Liebe! 
